VITOR NEVES HARTMANN

UMA CONTRIBUIÇÃO PARA O DESENVOLVIMENTO DE UMA MÁQUINA FRESADORA DE ARQUITETURA PARALELA 
VITOR NEVES HARTMANN

UMA CONTRIBUIÇÃO PARA O DESENVOLVIMENTO DE UMA MÁQUINA FRESADORA DE ARQUITETURA PARALELA

Dissertação apresentada à Escola

Politécnica da Universidade de São Paulo para a obtenção do título de Mestre em Engenharia 
Este exemplar foi revisado e alterado em relação à versão original, sob responsabilidade única do autor e com a anuência de seu orientador.

São Paulo, de junho de 2011.

Assinatura do autor

Assinatura do orientador

FICHA CATALOGRAFICA

Hartmann, Vitor Neves

Uma contribuição para o desenvolvimento de uma máquina fresadora de arquitetura paralela / V.N. Hartmann. -- ed.rev. -São Paulo, 2011.

$134 \mathrm{p}$.

Dissertação (Mestrado) - Escola Politécnica da Universidade de São Paulo. Departamento de Engenharia Mecatrônica e de Sistemas Mecânicos.

1.Máquinas-ferramenta 2.Arquiteturas paralelas 3.Fresadoras 4.Deformação e estresses (Análise) I.Universidade de São Paulo. Escola Politécnica. Departamento de Engenharia Mecatrônica e de Sistemas Mecânicos II.t. 
VITOR NEVES HARTMANN

\section{UMA CONTRIBUIÇÃO PARA O DESENVOLVIMENTO DE UMA MÁQUINA FRESADORA DE ARQUITETURA PARALELA}

Dissertação apresentada à Escola

Politécnica da Universidade de São Paulo para a obtenção do título de Mestre em Engenharia

Área de concentração:

Engenharia Mecatrônica

Orientador: Professor Doutor

Tarcísio Antônio Hess-Coelho 


\section{DEDICATÓRIA}

Para minha família. 


\section{AGRADECIMENTOS}

Esta dissertação seria de conclusão mais trabalhosa se não fosse a ajuda de Rodrigo, graduando que auxiliou na fabricação e montagem da máquina, e dos técnicos da oficina, em especial o Caio, cujas ferramentas e conselhos foram de grande valia.

Devo agradecer também o apoio e a presença constante do orientador, que permitiram liberdade nas ações e em sua conclusão, apesar da distância física; e também ao CNPq, pelo apoio inicial no trabalho.

Gilberto e Stipkovic fizeram parte de minha banca de qualificação, e contribuíram enormemente com suas orientações a respeito da tese e apoio ao projeto como um todo.

Agradeço também minha família, pela paciência e compreensão despendidas: minha mãe, pela logística e apoio; minha avó, por disponibilizar uma maneira rápida e eficiente de obter imagens num curto espaço de tempo; e meu irmão, por levar as cópias da tese num momento eu que eu não poderia.

Agradeço especialmente meu irmão e minha namorada, que revisaram este trabalho. 
Vencer a si próprio é a maior das vitórias.

(Platão) 


\section{RESUMO}

Tradicionalmente, em aplicações industriais predominam robôs cujas arquiteturas correspondem a estruturas cinemáticas seriais, ou seja, seus atuadores e peças movidas são dispostos em série, um após o outro, formando uma única cadeia cinemática aberta, de modo a posicionar o órgão terminal, a parte do robô que comumente contém uma garra ou um eletrodo de solda.

Esses robôs apresentam desempenho insatisfatório em aplicações que demandem precisão, rigidez, alta freqüência natural e baixo tempo de ciclo. Sendo assim, tanto a comunidade acadêmica como a industrial têm manifestado um interesse crescente pela utilização de outro tipo de estrutura cinemática, denominada paralela, que se caracteriza pela presença de várias cadeias cinemáticas independentes, atuando de forma paralela e simultânea sobre o órgão terminal.

Essa arquitetura não-convencional apresenta, potencialmente, uma série de vantagens, como: alta rigidez, leveza, rapidez, precisão e alta capacidade de carga. No entanto, existe uma série de problemas abertos que necessitam de uma investigação mais profunda, de modo a garantir que essa mudança de tendência venha a ser implementada com eficácia. $O$ objetivo desta pesquisa é contribuir para o desenvolvimento de uma máquina fresadora de arquitetura paralela que seja promissora quanto à sua simplicidade construtiva, bem como a precisão de posicionamento da ferramenta, se comparada com os robôs paralelos tradicionais.

Esses dois requisitos - simplicidade e precisão - serão alcançados mediante o emprego de uma estrutura modular e a utilização de uma barra de ancoragem ativa, de forma que a estrutura final apresente três atuadores operando em conjunto. Sendo assim, serão empregados três membros, todos ativos, formando uma estrutura cinemática redundante com mobilidade igual a dois. A avaliação do comportamento da arquitetura proposta para a fresadora será realizada por meio de simulações, com o mapeamento dos erros estáticos, de modo a identificar a sua precisão de posicionamento ao longo dos seus eixos de movimentação.

Palavras-chave: Máquinas-ferramenta. Arquiteturas paralelas. Fresadoras. Deformação e estresses (Análise). 


\section{ABSTRACT}

Traditionally, in industrial activities, there is a preference over robots whose architectures correspond to serial kinematic structures, i.e., its actuators and moving parts are arranged in series, one after another, forming a single open kinematic chain, in order to position the body terminal, the part of the robot that commonly contain a claw or a welding electrode.

However, these robots have poor performance in applications that require precision, rigidity, high natural frequency and low cycle time. Due to these factors, both academic and industrial communities have expressed a growing interest in the use of another type of kinematic structure, called parallel, which is characterized by the presence of several independent kinematic chains, operating in parallel and simultaneously on the terminal organ.

This unconventional architecture has potentially a number of advantages, such as high stiffness, lightness, speed, precision and high load capacity. However, there are a number of open problems that need further investigation in order to ensure that this trend change will be implemented effectively. The objective of this research is to contribute for the development of a parallel milling machine that presents a promising behavior in terms of precision and simplicity in construction, compared with the traditional parallel robots.

Both requirements - simplicity and precision - will be achieved with the utilization of a modular structure and the introduction of an active docking bar, so that the final structure has three actuators working simultaneously. Thus, three members will be used, all active, forming a kinematic redundant structure with mobility equal to two. The expected behavior of the proposed architecture for the milling machine is evaluated through simulations, with the mapping of static errors that allow the identification of its positioning accuracy along the motion axes.

Keywords: Milling machines. Parallel architectures. Milling. Strain and stress (Analysis). 


\section{LISTA DE ILUSTRAÇÕES}

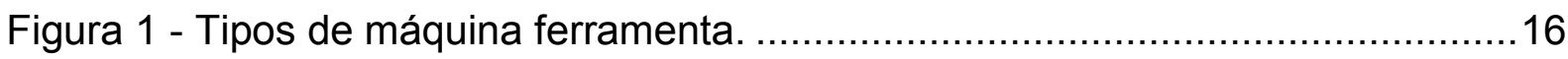

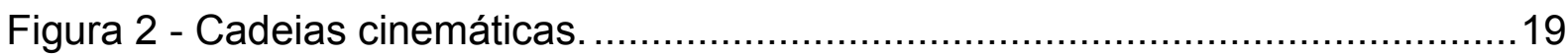

Figura 3 - Diagrama cinemático de um mecanismo paralelo e suas partes. ............20

Figura 4 - Tipos de estruturas paralelas............................................... 21

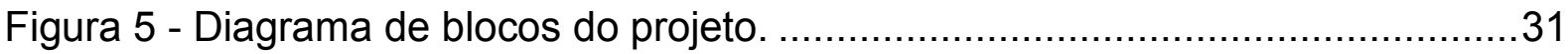

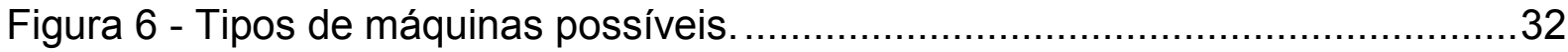

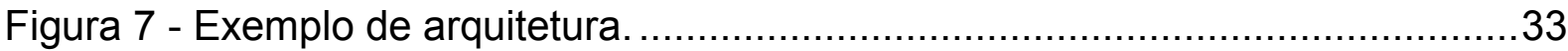

Figura 8 - Exemplo de união do anel central e conexão de potência por juntas

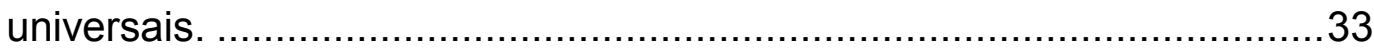

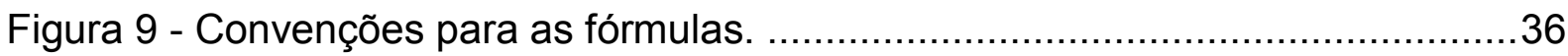

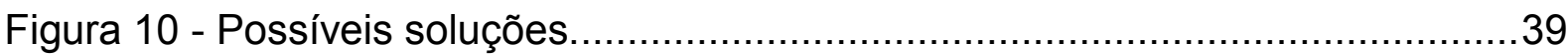

Figura 11 - Representação do sistema. ...........................................................41

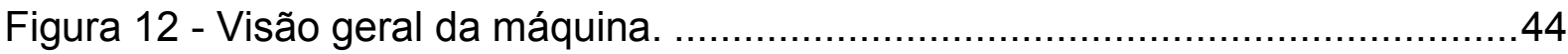

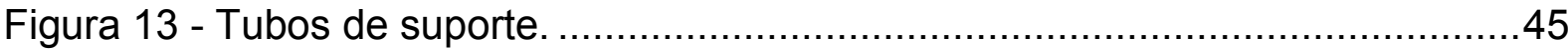

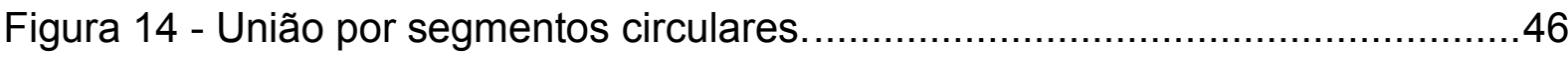

Figura 15 - União por segmentos lineares nos centros. ...............................47

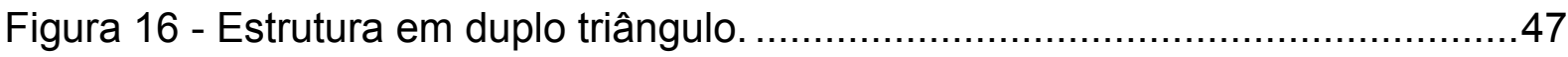

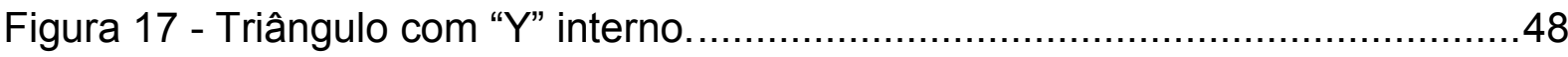

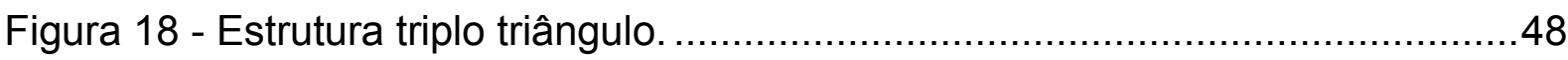

Figura 19 - Penúltima estrutura de suporte da máquina. ..................................49

Figura 20 - Estrutura final de montagem triplo "T" ......................................49

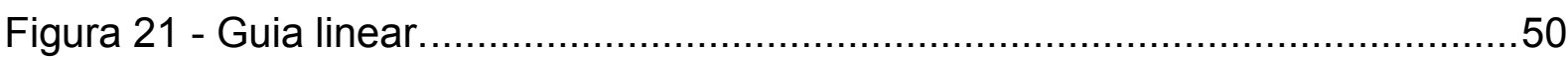

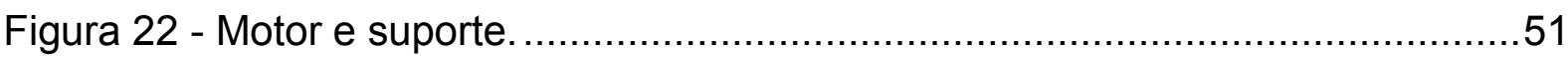

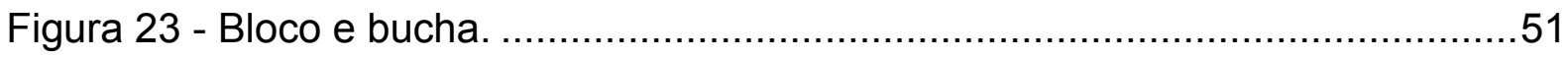

Figura 24 - Eixo de rotação do braço de acionamento. ......................................52 
Figura 25 - Braço de acionamento.

Figura 26 - Garra do braço de acionamento.............................................53

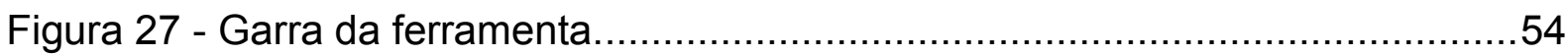

Figura 28 - Geometria padrão do fresamento facial (ALTINTAS, 2000) .................55

Figura 29 - Operações no fresamento (ALTINTAS, 2000). ...............................56

Figura 30 - Discos de fixação do motor................................................. 57

Figura 31 - Disco de fixação da peça. ....................................................... 57

Figura 32 - Forças consideradas e seu ponto de aplicação. ...............................59

Figura 33 - Deflexão na origem, 750N, horizontal, com dois atuadores, pelo FTool. 61

Figura 34 - Deflexão na origem, 750N, vertical, com dois atuadores, pelo FTool. ....61

Figura 35 - Deflexão na origem, $750 \mathrm{~N}$, a $45^{\circ}$, com dois atuadores, pelo FTool. .......62

Figura 36 - Deflexão na origem, 3500N, horizontal, com dois atuadores, pelo FTool.

Figura 37 - Deflexão na origem, 3500N, vertical, com dois atuadores, pelo FTool. ..63

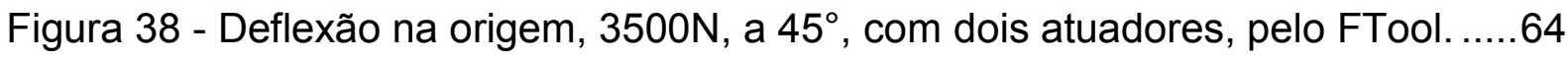

Figura 39 - Deflexão na origem, com dois atuadores, pelo MatLab. 65

Figura 40 - Deflexão na origem, 750N, horizontal, com dois atuadores, pelo Ansys. 66

Figura 41 - Deflexão na origem, 3500N, horizontal, com dois atuadores, pelo Ansys. 66

Figura 42 - Deflexão na origem, 750N, vertical, com dois atuadores, pelo Ansys.....67

Figura 43 - Deflexão na origem, 3500N, vertical, com dois atuadores, pelo Ansys...68

Figura 44 - Deflexão na origem, $750 \mathrm{~N}$, a $45^{\circ}$, com dois atuadores, pelo Ansys. ......69

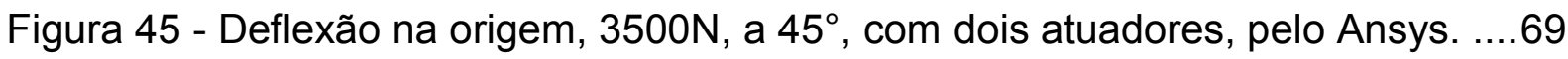

Figura 46 - Deflexão na origem, 750N, horizontal, com três atuadores, pelo FTool..70

Figura 47 - Deflexão na origem, 3500N, horizontal, com três atuadores, pelo FTool.

Figura 48 - Deflexão na origem, 750N, vertical, com três atuadores, pelo FTool......71

Figura 49 - Deflexão na origem, $750 \mathrm{~N}$, a $45^{\circ}$, com três atuadores, pelo FTool.........72 
Figura 50 - Deflexão na origem, 3500N, vertical, com três atuadores, pelo FTool....72 Figura 51 - Deflexão na origem, $3500 \mathrm{~N}$, a $45^{\circ}$, com três atuadores, pelo FTool.......73

Figura 52 - Deflexão na origem, com três atuadores, pelo MatLab. 74

Figura 53 - Deflexão na origem, 750N, horizontal, com três atuadores, pelo Ansys. 75

Figura 54 - Deflexão na origem, 3500N, horizontal, com três atuadores, pelo Ansys.

Figura 55 - Deflexão na origem, 750N, vertical, com três atuadores, pelo Ansys. ....76

Figura 56 - Deflexão na origem, 3500N, vertical, com três atuadores, pelo Ansys. ..77

Figura 57 - Deflexão na origem, $750 \mathrm{~N}$, a $45^{\circ}$, com três atuadores, pelo Ansys........77

Figura 58 - Deflexão na origem, $3500 \mathrm{~N}$, a $45^{\circ}$, com três atuadores, pelo Ansys. .....78

Figura 59 - Modelo utilizado e representação esquemática.

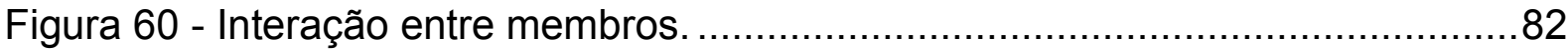

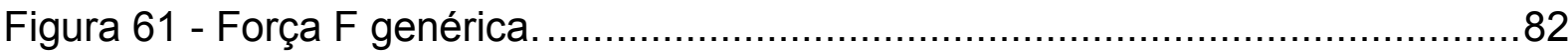

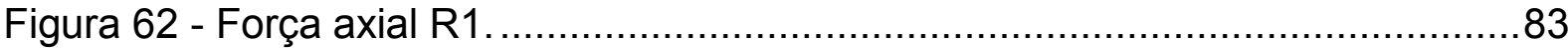

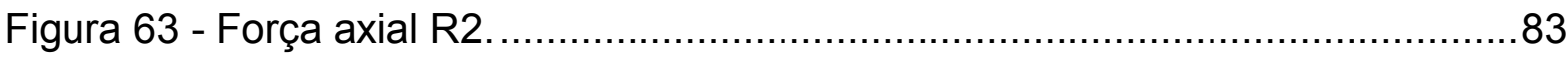

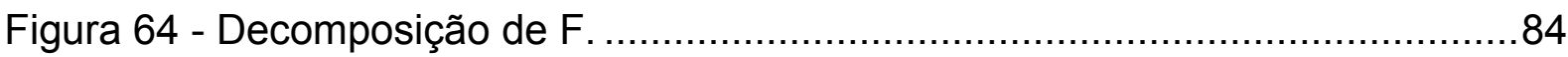

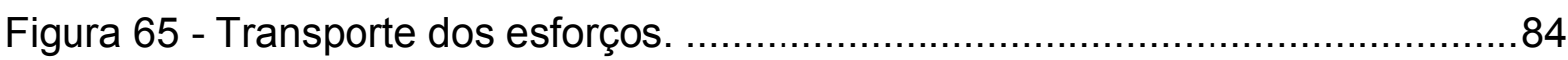

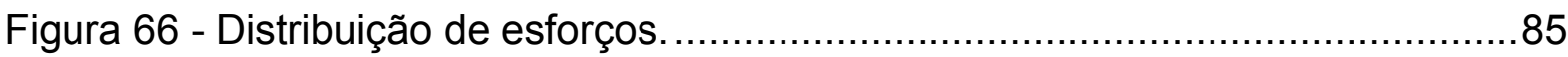

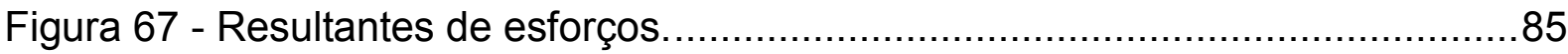

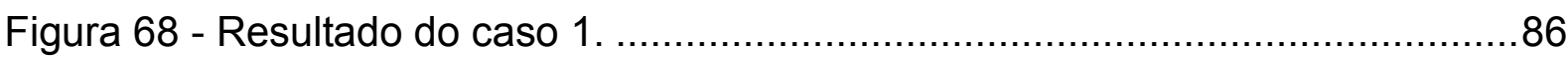

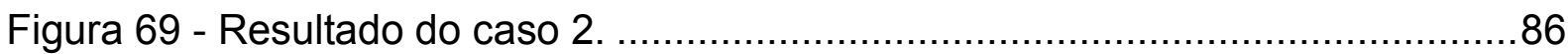

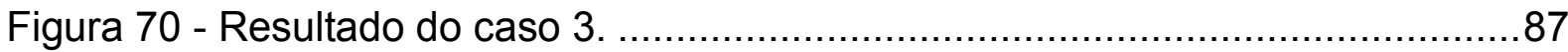

Figura 71 - Erro estático na área de trabalho, com dois atuadores, para $750 \mathrm{~N}$, horizontal.

Figura 72 - Erro estático na área de trabalho, com dois atuadores, para 3500N, horizontal.

Figura 73 - Erro estático na área de trabalho, com dois atuadores, para 750N, vertical. 
Figura 74 - Erro estático na área de trabalho, com dois atuadores, para 3500N, vertical.

Figura 75 - Erro estático na área de trabalho, com dois atuadores, para $750 \mathrm{~N}$, a $45^{\circ}$.

Figura 76 - Erro estático na área de trabalho, com dois atuadores, para 3500N, a $45^{\circ}$.

Figura 77 - Curvas de nível para máquina com dois braços, $750 \mathrm{~N}$, horizontal. .......95

Figura 78 - Curvas de nível para máquina com dois braços, $3500 \mathrm{~N}$, horizontal. ......96

Figura 79 - Curvas de nível para máquina com dois braços, $750 \mathrm{~N}$, vertical. ...........97

Figura 80 - Curvas de nível para máquina com dois braços, $3500 \mathrm{~N}$, vertical. .........98

Figura 81 - Curvas de nível para máquina com dois braços, $750 \mathrm{~N}$, a $45^{\circ}$..............99

Figura 82 - Curvas de nível para máquina com dois braços, $3500 \mathrm{~N}$, a $45^{\circ}$..........100

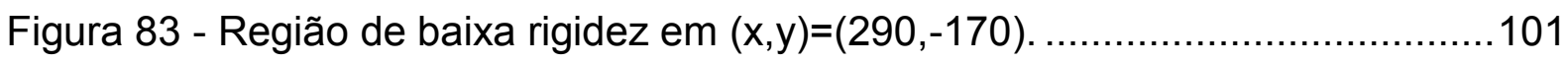

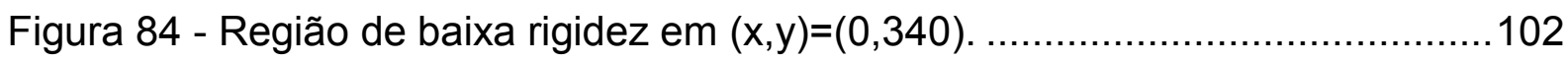

Figura 85 - Erro estático na área de trabalho, com três atuadores, 750N, horizontal. 103

Figura 86 - Erro estático na área de trabalho, com três atuadores, 3500N, horizontal.

Figura 87 - Erro estático na área de trabalho, com três atuadores, 750N, vertical..105

Figura 88 - Erro estático na área de trabalho, com três atuadores, 3500N, vertical.

Figura 89 - Erro estático na área de trabalho, com três atuadores, $750 \mathrm{~N}$, a $45^{\circ} . \ldots 107$

Figura 90 - Erro estático na área de trabalho, com três atuadores, $3500 \mathrm{~N}$, a $45^{\circ} \ldots 108$

Figura 91 - Curvas de nível para máquina com três braços, $750 \mathrm{~N}$, horizontal........109

Figura 92 - Curvas de nível para máquina com três braços, $3500 \mathrm{~N}$, horizontal......110

Figura 93 - Curvas de nível para máquina com três braços, 750N, vertical. 111

Figura 94 - Curvas de nível para máquina com três braços, $3500 \mathrm{~N}$, vertical.

Figura 95 - Curvas de nível para máquina com três braços, $750 \mathrm{~N}$, a $45^{\circ}$. 113

Figura 96 - Curvas de nível para máquina com três braços, $3500 \mathrm{~N}$, a $45^{\circ}$. 114 


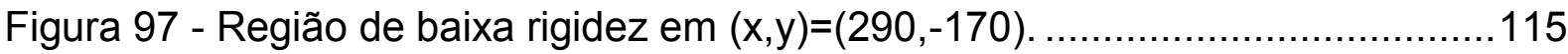

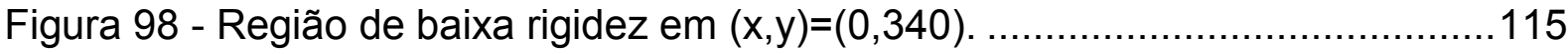

Figura 99 - Deflexão máxima para máquina na horizontal. ...............................117

Figura 100 - Deflexão máxima para máquina na vertical. ..................................118

Figura 101 - Visão geral do protótipo. ......................................................119

Figura 102 - Alterações efetuadas. ............................................................. 120

Figura 103 - Detalhe das alterações. .........................................................121

Figura 104 - Fim de curso dos membros atuadores........................................121

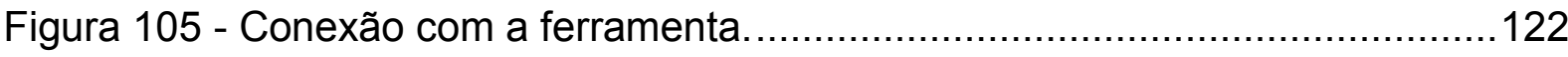

Figura 106 - Intercambiabilidade das peças............................................123 


\section{LISTA DE TABELAS}

Tabela 1 - Comparação das velocidades máximas entre máquinas fresadoras. ......17

Tabela 2 - Comparação dos níveis de precisão entre máquinas fresadoras.............17

Tabela 3 - Relação entre as juntas e os ligamentos........................................ 32

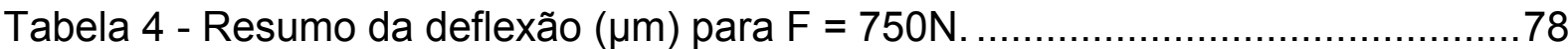

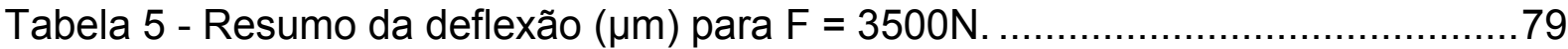

Tabela 6 - Folga média normal dos rolamentos. ............................................ 79

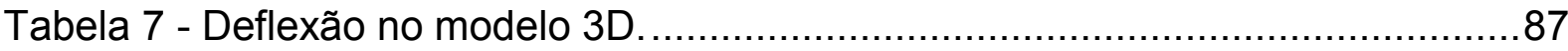

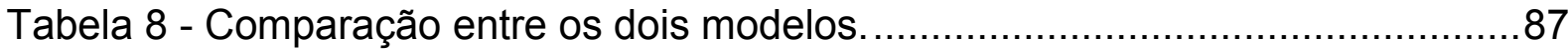

Tabela 9 - Análise dos ganhos entre as simulações para o pior caso de deflexão

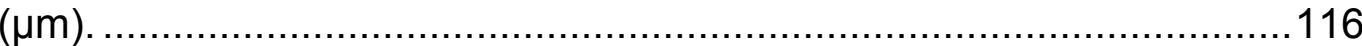




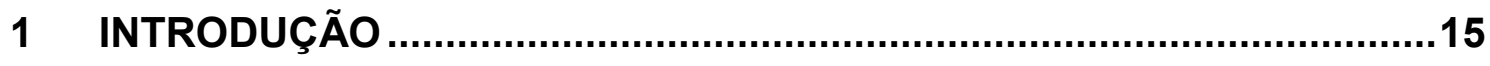

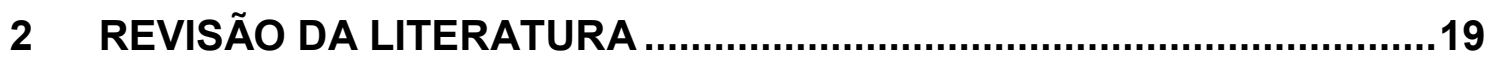

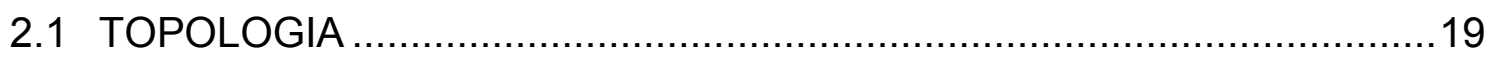

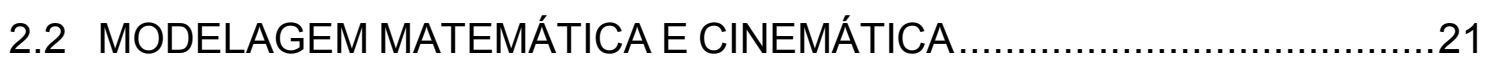

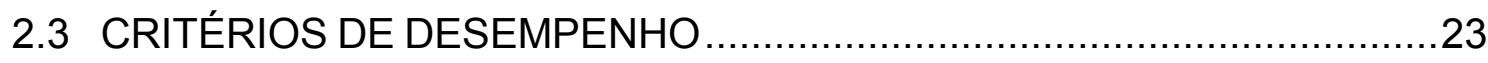

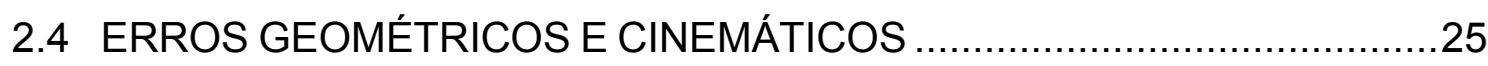

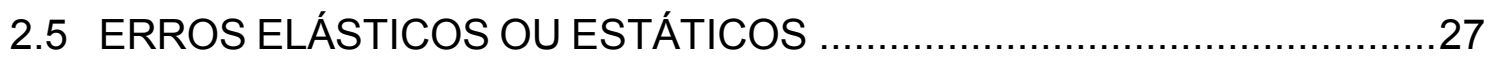

3 METODOLOGIA PARA O DESENVOLVIMENTO DO TRABALHO .........28

3.1 SÍNTESE DE NOVA ARQUITETURA PARA MÁQUINA FRESADORA .....29

3.2 DESENVOLVIMENTO DE MODELOS MATEMÁTICOS E COMPUTACIONAIS PARA AVALIAR O COMPORTAMENTO CINEMÁTICO E ESTÁTICO.

3.3 MAPEAMENTO DOS ERROS PREVISTOS DE POSICIONAMENTO DA FERRAMENTA DE CORTE DURANTE O FRESAMENTO …...................30

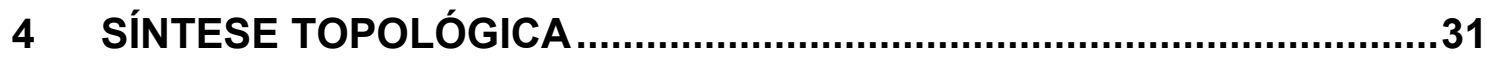

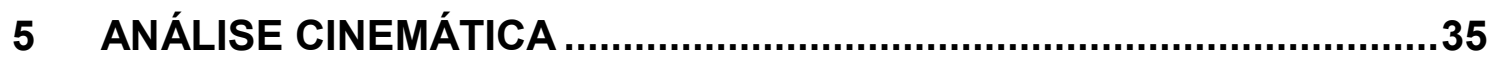

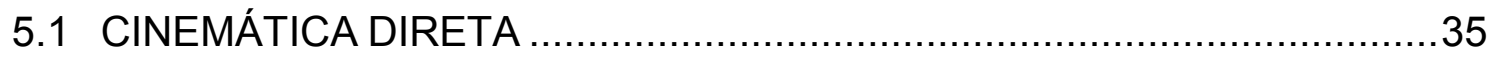

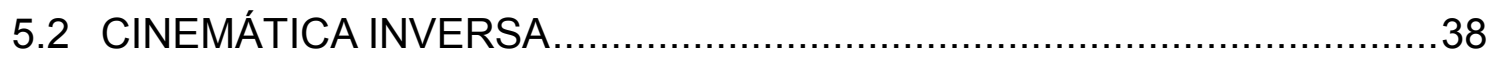

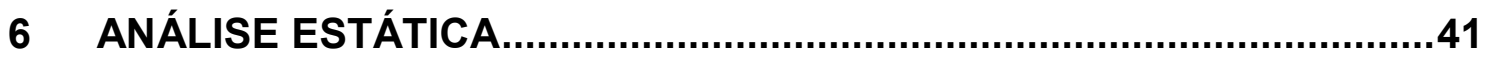

7 DESCRIÇÃO DO SUBSISTEMA MECÂNICO PROJETADO PARA A MÁQUINA FRESADORA PARALELA ............................................44

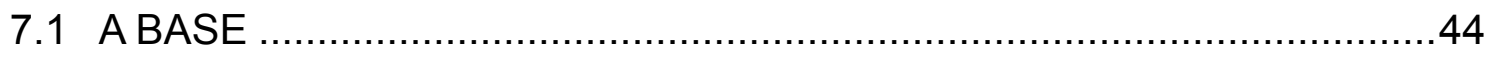

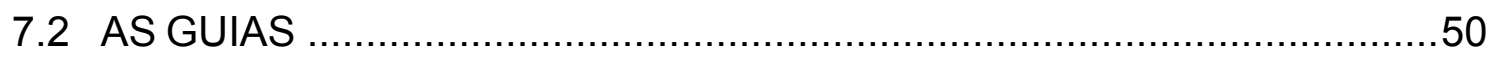

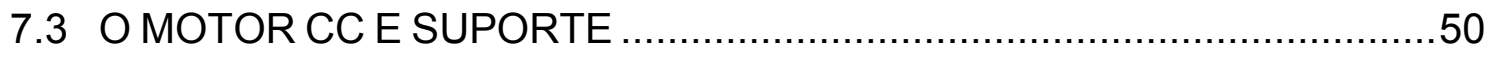

7.4 BLOCO DE FIXAÇÃO DA BUCHA E A BUCHA ......................................

7.5 EIXO DE ROTAÇÃO DO BRAÇO DE ACIONAMENTO..............................52

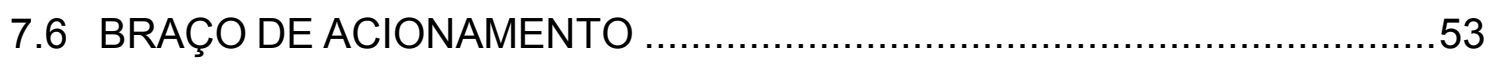

7.7 BUCHA DA FERRAMENTA E CILINDRO DE FIXAÇÃO ...........................54

7.8 DISCOS DE FIXAÇÃO DO MOTOR AC E DA PEÇA ...............................57

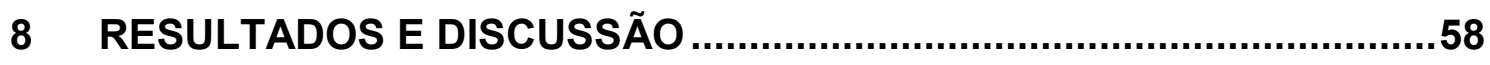

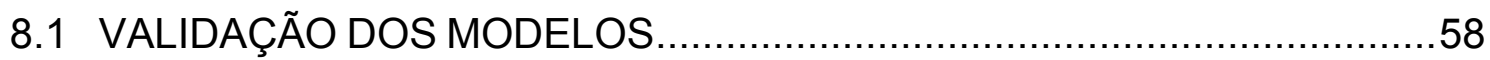

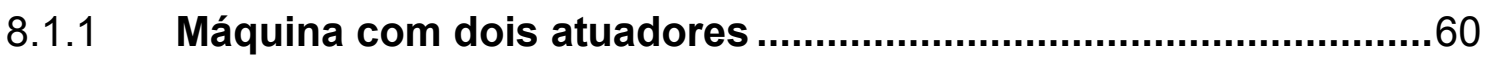

8.1.2 Máquina com três atuadores ......................................................... 


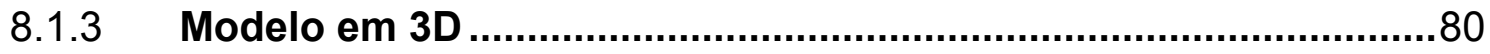

8.2 MAPEAMENTO DO ERRO DEVIDO A CARGA ESTÁTICA .....................89

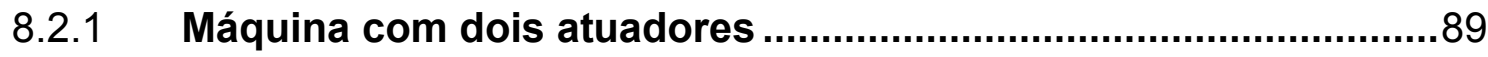

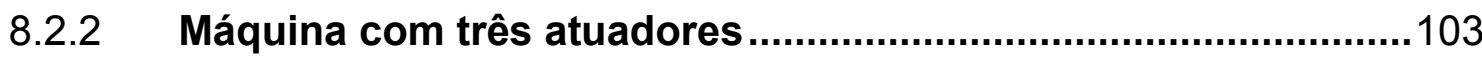

8.3 DISCUSSÃO SOBRE O PLANO DE OPERAÇÃO DA MÁQUINA: HORIZONTAL OU VERTICAL? .......................................................116

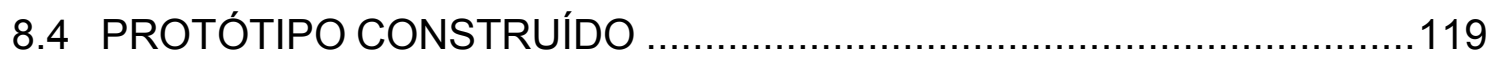

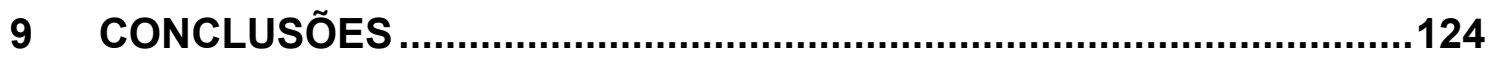

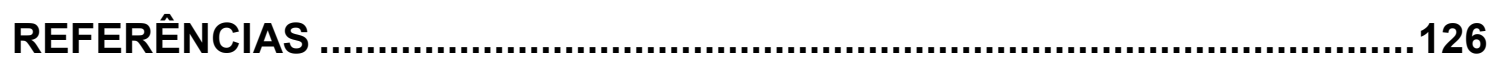

APÊNDICE A - DESENHO DE CONJUNTO DA MÁQUINA........................130

APÊNDICE B - DESENHOS DE MONTAGEM ........................................132 


\section{INTRODUÇÃO}

As máquinas-ferramentas, normalmente empregadas nas operações de fresamento, executam o processo de usinagem através do movimento relativo entre ferramenta e peça de trabalho, ao longo de três eixos ortogonais. Dessa forma, dependendo da massa e do tamanho da peça de trabalho, as estruturas dessas máquinas se enquadram em três categorias: tipo "C", pórtico fixo ou pórtico móvel.

Essas máquinas seriais (Figura 1a) apresentam seus eixos de movimentação, formando uma estrutura cartesiana com sistema de atuação em série. No entanto, a busca por novos equipamentos, com elevados níveis de desempenho, propiciou o desenvolvimento de estruturas robóticas alternativas que demonstrassem um comportamento promissor quanto à redução dos tempos de ciclo e a diminuição da potência consumida nas operações.

Vale ressaltar que qualquer operação, seja de posicionamento ou de usinagem, tem um consumo de energia inerente à sua realização, que independe da utilização de máquina serial ou paralela, e que não pode ser reduzido.

No entanto, o que se ganha na construção paralela é justamente a velocidade nas operações em vazio, quer sejam de aproximação ou afastamento, troca de ferramenta ou seu posicionamento relativo em relação à peça. A inércia dos atuadores, que deve ser vencida para que um determinado objetivo seja atingido, também é um ponto em favor da redução da energia requerida, pois as massas posicionadas serialmente na máquina são reduzidas.

Da mesma maneira, a modularidade que pode ser obtida na arquitetura paralela facilita o manuseio, a intercambiabilidade e o custo da máquina, tanto de aquisição quanto de manutenção. Numa máquina serial pode-se observar a redução de tamanho e potência dos motores e dos braços articulados, conforme se percorre a estrutura da base até a ponta da ferramenta.

Numa máquina paralela, ao contrário, o posicionamento dos atuadores na base permite que esses sejam similares, assim como seus membros movidos, contribuindo também para o aumento da rigidez de trabalho e de sua freqüência natural de vibração. 
Assim, tanto a comunidade acadêmica quanto a industrial passaram a demonstrar um interesse crescente em relação às máquinas baseadas em estruturas robóticas paralelas, com arquiteturas multimembros (Figura 1b), que se caracterizam por um esquema de atuação paralelo ou simultâneo sobre a plataforma móvel que geralmente transporta a ferramenta.

Tal fato representa, segundo Broghard (2002), uma tendência mundial no sentido de expandir as aplicações atuais dos robôs industriais para tarefas envolvendo corte e solda a laser, montagem de alta precisão, retificação, fresamento, dentre outras. Considerando que os robôs seriais apresentam desempenho insatisfatório para tais tarefas por requererem elevada precisão, rigidez, alta freqüência natural e baixo tempo de ciclo, as estruturas robóticas paralelas constituem-se numa alternativa promissora às novas demandas de mercado, como produtos de maior precisão dimensional e menor custo de produção, associados à autocalibração, tratada mais adiante.

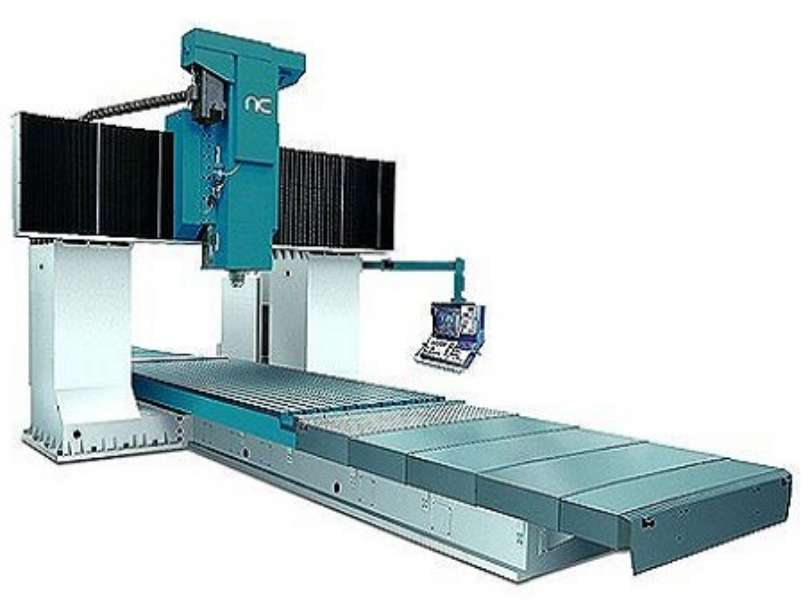

(a)

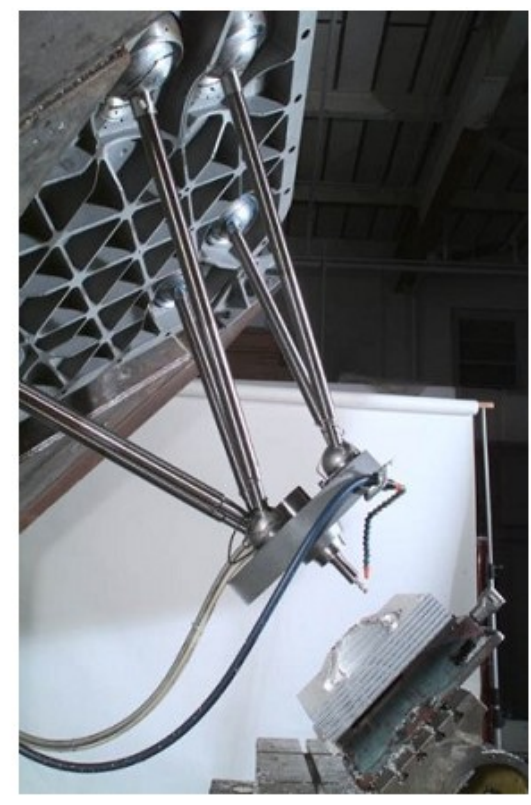

(b)

Figura 1 - Tipos de máquina ferramenta.

(a) Máquina-ferramenta serial, tipo "pórtico fixo";

(b) Estrutura robótica paralela para usinagem (PARALLEMIC, 2009).

A Tabela 1 apresenta uma comparação considerando como critério a velocidade de avanço rápido. Nota-se que estas estruturas robóticas paralelas chegam a ser de 2 a 12 vezes mais rápidas do que as máquinas seriais. 
No entanto, apesar das vantagens das estruturas robóticas paralelas em termos de velocidade de avanço, a questão da precisão de posicionamento e da orientação da ferramenta durante a operação de fresamento tem se demonstrado um dos principais problemas para a sua utilização prática. De acordo com a Tabela 2, observa-se que o nível de repetitividade das estruturas robóticas paralelas é, em média, cerca de três vezes inferior ao das máquinas fresadoras seriais. Da mesma forma, observa-se um nível de exatidão cerca de seis vezes menor. A imprecisão dessas estruturas deve-se aos erros decorrentes de deformações elásticas, imprecisões geométricas e cinemáticas, dilatações térmicas, entre outros.

Tabela 1 - Comparação das velocidades máximas ${ }^{1}$ entre máquinas fresadoras.

\begin{tabular}{|c|c|c|}
\hline & Tipo de Estrutura & Velocidade (m/min) \\
\hline Arrow 1000 & Serial & 25 \\
\hline VMC 135E & Serial & 15 \\
\hline SMT Tricept 805 & Paralela & 50 \\
\hline Genius 500 & Paralela & 180 \\
\hline
\end{tabular}

Tabela 2 - Comparação dos níveis de precisão entre máquinas fresadoras.

\begin{tabular}{|c|c|c|c|}
\hline & Tipo de Estrutura & Exatidão $(\mu \mathrm{m})$ & Repetitividade $(\mu \mathrm{m})$ \\
\hline Arrow 1000 & Serial & 4 & 1 \\
\hline VMC 135E & Serial & 3 & 3 \\
\hline Tornado Hexel & Paralela & 25 & 10 \\
\hline CMW 300 & Paralela & 10 & 3 \\
\hline
\end{tabular}

Fonte: Hess-Coelho, Raszl (2006).

Portanto, investigações acerca da estimativa da precisão dessas arquiteturas alternativas e de sua relação com os seus parâmetros mais significativos poderão fornecer contribuições importantes no sentido de reduzir o tempo de amadurecimento dessa nova tecnologia, em comparação com a serial, muito mais consolidada.

Os objetivos deste trabalho são descritos a seguir:

a) Síntese de uma nova arquitetura para máquina fresadora;

b) Desenvolver modelos matemáticos e algoritmos computacionais para avaliar seu comportamento cinemático e estático.

\footnotetext{
${ }^{1}$ Para os fins deste trabalho, a velocidade máxima aqui referida é a maior velocidade que pode ser atingida pelos atuadores, sendo associada à velocidade de aproximação (em vazio), ou à instrução G00 do conhecido código G para máquinas CNC.
} 
No capítulo 2, apresenta-se uma breve revisão da literatura sobre o assunto deste trabalho. 


\section{REVISÃO DA LITERATURA}

\subsection{TOPOLOGIA}

Uma estrutura cinemática paralela pode ser definida como um mecanismo de cadeia fechada em que o órgão terminal (plataforma móvel) esteja conectado a uma base fixa por meio de pelo menos duas cadeias cinemáticas independentes (HESSCOELHO, 2005; GOJTAN, 2007). Alguns autores costumam atribuir a essas cadeias cinemáticas a denominação de membros (limbs) (TSAI, 1999) ou pernas (legs) (HESS-COELHO, 2005).

Entende-se por cadeia cinemática o sistema mecânico composto de peças ou segmentos (limbs) conectados por juntas ou pares cinemáticos, que são responsáveis pela definição do movimento relativo entre duas peças por ela vinculadas. Observe a figura seguinte.

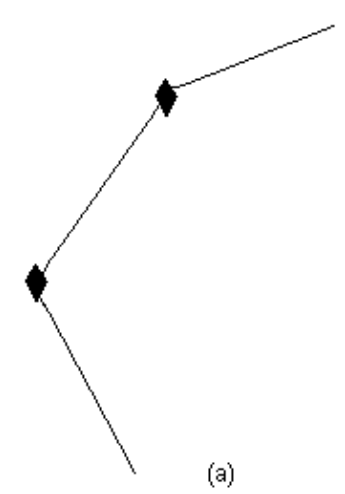

(a)

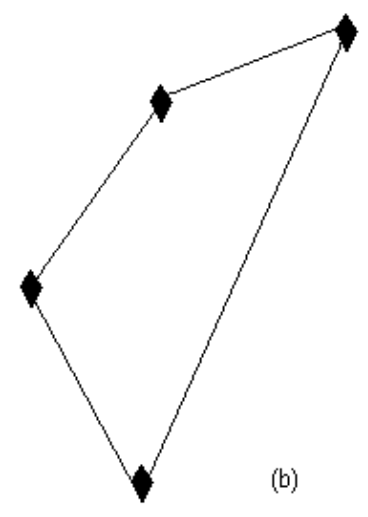

(b)

Figura 2 - Cadeias cinemáticas.

(a) Aberta;

(b) Fechada.

Dessa forma, a caracterização de um determinado tipo de junta está intimamente associada ao número de graus de liberdade que ela permite ou restringe. Uma cadeia é dita fechada se as suas duas extremidades encontram-se unidas. Quando as duas extremidades da cadeia estão separadas a cadeia é denominada aberta. Duas cadeias são dependentes quando o movimento de uma cadeia é determinado 
pelo da outra. Por outro lado, consideram-se duas cadeias como independentes no caso em que o movimento de uma cadeia não é afetado pelo movimento da outra.

$\mathrm{O}$ adjetivo paralelo refere-se à forma de atuação ou acionamento do mecanismo, como mostra a Figura 3. Tal qualificativo existe em contraposição ao termo serial, que corresponde à arquitetura predominante de robôs e máquinas-ferramenta industriais.

Tradicionalmente, os mecanismos ditos paralelos são empregados como simuladores de vôo para treinamento de pilotos ou entretenimento em centros de lazer. Também podem ser utilizados para operações de pega-e-solta, como em linhas de produção que exijam separação de produtos em alta velocidade, tanto para fins industriais como comerciais.

Um exemplo já implantado e em funcionamento é o de uma companhia de manufatura de pretzels na Suíça, que possui cerca de oito robôs de cinemática paralela em suas linhas de produção. Essa medida aumentou a velocidade em $20 \%$ ao mesmo tempo em que reduziu a taxa de perda de produto de $12 \%$ para $4 \%$.

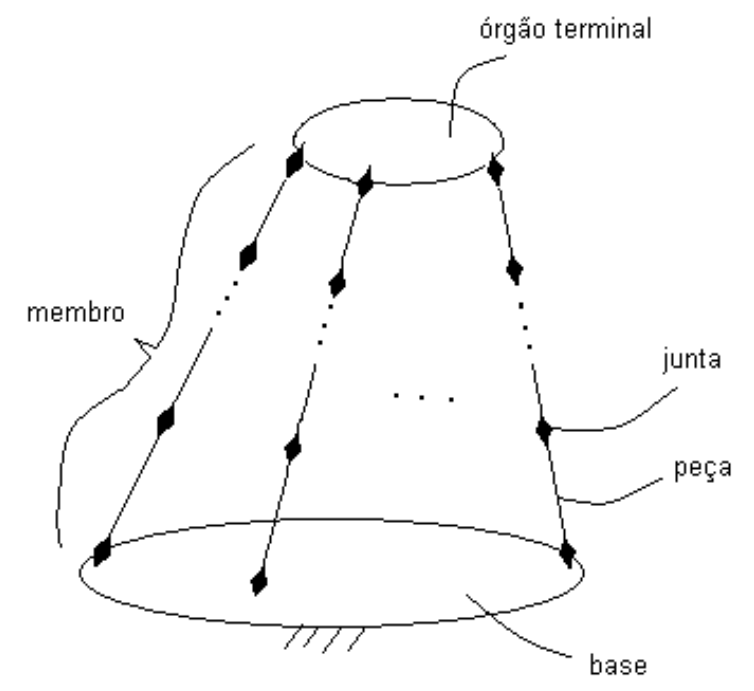

Figura 3 - Diagrama cinemático de um mecanismo paralelo e suas partes.

As máquinas que se baseiam em estruturas robóticas paralelas para operações de usinagem podem ser classificadas em duas categorias: estruturas formadas por membros de comprimento variável (Figura 4a) ou fixo (Figura 4b). Em ambas as situações, o movimento das juntas prismáticas é obtido por atuadores rotativos acoplados a fusos de esferas recirculantes, que provocam o movimento de um bloco deslizante (BRANCHINI; HESS-COELHO; MALVEZZI, 2006). 
Quando os membros possuem comprimento fixo as carcaças dos motores estão vinculadas à base. Já nas estruturas formadas por membros de comprimento variável, as carcaças dos motores realizam movimento de rotação em torno de juntas universais.

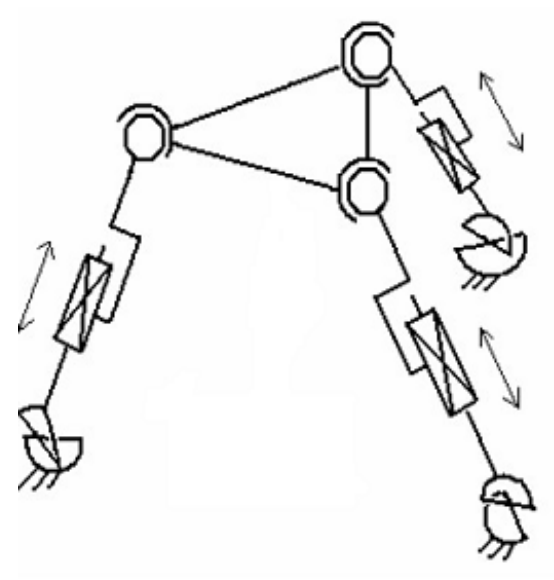

(a)

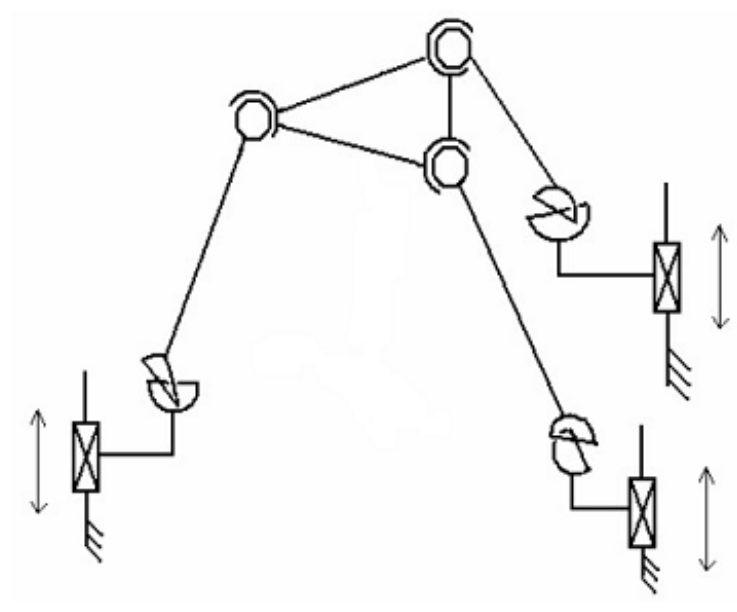

(b)

Figura 4 - Tipos de estruturas paralelas.

(a) Membros com comprimento variável;

(b) Membros com comprimento fixo (BRANCHINI; HESSCOELHO; MALVEZZI, 2006).

Assim, observa-se que, para mecanismos paralelos redundantes, a própria redundância pode eliminar as singularidades (Zhang, 2007). Pode-se evitar que o sistema entre em posições de singularidades (região de baixa rigidez e controle) numa máquina de cinemática paralela, já que os atuadores podem mover o sistema mesmo que os demais estejam travados.

\subsection{MODELAGEM MATEMÁTICA E CINEMÁTICA}

A análise cinemática de uma estrutura robótica paralela tem por finalidade relacionar a localização da plataforma móvel, onde se encontra a ferramenta, com os deslocamentos impostos pelos seus atuadores ou motores. Em termos de 
importância, a análise cinemática é fundamental para o levantamento do espaço de trabalho disponível, na verificação de ocorrência de singularidades, no planejamento de trajetórias da ferramenta e na avaliação do desempenho de uma estrutura robótica.

A análise cinemática de posição pode ser de dois tipos: direta ou inversa. $\mathrm{Na}$ cinemática direta, deseja-se determinar a localização da plataforma móvel a partir dos deslocamentos impostos pelos seus motores, admitidos conhecidos. $\mathrm{Na}$ cinemática inversa, pretende-se determinar os deslocamentos impostos pelos motores a partir da localização conhecida da plataforma móvel. Deve-se enfatizar que o termo 'localização' incorpora tanto a posição, referente às coordenadas de um ponto notável da plataforma, como a orientação, normalmente descrita por uma seqüência de ângulos de Euler (TSAl, 1999).

Para a realização da análise cinemática são admitidos conhecidos todos os parâmetros geométricos e dimensionais dos elos e das juntas. Tais parâmetros estão contidos num vetor $\Pi$. O vetor $\boldsymbol{q}$ representa os deslocamentos impostos pelos motores, enquanto que o vetor $\boldsymbol{x}$ contém os elementos necessários para definir a localização da plataforma móvel. Assim, a relação entre os vetores $\boldsymbol{q}, \boldsymbol{x}$ e $\boldsymbol{\Pi}$ pode ser representada matematicamente por um vetor $\boldsymbol{f}$ de funções nulas. Este vetor possui dimensão $M$, que corresponde à própria mobilidade da estrutura robótica.

$$
\boldsymbol{f}(\boldsymbol{q}, \boldsymbol{x}, \boldsymbol{\Pi})=\left[f_{1}, f_{2}, \ldots f_{M}\right]^{t}=\mathbf{0}
$$

Dentre os vários métodos para a obtenção do vetor $\boldsymbol{f}$, convém destacar aquele que se baseia em transformações homogêneas para relacionar as coordenadas definidas num sistema de referência local vinculado à plataforma móvel com aquelas definidas num sistema de referência global vinculado à base fixa (CRAIG, 1989).

Para se determinar o Jacobiano associado a uma estrutura paralela, deriva-se em relação ao tempo o vetor $\boldsymbol{f}$ da equação (1):

$$
J_{x} \cdot \dot{x}=J_{q} \cdot \dot{q}
$$

Sendo $\dot{\boldsymbol{q}} \circ$ vetor cujos elementos representam as velocidades associadas aos atuadores, $\dot{x}$ o vetor cujos elementos correspondem às velocidades associadas à plataforma móvel e $J_{q}$ e $J_{x}$ as matrizes que correspondem aos dois tipos de 
jacobianos associados às estruturas paralelas. Os vetores mencionados são $M \times 1$, enquanto que as matrizes são $M x M$, sendo $M$ a mobilidade do mecanismo.

Uma vez que os Jacobianos de uma estrutura paralela estejam determinados, é possível encontrar as suas configurações singulares e as velocidades dos motores em função de uma dada velocidade de operação prevista para a plataforma móvel.

As singularidades podem ser determinadas impondo-se que os determinantes das matrizes $J_{q}$ e $J_{x}$ sejam nulos. Quando uma estrutura paralela atinge uma configuração singular, ela pode perder completamente a sua inerente rigidez, adquirindo mobilidade adicional, tornando-se incontrolável (MERLET, 2000). Por outro lado, quando a plataforma móvel se aproxima dos limites de seu espaço de trabalho a estrutura paralela pode perder uma ou mais mobilidades, ocupando também uma configuração singular, porém de natureza distinta (TSAI, 1999).

Outra utilidade relevante para o Jacobiano é permitir a determinação de erros de localização da plataforma móvel, provocados por imprecisões nos deslocamentos impostos pelos motores. Costuma-se relacionar esses dois erros por meio de uma aproximação de primeira ordem para a série de Taylor do vetor de funções $f$ :

$$
\delta x=J_{x}^{-1} \cdot J_{q} \cdot \delta q
$$

Sendo $\boldsymbol{\delta} \boldsymbol{q}$ o vetor cujos elementos representam as imprecisões nos deslocamentos impostos pelos motores e $\delta \boldsymbol{x}$ o vetor cujos elementos correspondem aos erros de localização da plataforma móvel.

\subsection{CRITÉRIOS DE DESEMPENHO}

A síntese dimensional de uma estrutura paralela tem por finalidade determinar parâmetros como, por exemplo, as dimensões dos elos, as direções dos eixos de rotação das juntas e seus cursos, de modo a satisfazer determinados critérios de desempenho (CHABLAT; WENGER, 2003). Tais critérios podem ser o tamanho do 
espaço de trabalho, a velocidade e a aceleração da ferramenta, a precisão de posicionamento e orientação da ferramenta, a capacidade de carga, entre outros. 


\subsection{ERROS GEOMÉTRICOS E CINEMÁTICOS}

Os erros geométricos são aqueles devidos a imprecisões ocorridas durante a fabricação e montagem dos componentes da estrutura paralela. Ramesh et al. (2000) consideram que tais erros são as principais fontes de imprecisão das máquinas-ferramentas. Esses erros são normalmente afetados por diversos fatores, tais como acabamento superficial, pré-carga em mancais, folgas, dentre outros.

Os erros cinemáticos são particularmente significativos quando há movimento combinado de diferentes eixos de uma máquina-ferramenta. Tais erros ocorrem durante a execução de algoritmos de interpolação de trajetórias para a ferramenta de corte.

Com relação aos erros cinemáticos, a maioria dos autores utiliza a matriz jacobiana $\boldsymbol{J}$ para definir índices de desempenho que quantifiquem, ainda que indiretamente, a precisão de uma estrutura paralela.

Dentre os vários índices propostos para este fim, encontram-se a manipulabilidade (MERLET, 2006), o índice de condicionamento (STAMPER et al.,1997; TSAI, 1999; CHABLAT et al.,2004) e a isotropia. Convém ressaltar que esses índices podem ser definidos tanto localmente, para uma determinada configuração, como também globalmente, ao longo de todo o espaço de trabalho. Tais índices foram inicialmente propostos para robôs seriais (TSAI, 1999) e, posteriormente, passaram a ser também adotados para robôs paralelos.

Gojtan e Hess-Coelho (GOJTAN; HESS-COELHO, 2007) estudam as influências do processo de fabricação, da deformação elástica pelas forças de usinagem e da expansão térmica num intervalo de valores de comprimento da estrutura. Com os resultados obtidos verifica-se que a tolerância dimensional e a deformação elástica são preponderantes sobre a deformação térmica, e o erro depende da localização no espaço da ferramenta.

Outro ponto importante (VALÁŠEK, 2007) é que a medição da posição feita diretamente nos atuadores, caso das máquinas seriais, não pode ser feita nas máquinas de cinemática paralela, pois elas possuem muitos erros devido ao grande comprimento dos ligamentos, devendo, a princípio, ser feita externamente. 
O ponto crítico dessa abordagem é que a exatidão do posicionamento da ferramenta é influenciada por diversos fatores, como sua estrutura, o posicionamento dos sensores, o conjunto de calibração, a exatidão dos próprios sensores e seus parâmetros geométricos, considerados constantes, mas que, em verdade, diferem de um valor médio de projeto.

No entanto, a construção paralela permite uma coisa que as máquinas seriais não são capazes de fornecer: o conceito de autocalibração. Por possuírem um número maior de atuadores, além dos seus graus de liberdade, permitem que um número maior de sensores seja posicionado e colete dados de sua posição. Dessa forma, a exatidão da calibração redundante pode ser significativamente aumentada quanto mais sensores forem utilizados.

Isso também permite uma melhora do próprio desenho da máquina, já que podem ser adicionadas mais variáveis ao sistema e analisadas maiores variações geométricas de suas soluções.

Por fim, esse tipo de abordagem pode fazer com que a exatidão de medição de um determinado ponto ou corpo no espaço chegue a ter a mesma exatidão da medição de um sensor em particular. Isso significa que a transferência de erros entre as coordenadas de entrada e de saída pode chegar a 1:1, ou seja, o mesmo erro de um sensor individual seria transmitido para a peça, não aumentando a incerteza do produto devido à incerteza de posicionamento.

Ao se determinar analiticamente a variação da precisão de posicionamento devido ao afastamento dos atuadores, pode-se obter uma solução genérica de um mapa da rigidez. O mapa pode ser utilizado para a avaliação dessa precisão em várias máquinas, e evidencia essa característica das máquinas de cinemática paralela (FRISOLI, 2007).

Numa estrutura hexapod, por exemplo, podem-se medir as coordenadas de seus seis eixos passivos e se observará que a maior causa de erros é a distância entre os dois extremos de um determinado braço, sendo que as outras grandezas não influem de forma significativa (OIWA, 2007). Assim, para o correto posicionamento da ferramenta é necessário determinar suas coordenadas através de medições externas. 


\subsection{ERROS ELÁSTICOS OU ESTÁTICOS}

A rigidez insuficiente dos elos e juntas de uma estrutura paralela pode acarretar deformações elásticas inaceitáveis, devido às forças e aos momentos aplicados (ZHANG, 2000). Tais deformações provocam desvios na localização ideal programada para a plataforma móvel, que sustenta a ferramenta, dentro do espaço de trabalho. Assim, a rigidez global da estrutura não só afeta a sua precisão como também a sua capacidade de carga e as suas características dinâmicas por conta das vibrações (CARBONE; CECCARELLI, 2007). A relação entre as forças e os momentos atuantes na plataforma móvel com as suas deformações elásticas é dada pela equação (4):

$$
\boldsymbol{W}=\boldsymbol{K} \cdot \Delta \boldsymbol{x}
$$

Sendo $\boldsymbol{W}$ o vetor de forças e momentos atuantes na plataforma móvel, $\boldsymbol{K}$ a matriz de rigidez global e $\boldsymbol{\Delta x}$ o vetor de deformações elásticas correspondentes à plataforma móvel.

Para avaliar o comportamento da rigidez global de uma estrutura paralela, em todo seu espaço de trabalho, toma-se como ponto de partida a determinação da sua correspondente matriz de rigidez.

Há pelo menos três métodos para a obtenção da matriz de rigidez (RIZK et al., 2007): a análise por elementos finitos, o método da análise da matriz estrutural (CORRADINI et al., 2003; ZHANG e ANGELES, 2005; PASKHEVICH et al., 2007) e a modelagem adotando-se parâmetros de rigidez concentrados (TSAI, 1999; ZHANG et al.,2004;PASKHEVICH et al.,2007, 2009).

Uma vez determinada a matriz de rigidez, podem ser calculados diferentes índices de desempenho locais, correspondentes a uma dada configuração da estrutura paralela. É usual empregar os seguintes índices de rigidez local: o determinante, o traço (XI et al., 2003), a norma, o índice de condicionamento, os autovalores e autovetores associados à inversa da matriz de rigidez (CARBONE; CECCARELLI, 2007). 


\section{METODOLOGIA PARA O DESENVOLVIMENTO DO TRABALHO}

Propõe-se que a máquina para este trabalho seja capaz de efetuar operações de fresamento em materiais como alumínio, madeira e plástico. Outros materiais como aço e ligas de metais também podem ser usinados, desde que seja mantida coerência com as forças admissíveis, em função da profundidade e velocidades de corte e avanço.

Deseja-se que a atividade fim da máquina seja o trabalho em oficinas educacionais, para estudo das atividades fabris de produtos elaborados com os materiais acima indicados. No entanto, seu nicho de aplicação poderá ser estendido para as áreas industrial e comercial.

Sendo assim, e de modo a analisar a estrutura da máquina proposta, foi utilizada a seguinte metodologia de trabalho, compreendendo três etapas:

a) Síntese de nova arquitetura para máquina fresadora;

b) Desenvolvimento de modelos matemáticos e computacionais para avaliar o comportamento cinemático e estático;

c) Mapeamento dos erros previstos de posicionamento da ferramenta de corte durante o fresamento.

Uma vez que os resultados dos modelos sejam obtidos, pretende-se também:

- Validar os modelos computacionais elaborados, comparando seus resultados com os fornecidos por programas comerciais;

- Projetar e construir um protótipo da máquina proposta.

A seguir, apresentam-se comentários adicionais referentes às três etapas da metodologia. 


\subsection{SÍNTESE DE NOVA ARQUITETURA PARA MÁQUINA FRESADORA}

Para a síntese de uma nova arquitetura adequada a operações de fresamento, pretende-se empregar o método de Kutzbach-Gruebler. O ponto de partida corresponde à determinação da relação entre o número de juntas e o número de ligamentos.

O processo de síntese da arquitetura será descrito no capítulo 4.

\subsection{DESENVOLVIMENTO DE MODELOS MATEMÁTICOS E COMPUTACIONAIS PARA AVALIAR O COMPORTAMENTO CINEMÁTICO E ESTÁTICO}

Nesta etapa, apresentada nos capítulos 5 e 6, pretende-se desenvolver modelos cinemáticos que permitam, primeiramente, relacionar as coordenadas da ferramenta com os deslocamentos proporcionados pelos atuadores.

Em segundo lugar, pela derivação no tempo das equações de posição, será possível determinar as matrizes jacobianas, necessárias para um levantamento de eventuais configurações singulares.

Finalmente, de posse dos modelos anteriores mencionados, será apresentado um método para avaliação do espaço de trabalho disponível, ou seja, a região de alcance da ferramenta. 
3.3 MAPEAMENTO DOS ERROS PREVISTOS DE POSICIONAMENTO DA FERRAMENTA DE CORTE DURANTE O FRESAMENTO

No desenvolvimento do presente estudo serão considerados os erros elásticos, que são devidos às deformações elásticas nos componentes da estrutura paralela, em função da rigidez e dos esforços atuantes. Assim, a rigidez global afeta a sua capacidade de carga e, por conseguinte, a sua precisão. 


\section{SÍNTESE TOPOLÓGICA}

Antes de tratar da síntese topológica propriamente dita, para melhor organização e visualização do desenvolvimento da máquina, entende-se que o projeto seja subdividido em alguns tópicos: controle, mecânica, usinagem e deformações na estrutura (Figura 5).

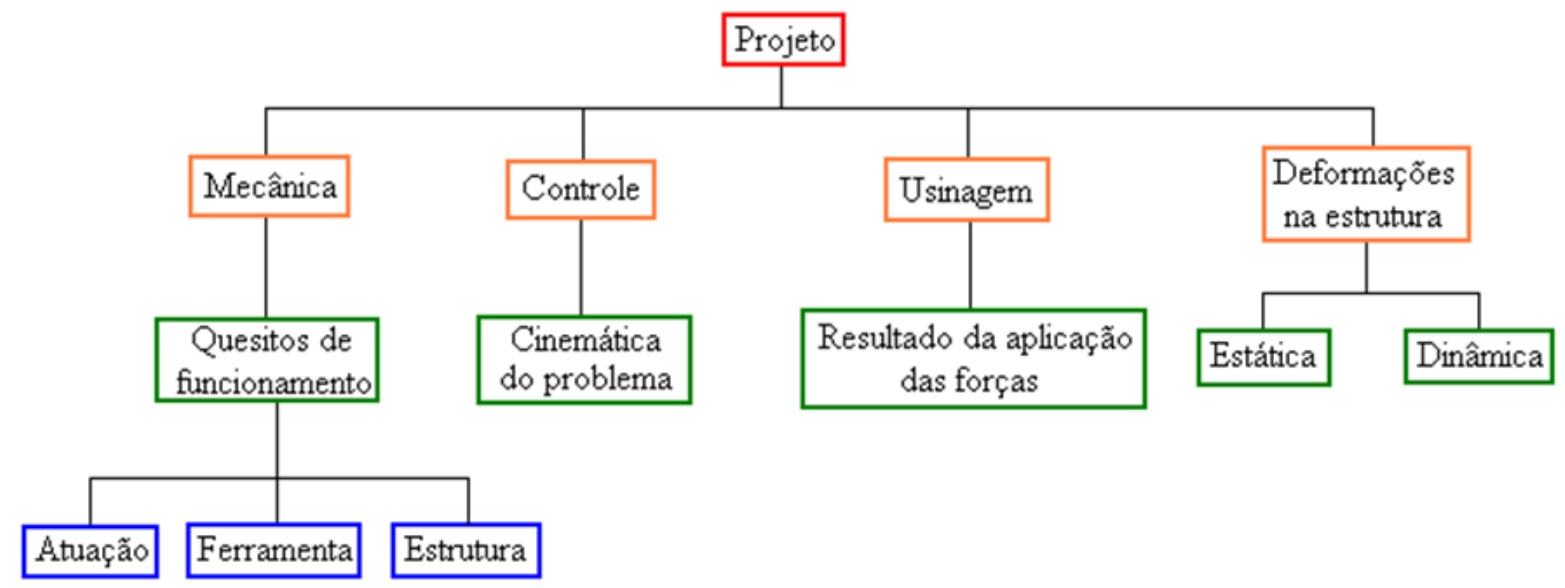

Figura 5 - Diagrama de blocos do projeto.

Através do critério de Kutzbach-Gruebler podemos destacar a seguinte expressão:

$$
M=3 \cdot(n-1)-2 \cdot n_{P 1}-n_{P 2}
$$

Onde $M$ é a mobilidade do sistema, $n$ é o número de ligamentos e $n_{P 1}$ e $n_{P 2}$ são os números de juntas com um e dois graus de liberdade, respectivamente. Para a máquina em questão, como se deseja translação apenas no plano horizontal, tem-se que $M=2$, e só existem juntas com um grau de liberdade apenas. Assim, pode-se simplificar a equação acima para:

$$
5+2 \cdot n_{P 1}=3 \cdot n
$$


Podemos escrever a relação entre o número de juntas com um grau de liberdade e o número total de juntas, expresso acima, como segue na tabela abaixo.

Tabela 3 - Relação entre as juntas e os ligamentos.

\begin{tabular}{|c|c|}
\hline $\mathbf{n p 1}$ & $\mathbf{n}$ \\
\hline 1 & 2,3 \\
\hline 2 & 3,0 \\
\hline 3 & 3,7 \\
\hline 4 & 4,3 \\
\hline 5 & 5,0 \\
\hline 6 & 5,7 \\
\hline 7 & 6,3 \\
\hline 8 & 7,0 \\
\hline
\end{tabular}

Observe que só podem existir números inteiros de peças. Assim, existem três prováveis tipos de máquinas que podem ser construídas pela tabela indicada, como mostra a figura abaixo.

$$
\begin{aligned}
& n p 1=2 \\
& n=3
\end{aligned}
$$

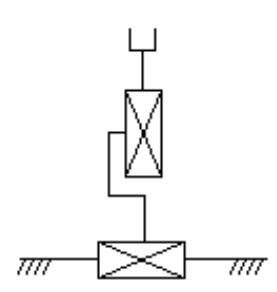

$\underline{P} \underline{P}$ $\mathrm{np} 1=5$

$n=5$

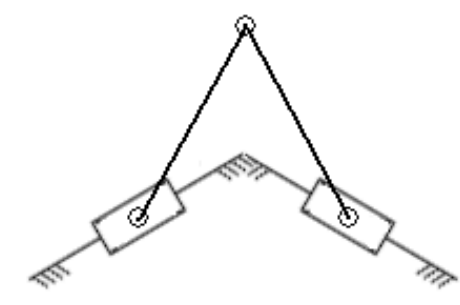

PRRRP $\mathrm{np} 1=8$

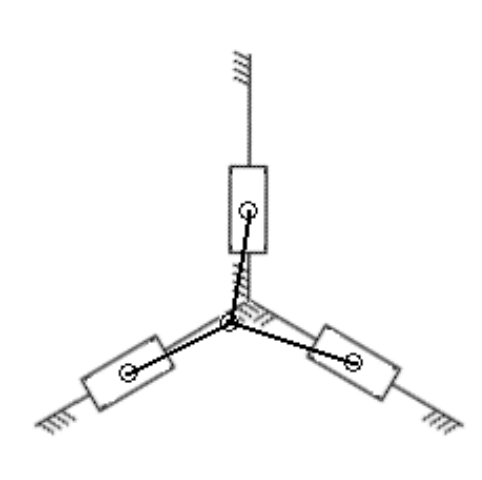

$3 \underline{P} R R$

Figura 6 - Tipos de máquinas possíveis.

Assim, como a proposta para a construção da máquina é uma estrutura em estrela, o último caso é o ideal. Os atuadores devem, portanto, ser lineares, como mostra a junta prismática do croqui.

Dada a facilidade de se encontrar no mercado atuadores lineares de vários tipos, foram escolhidas duas possíveis soluções para essa máquina em particular: mesas deslizantes e braços retráteis. As mesas deslizantes compõem uma estrutura 3ㅁR e os braços retráteis uma $3 \mathrm{R} \underline{\mathrm{PR}}$, como mostra a Figura 7. 


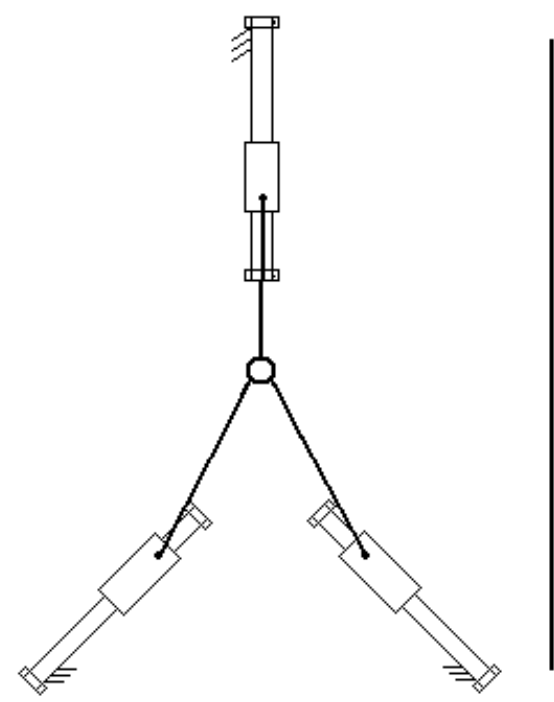

(A)

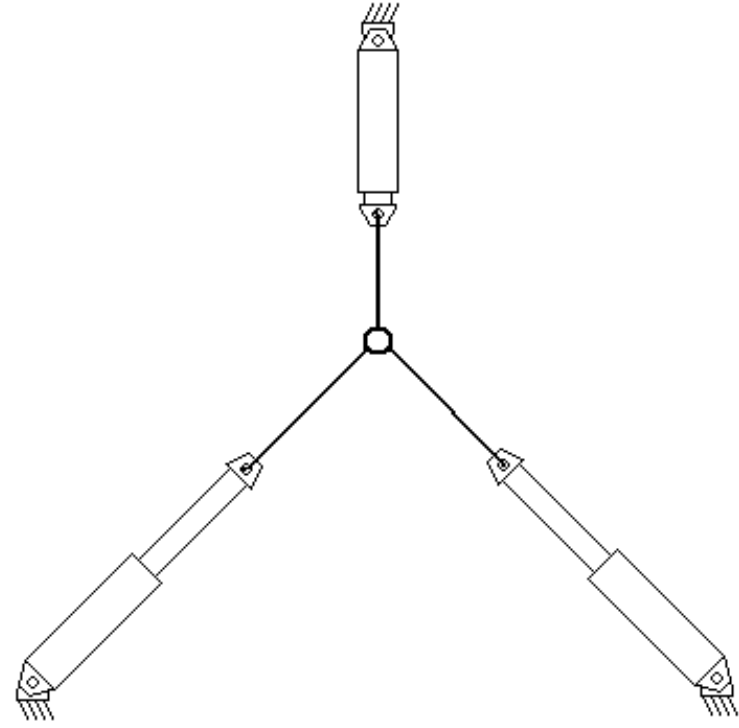

(B)

Figura 7 - Exemplo de arquitetura.

(a) Com mesas deslizantes;

(b) Com braços retráteis.

Aqui se deve fazer uma observação sobre o anel central. Para que a estrutura ainda apresente os graus de liberdade calculados, não pode haver conexões entre os braços e uma plataforma central, ou seja, as conexões dos braços devem ser feitas diretamente na ferramenta, como exemplifica a figura abaixo:

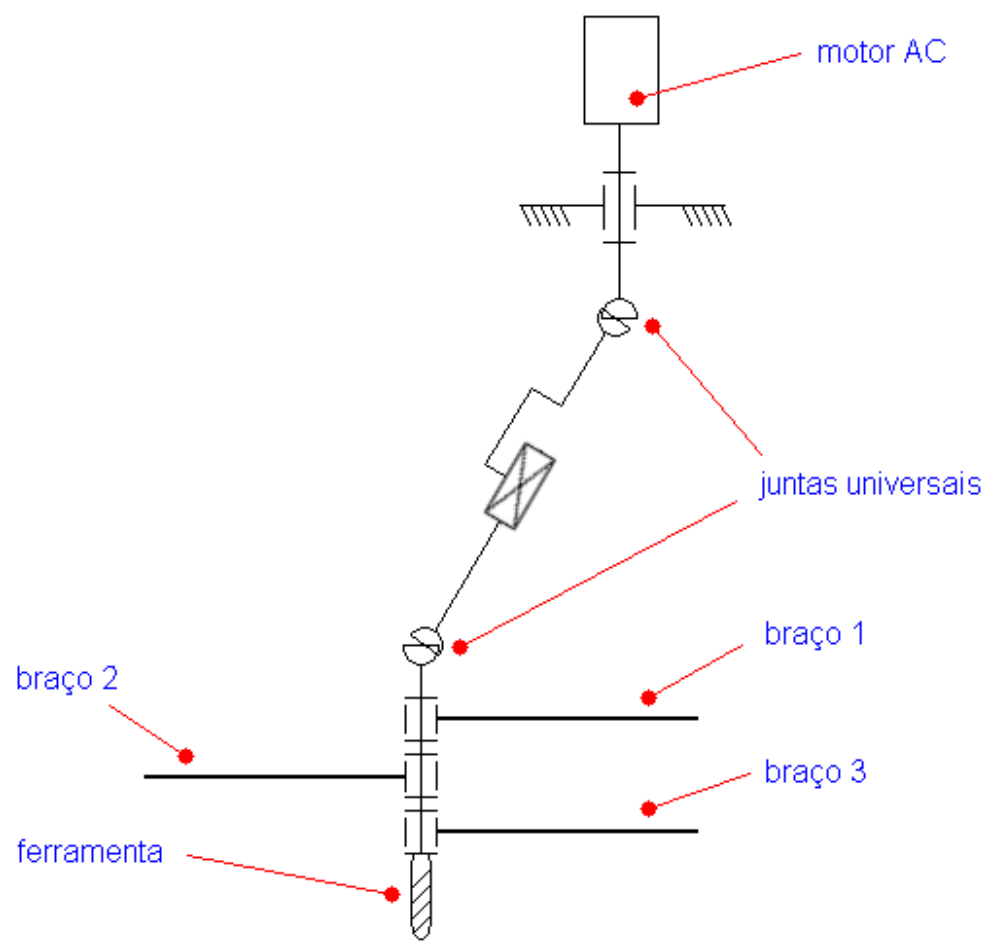

Figura 8 - Exemplo de união do anel central e conexão de potência por juntas universais. 
Até aqui foram mostrados os mecanismos para a movimentação da estrutura no plano 2D. A construção utilizada é paralela, ou seja, existem braços articulados com atuadores fixos na base, que controlam a posição da ferramenta, sendo que sua rotação é dada também por um motor fixo na base.

No entanto, a concepção original do projeto (STIPKOVIC et al., 2007), oriunda de um projeto PITE da Fapesp, previa que a máquina trabalhasse nos três planos. Isso se dá devido a uma razão bem simples: a utilidade prática de uma máquina de usinagem que tem seus movimentos limitados no plano é bem reduzida.

Sendo assim, foi prevista no projeto estrutural a possibilidade de se adicionar um atuador central, também fixo à base, que realizasse os movimentos no eixo perpendicular ao plano dos braços, contemplando assim um espaço de trabalho. Toda a estrutura, ao final, continuaria sendo paralela, composta por cinco motores responsáveis por posicionar a mesa de usinagem, movimentar a ferramenta e fornecer potência para a realização de trabalhos.

Essa possibilidade não foi considerada no desenvolvimento do trabalho, pois o foco, nesse caso particular, era a determinação da rigidez na área de trabalho e o controle para a realização da usinagem. 


\section{ANÁLISE CINEMÁTICA}

Para o controle dos motores deve ser encontrada a relação existente entre os três motores e o plano de trabalho. Essa relação é determinada através da cinemática direta ou inversa. A diferença entre elas é que, na cinemática direta, impomos como variáveis independentes os deslocamentos impostos pelos atuadores e como dependentes a posição no espaço x, y e z.

$\mathrm{Na}$ cinemática inversa ocorre o contrário: adota-se como variável independente a posição no espaço x, y e z, e as dependentes são os deslocamentos impostos pelos motores. Para o caso específico dessa máquina, existe apenas o movimento da ferramenta no plano horizontal, ou seja, apenas x e y. As convenções utilizadas nas deduções podem ser vistas na Figura 9.

Seria possível utilizar a cinemática direta e, através de manipulação adequada, encontrar a relação inversa. No entanto, por uma questão de simplificação de cálculos e redução de uso de CPU, optou-se por apenas enunciar a cinemática direta, mas utilizar no trabalho a cinemática inversa.

\subsection{CINEMÁTICA DIRETA}

A máquina é composta de três atuadores, mas seriam suficientes dois apenas para controlá-la. Sendo assim, devem-se apenas resolver as equações para dois atuadores e colocar o terceiro em função deles. Abaixo está a figura com a nomenclatura considerada. 


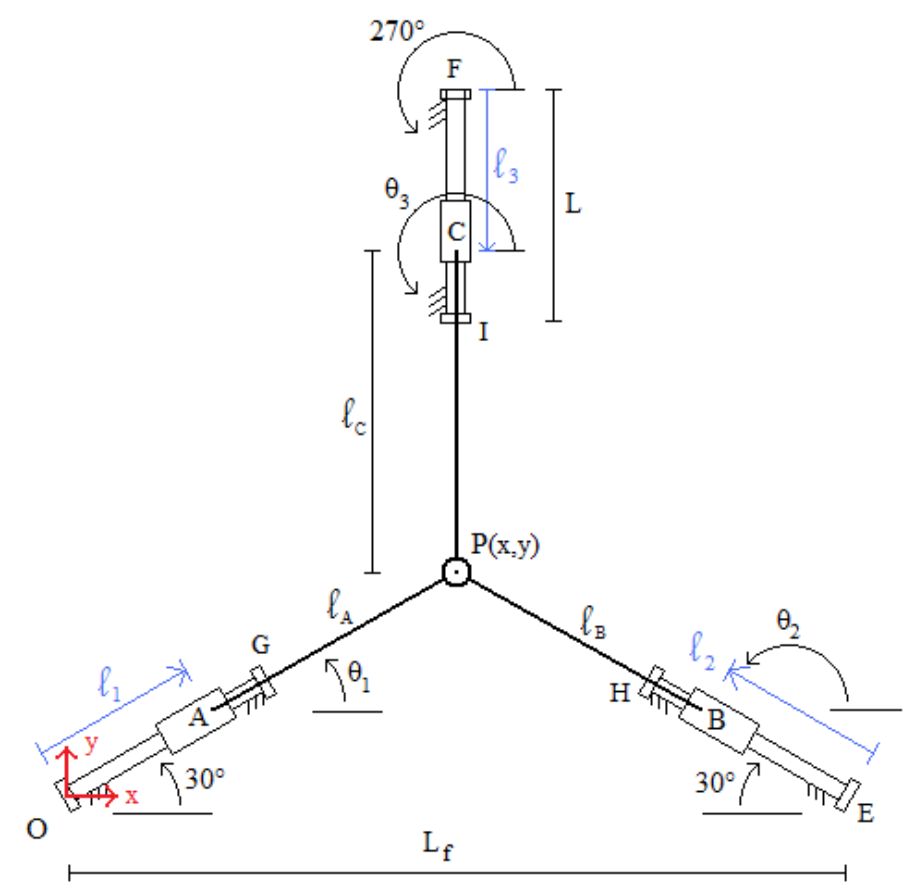

Figura 9 - Convenções para as fórmulas.

As variáveis independentes aqui são $l_{1}$ e $l_{2}$. As demais, $l_{3}, P, \theta_{1}, \theta_{2}$ e $\theta_{3}$ são as dependentes. Precisa-se então definir $\theta_{1}=f\left(l_{1}, l_{2}\right), \quad \theta_{2}=f\left(l_{1}, l_{2}\right), \quad \theta_{3}=f\left(l_{1}, l_{2}\right)$, $l_{3}=f\left(l_{1}, l_{2}\right) \quad$ e $\quad P=f\left(l_{1}, l_{2}\right)$. Inicia-se pelos ângulos $\theta_{1}$ e $\theta_{2}$. Assim, $(P-B)+(A-P)+(B-A)=\overrightarrow{0}$. Da figura pode-se obter:

$$
\left\{\begin{array}{l}
(P-B)=l_{B} \cdot e^{j \theta 2} \\
(A-P)=-(P-A)=-l_{A} \cdot e^{j \theta 1} \\
(B-A)=l_{2} \cdot e^{j 150}+L_{f}-l_{1} \cdot e^{j 30}
\end{array}\right.
$$

Substituindo essas equações na original, admitindo $l_{A}=l_{B}=l_{C}=l$, isolando $\theta_{1}$, e fazendo as devidas simplificações, ela pode ser simplificada para: $\bar{A} \cdot \cos \left(\theta_{1}\right)+\bar{B} \cdot \operatorname{sen}\left(\theta_{1}\right)+\bar{G}=0$, onde as funções $\bar{A}, \bar{B}$ e $\bar{G}$ são dadas por: 


$$
\left\{\begin{array}{l}
\bar{A}=l_{1} \cdot \operatorname{sen}(30)-L_{f}-l_{2} \cdot \cos (150) \\
\bar{B}=l_{1} \cdot \operatorname{sen}(30)-l_{2} \cdot \operatorname{sen}(150) \\
\bar{G}=\frac{\left(\bar{A}^{2}+\bar{B}^{2}\right)}{2 \cdot l}
\end{array}\right.
$$

Escrevendo que $u=\operatorname{tg}\left(\frac{\theta_{1}}{2}\right)$, os termos da equação 7 podem ser reescritos da seguinte forma: $\cos \left(\theta_{1}\right)=\frac{1-u^{2}}{1+u^{2}}$ e $\operatorname{sen}\left(\theta_{1}\right)=\frac{2 \cdot u}{1+u^{2}}$. Ao se resolver a equação e substituir todos os valores para se achar $\theta_{1}$, encontra-se o seguinte resultado:

$$
\theta_{1}=\arccos \left(\frac{1-u^{2}}{1+u^{2}}\right)=\operatorname{arcsen}\left(\frac{2 \cdot u}{1+u^{2}}\right)
$$

Através do mesmo raciocínio, pode-se identificar $\theta_{2}$, como se segue:

$$
\theta_{2}=\arccos \left(\frac{1-v^{2}}{1+v^{2}}\right)=\operatorname{arcsen}\left(\frac{2 \cdot v}{1+v^{2}}\right)
$$

Onde $v=\operatorname{tg}\left(\frac{\theta_{2}}{2}\right)$. Assim, foram definidas duas das cinco funções desejadas. Para determinar $P$, a seguinte equação deve ser resolvida: $(P-E)=(B-E)+(P-B)$. Como o primeiro termo é exatamente as coordenadas do ponto, tem-se:

$$
\left\{\begin{array}{l}
x=l_{2} \cdot \cos (150)+l \cdot \cos \left(\theta_{2}\right) \\
y=l_{2} \cdot \operatorname{sen}(150)+l \cdot \operatorname{sen}\left(\theta_{2}\right)
\end{array}\right.
$$

Analogamente, para $l_{3}$ e $\theta_{3}$, omitindo já os cálculos, pode-se escrever: 


$$
\begin{gathered}
l_{3}=\frac{2 \cdot \bar{S} \cdot \operatorname{sen}(270) \pm \sqrt{4 \cdot\left(l^{2}-\bar{R}^{2}\right)}}{2} \\
\theta_{3}=\arccos \left(\frac{\bar{R}-l_{3} \cdot \cos (270)}{l}\right)=\operatorname{arcsen}\left(\frac{\bar{S}-l_{3} \cdot \operatorname{sen}(270)}{l}\right) \\
\text { Onde }\left\{\begin{array}{l}
\bar{R}=l \cdot \cos \left(\theta_{2}\right)+l_{2} \cdot \cos (150)-L_{f} \cdot \cos (120) \\
\bar{S}=l \cdot \operatorname{sen}\left(\theta_{2}\right)+l_{2} \cdot \operatorname{sen}(150)-L_{f} \cdot \operatorname{sen}(120)
\end{array}\right.
\end{gathered}
$$

\subsection{CINEMÁTICA INVERSA}

Pode-se observar, do tópico anterior, que a cinemática direta é muito eficiente para se determinar a posição do ponto $P$ em função da posição dos atuadores. No entanto, como o objetivo de uma máquina é seguir uma trajetória definida, esse tipo de equacionamento não é ideal. Assim, é necessário reescrever as equações de forma que a posição dos atuadores seja uma função das coordenadas do ponto $P$. Da mesma forma, nota-se que a simples inversão de variáveis tornaria a resolução computacional complicada, já que $l_{3}$ e $\theta_{3}$ estão em função de $l_{1}, \theta_{1}, l_{2}$ e $\theta_{2}$ que, por sua vez, estão escritos em função das coordenadas do ponto $P$.

Assim, optou-se por utilizar outra forma de se escrever as mesmas equações, descrita a seguir.

$$
\begin{gathered}
f_{1}\left(l_{1}\right)=(P-A)^{2}=l_{A}^{2}=l^{2} \\
f_{1}\left(l_{1}\right)=(P-A)^{2}-l^{2}=0 \\
f_{1}\left(l_{1}\right)=\left[(x, y)-\left(l_{1} \cdot \cos (30), l_{1} \cdot \operatorname{sen}(30)\right)\right]^{2}-l^{2}=0 \\
f_{1}\left(l_{1}\right)=\left(x-l_{1} \cdot \cos (30), y-l_{1} \cdot \operatorname{sen}(30)\right)^{2}-l^{2}=0
\end{gathered}
$$




$$
f_{1}\left(l_{1}\right)=\left(x-l_{1} \cdot \cos (30), y-l_{1} \cdot \operatorname{sen}(30)\right) \cdot\left(\begin{array}{l}
x-l_{1} \cdot \cos (30) \\
y-l_{1} \cdot \operatorname{sen}(30)
\end{array}\right)-l^{2}=0
$$

Realizando a multiplicação indicada, que é o produto escalar do vetor $(P-A)$ por si mesmo, e realizando as simplificações necessárias, pode-se obter a seguinte equação de posição:

$$
f_{1}\left(l_{1}\right)=l_{1}^{2}-2(x \cdot \cos (30)+y \cdot \operatorname{sen}(30)) \cdot l_{1}+x^{2}+y^{2}-l^{2}=0
$$

Analogamente, para os membros $l_{2}$ e $l_{3}$, pode-se obter as seguintes equações:

$$
\begin{gathered}
f_{2}\left(l_{2}\right)=l_{2}^{2}+2\left[\left(x-L_{f}\right) \cdot \cos (30)-y \cdot \operatorname{sen}(30)\right] \cdot l_{2}+\left(x-L_{f}\right)^{2}+y^{2}-l^{2}=0 \\
f_{3}\left(l_{3}\right)=l_{3}^{2}+2\left(y-\frac{L_{f} \cdot \sqrt{3}}{2}\right) \cdot l_{3}+\left(x-\frac{L_{f}}{2}\right)^{2}+\left(y-\frac{L_{f} \cdot \sqrt{3}}{2}\right)^{2}-l^{2}=0
\end{gathered}
$$

As equações de segundo grau podem ser resolvidas facilmente, e seu resultado fornecerá duas soluções possíveis, $l^{(1)}$ e $l^{(2)}$, determinando sempre duas posições dos atuadores para um determinado ponto $P$. O resultado pode ser interpretado como a intersecção entre um círculo de raio $l$ e um segmento de reta, como mostra a figura abaixo:

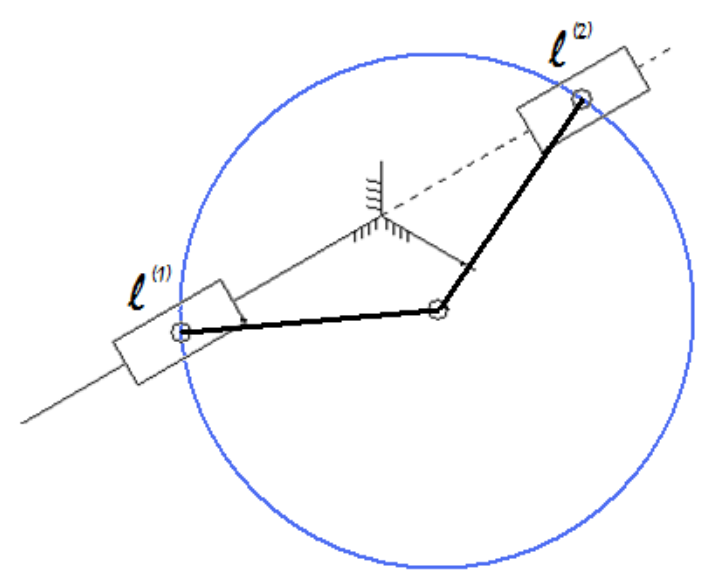

Figura 10 - Possíveis soluções. 
Devido às condições de construção da máquina e do modelo matemático assumido, desde que os dados de entrada estejam dentro da área de trabalho, deve-se sempre utilizar a menor solução positiva das equações, $l^{(l)}$, o que garante que o comprimento encontrado estará dentro do limite físico da guia.

De posse dos resultados, podemos ainda determinar os ângulos formados pelos membros, em uma determinada posição da ferramenta:

$$
\begin{gathered}
\theta_{1}=\arccos \left(\frac{x-l_{1} \cdot \cos (30)}{l}\right) \\
\theta_{2}=\arccos \left(\frac{x+l_{2} \cdot \cos (30)-L_{f}}{l}\right) \\
\theta_{3}=\arccos \left(\frac{x-\frac{L_{f}}{2}}{l}\right)
\end{gathered}
$$

Vale ressaltar que, assim como na determinação das posições dos atuadores, os resultados da determinação dos ângulos também devem ser tratados. No caso das equações 22 e 23, deve-se utilizar o valor dos ângulos que estejam entre 0 e m e, no caso da equação 24 , o valor entre $\pi$ e $2 \pi$.

A determinação desses ângulos é importante para a verificação geométrica do algoritmo desenvolvido: através deles foi programada uma rotina que desenha o ponto escolhido na área de trabalho através tanto das soluções lineares quanto das angulares, de forma que incoerências puderam ser localizadas antes de executado o programa principal. 


\section{ANÁLISE ESTÁTICA}

A análise estática será descrita para a máquina com três atuadores, sendo que será feita, ao final, uma consideração para o caso com dois atuadores apenas.

Para o modelo desenvolvido, foi considerada a estrutura das guias como sendo totalmente rígida, sendo que as deformações ocorrem apenas nos braços. Dessa forma, o sistema pode ser representado como mostra a figura abaixo:

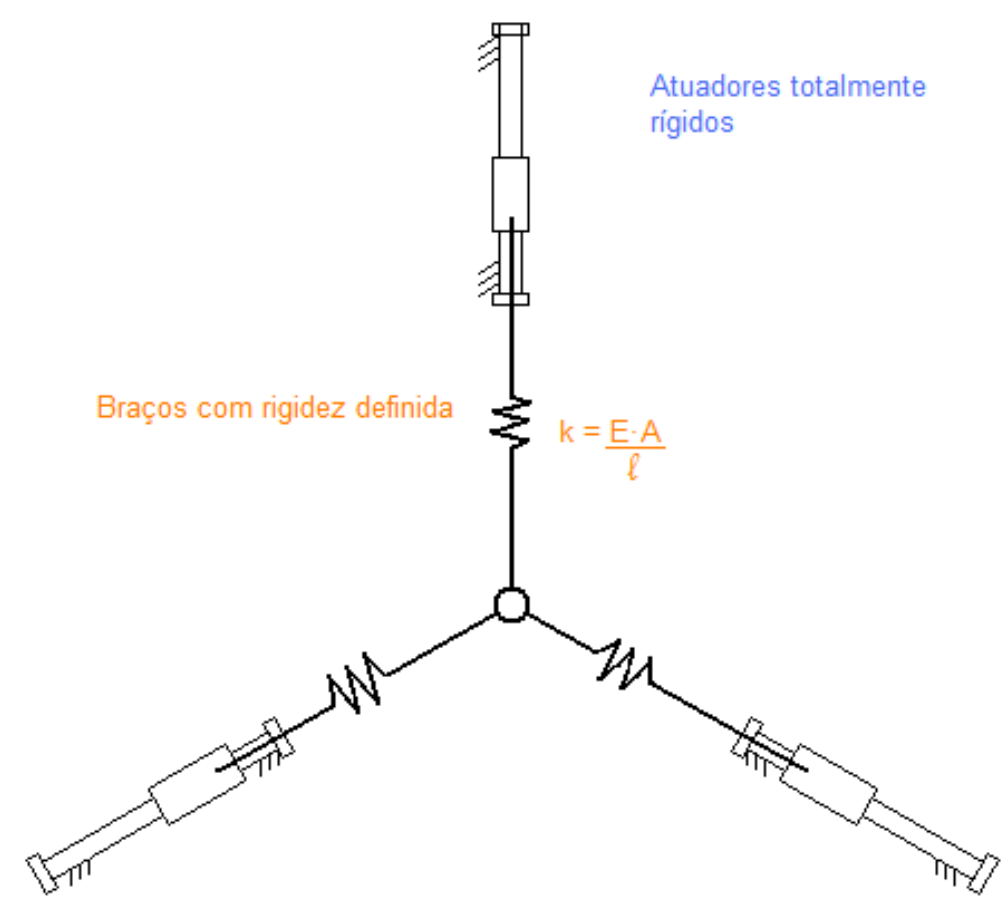

Figura 11 - Representação do sistema.

Será utilizado o modelo do Princípio dos Trabalhos Virtuais (PTV). Nesse modelo, o trabalho exercido pela força de usinagem, $F$, no percurso do trajeto da operação, é relacionado com o trabalho virtual exercido pelas forças nas barras para compensar a força F. Essa relação pode ser escrita da seguinte forma:

$$
\vec{\tau} \cdot \delta \overrightarrow{\mathrm{q}}=\overrightarrow{\mathrm{F}} \cdot \delta \overrightarrow{\mathrm{x}}
$$

O termo $\vec{\tau} \cdot \delta \vec{q}$ corresponde, nesse caso, ao trabalho virtual das forças internas nas barras para suas respectivas deformações. Da mesma forma, o termo $\vec{F} \cdot \delta \vec{x}$ 
corresponde ao trabalho exercido pelo deslocamento da ferramenta no trajeto da usinagem.

A matriz de rigidez, em função da rigidez de cada braço, pode ser escrita da seguinte forma:

$$
\chi=\left[\begin{array}{ccc}
\mathrm{k} & 0 & 0 \\
0 & \mathrm{k} & 0 \\
0 & 0 & \mathrm{k}
\end{array}\right]
$$

No entanto, devido à rotação de cada braço, a matriz final terá outro formato. Para determiná-la é necessário encontrar os Jacobianos da ferramenta e dos atuadores. Escrevendo as equações de posição da seguinte maneira os Jacobianos podem ser facilmente encontrados:

$$
\begin{aligned}
& X_{a}=l_{1} \cdot \operatorname{cosd}(30) \\
& Y_{a}=l_{1} \cdot \operatorname{sind}(30) \\
& X_{b}=L_{f}-l_{2} \cdot \operatorname{cosd}(30) \\
& Y_{b}=l_{2} \cdot \operatorname{sind}(30) \\
& X_{c}=\frac{L_{f}}{2} \\
& Y_{c}=L_{f} \cdot \frac{\sqrt{3}}{\left(2-l_{3}\right)}
\end{aligned}
$$

As funções cosd e sind são as próprias funções cosseno e seno, mas diferenciadas de forma a deixar claro que a entrada de dados é feita em graus, e não em radianos. Através delas pode-se obter:

$$
\begin{aligned}
& J_{x}=\left[\begin{array}{ll}
x-x_{a} & y-y_{a} \\
x-x_{b} & y-y_{b} \\
x-x_{c} & y-y_{c}
\end{array}\right] \\
& J_{q}=\left[\begin{array}{lll}
1 & 0 & 0 \\
0 & 1 & 0 \\
0 & 0 & 1
\end{array}\right]
\end{aligned}
$$




$$
\mathrm{J}=\mathrm{J}_{\mathrm{q}}^{-1} \cdot \mathrm{J}_{\mathrm{x}}
$$

Utilizando as equações 26 e 35 , a matriz de rigidez final do sistema toma a seguinte forma:

$$
\mathrm{K}=\mathrm{J}^{\mathrm{t}} \cdot \chi \cdot \mathrm{J}
$$

Através dessa matriz e do vetor de forças aplicadas, os deslocamentos podem ser determinados a partir de um sistema simples de equações:

$$
\mathrm{F}_{\mathrm{p}}=\mathrm{K} \cdot \delta \mathrm{x}
$$

Onde: $F_{p}=\left[\begin{array}{l}P \\ Q\end{array}\right]$

A solução do sistema para o caso de uma máquina com apenas dois atuadores é análoga ao apresentado acima, com a diferença de que as matrizes correspondentes devem ser representadas com duas dimensões somente, e não três como é o caso descrito. 


\section{DESCRIÇÃO DO SUBSISTEMA MECÂNICO PROJETADO PARA A MÁQUINA FRESADORA PARALELA}

Neste capítulo, descreve-se o subsistema mecânico projetado para a máquina fresadora paralela (Figura 12). Nas seções a seguir, são incluídos comentários específicos acerca da fabricação dos seus componentes e sua montagem.

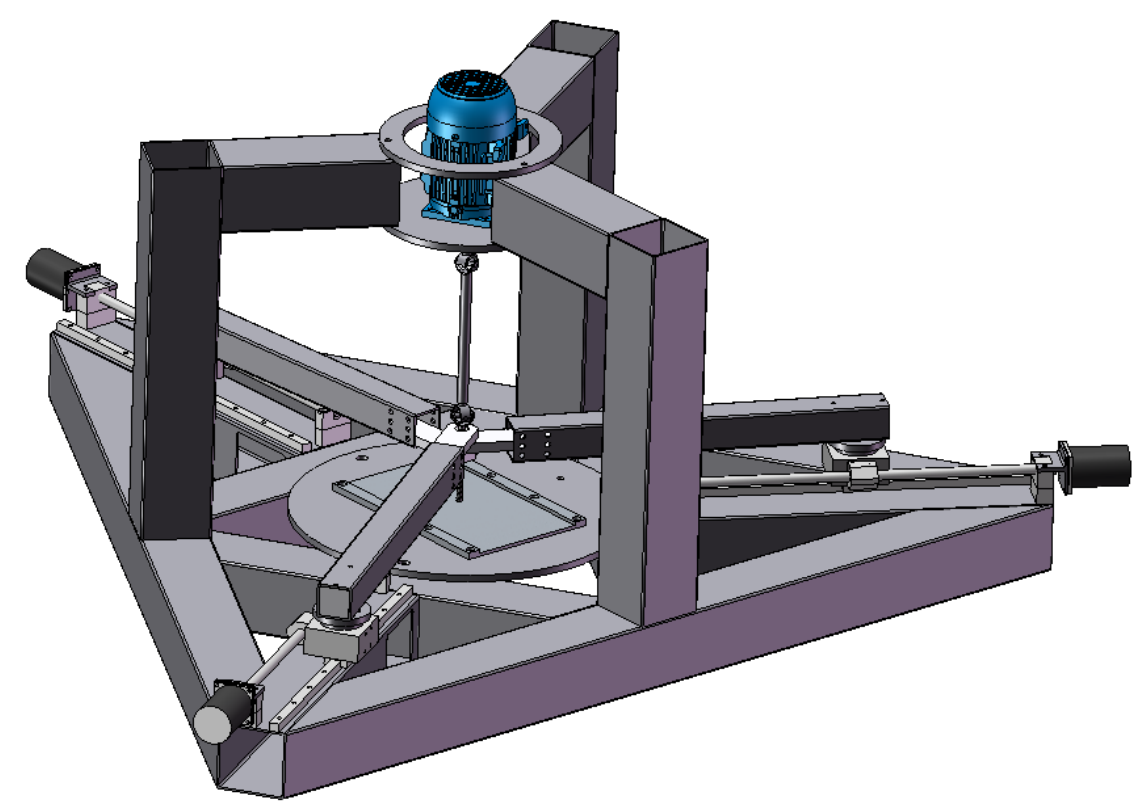

Figura 12 - Visão geral da máquina.

\subsection{A BASE}

A base é composta por tubos de aço de seção quadrada com lado $100 \mathrm{~mm}$ e espessura $3 \mathrm{~mm}$. Os tubos foram separados e classificados de acordo com sua forma e função exercida, existindo cinco tipos diferentes, listados abaixo. 


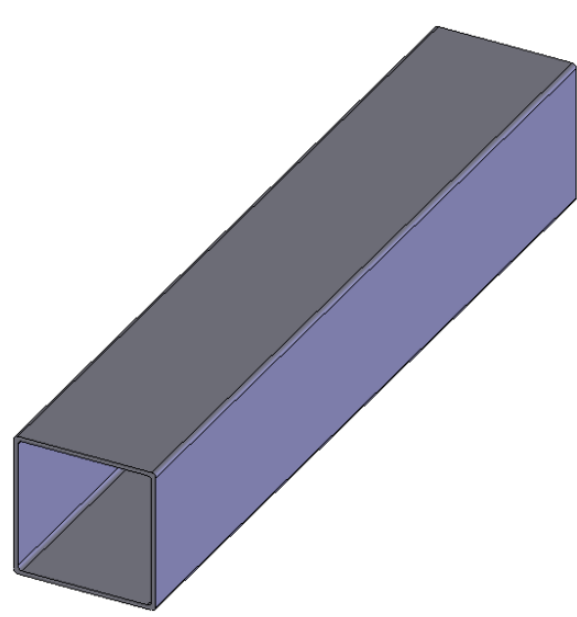

(a)

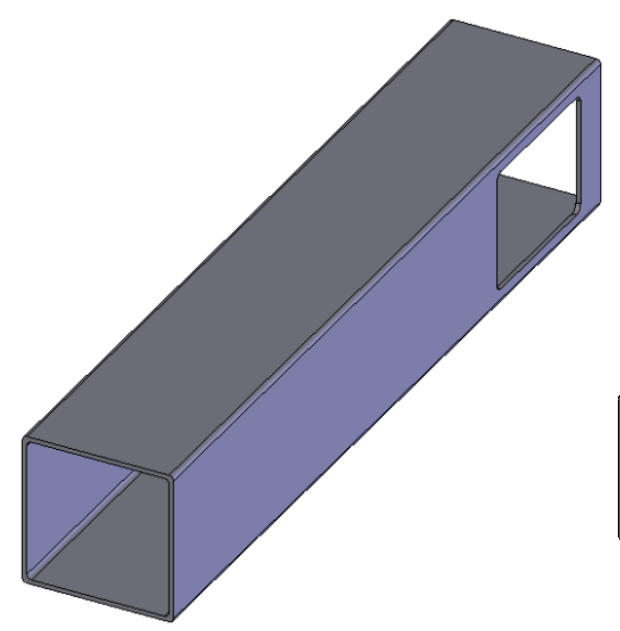

(c)

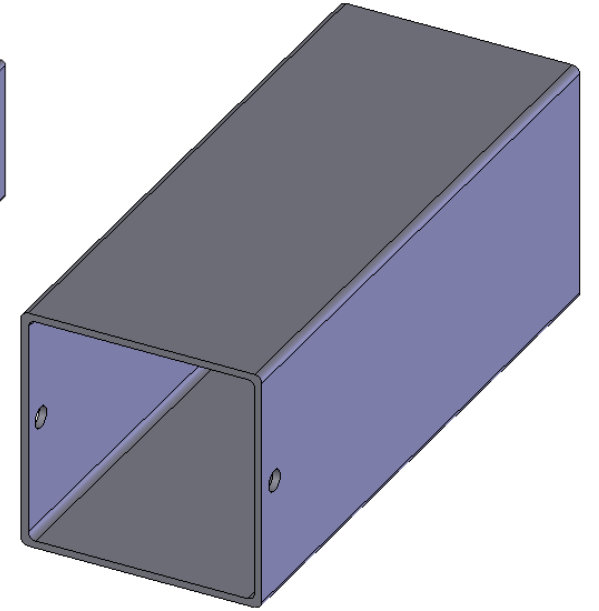

(b)

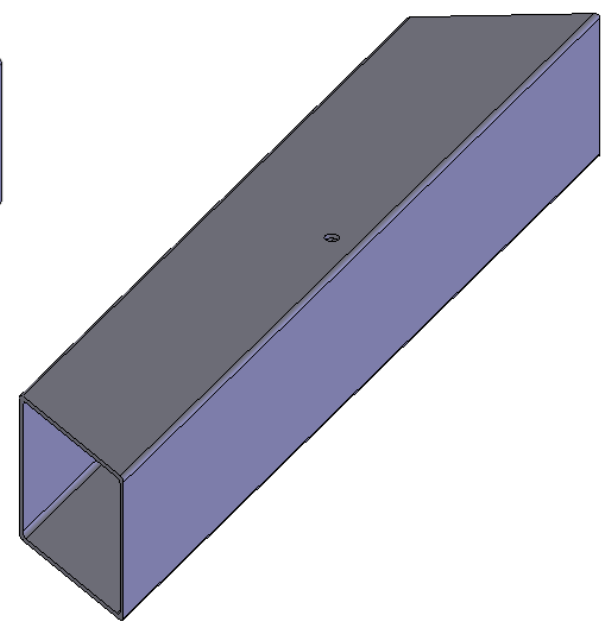

(d)

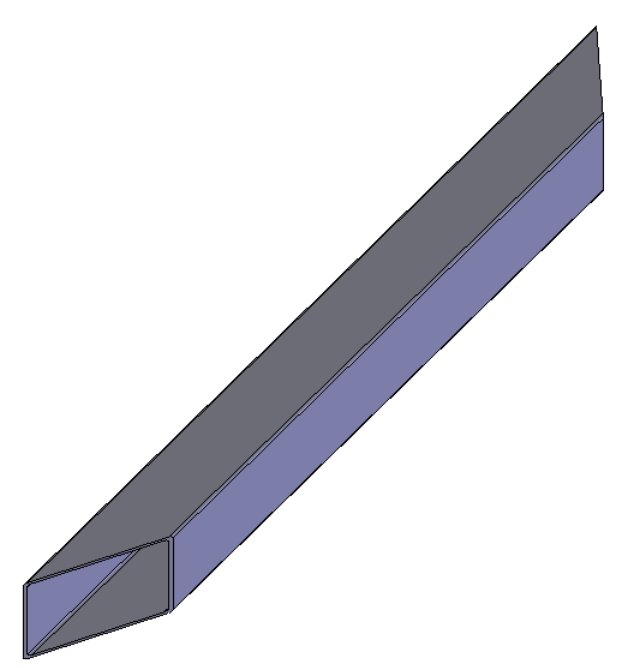

(e)

Figura 13 - Tubos de suporte.

(a) Tubo vertical para sustentação do motor;

(b) Tubo para fixação do motor;

(c) Tubo para fixação das guias e trilhos;

(d) Tubo para fixação interna das guias e trilhos;

(e) Tubo de interconexão lateral. 
Todos os tubos serão soldados entre si e não haverá tratamento especial de quaisquer superfícies. Os furos também estão isentos de tratamento, salvo remoção de rebarbas.

Definido o posicionamento dos atuadores, seguimos na determinação da base de sustentação que definirá o corpo principal da máquina. A seguir são mostrados os principais esquemas de construção considerados, seguidos de uma breve descrição de suas características.

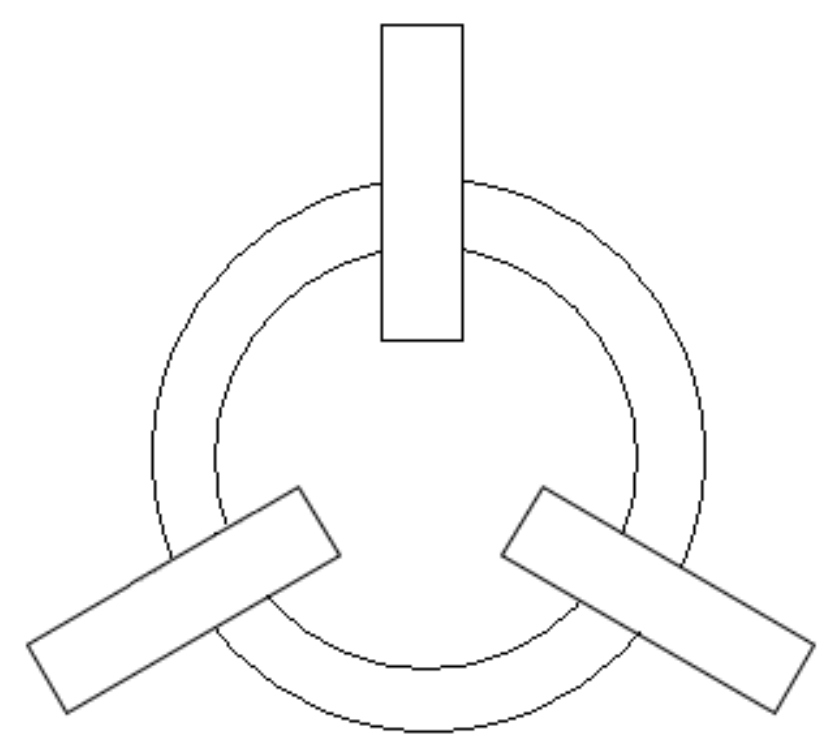

Figura 14 - União por segmentos circulares.

A primeira idéia baseou-se numa união ideal e serviu apenas de ponto de partida para as escolhas. Segmentos circulares são difíceis de fazer, mesmo com baixa precisão. Além disso, posicionar corretamente o ângulo entre as guias seria complicado, pois não existem segmentos lineares de referência. Sendo assim, passou-se a uma simplificação linear da construção acima. 


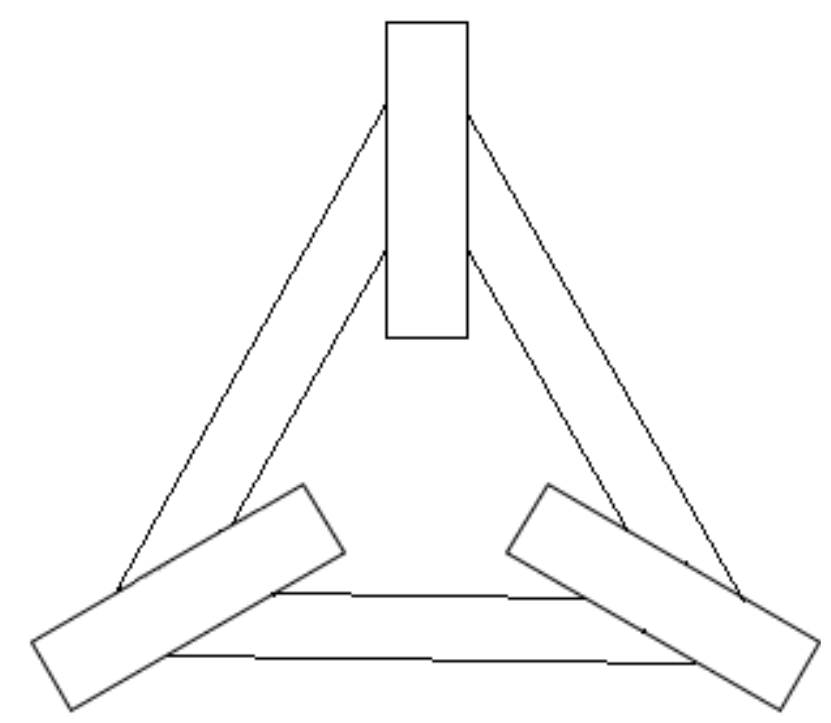

Figura 15 - União por segmentos lineares nos centros.

A idéia principal de conexão aqui continua a mesma, porém muito mais fácil de ser fabricada. A razão pela qual não foi escolhida foi a possibilidade de que houvesse torção devido aos esforços de usinagem. Os pontos de apoio, nesse caso os extremos dos tubos onde serão presos os atuadores, estão livres, tendo a estrutura maior liberdade para a torção.

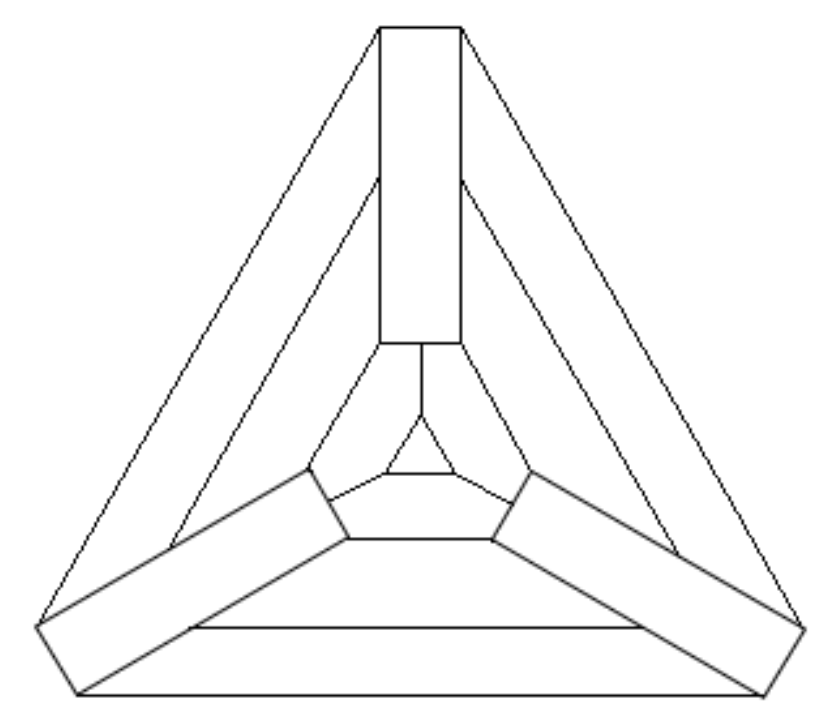

Figura 16 - Estrutura em duplo triângulo.

A estrutura em duplo triângulo mostrou-se vantajosa nesse aspecto, já que todas as extremidades dos tubos estão conectadas. O limitador aqui foi a quantidade de material que deveria ser utilizada para que as distâncias fossem respeitadas. $O$ fato de haver dois triângulos concêntricos aumenta consideravelmente o peso e o 
tamanho da estrutura. Substituindo-se o triângulo interno por um "Y", pôde-se obter uma estrutura mais leve e firme de tal maneira que possibilitasse a inclusão do suporte da ferramenta em um de seus lados.

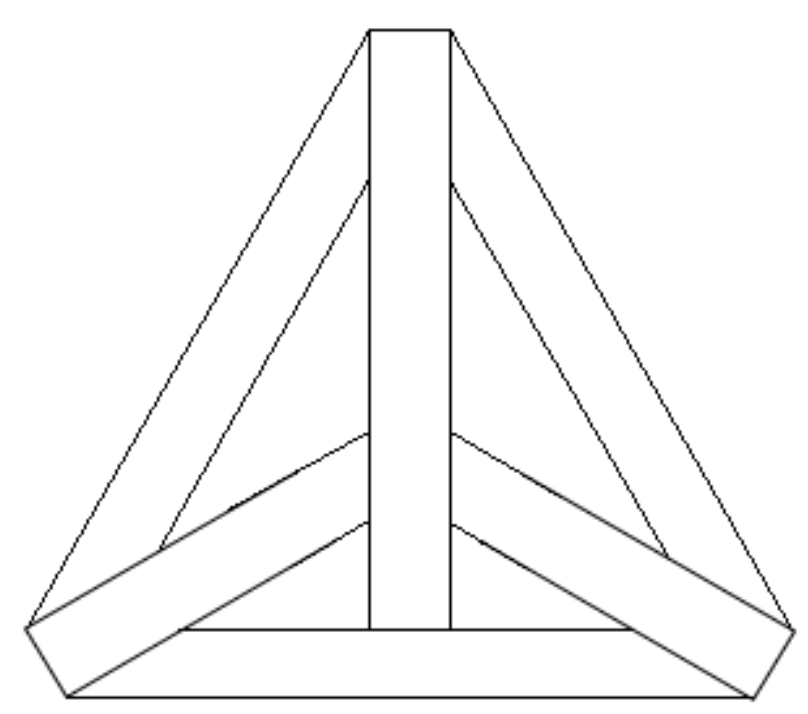

Figura 17 - Triângulo com "Y" interno.

Nesse caso aparece outro problema: a simetria da máquina só existe lateralmente, e em apenas uma linha de centro. Como as propriedades e a maioria dos comportamentos que ela pode apresentar serão determinadas experimentalmente, é desejável que a estrutura seja integralmente simétrica, para evitar que, para um mesmo modo, diferentes freqüências de ressonância ocorram em lugares diferentes da máquina.

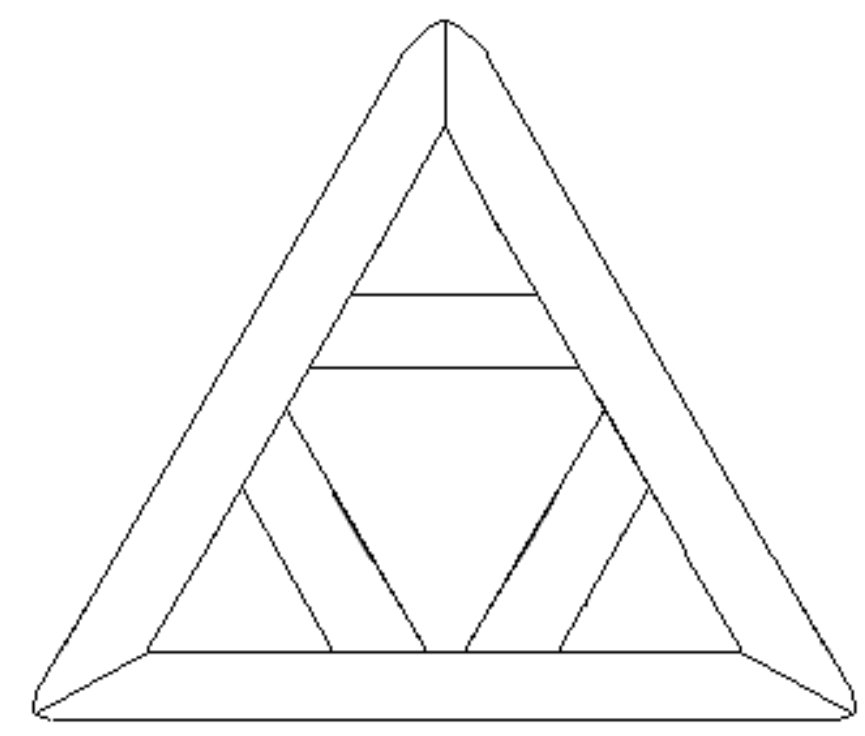

Figura 18 - Estrutura triplo triângulo. 
Outra alternativa era o uso de triplo triângulo. O problema dessa estrutura é a colocação das guias na união entre os tubos. Como a soldagem é manual e sem precisão, a guia pode não se apoiar corretamente nesses extremos. Optou-se então por tubos colocados nas extremidades, como mostra a figura seguinte:

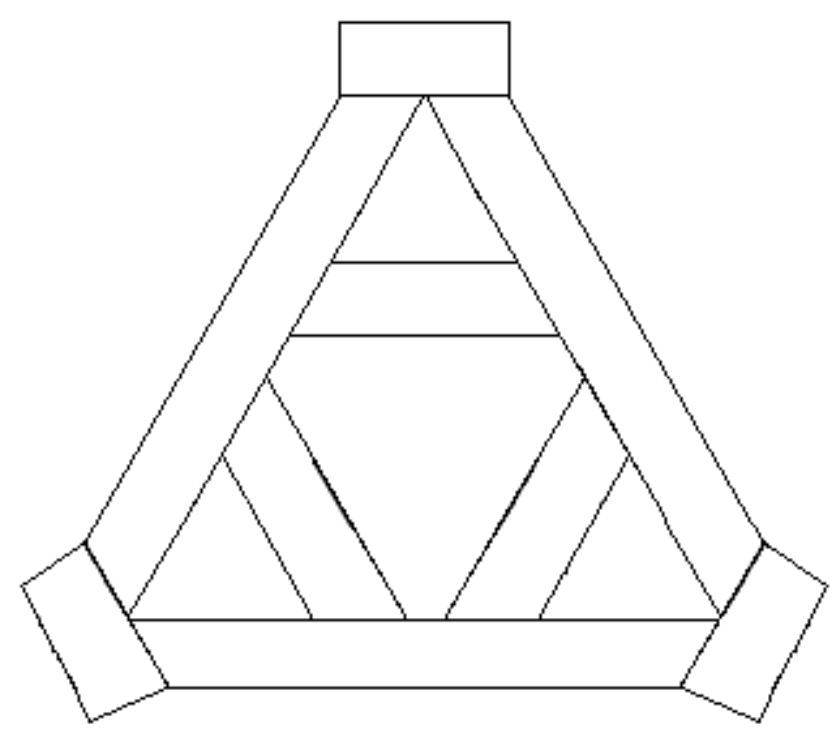

Figura 19 - Penúltima estrutura de suporte da máquina.

Após análise das opções anteriores, e considerando que, para uma fixação dos atuadores diretamente nos tubos seria necessária a fabricação de um adaptador da largura, chegou-se à forma da estrutura final, que é a estrutura triplo " $T$ " abaixo:

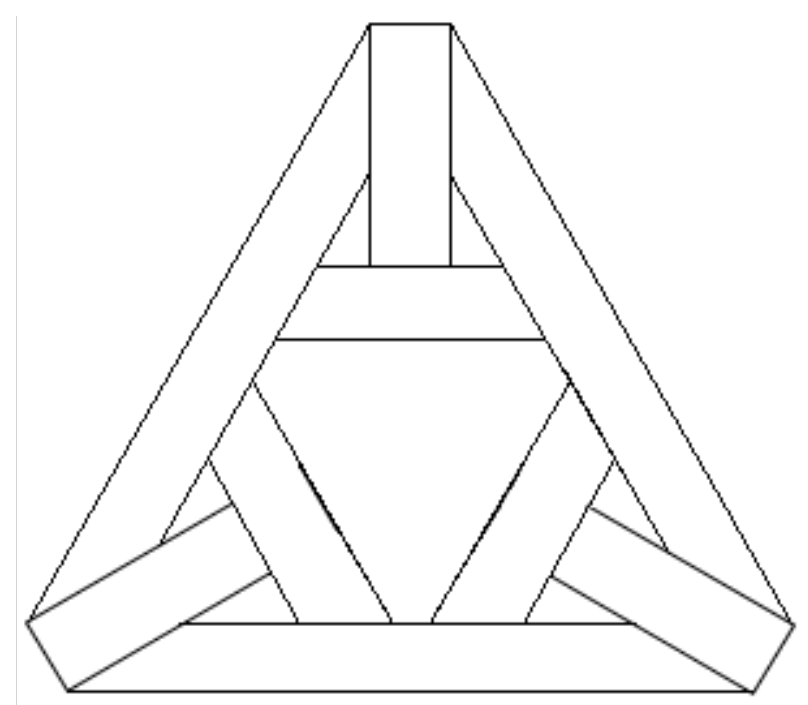

Figura 20 - Estrutura final de montagem triplo "T". 


\subsection{AS GUIAS}

Serão utilizadas três guias de $450 \mathrm{~mm}$ de comprimento. Nenhuma de suas partes será alterada, sendo aplicadas em seu estado de aquisição. Para este trabalho ela foi dividida em duas partes principais, como mostra a figura abaixo.

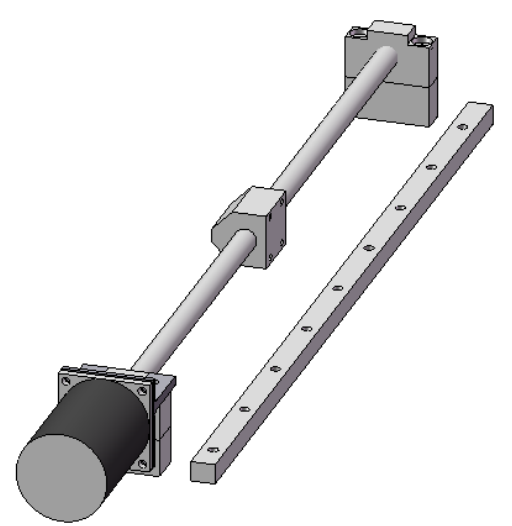

(a)

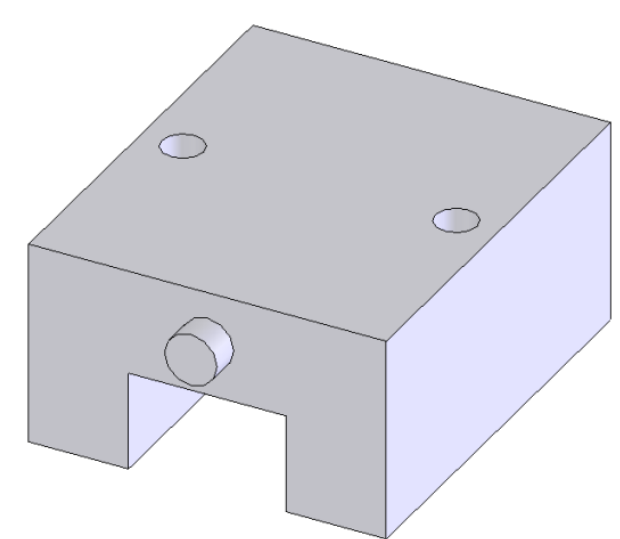

(b)

Figura 21 - Guia linear.

(a) Guia e fuso de acionamento;

(b) Patim deslizante.

\subsection{O MOTOR CC E SUPORTE}

Os motores utilizados serão de passo, sem alteração em sua estrutura. Para fixação nas guias, deverão ser confeccionados suportes, como mostrados a seguir. 


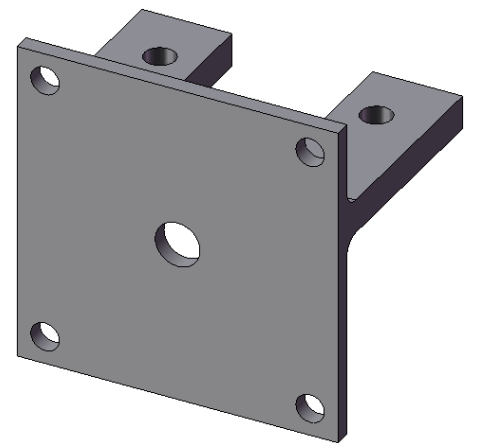

(a)

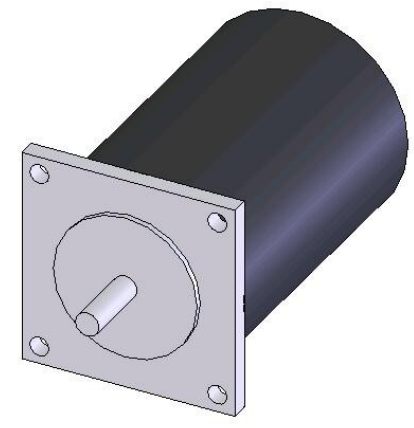

(b)

Figura 22 - Motor e suporte.

(a) Suporte de sustentação do motor;

(b) Motor de passo.

Os suportes são de aço e não terão nenhum tratamento de sua superfície, salvo novamente remoção de rebarbas.

\subsection{BLOCO DE FIXAÇÃO DA BUCHA E A BUCHA}

O bloco de fixação da bucha possui as mesmas dimensões laterais da mesa deslizante, alterando somente sua altura, $50 \mathrm{~mm}$. A união da bucha com o bloco será feita no diâmetro de 59mm, e será incerta, para facilitar a manutenção. Os materiais utilizados serão alumínio para o bloco e cobre para a bucha.

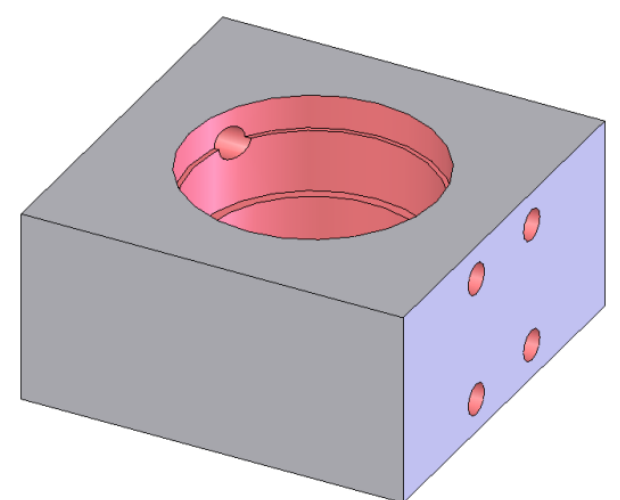

(a)

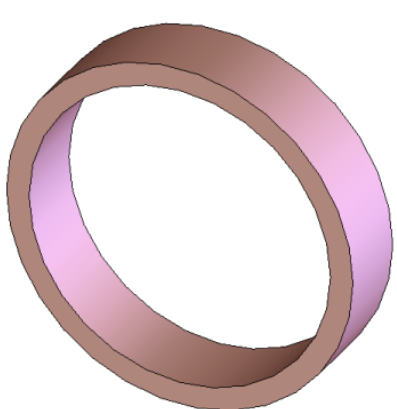

(b)

Figura 23 - Bloco e bucha.

(a) Bloco de alumínio;

(b) Bucha de cobre. 
A fabricação da parte externa da bucha deverá ser com tolerância r6, e a parte interna do bloco com H7. Isso garante ajuste incerto e a fixação da bucha no bloco. Sua parte interna terá qualidade $\mathrm{H} 9$, sendo que a rugosidade não será determinada devido ao pequeno movimento de rotação envolvido nessas peças, não impactando em grande desgaste.

\subsection{EIXO DE ROTAÇÃO DO BRAÇO DE ACIONAMENTO}

O eixo de rotação de acionamento, feito de aço, possui três cilindros de dimensões crescentes, cada qual com sua finalidade. Veja a figura.

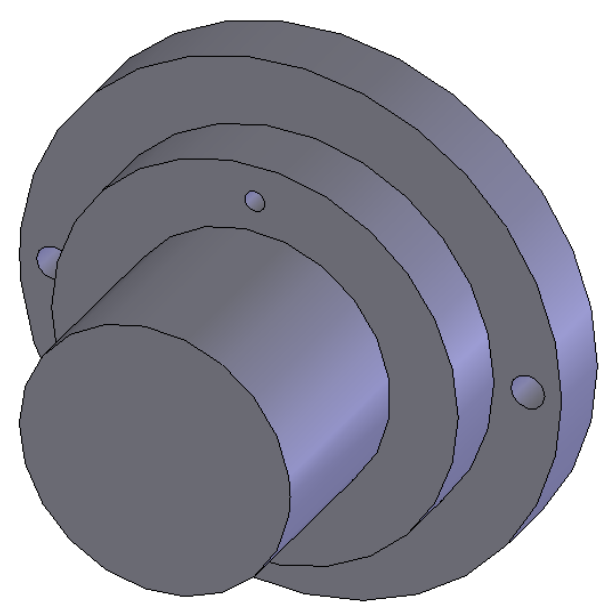

Figura 24 - Eixo de rotação do braço de acionamento.

Denota-se de 1 a 4 as superfícies cilíndricas, da menor para a maior. A superfície 1 deve passar por filetagem para a criação da rosca para a fixação da porca que irá impedir o braço de subir. Isso aumenta a rigidez do sistema na medida em que elimina mais um grau de liberdade do eixo.

A superfície 2, seguida do anel que contem o furo de lubrificação, é para a rotação, devendo ter qualidade h8; H9 na bucha (tratada no item anterior). De uma forma geral, a rugosidade das superfícies do cilindro e da bucha pode ser alterada de acordo com a facilidade de fabricação e manutenção desejada. 
Os demais furos e superfícies, incluindo o furo de lubrificação, não terão nenhum tratamento especial, salvo a tradicional eliminação de rebarbas.

\subsection{BRAÇO DE ACIONAMENTO}

O braço de acionamento possui três componentes principais: um tubo de seção quadrada, um prisma paralelepipédico sólido e uma garra sólida na extremidade. Todos eles são feitos de alumínio e, com exceção da garra, nenhum recebe tratamento especial de suas superfícies.

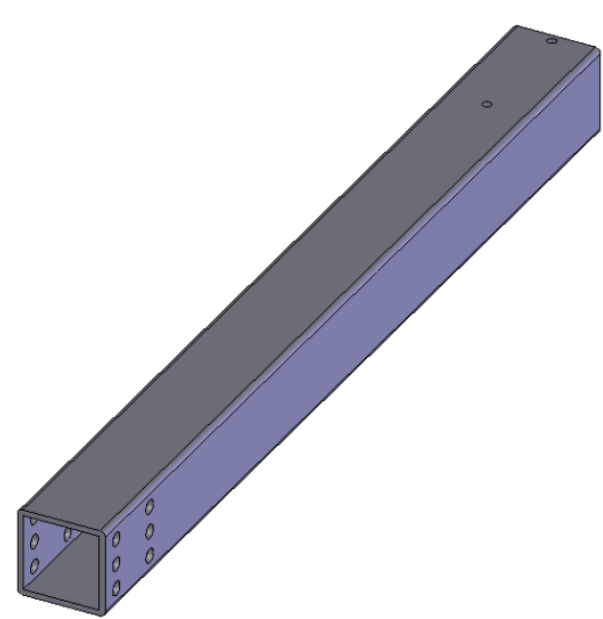

(a)

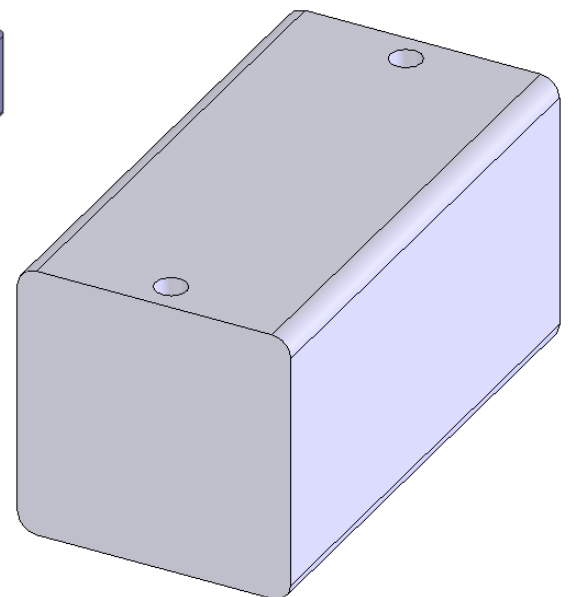

(b)

Figura 25 - Braço de acionamento.

(a) Tubo retangular;

(b) Prisma sólido.

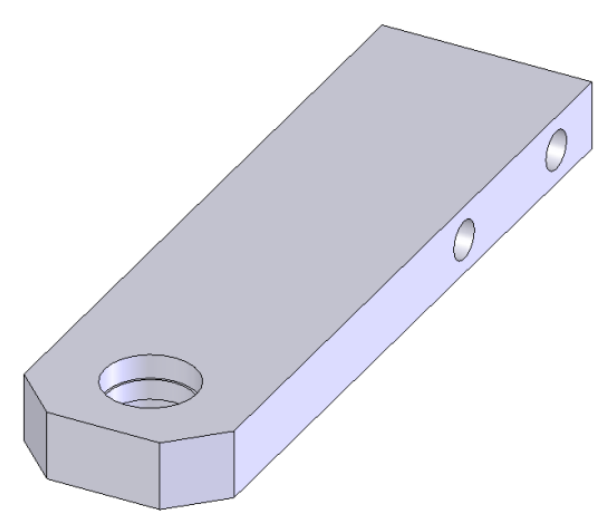

Figura 26 - Garra do braço de acionamento. 
A garra possui, em uma de suas extremidades, um furo de lubrificação. Esse furo serve para facilitar o escorregamento existente entre a garra e a bucha da ferramenta. A superfície interna que contém a bucha deve ser fabricada com qualidade $\mathrm{H} 7$.

\subsection{BUCHA DA FERRAMENTA E CILINDRO DE FIXAÇÃO}

A bucha da ferramenta é feita de cobre, inteiriça, com qualidade externa r6 e qualidade interna H9, por também possuir rotação.

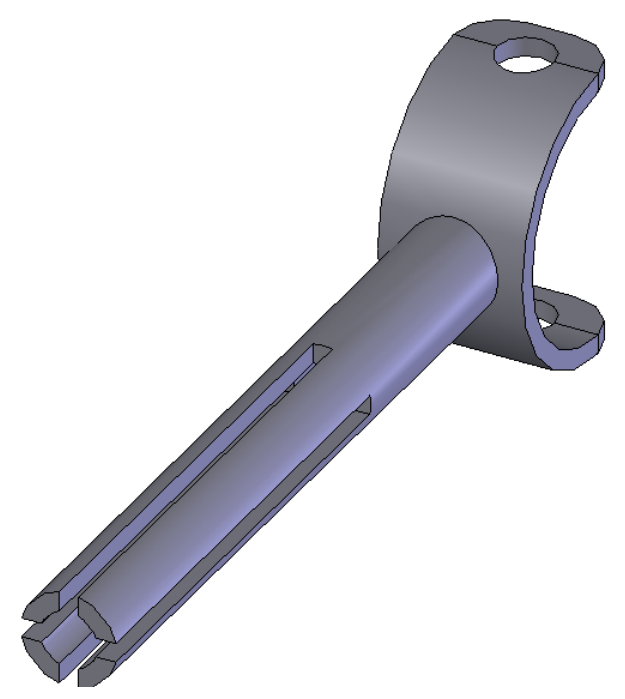

Figura 27 - Garra da ferramenta.

O cilindro de aço de fixação, em sua parte externa, tem fabricação análoga ao eixo de rotação, h8. No entanto, a parte para fixação da ferramenta deve ter maior flexibilidade, dado que não se sabe ao certo como estará a ferramenta e, além disso, a própria fixação será com braçadeiras. Portanto, foi considerado $\mathrm{H} 7$, sem controle da rugosidade.

Com relação à fresa, pode-se fazer as seguintes considerações. A geometria de fresamento pode ser negativa ou positiva, como mostra a Figura 28. Ferramentas com inclinação dupla negativa são bem resistentes ao choque em operações 
pesadas de fresamento facial. Já as com inclinação dupla positiva devem ser utilizadas em operações leves e que exijam grande exatidão.

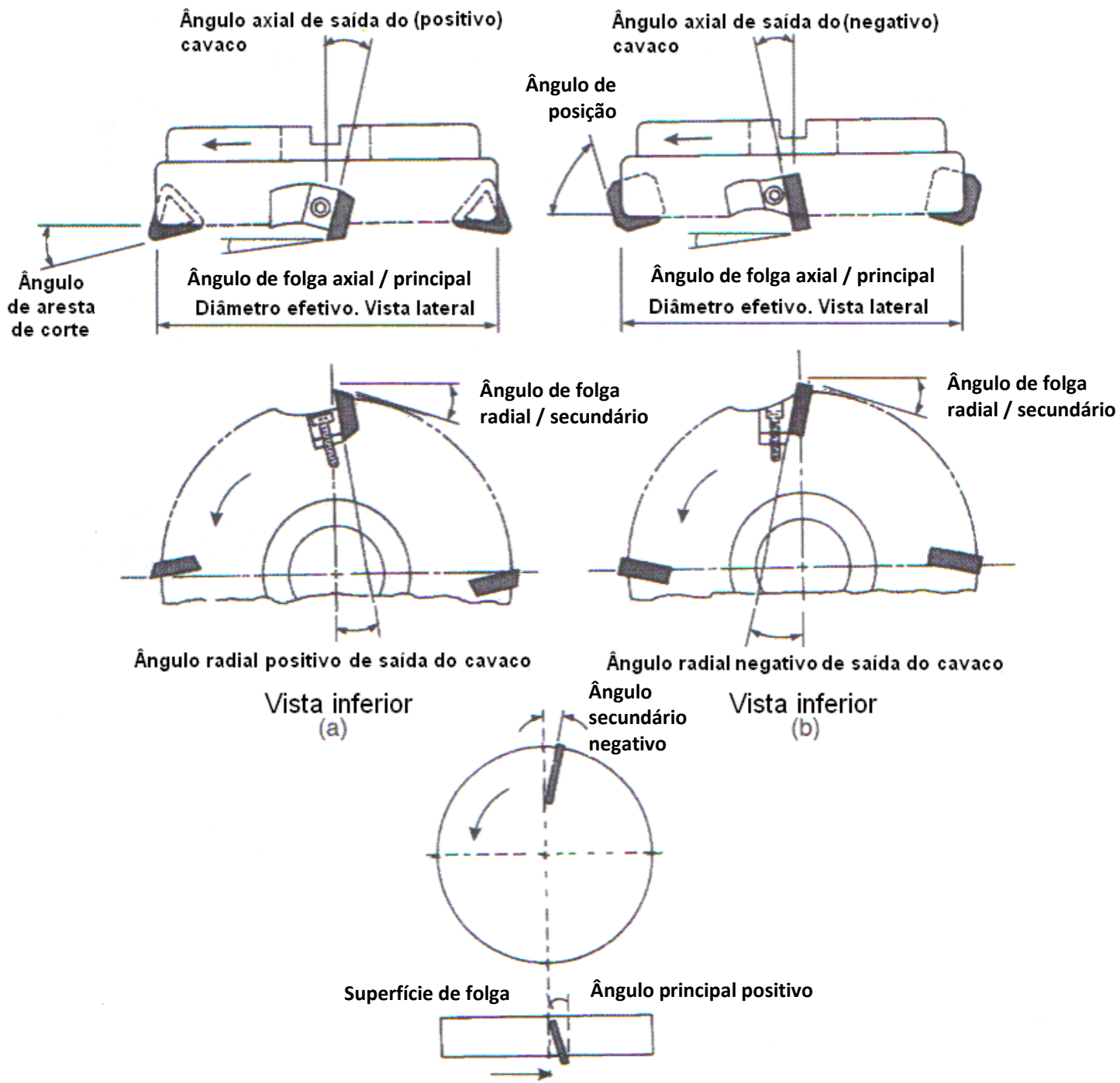

(c)

Figura 28 - Geometria padrão do fresamento facial (ALTINTAS, 2000).

Ferramentas que são utilizadas com ângulos negativo-positivo oferecem um bom acabamento superficial, justamente por removerem com maior eficiência os cavacos gerados. Na figura abaixo estão descritas as operações de fresamento mais utilizadas: 


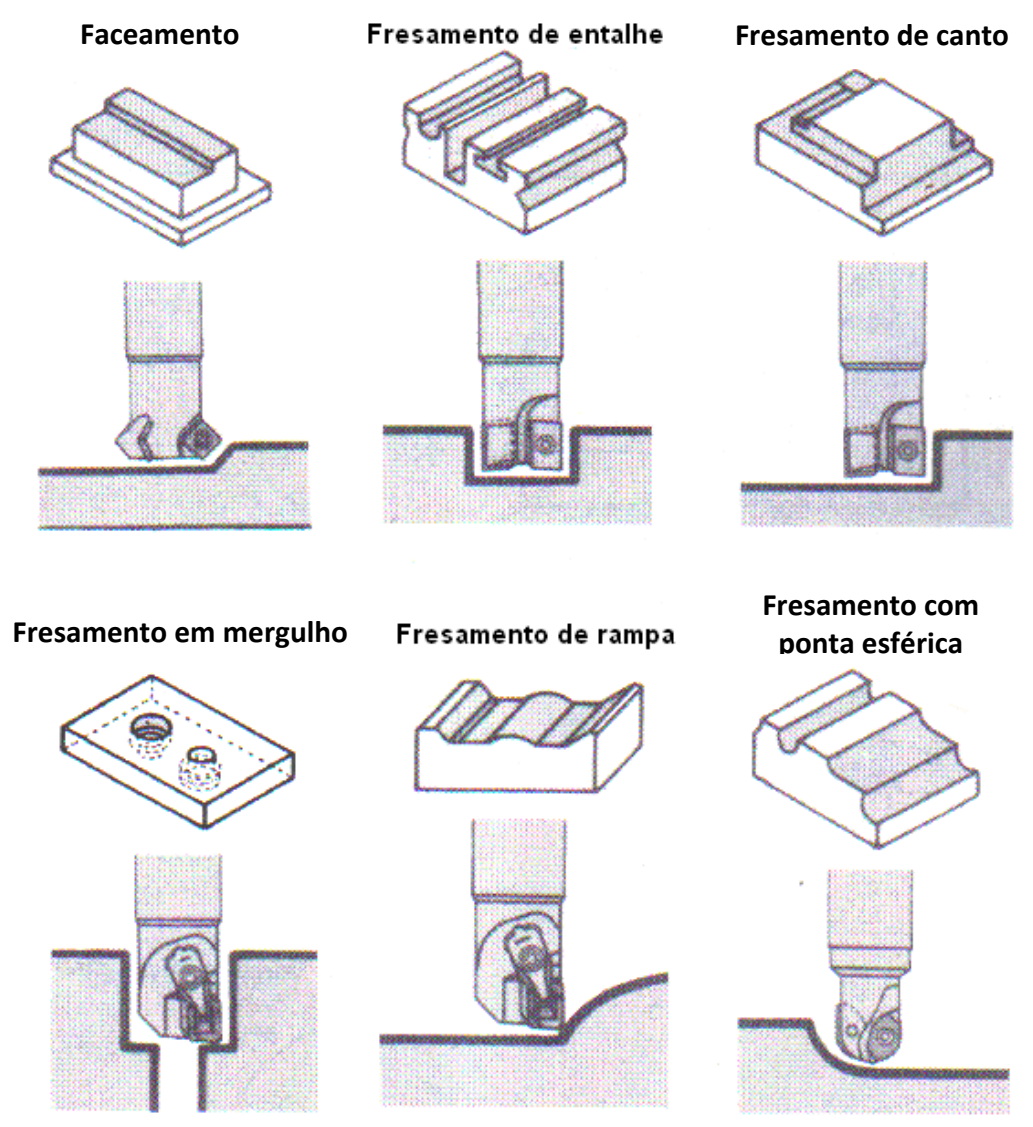

Figura 29 - Operações no fresamento (ALTINTAS, 2000).

Nas operações de fresamento facial os ângulos de entrada e saída da fresa em relação à peça são diferentes de zero. Já no fresamento discordante o ângulo de entrada é zero, mas o ângulo de saída é diferente de zero. Para grandes taxas de remoção de material é a operação mais recomendada, pois reduz as cargas de choque. O inverso ocorre no fresamento concordante: na entrada, é diferente de zero, mas na saída é zero. Essa configuração permite um acabamento superficial mais suave, e, por isso, é a mais indicada para cortes de acabamento.

O fresamento simétrico gera cargas pulsantes na ferramenta que podem entrar em ressonância com os vários modos de vibração estrutural, assim como causar vibrações transientes nas regiões de entrada e saída da ferramenta. Por isso esse tipo de fresamento não é recomendado para máquinas leves ou que utilizem ângulos positivos de inclinação.

Tendo isso em mente, e considerando que a máquina a ser construída é de pequeno porte, fresas helicoidais podem ser utilizadas para reduzir as variações das componentes oscilatórias das forças de fresamento, e são mais utilizadas quando a profundidade de corte é grande e a largura de corte pequena. 


\subsection{DISCOS DE FIXAÇÃO DO MOTOR AC E DA PEÇA}

Os discos de fixação e usinagem, feitos de aço, não necessitam de maiores cuidados com suas superfícies. Salvo, novamente, a remoção de quaisquer resíduos que possam interferir na usinagem.

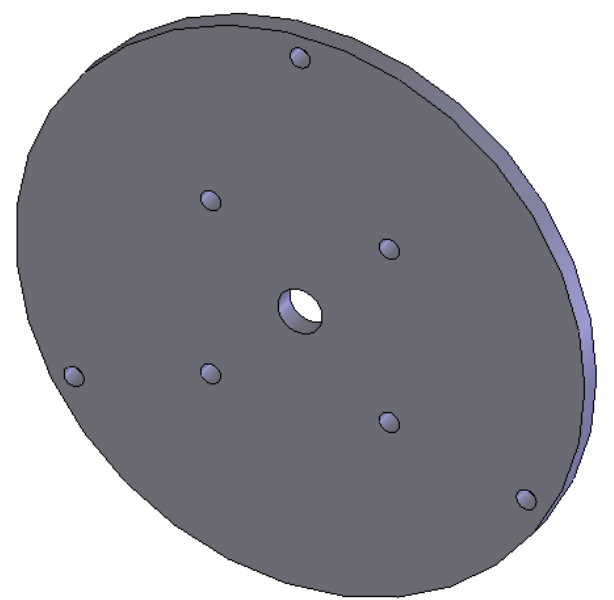

(a)

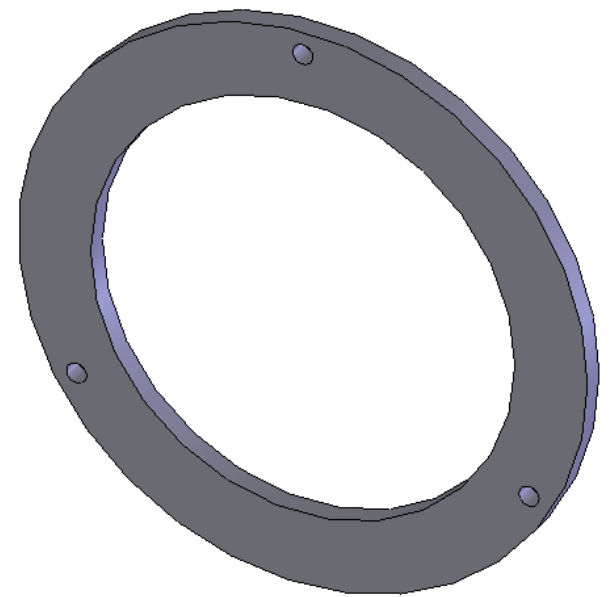

(b)

Figura 30 - Discos de fixação do motor.

(a) Fixação;

(b) Suporte.

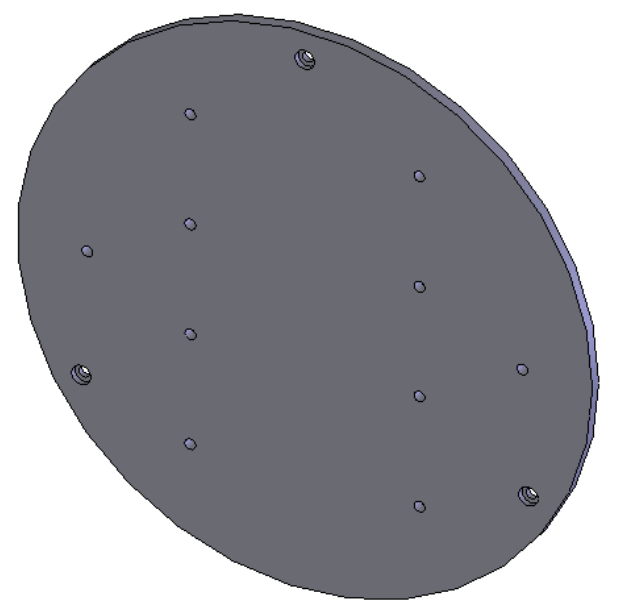

Figura 31 - Disco de fixação da peça. 


\section{RESULTADOS E DISCUSSÃO}

\subsection{VALIDAÇÃO DOS MODELOS}

Toda a máquina possui, em seu espaço de trabalho, propriedades inerentes de sua construção e de seu funcionamento. A rigidez é apenas uma delas, e será utilizada neste capítulo para a validação do modelo proposto da rigidez da área de trabalho.

Para avaliar a rigidez utilizou-se o PTV, que foi validado por programas que utilizam a resolução analítica e por elementos finitos. Sendo assim, três métodos diferentes foram aplicados. Primeiro usando o programa FTool, aberto e de resolução analítica. Em seguida, descrevendo o modelo no Ansys, baseado em MEF e, depois, com a implementação de um código trabalhando com o PTV. O código foi desenvolvido em MatLab, utilizando a teoria de Lung-Wen Tsai (TSAI, 1999).

Foram tomados como dados comparativos os resultados obtidos para uma máquina com dois atuadores apenas. Sendo assim, os resultados para a máquina com três atuadores deveriam ser, no mínimo, iguais aos da de referência. Mas eles foram melhores.

Foram feitas as seguintes considerações sobre as simulações:

- Força de $750 \mathrm{~N}$ (média de trabalho, para profundidade entre $0,5 \mathrm{~mm}$ a $3 \mathrm{~mm}$, avanço de cerca de $0,15 \mathrm{~mm} /$ dente e velocidade de corte de cerca de $100 \mathrm{~m} / \mathrm{min}$ );

- Força de $3500 \mathrm{~N}$ (pior caso, para profundidade entre $0,5 \mathrm{~mm}$ a $3 \mathrm{~mm}$, avanço de cerca de $0,25 \mathrm{~mm} /$ dente e velocidade de corte abaixo de $50 \mathrm{~m} / \mathrm{min}$ );

- Ponto de aplicação: ferramenta no plano 2D;

- Configuração de aplicação: zero máquina (posição de maior simetria da máquina, em que os braços formam um triângulo eqüilátero);

- $\mathrm{L}=516 \mathrm{~mm}$;

- $\mathrm{Lf}=1417 \mathrm{~mm}$;

- $1_{A}=1_{B}=1_{C}=1=625 \mathrm{~mm}$;

- Área da seção transversal $=6,0871 \mathrm{e}+02 \mathrm{~mm}^{2}$;

- $E=200000 \mathrm{MPa}$ (módulo de elasticidade);

- $Y=77,4 \mathrm{kN} / \mathrm{m}^{3}$ (peso específico);

- $u=0,3$ (coeficiente de Poisson). 
As forças são aplicadas no plano XY, sendo que é desconsiderada a componente passiva da força de usinagem, perpendicular a esse plano. Essa força, apesar de não contribuir para o trabalho realizado pelos atuadores, pode ter grande influência na rugosidade da peça usinada, assim como no valor da deflexão na direção em que atua (KALPAKJIAN; SCHMID, 2000). No entanto, como o propósito deste trabalho é a análise de deflexão no referido plano, ela não será utilizada.

Outro ponto importante é que, no fresamento, o módulo da resultante oscila em torno de um valor médio, porém sempre apresentando componentes oscilatórias de freqüências diversas oriundas das forças de interação entre a ferramenta e a peça. Essas componentes oscilatórias não são consideradas, e maiores informações sobre elas podem ser encontradas em ALTINTAS, 2000.
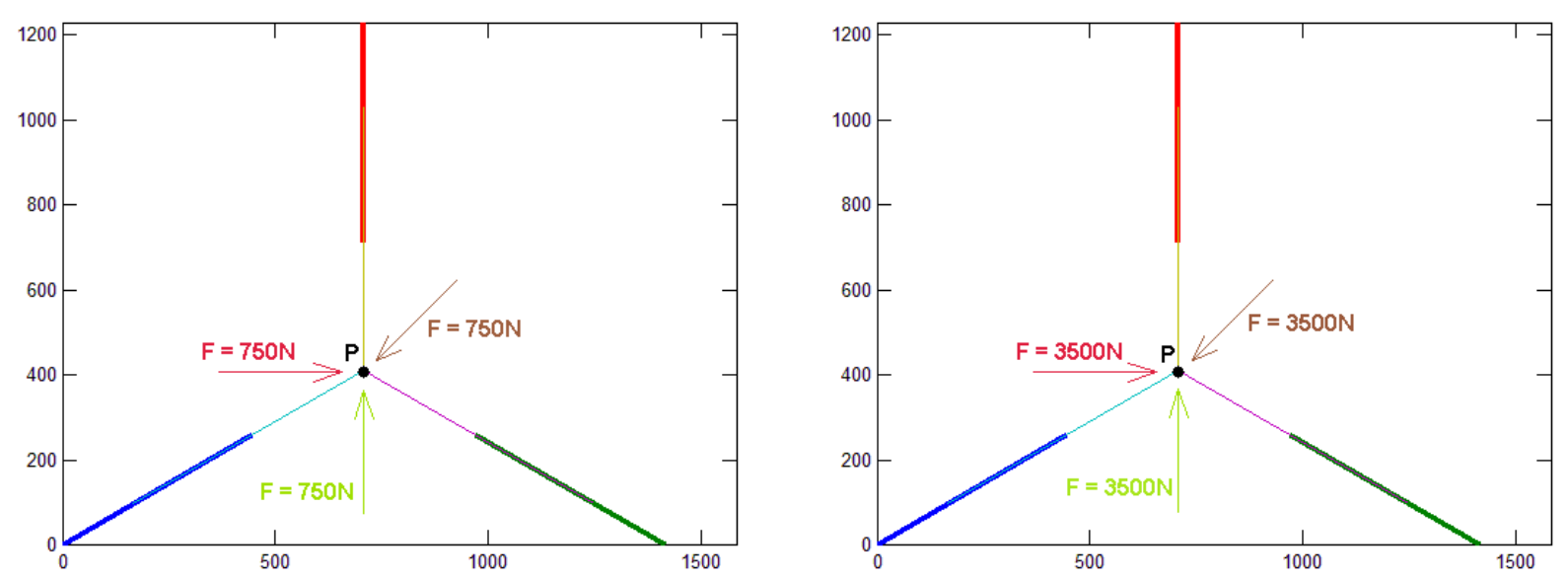

Figura 32 - Forças consideradas e seu ponto de aplicação.

Apesar de várias hipóteses serem assumidas para esta pesquisa, reconhece-se que a força de usinagem constitui-se num fator determinante para a análise do comportamento estático e dinâmico de uma máquina de usinagem, sendo dependente do processo de fabricação da peça de trabalho. Por outro lado, este trabalho não se propõe a apresentar um estudo sobre a determinação das forças de usinagem no fresamento.

Assim, serão assumidas forças de usinagem encontradas na literatura (HESSCOELHO et al., 2006; HASSUI et al., 2007; TRENT et al., 2000; MARCELINO et al., 2004; TANAKA et al., 2009; BERNARDES et al., 2007; RIBEIRO et al., 2006), para seus valores médios e seus picos, de acordo com as condições estabelecidas acima. 
Por fim, para tornar a análise o mais abrangente possível, além das duas situações consideradas (média e pior caso), para cada uma delas também serão feitas simulações em três direções e sentidos variados, como pode ser observado na Figura 32, onde cada seta (vermelha, verde e marrom) representa cada uma dessas possibilidades.

Essas direções escolhidas abrangem uma gama de variações maior do que está apenas indicado. Isso pois, devido à simetria da máquina, a deflexão causada por uma determinada força será, em módulo, igual àquela causada pela mesma força com sinal contrário. Ou seja, para cada ângulo de força com um determinado membro existem duas análises, uma positiva e outra negativa. Observando as figuras acima, pode-se verificar que o total de análises é de 10, distribuídos em dois sentidos (positivo e negativo) nos seguintes ângulos de posição com um determinado membro: $30^{\circ}, 45^{\circ}, 60^{\circ}, 75^{\circ}$ e $90^{\circ}$.

\subsubsection{Máquina com dois atuadores}

As figuras abaixo mostram o resultado da simulação no FTool para a área de trabalho da máquina com 2 eixos e forças de magnitude $750 \mathrm{~N}$ e 3500N, aplicadas horizontalmente, verticalmente e também orientadas a $45^{\circ}$ do horizonte. 


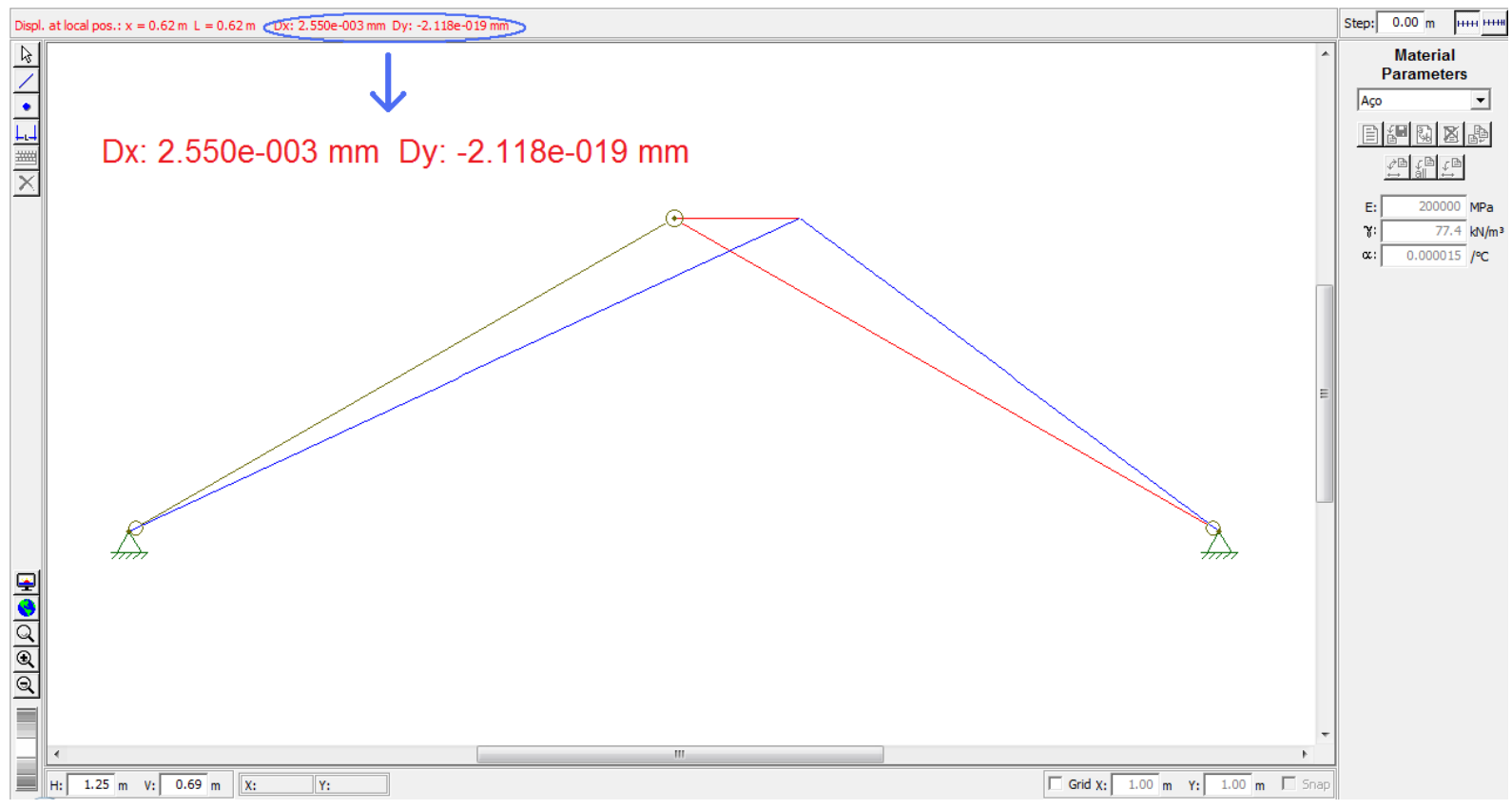

Figura 33 - Deflexão na origem, 750N, horizontal, com dois atuadores, pelo FTool.

Pode-se observar que o deslocamento causado na ponta da ferramenta é de $2,55 \mu \mathrm{m}$ na direção $x$, e que quase não ocorre deslocamento em $y$, podendo ser o valor considerado zero. Deve-se ter em mente que o posicionamento do cursor na articulação é manual, e que pequenos erros podem ocorrer.

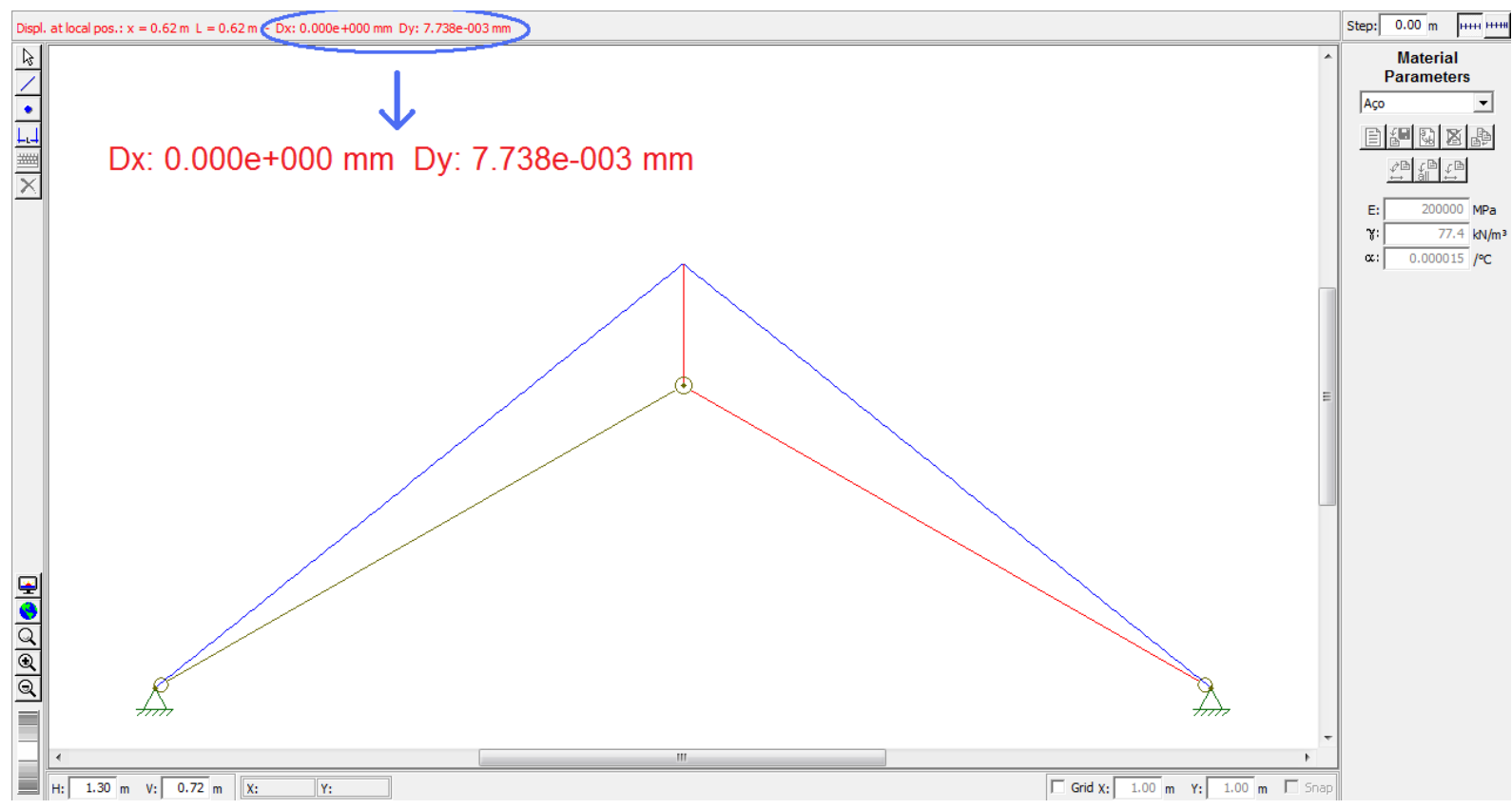

Figura 34 - Deflexão na origem, 750N, vertical, com dois atuadores, pelo FTool. 
Analogamente, para a posição vertical existe deflexão apenas no sentido da força aplicada, devido à simetria da máquina. Observamos um aumento no seu valor, em relação ao caso horizontal, pois existe maior proximidade de uma região singular, para essa direção e sentido da força.

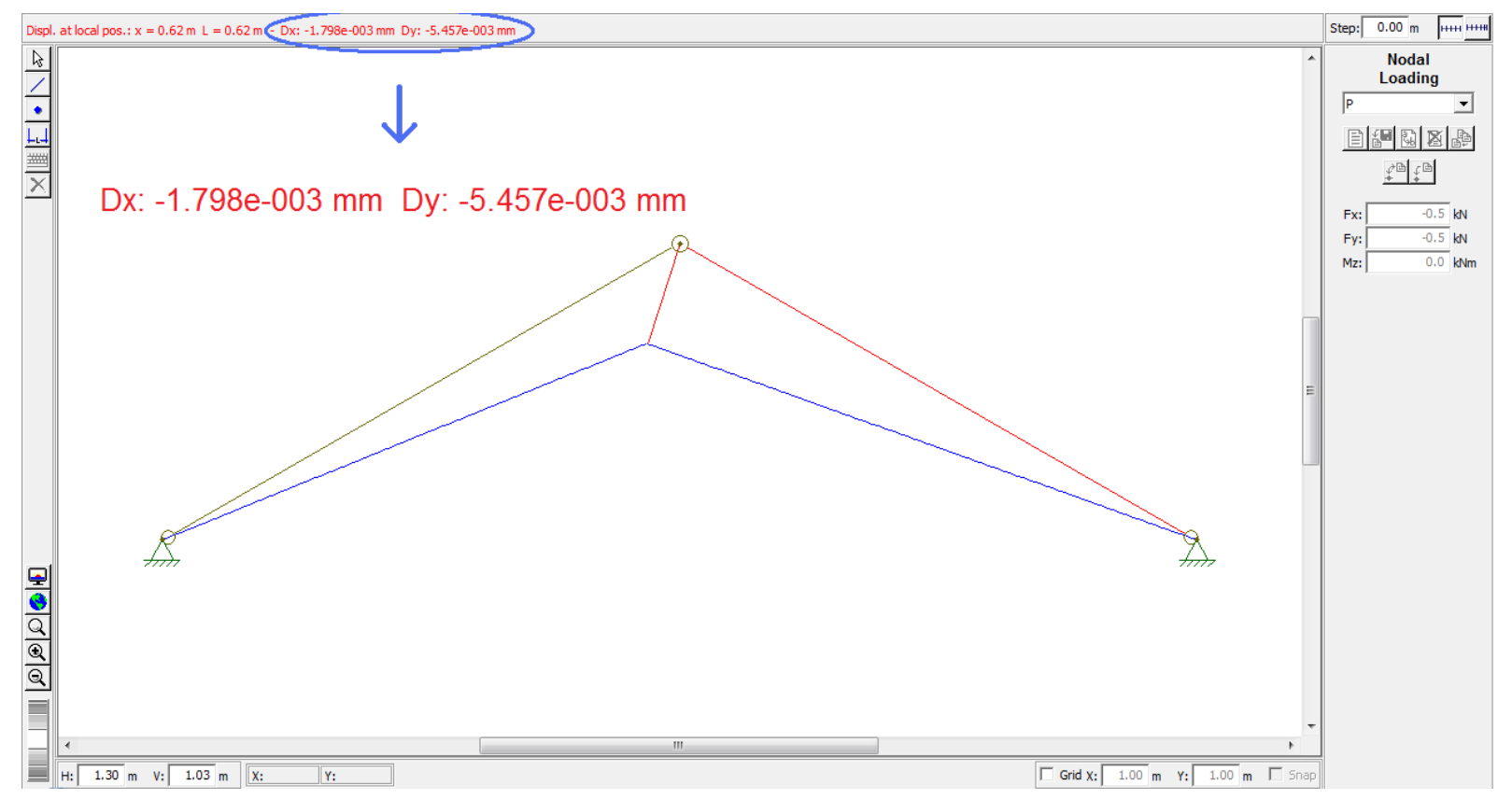

Figura 35 - Deflexão na origem, $750 \mathrm{~N}$, a $45^{\circ}$, com dois atuadores, pelo FTool.

Da mesma forma, para o pior caso, ilustrado abaixo, pode-se observar que o deslocamento causado na ponta da ferramenta é de $11,86 \mu \mathrm{m}$ na direção x, e que o deslocamento em y está totalmente anulado. Aqui fica clara a relação direta entre a força aplicada e a deflexão observada de um valor de 4,6 vezes aproximadamente. 


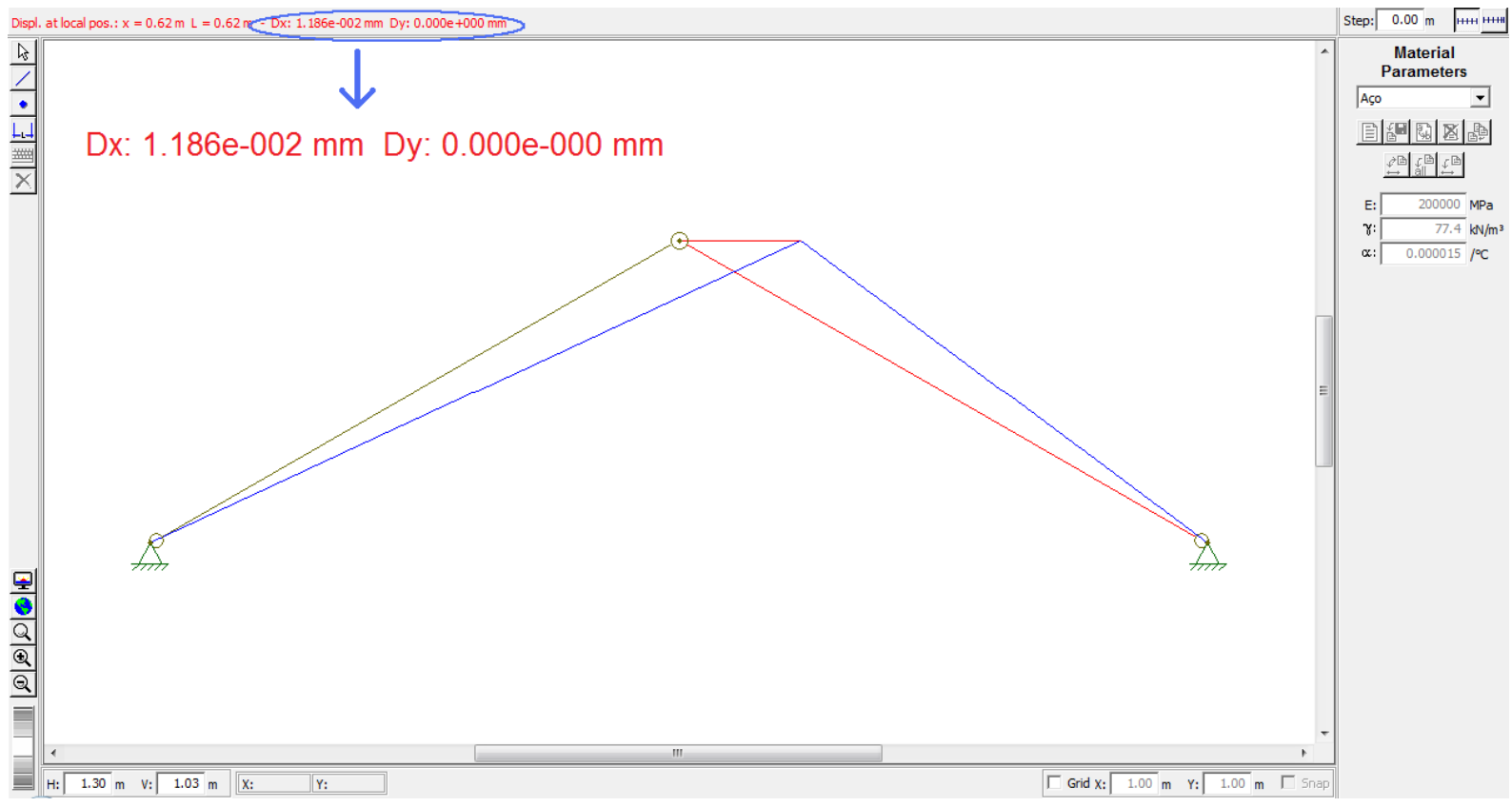

Figura 36 - Deflexão na origem, 3500N, horizontal, com dois atuadores, pelo FTool.

Observando agora o resultado com força vertical, comparado ao seu respectivo anterior, pode-se verificar que o comportamento mantém-se o mesmo, dado que o limite de elasticidade do material não é atingido.

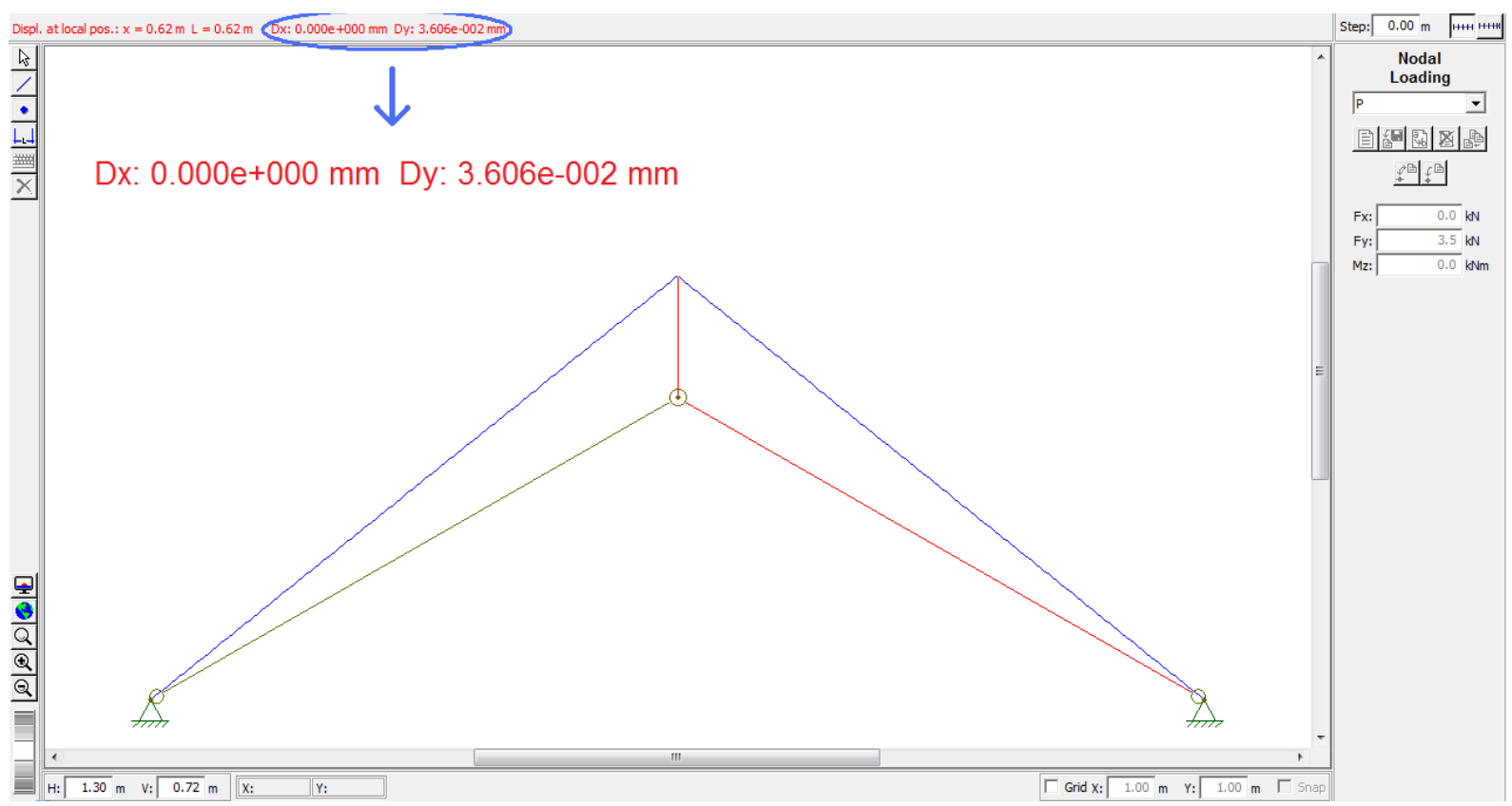

Figura 37 - Deflexão na origem, 3500N, vertical, com dois atuadores, pelo FTool.

Por fim, calculando a deflexão máxima da situação de força a $45^{\circ}$, chega-se no valor de $-27,14 \mu \mathrm{m}$. O valor corresponde ao esperado, encontrando-se entre os valores 
observados na horizontal e vertical. A componente vertical é a de maior relevância, mesmo sendo as duas iguais em valor. Isso ocorre pois o posicionamento próximo de uma região singular reduz a capacidade de resistir a forças no sentido vertical.

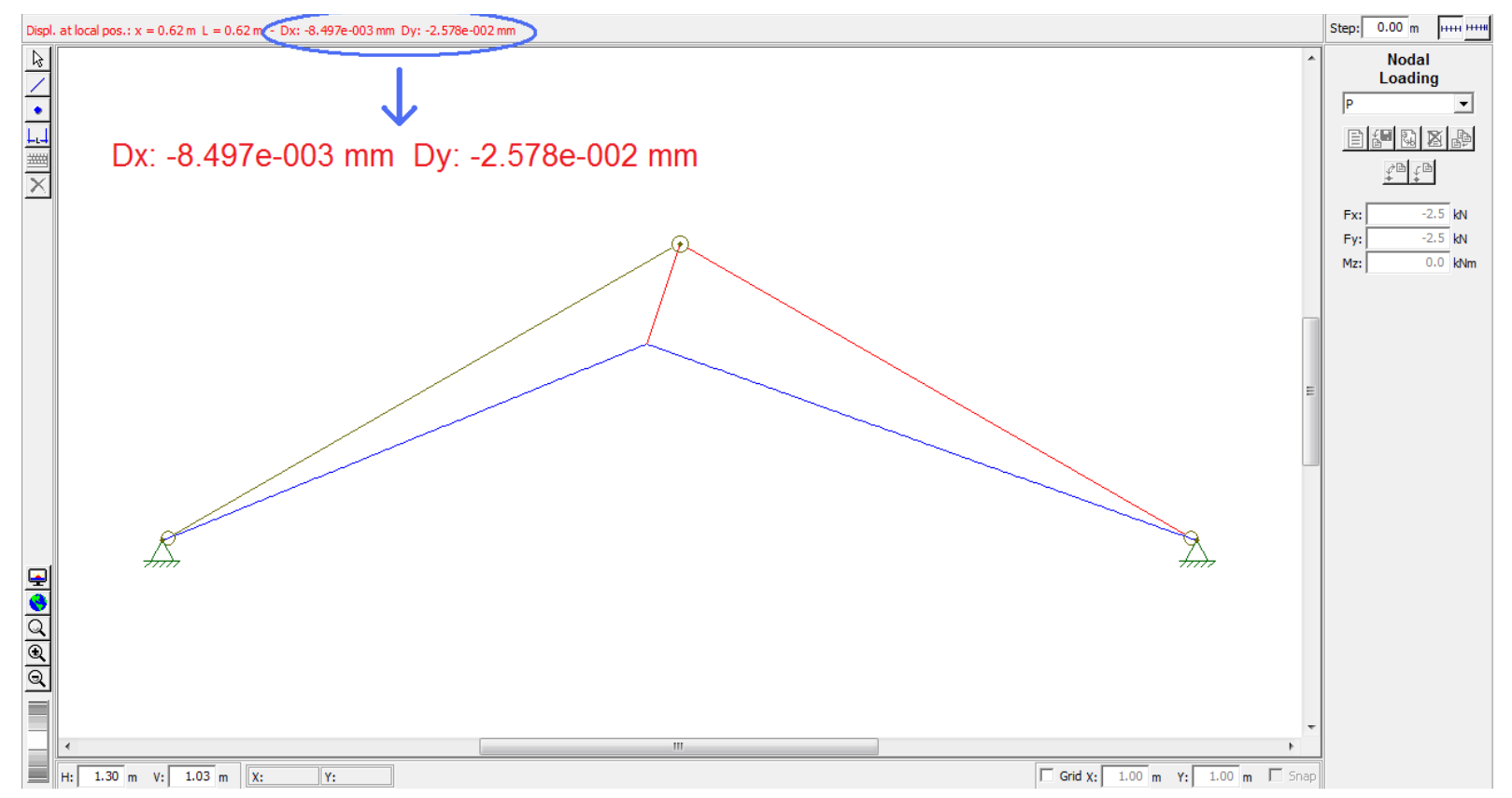

Figura 38 - Deflexão na origem, $3500 \mathrm{~N}$, a $45^{\circ}$, com dois atuadores, pelo FTool.

Executando a simulação no MatLab para o programa PTV correspondente, pode-se verificar os deslocamentos obtidos com o FTool, com os seguintes resultados:

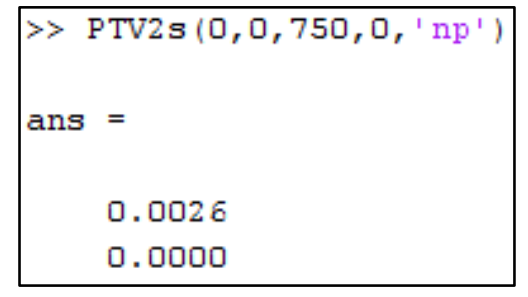

(a)

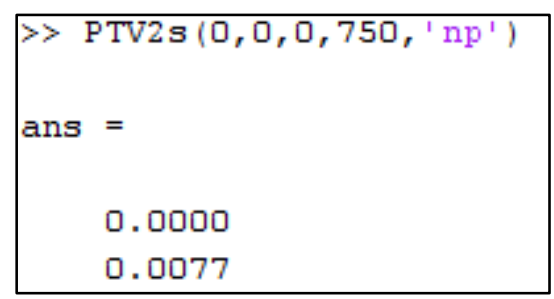

(c)

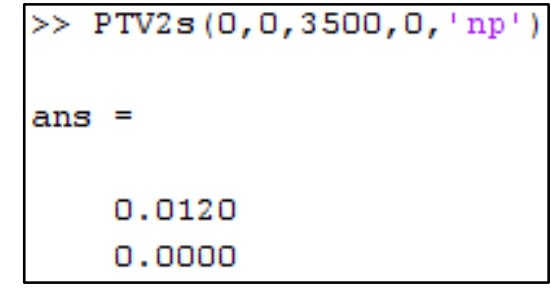

(b)

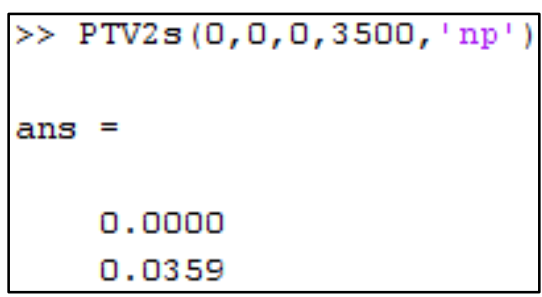

(d) 


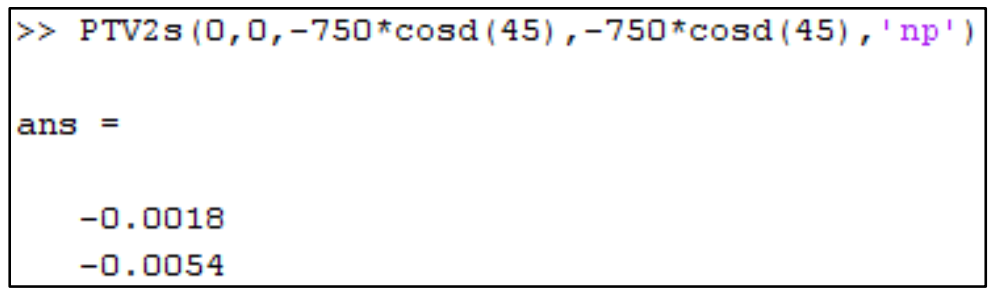

(e)

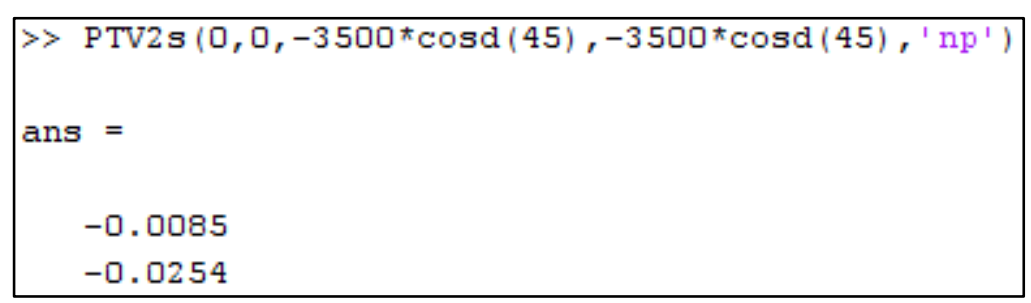

(f)

Figura 39 - Deflexão na origem, com dois atuadores, pelo MatLab.

(a) Força horizontal de $750 \mathrm{~N}$;

(b) Força horizontal de $3500 \mathrm{~N}$;

(c) Força vertical de $750 \mathrm{~N}$;

(d) Força vertical de $3500 \mathrm{~N}$;

(e) Força a $45^{\circ}$ de $750 \mathrm{~N}$ (negativa nos dois eixos);

(f) Força a $45^{\circ}$ de $3500 \mathrm{~N}$ (negativa nos dois eixos).

Analogamente, a Figura 40 e a Figura 41 apresentam os resultados obtidos no Ansys para o elemento de treliça plana com dois nós. Esse tipo de análise foi modelado com juntas rotativas (articulações) em todas as uniões, sendo que as correspondentes aos nós 1, 2 e 3 (veja figura da página 36) são fixas, e a correspondente ao ponto $P$ é livre.

Como já era de se esperar, são equivalentes aos obtidos anteriormente, servindo como mais uma evidência comparativa do método testado. 


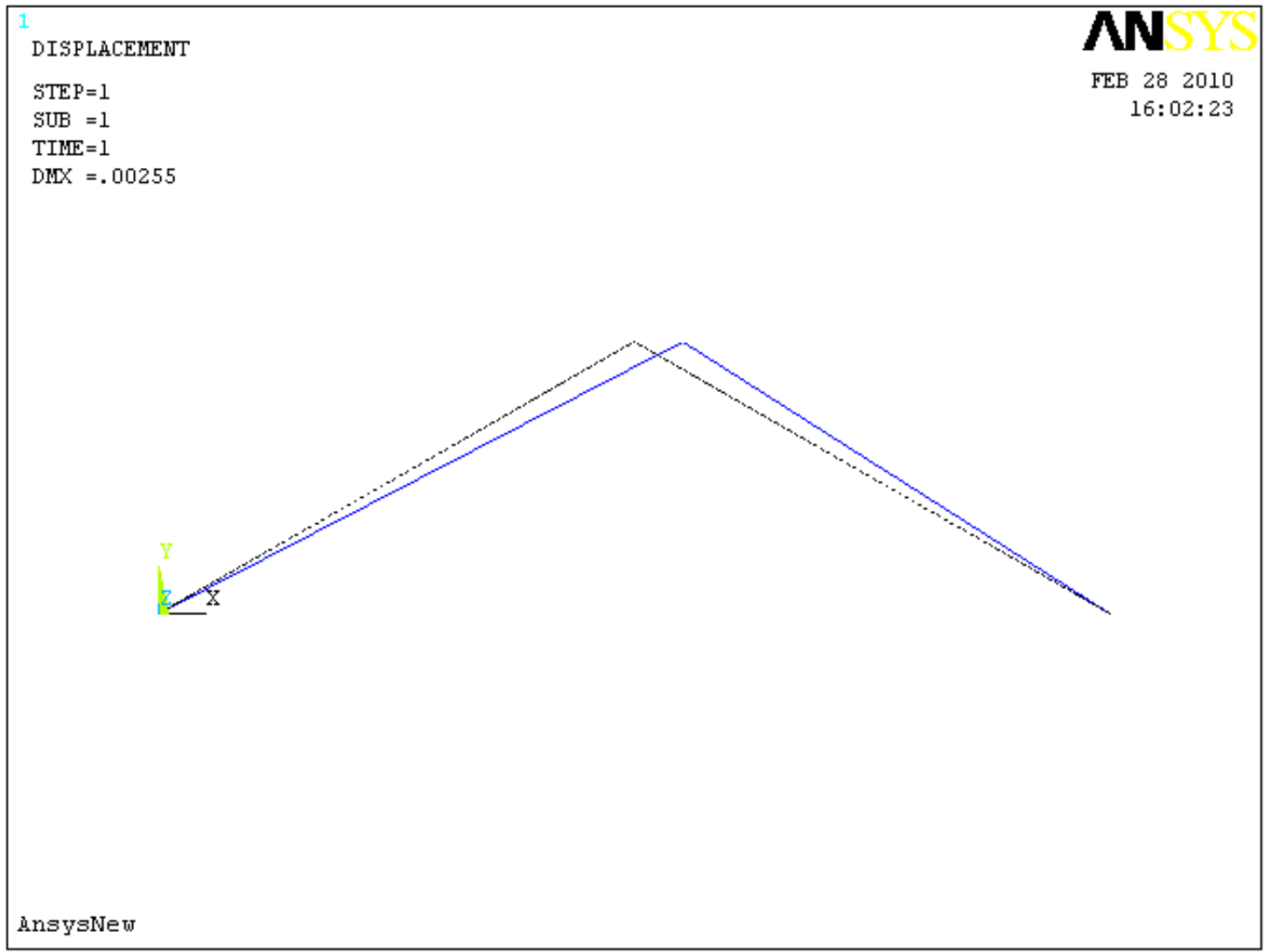

Figura 40 - Deflexão na origem, $750 \mathrm{~N}$, horizontal, com dois atuadores, pelo Ansys.

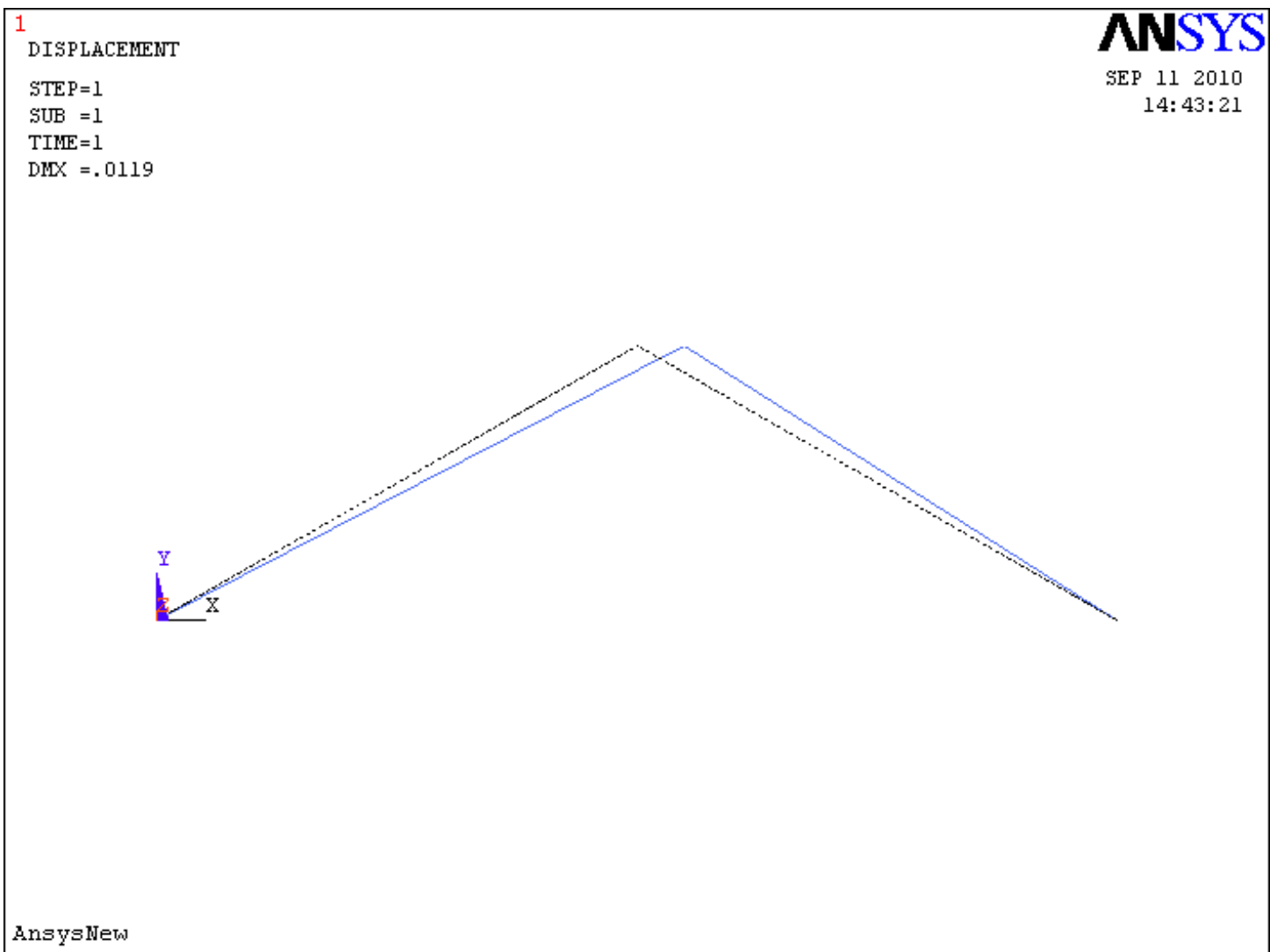

Figura 41 - Deflexão na origem, 3500N, horizontal, com dois atuadores, pelo Ansys. 
As figuras a seguir mostram a deflexão na direção vertical causadas pelas forças de $750 \mathrm{~N}$ e $3500 \mathrm{~N}$ aplicadas da mesma maneira que nos casos anteriores.

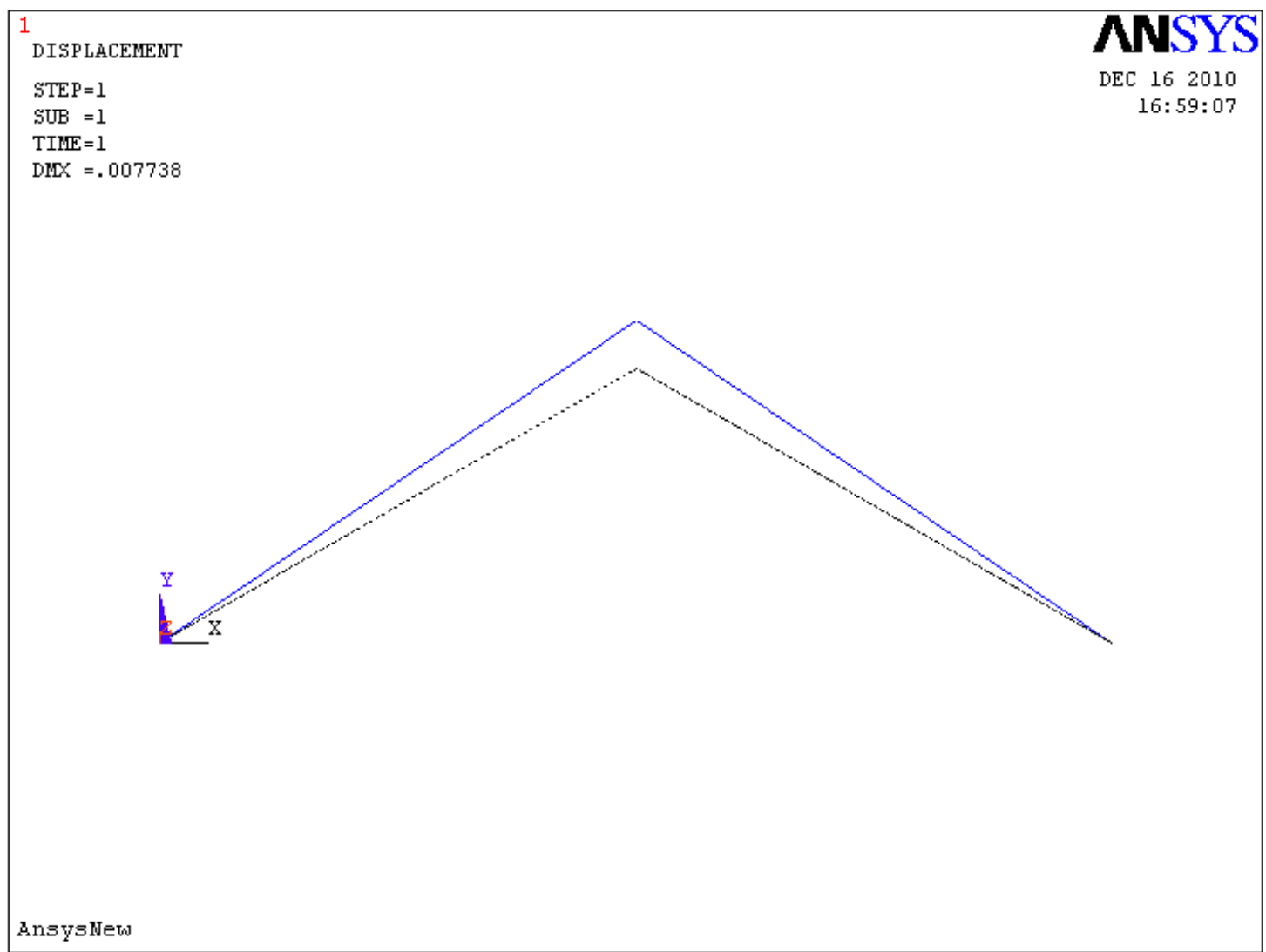

Figura 42 - Deflexão na origem, 750N, vertical, com dois atuadores, pelo Ansys. 


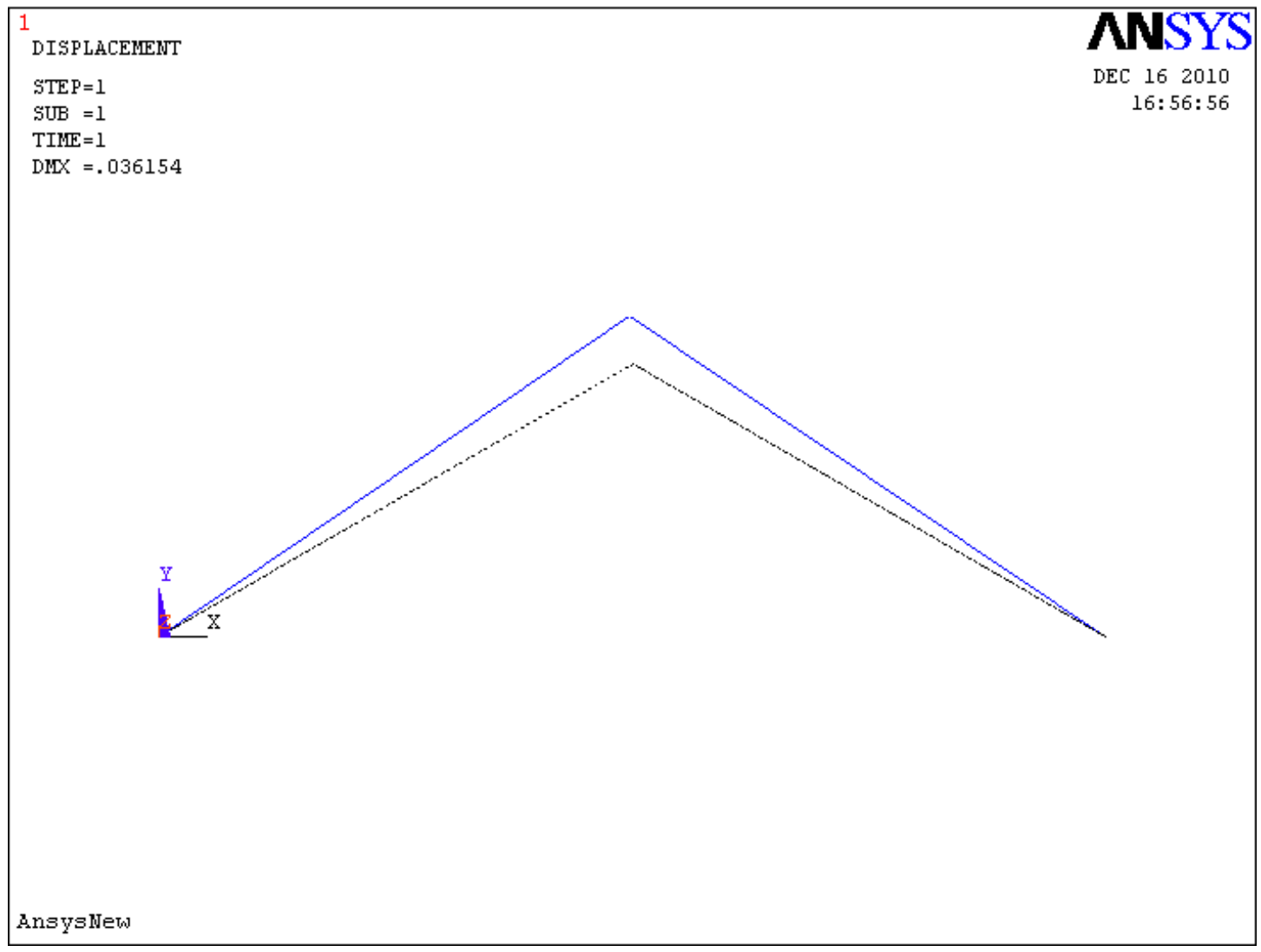

Figura 43 - Deflexão na origem, 3500N, vertical, com dois atuadores, pelo Ansys.

Por fim, o último caso estudado para a máquina com dois atuadores está indicado nas duas figuras abaixo. Repare que os valores encontrados, 5,8 $\mu \mathrm{m}$ e $26,9 \mu \mathrm{m}$ são compatíveis com os já observados anteriormente. 


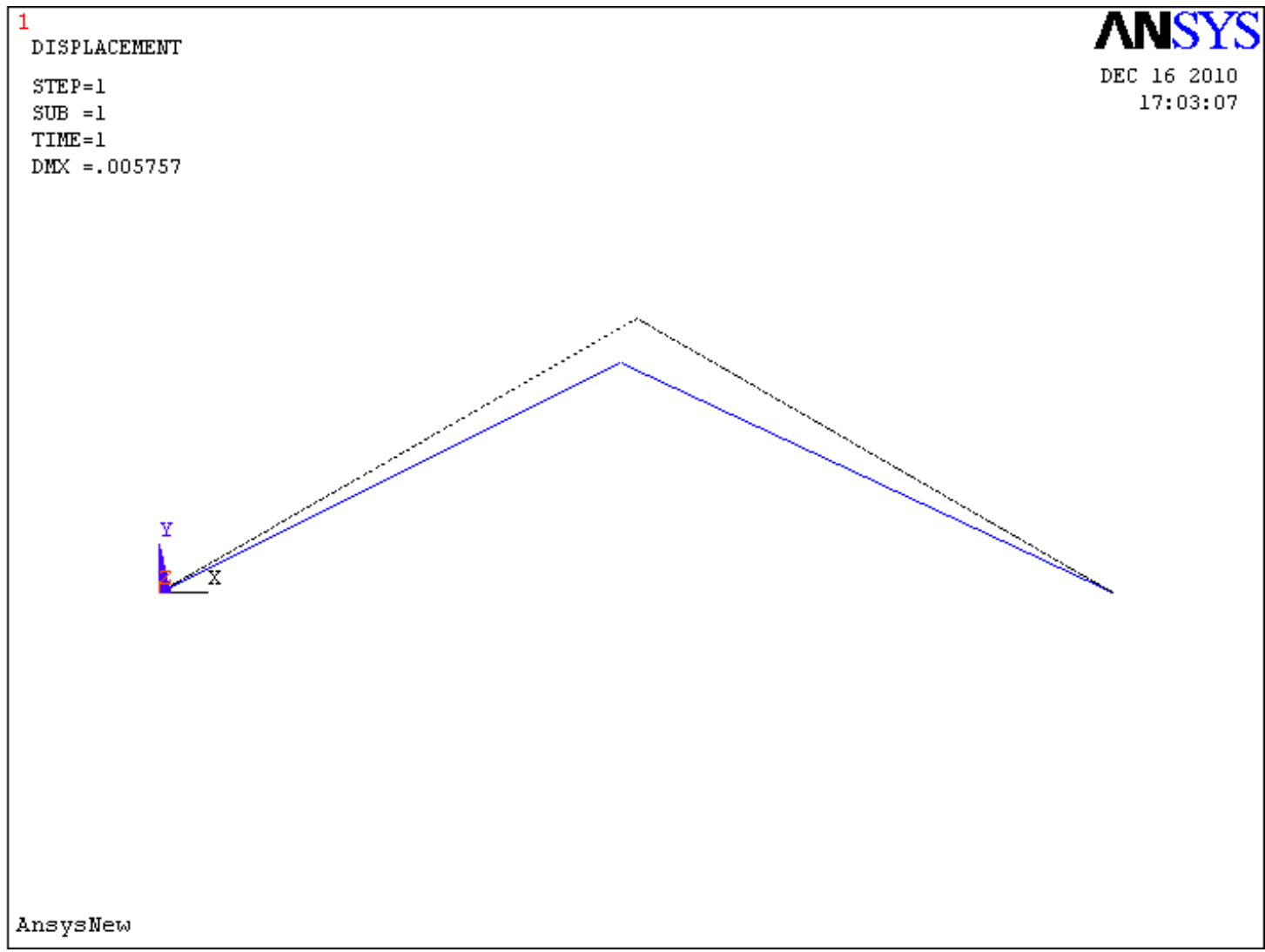

Figura 44 - Deflexão na origem, $750 \mathrm{~N}$, a $45^{\circ}$, com dois atuadores, pelo Ansys.

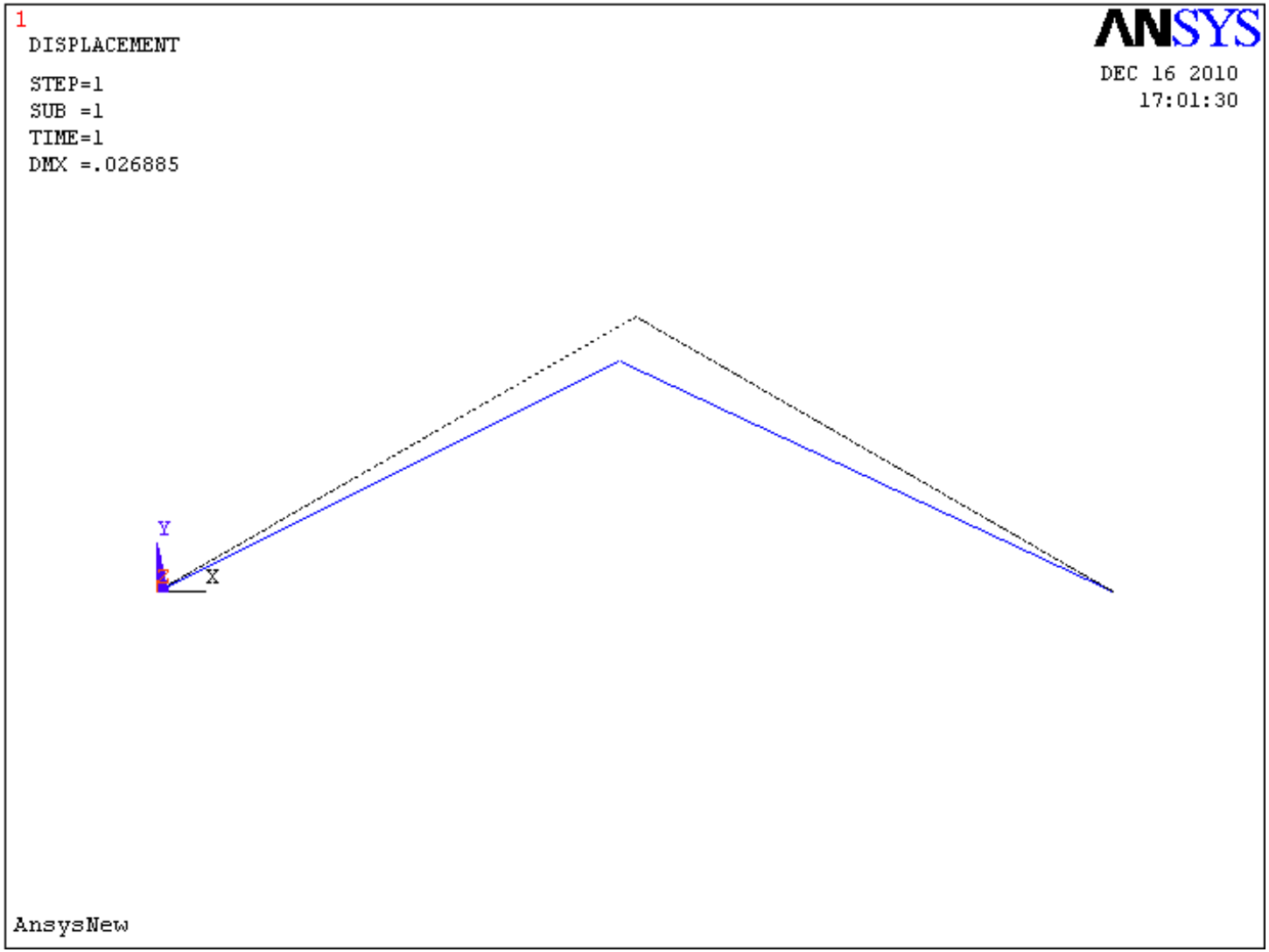

Figura 45 - Deflexão na origem, $3500 \mathrm{~N}$, a $45^{\circ}$, com dois atuadores, pelo Ansys. 


\subsubsection{Máquina com três atuadores}

A Figura 46 mostra o resultado da simulação no FTool para a área de trabalho da máquina com 3 eixos e uma força horizontal de magnitude $750 \mathrm{~N}$.

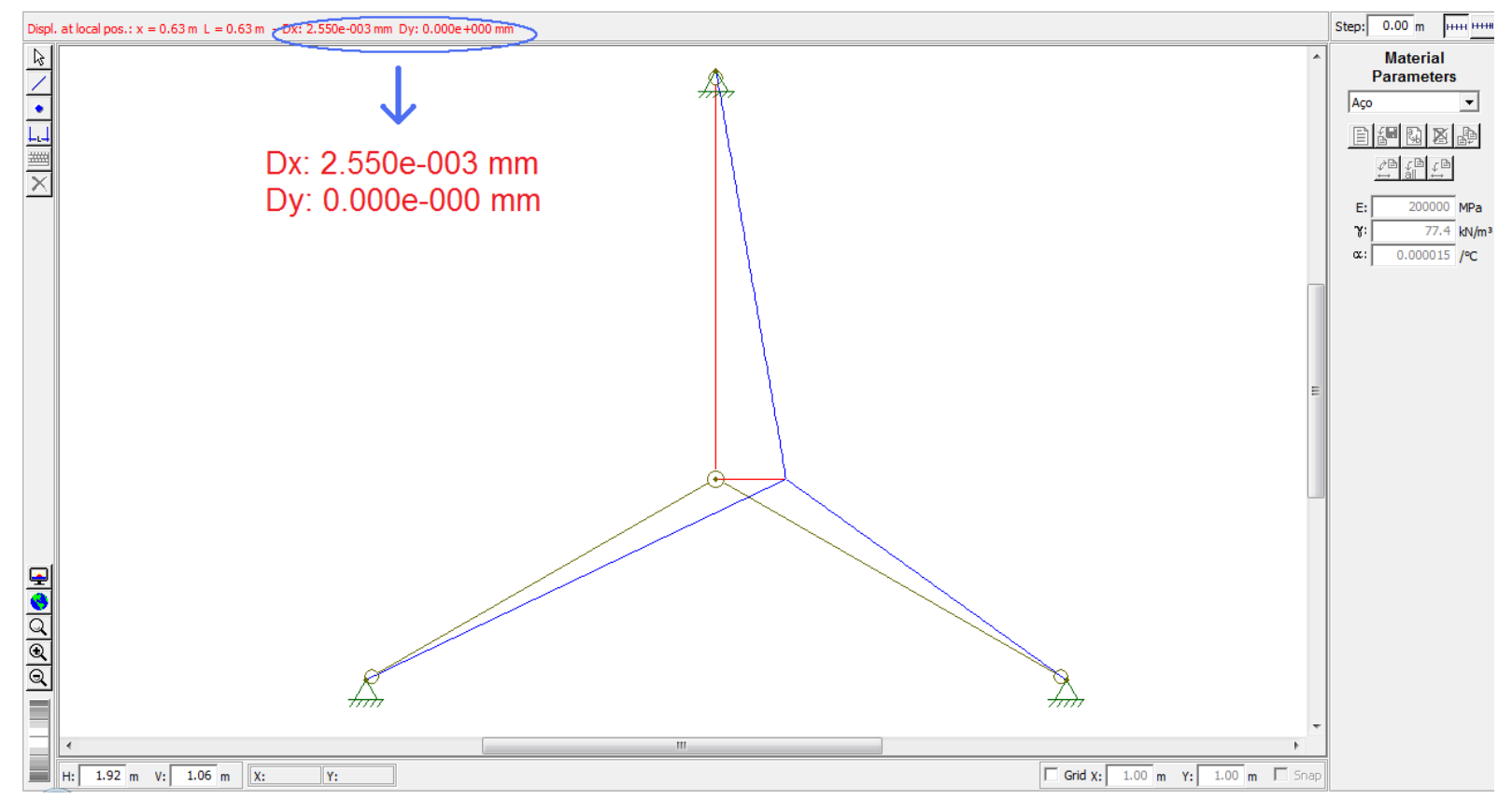

Figura 46 - Deflexão na origem, 750N, horizontal, com três atuadores, pelo FTool.

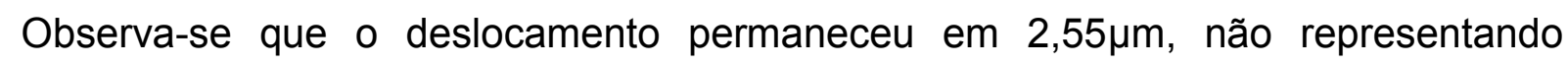
nenhuma melhora em relação ao caso anterior. O mesmo comportamento pode ser

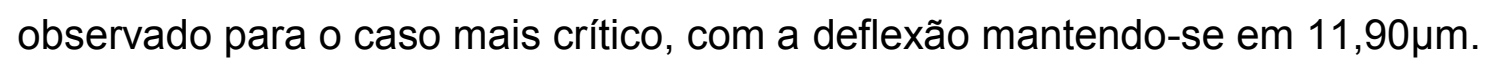




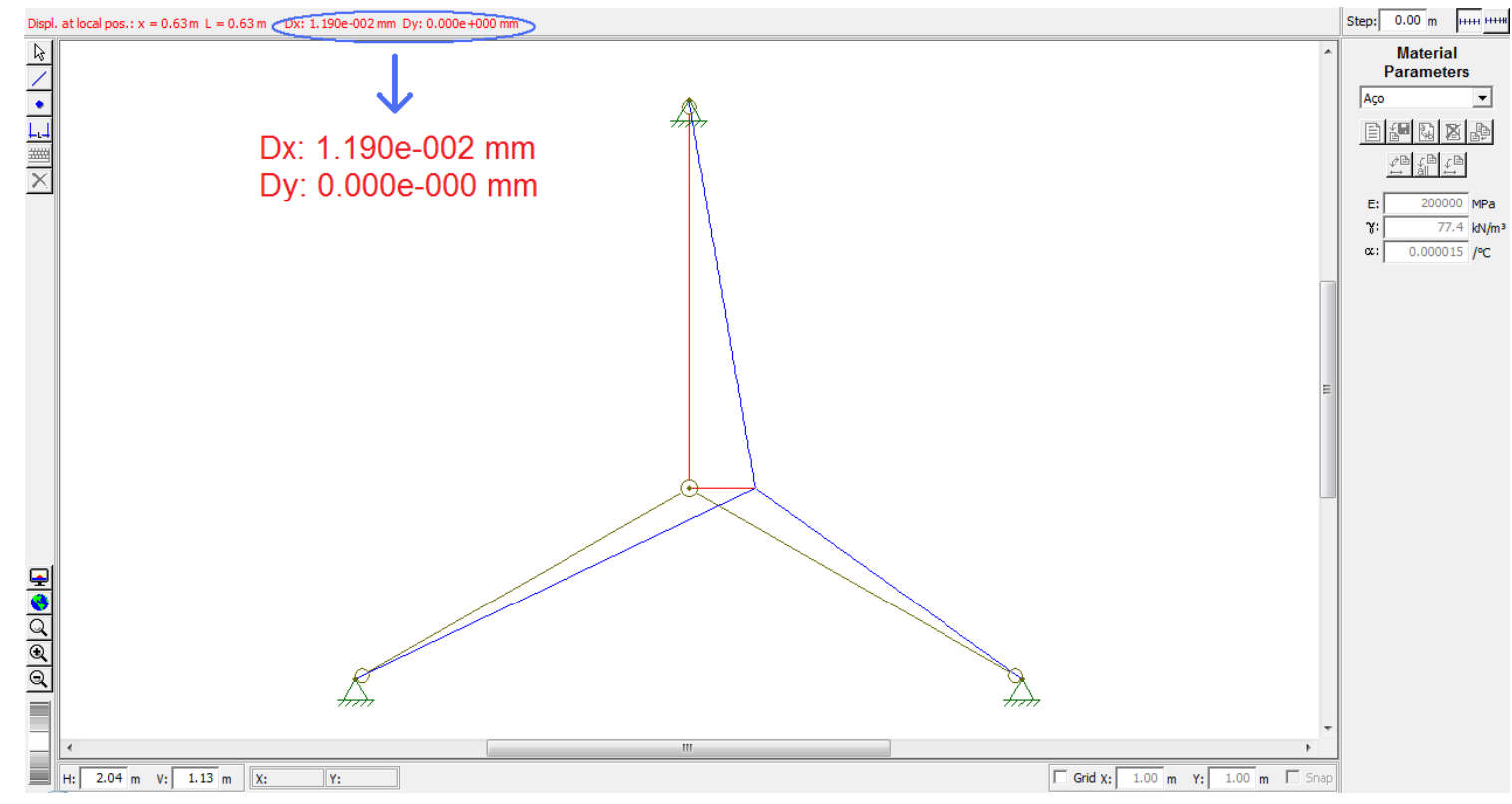

Figura 47 - Deflexão na origem, 3500N, horizontal, com três atuadores, pelo FTool.

Erroneamente se poderia pensar que o terceiro membro, devido a esse resultado, seria desnecessário. O posicionamento escolhido, de $90^{\circ} \mathrm{em}$ relação à aplicação da força, faz com que não exista reação nesse membro, devido à articulação da base (topo da figura). No entanto, o mesmo não ocorreria caso o posicionamento fosse de $0^{\circ}$ ou $180^{\circ}$ em relação ao membro.

No entanto, o mesmo não pode ser dito das forças aplicadas na vertical e a $45^{\circ}$, como mostram as figuras abaixo.

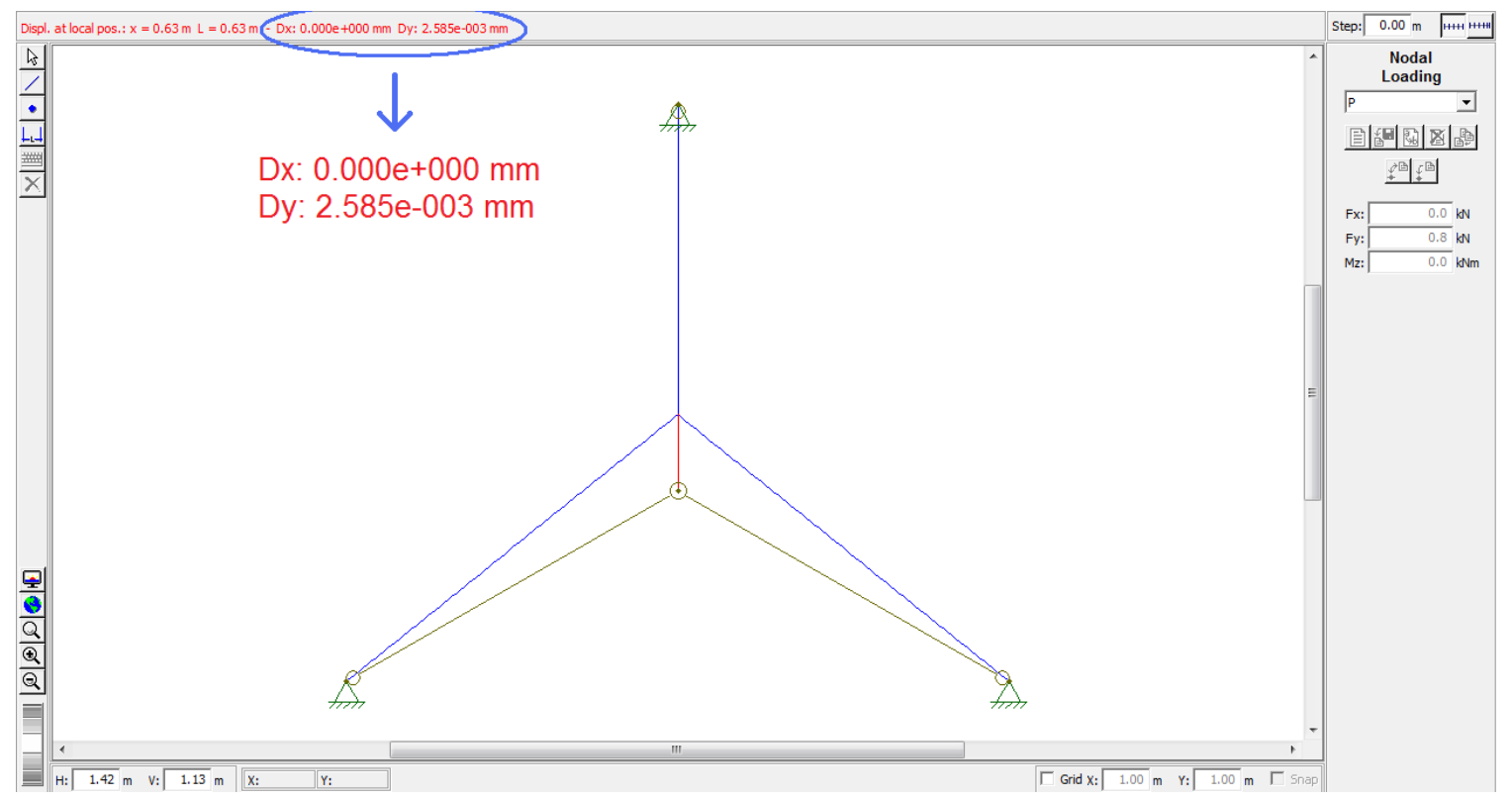

Figura 48 - Deflexão na origem, 750N, vertical, com três atuadores, pelo FTool. 
Nos dois casos para aplicação na vertical houve uma redução de praticamente $67 \%$ do valor em relação ao observado para dois membros apenas.

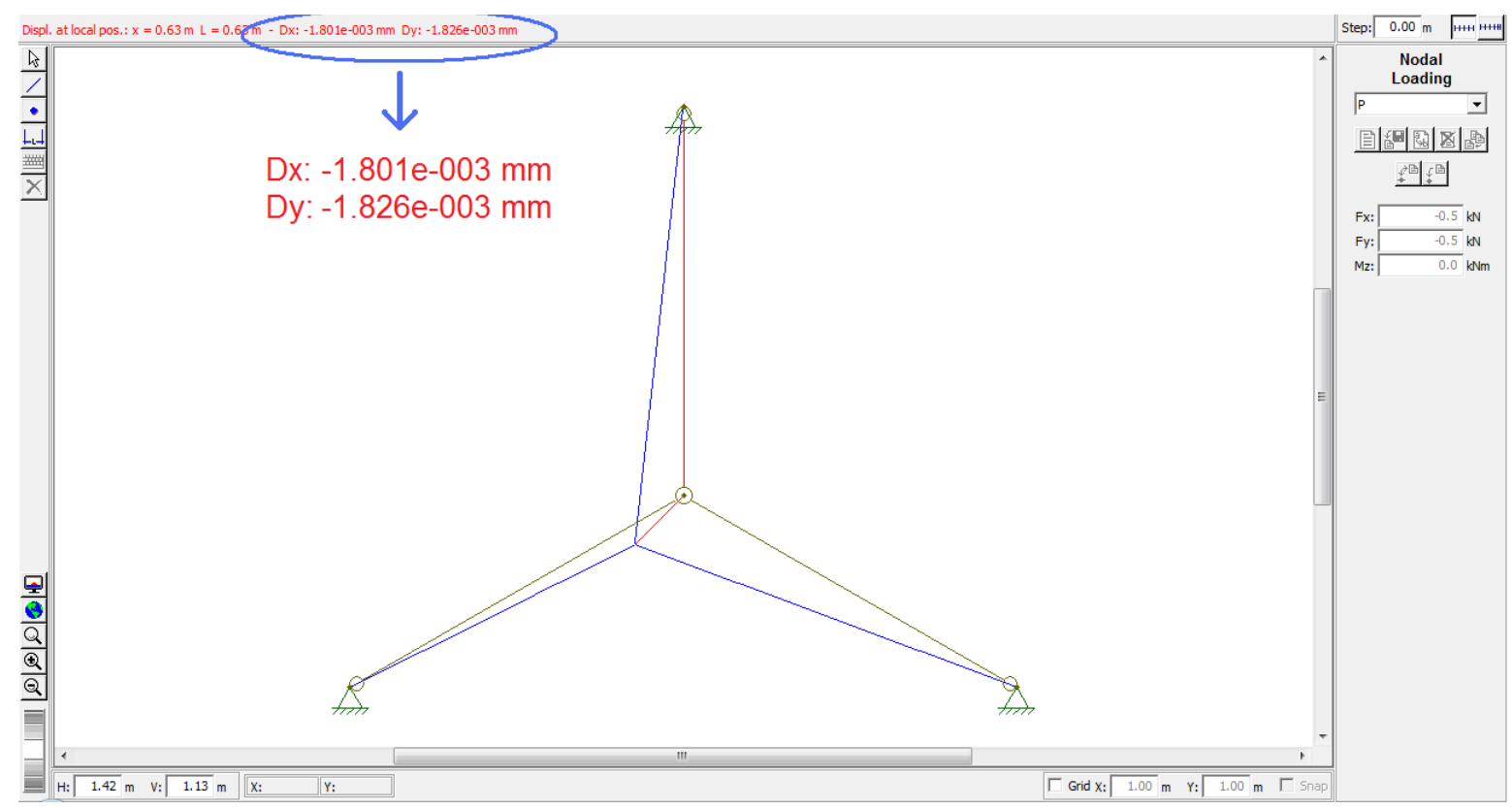

Figura 49 - Deflexão na origem, $750 \mathrm{~N}$, a $45^{\circ}$, com três atuadores, pelo FTool.

Analogamente, essa redução foi de cerca de $55 \%$ para a força a $45^{\circ}$. Isso pois a componente horizontal não apresenta redução em função do acréscimo do membro superior.

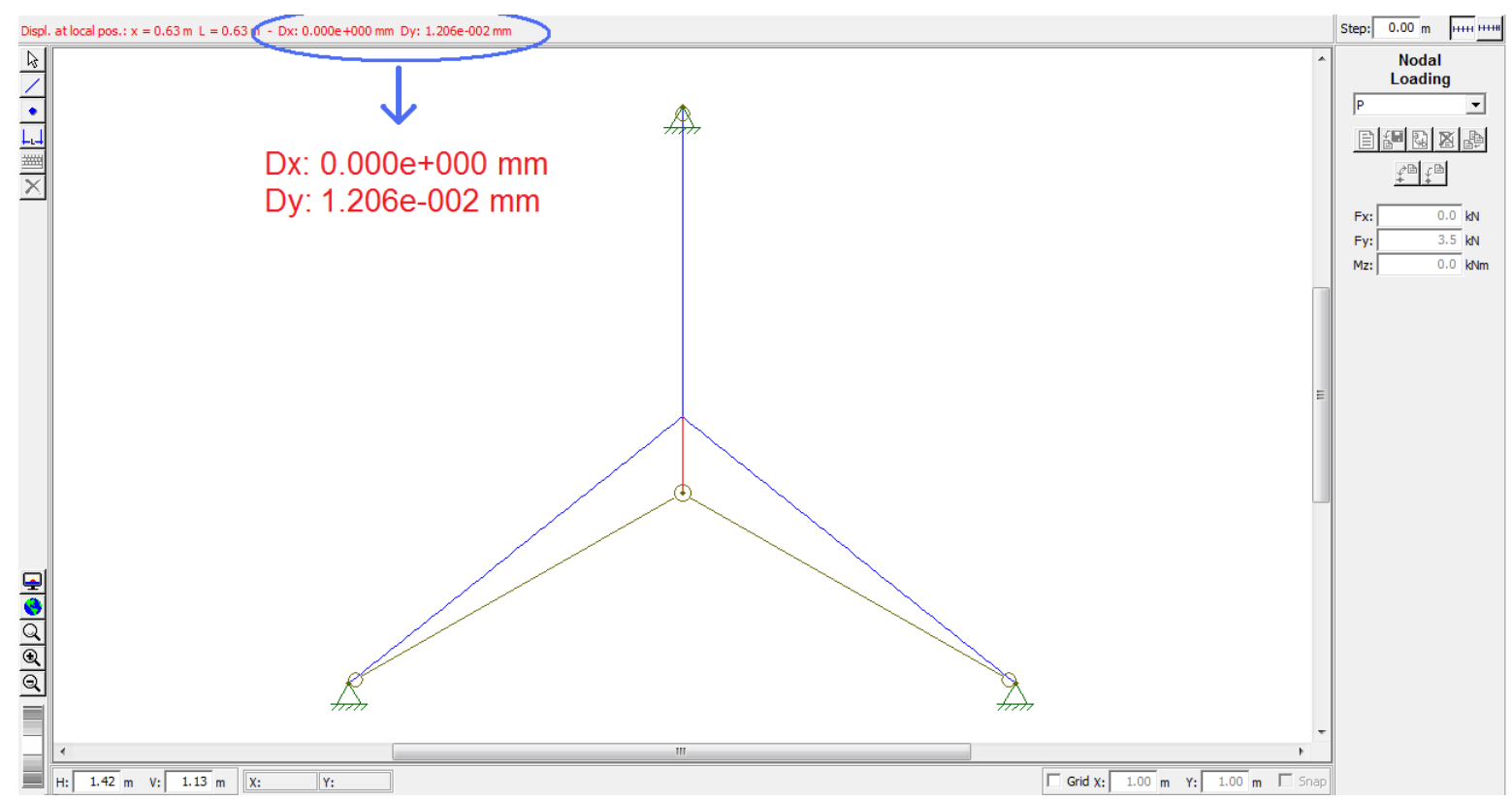

Figura 50 - Deflexão na origem, 3500N, vertical, com três atuadores, pelo FTool. 
É importante observar que o comportamento da estrutura é sempre o mesmo nas diversas situações, excetuando o valor propriamente dito da deflexão. Isso pois a simetria é ótima, ou seja, para pequenas deflexões a rigidez é sempre a mesma em qualquer direção.

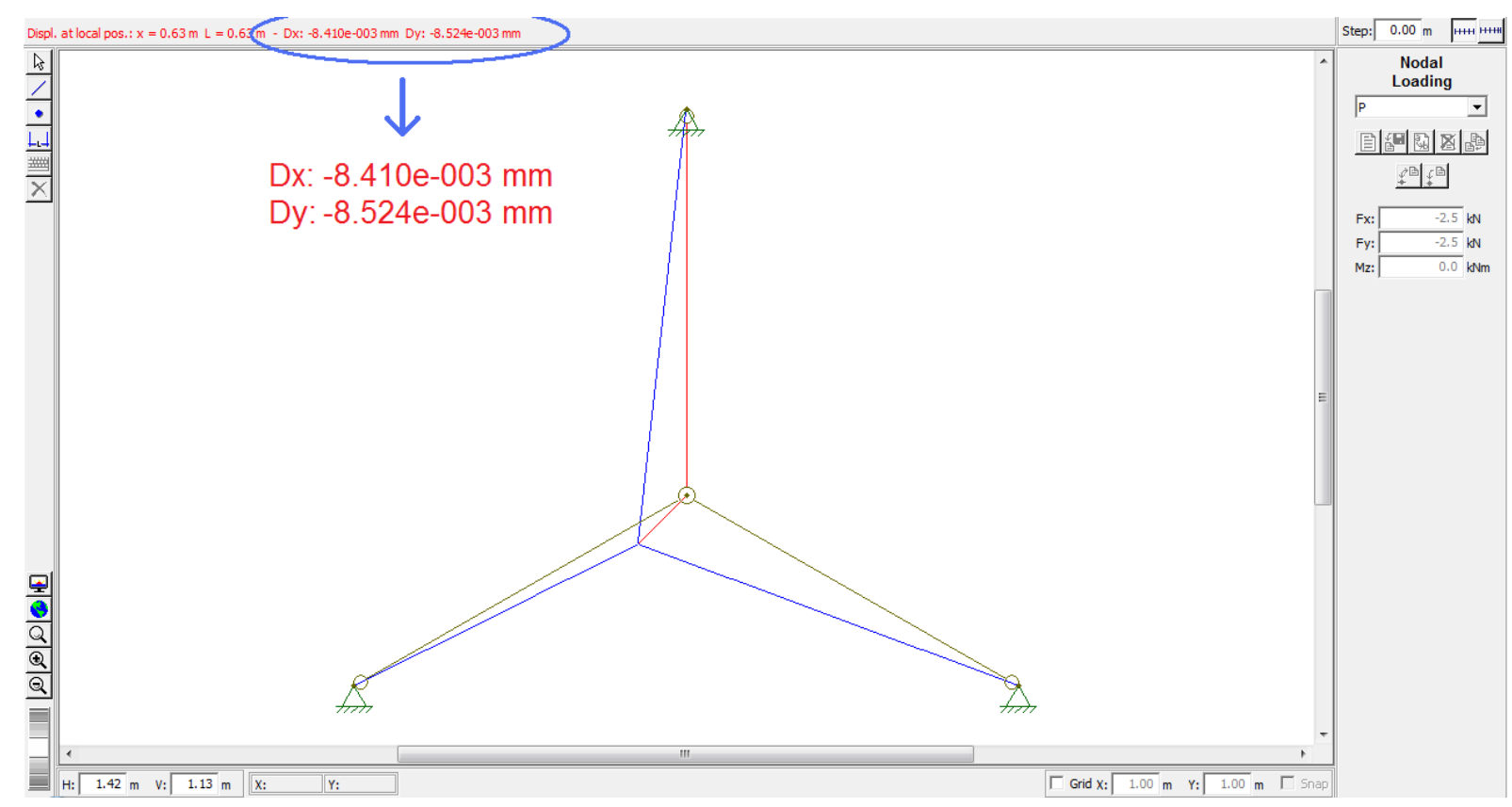

Figura 51 - Deflexão na origem, $3500 \mathrm{~N}$, a $45^{\circ}$, com três atuadores, pelo FTool.

Executando a simulação no MatLab para o programa PTV correspondente, pode-se verificar os deslocamentos obtidos com o FTool, com os seguintes resultados:

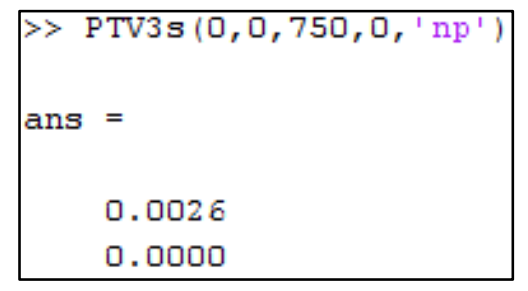

(a)

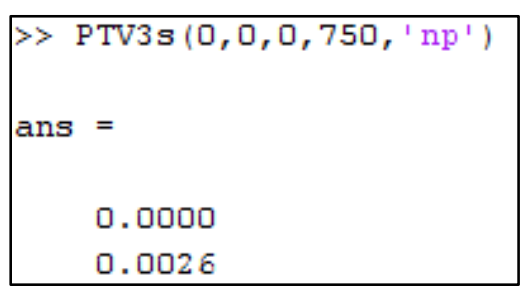

(c)

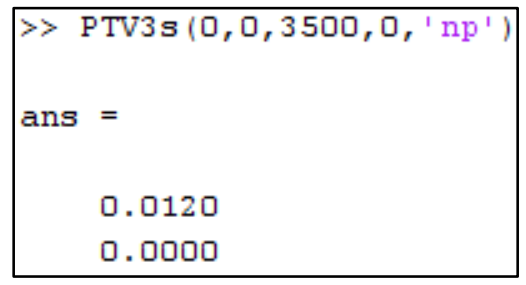

(b)

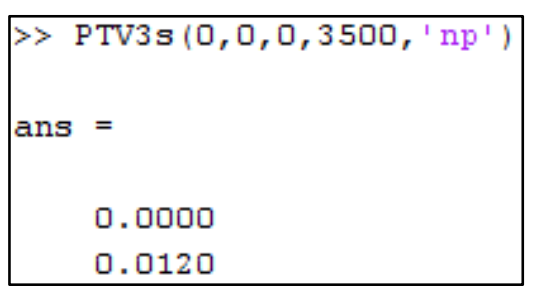

(d) 


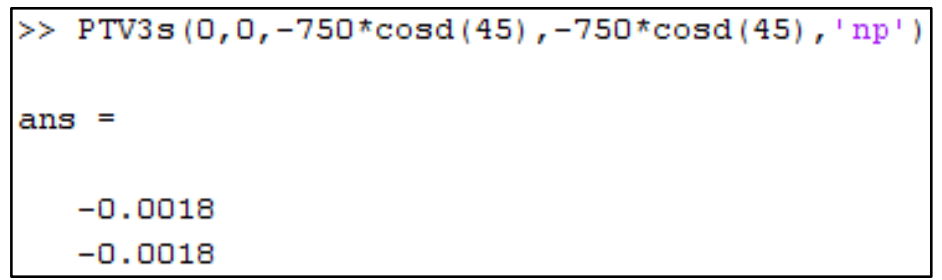

(e)

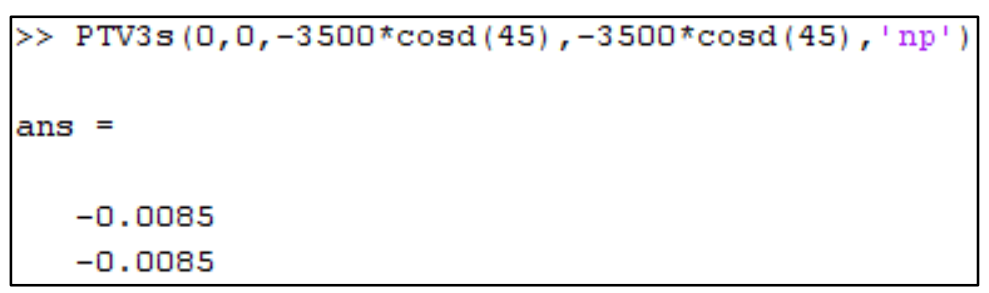

(f)

Figura 52 - Deflexão na origem, com três atuadores, pelo MatLab.

(a) Força horizontal de $750 \mathrm{~N}$;

(b) Força horizontal de $3500 \mathrm{~N}$;

(c) Força vertical de $750 \mathrm{~N}$;

(d) Força vertical de $3500 \mathrm{~N}$;

(e) Força a $45^{\circ}$ de $750 \mathrm{~N}$ (negativa nos dois eixos);

(f) Força a $45^{\circ}$ de $3500 \mathrm{~N}$ (negativa nos dois eixos).

A seguir são listados os resultados observados através do Ansys, sob as mesmas condições expressas no caso com apenas dois atuadores. É interessante observar o comportamento análogo ao dos casos já apresentados. 


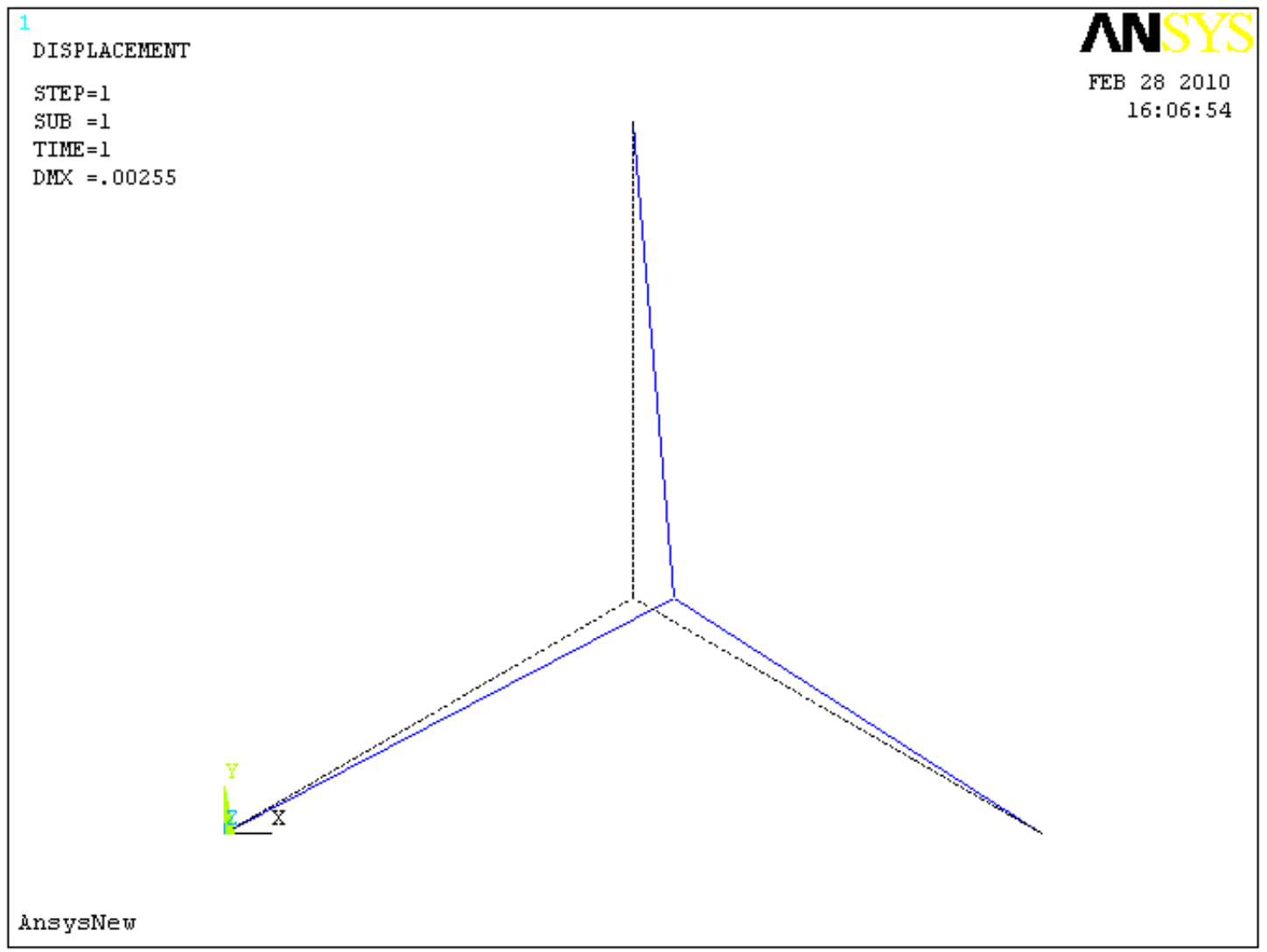

Figura 53 - Deflexão na origem, 750N, horizontal, com três atuadores, pelo Ansys.

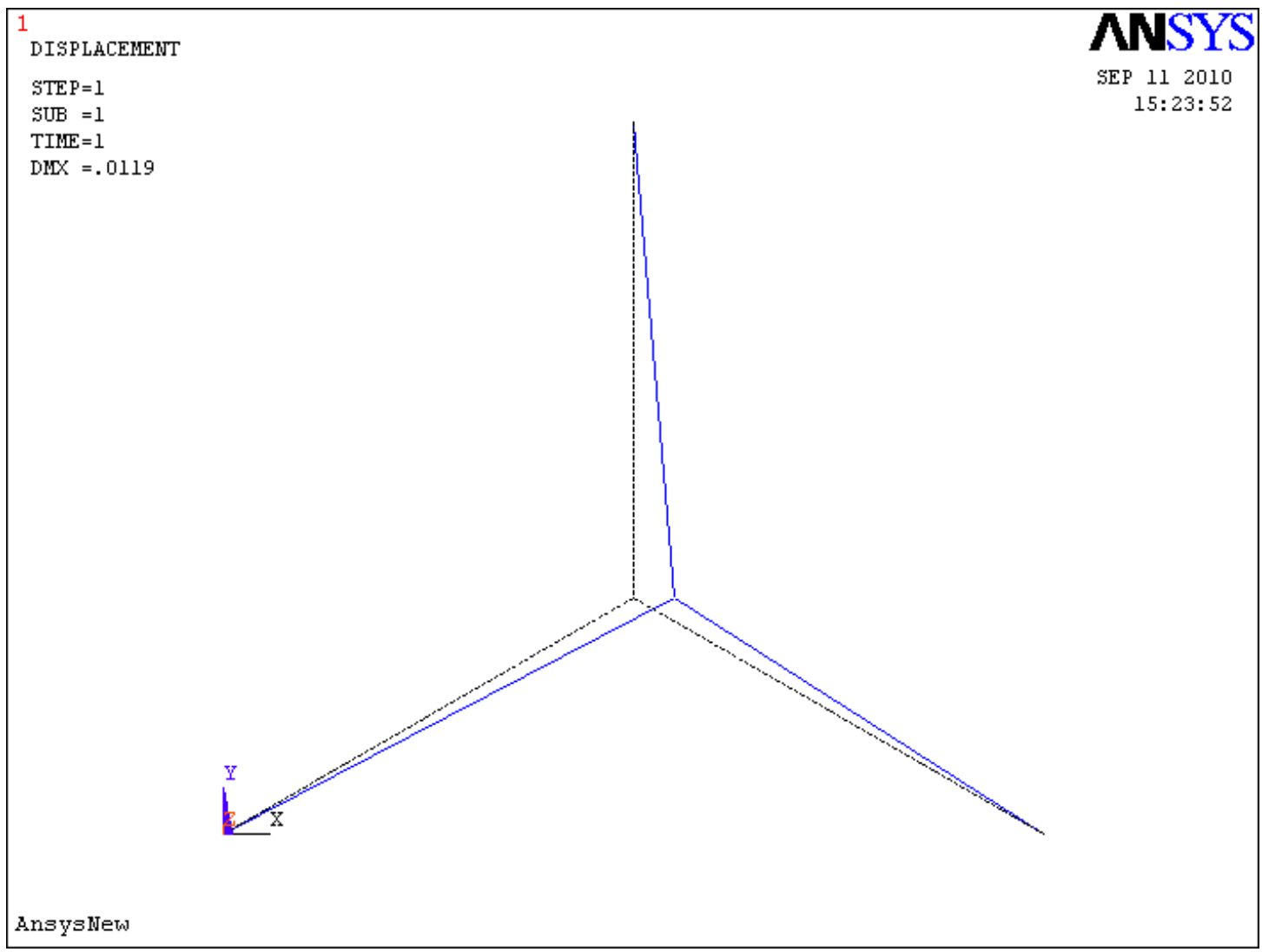

Figura 54 - Deflexão na origem, 3500N, horizontal, com três atuadores, pelo Ansys. 


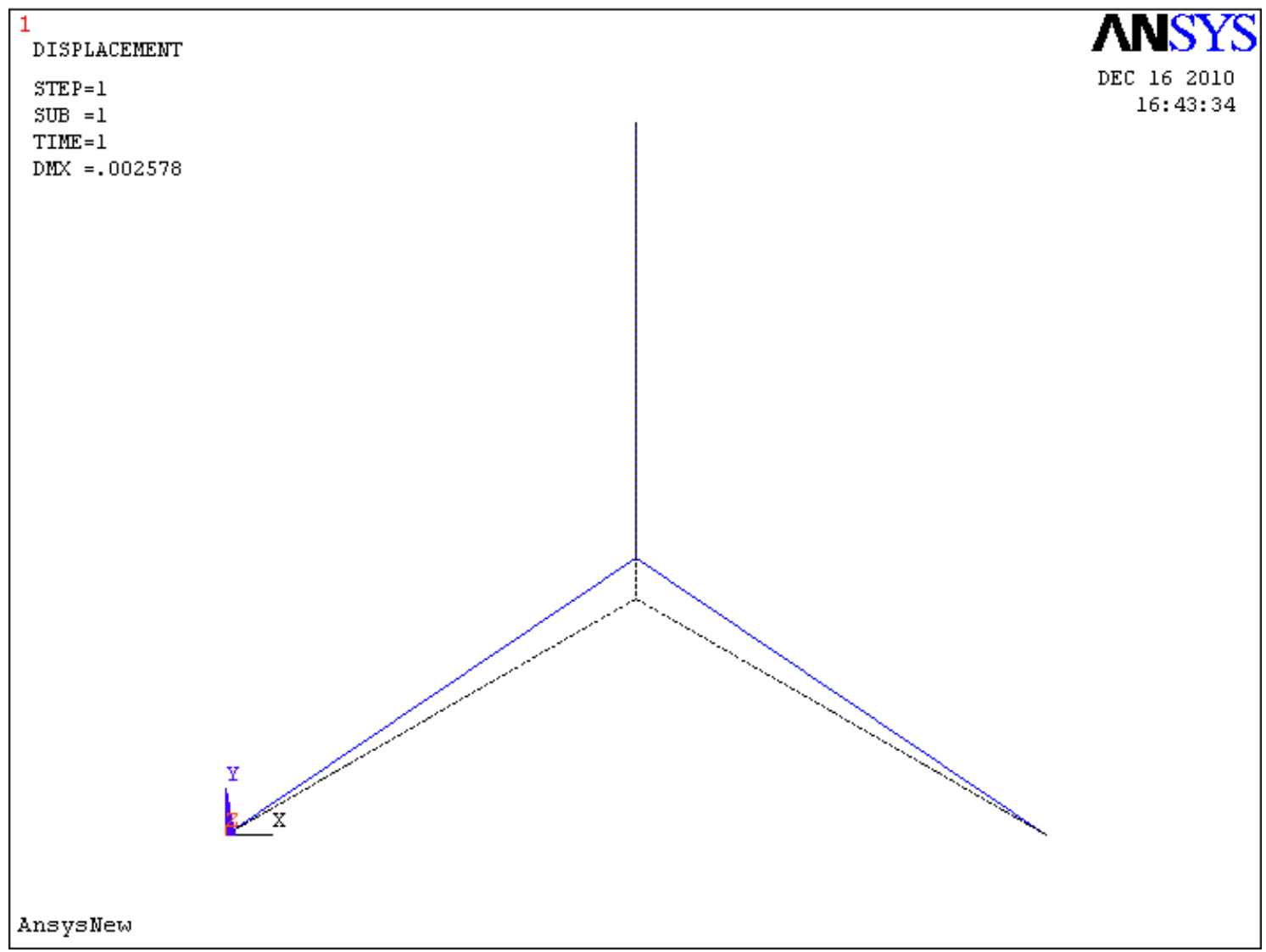

Figura 55 - Deflexão na origem, $750 \mathrm{~N}$, vertical, com três atuadores, pelo Ansys. 


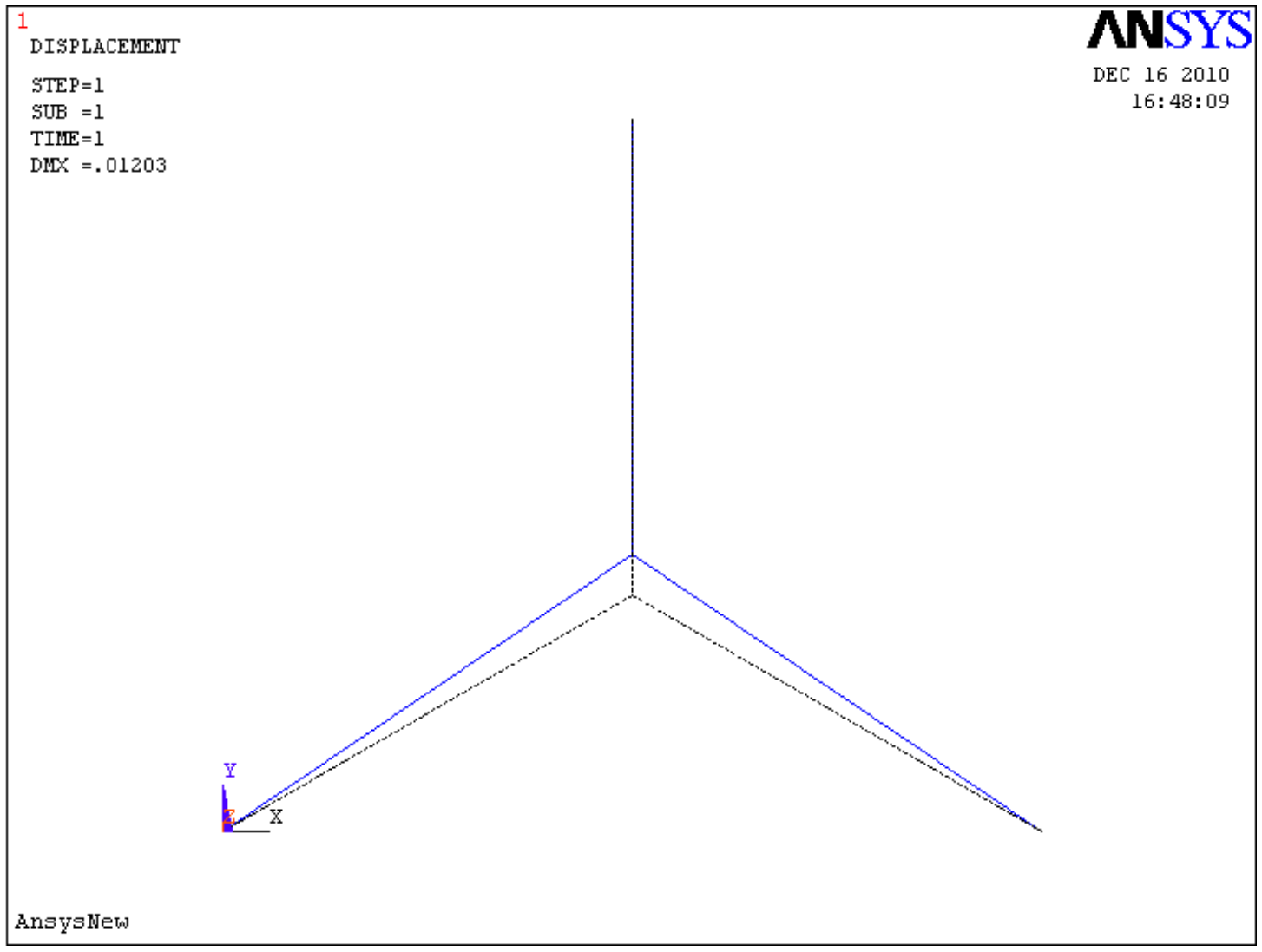

Figura 56 - Deflexão na origem, $3500 \mathrm{~N}$, vertical, com três atuadores, pelo Ansys.

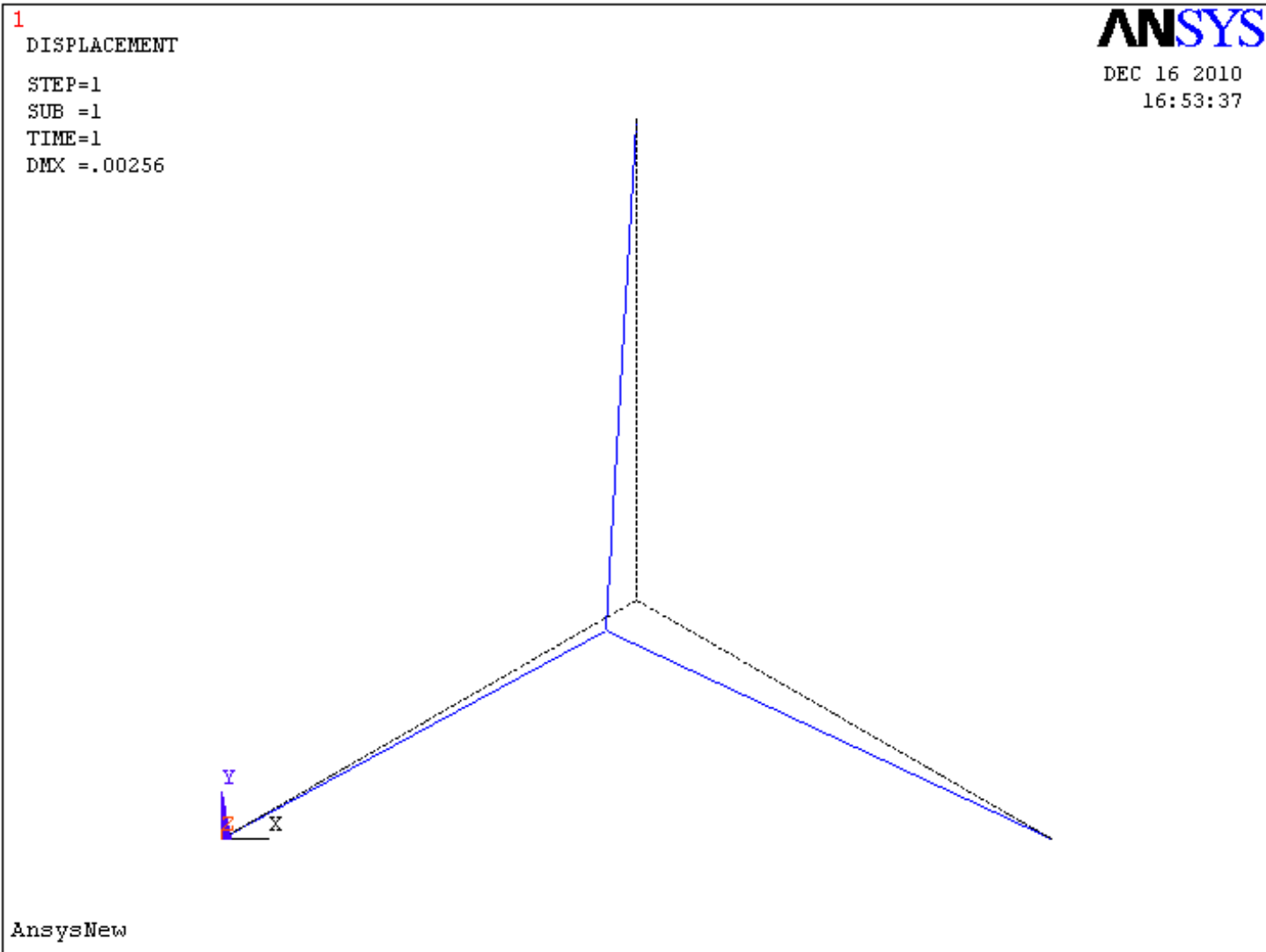

Figura 57 - Deflexão na origem, $750 \mathrm{~N}$, a $45^{\circ}$, com três atuadores, pelo Ansys. 


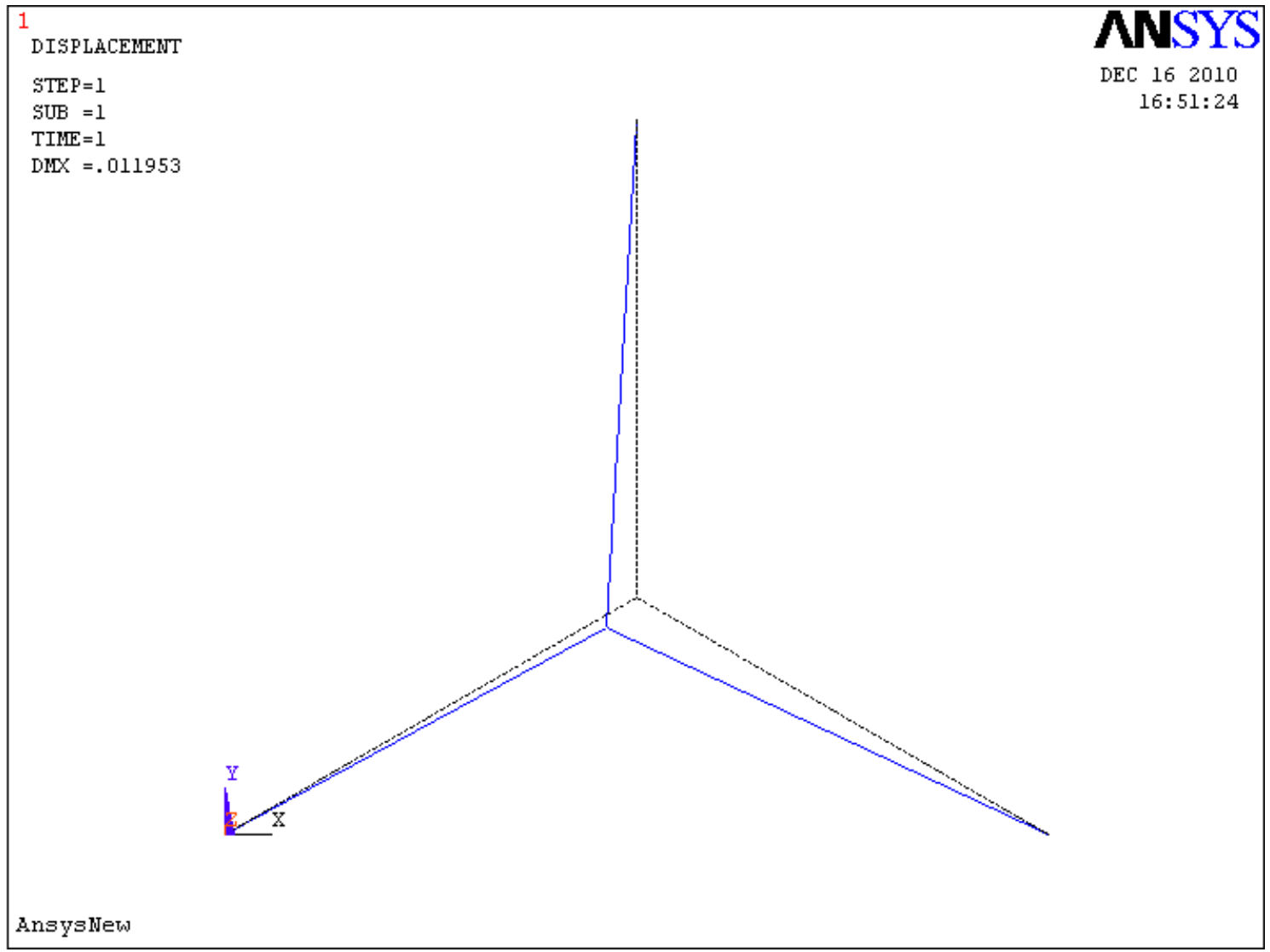

Figura 58 - Deflexão na origem, $3500 \mathrm{~N}$, a $45^{\circ}$, com três atuadores, pelo Ansys.

Como era de se esperar, por não existir resistência horizontal com a nova barra, a deflexão na ponta da ferramenta manteve-se em relação aos casos anteriores.

As tabelas Tabela 4 e Tabela 5 listam os resultados para todos os casos mostrados acima.

Tabela 4 - Resumo da deflexão $(\mu \mathrm{m})$ para $F=750 \mathrm{~N}$.

\begin{tabular}{|c|c|c|c|c|c|c|}
\hline \multirow{2}{*}{ Direção } & \multirow{2}{*}{ Braços } & \multicolumn{3}{|c|}{ Programa } & \multicolumn{2}{c|}{ Erro } \\
\cline { 3 - 7 } & & Ftool & Ansys & MatLab & Ftool & Ansys \\
\hline \multirow{2}{*}{ Hor. } & 2 & 2,55 & 2,55 & 2,57 & $0,8 \%$ & $0,8 \%$ \\
\cline { 2 - 7 } & 3 & 2,55 & 2,55 & 2,57 & $0,8 \%$ & $0,8 \%$ \\
\hline \multirow{2}{*}{ Vert. } & 2 & 7,74 & 7,74 & 7,70 & $-0,5 \%$ & $-0,5 \%$ \\
\cline { 2 - 7 } & 3 & 2,59 & 2,58 & 2,60 & $0,6 \%$ & $0,9 \%$ \\
\hline \multirow{2}{*}{$45^{\circ}$} & 2 & $-5,75$ & $-5,76$ & $-5,69$ & $-0,9 \%$ & $-1,1 \%$ \\
\cline { 2 - 7 } & 3 & $-2,56$ & $-2,56$ & $-2,55$ & $-0,7 \%$ & $-0,6 \%$ \\
\hline
\end{tabular}


Tabela 5 - Resumo da deflexão $(\mu \mathrm{m})$ para $\mathrm{F}=3500 \mathrm{~N}$.

\begin{tabular}{|c|c|c|c|c|c|c|}
\hline \multirow{2}{*}{ Direção } & \multirow{2}{*}{ Braços } & \multicolumn{3}{|c|}{ Programa } & \multicolumn{2}{c|}{ Erro } \\
\cline { 3 - 7 } & & Ftool & Ansys & MatLab & Ftool & Ansys \\
\hline \multirow{2}{*}{ Hor. } & 2 & 11,86 & 11,90 & 11,98 & $1,0 \%$ & $0,7 \%$ \\
\cline { 2 - 7 } & 3 & 11,90 & 11,90 & 11,98 & $0,7 \%$ & $0,7 \%$ \\
\hline \multirow{2}{*}{ Vert. } & 2 & 36,06 & 36,15 & 35,90 & $-0,4 \%$ & $-0,7 \%$ \\
\cline { 2 - 7 } & 3 & 12,06 & 12,03 & 12,00 & $-0,5 \%$ & $-0,2 \%$ \\
\hline \multirow{2}{*}{$45^{\circ}$} & 2 & $-27,14$ & $-26,89$ & $-26,78$ & $-1,3 \%$ & $-0,4 \%$ \\
\cline { 2 - 7 } & 3 & $-11,97$ & $-11,95$ & $-12,02$ & $0,4 \%$ & $0,6 \%$ \\
\hline
\end{tabular}

Como se pode observar, o modelo desenvolvido em MatLab utilizando o método PTV pôde ser validado tanto analiticamente quanto numericamente, com um erro médio menor que $1 \%$.

Os valores para a deflexão utilizando forças de $750 \mathrm{~N}$ e de $3500 \mathrm{~N}$ mostram o caráter linear do sistema, dado que as deflexões seguiram as alterações de forças na ordem de 4,6 vezes.

Para o caso horizontal fica clara a independência com relação ao membro superior. No entanto, para os casos vertical e a $45^{\circ}$ existe notório aumento de rigidez do sistema com sua introdução. Esse aumento depende diretamente da componente vertical considerada, e o membro adicional ativo permitiu uma homogeneidade da deflexão.

Assim, existe aumento na rigidez do sistema como um todo, sendo que o pior caso de deflexão que deve ser considerado é o realizado por duas barras apenas. Para qualquer caso com três membros ocorreu estabilização da deflexão em torno de um determinado valor, que no caso estudado é de $2,57 \mu \mathrm{m}$ e $12 \mu \mathrm{m}$, respectivamente para esforços de $750 \mathrm{~N}$ e de $3500 \mathrm{~N}$.

Nesse momento cabe comentário sobre as folgas da máquina construída. Levandose em consideração apenas os rolamentos utilizados, ou seja, as folgas nas guias lineares estão sendo desconsideradas, observa-se que as deflexões já são da mesma ordem das folgas desses componentes.

Tabela 6 - Folga média normal dos rolamentos.

\begin{tabular}{|c|c|c|c|c|}
\hline Componente & Item & Modelo & Quantidade & Folga $(\boldsymbol{\mu m})$ \\
\hline \multirow{2}{*}{ Rolamentos } & Ferramenta & 6800 & 6 & 8 \\
\cline { 2 - 5 } & Pino & 6808 & 6 & 13 \\
\hline
\end{tabular}


Assim, outros componentes devem ser selecionados em substituição aos indicados, ou então devem ser tomadas medidas para reduzir a folga daqueles já instalados no equipamento. De qualquer forma, o importante é enfatizar que se atingiu outro ponto crítico do projeto: a resistência dos materiais, arquitetura e esforços deixaram de ser o limite inferior de construção, passando a o ser a folga nos seus elementos constituintes.

\subsubsection{Modelo em 3D}

Apesar de terem sido feitas muitas análises no modelo 2D, para dois e três braços de atuação, houve necessidade de confirmar se esses resultados eram representativos de um fenômeno predominantemente espacial.

Para que essa comparação pudesse ser feita, foi produzido um modelo sólido da estrutura dos braços de atuação em sua posição central. O modelo foi desenhado no SolidWorks e exportado no formato IGES para o Ansys. A seguir, a Figura 59 mostra o modelo gerado e sua representação esquemática.

O elemento utilizado foi o SOLID187, que é tetragonal de 10 nós. Esse elemento tem um comportamento quadrático e é indicado para malhas irregulares. Uma malha irregular geralmente é gerada quando um desenho é oriundo de um programa de CAD ou CAM, que é o caso deste trabalho. 


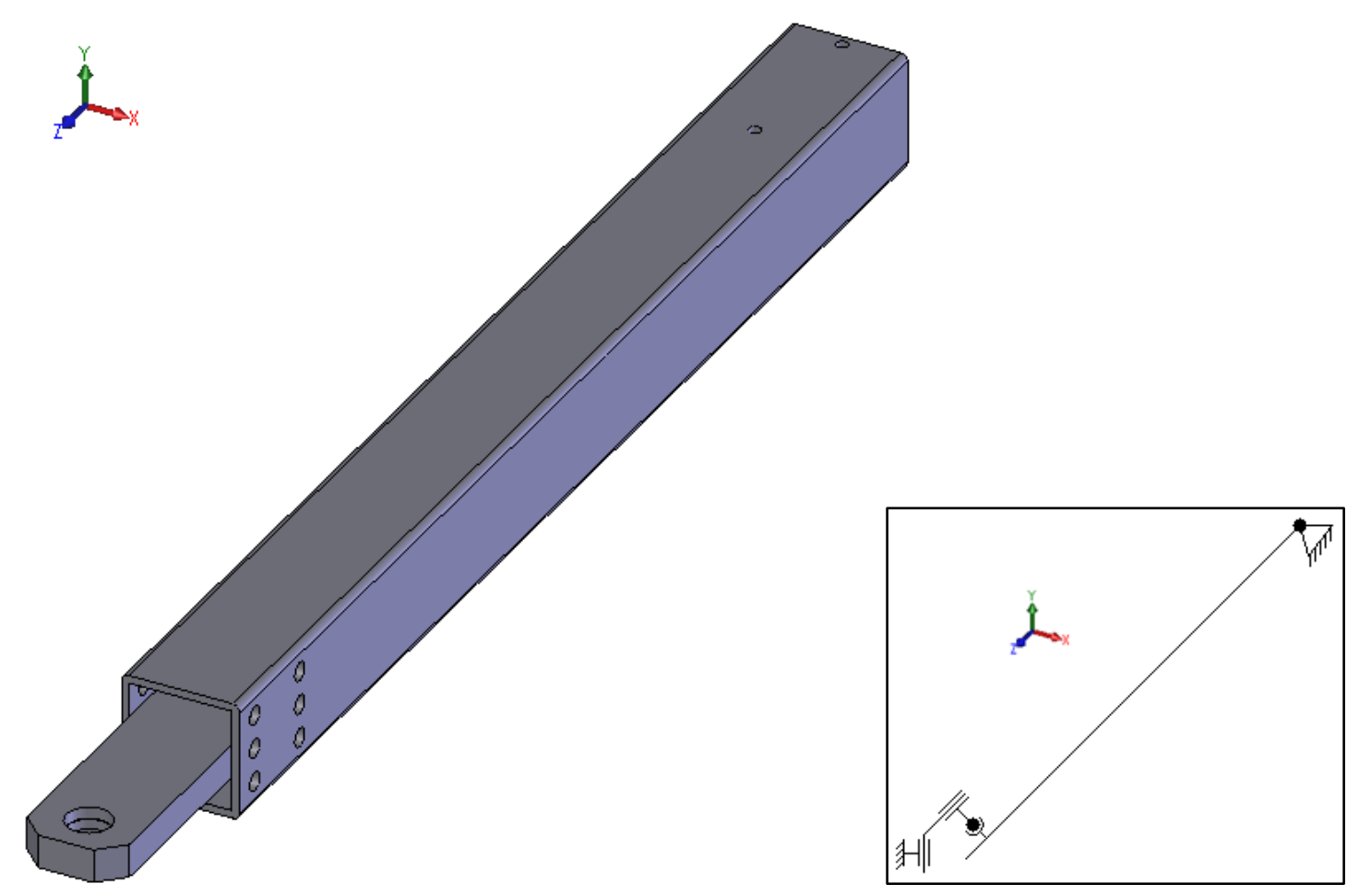

Figura 59 - Modelo utilizado e representação esquemática.

Aqui cabem algumas considerações sobre a figura. De forma a facilitar a análise, as uniões entre as peças foram consideradas extremamente rígidas, assumindo distribuição contínua de forças na interface. Assim, a conexão braço-garra foi construída como um único sólido. As condições de contorno utilizadas foram rotação em ' $y$ ' na base do braço e engaste em ' $x$ ' na extremidade da garra. Essa última foi necessária para permitir convergência dos resultados.

Outro ponto relevante é a presença da fresa e de seu suporte. Como a fresa está ligada ao motor AC através de uma conexão universal com junta prismática, todos os esforços na ponta da ferramenta devem ser considerados na análise, já que esses movimentos serão permitidos por essas juntas.

Assim, as forças atuantes nos braços são representadas numa treliça no espaço, cuja decomposição é dada pela resolução em PTV para uma determinada posição. O peso próprio da estrutura é considerado nas análises e é aplicado um momento torçor na extremidade da garra, simulando a relação existente entre os três membros. 


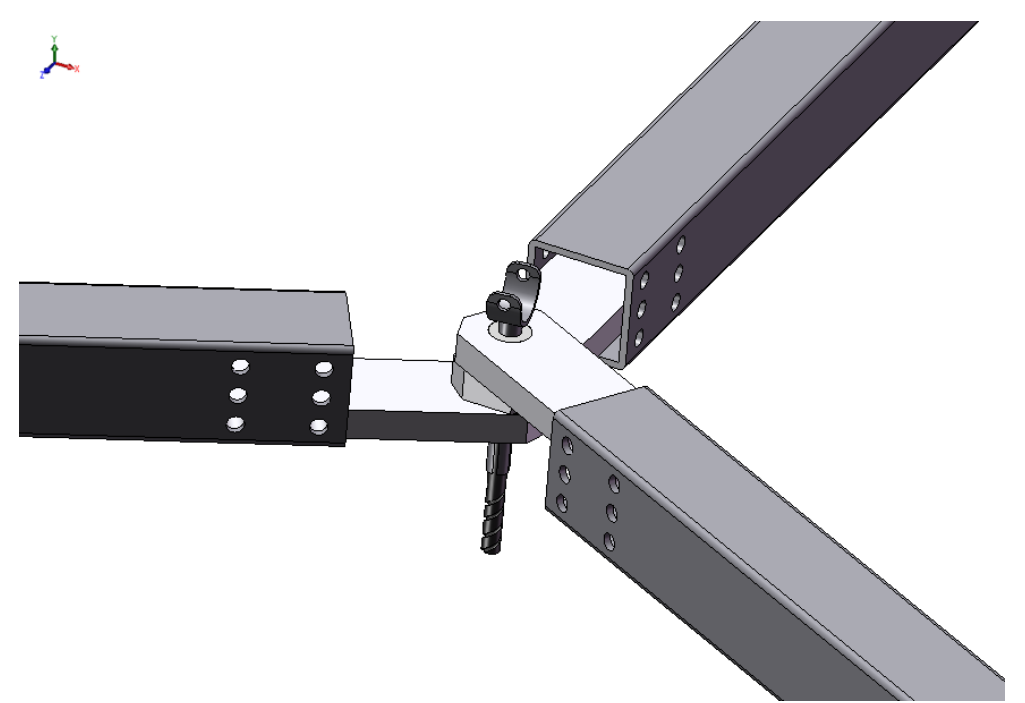

Figura 60 - Interação entre membros.

A figura acima mostra a construção e a relação existente entre braços, garras e a ferramenta. Quando aplicamos uma força genérica $F$ em sua extremidade, uma série de decomposições ocorre na estrutura.

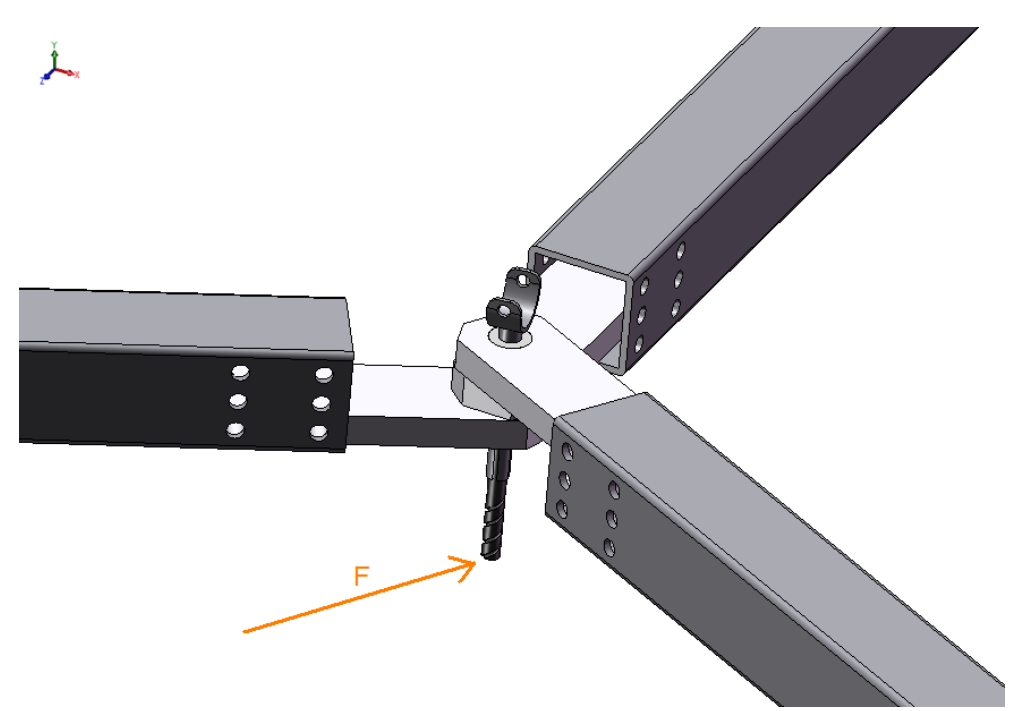

Figura 61 - Força F genérica.

Inicialmente podemos seccionar o braço 1 e substituí-lo por uma força axial R1, já que se está admitindo o membro como uma treliça. 


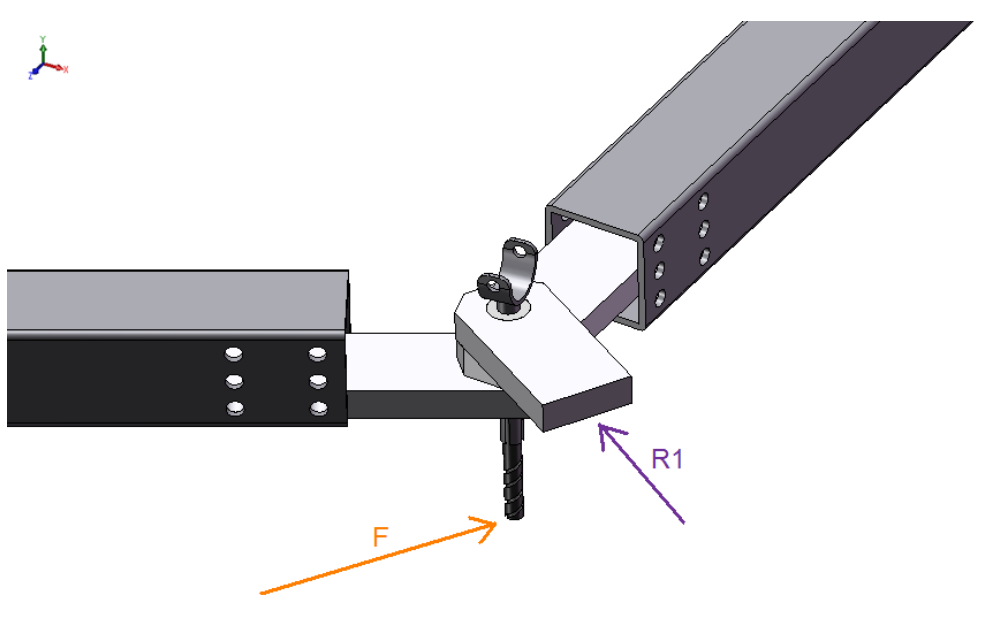

Figura 62 - Força axial R1.

Da mesma forma, o braço 3 pode ser substituído por uma força R3 igualmente representativa.

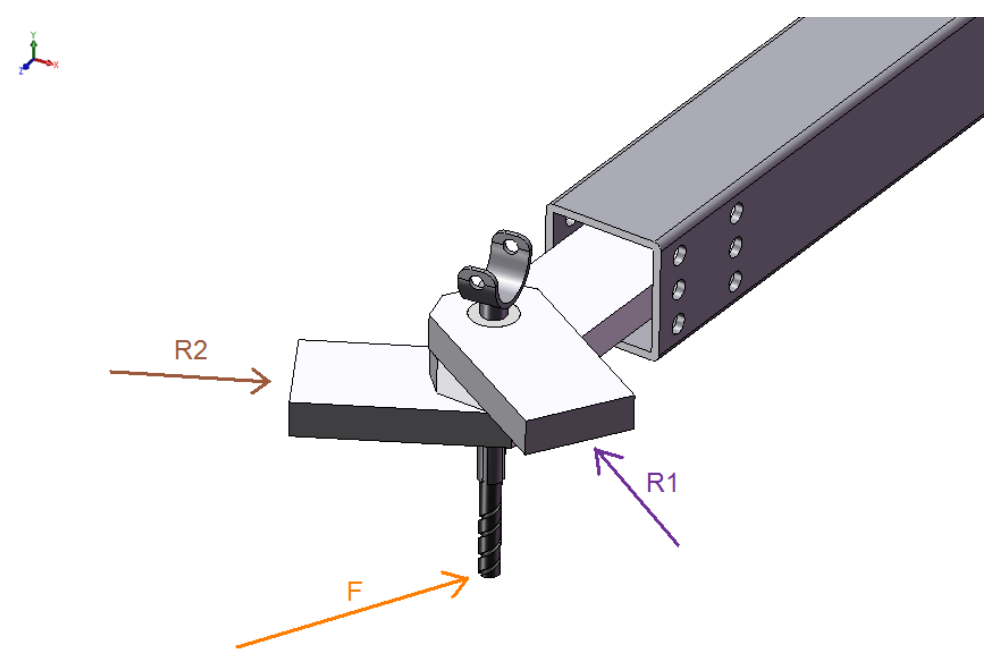

Figura 63 - Força axial R2.

A seguir, e tomando como base a orientação do braço 2, pode-se decompor a força $F$ em duas componentes: $F_{\text {Radial }}$ e $F_{\text {Axial, }}$ orientadas radialmente e axialmente em relação ao braço 2 . 


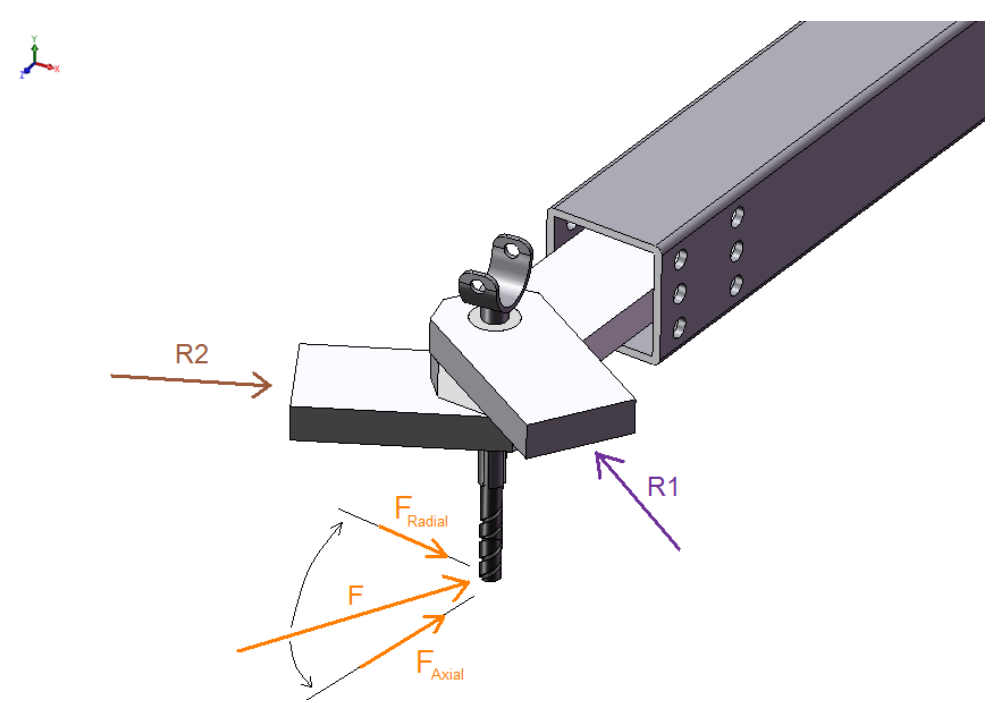

Figura 64 - Decomposição de F.

Devido ao comprimento da ferramenta, existe uma diferença de cota entre seu plano horizontal e o do braço. Deve-se então transportar os dois esforços para o mesmo plano. Existe então o aparecimento de mais dois momentos, um torçor e outro fletor do braço de acionamento, respectivamente $\mathrm{M}_{\text {Torçor }}$ e $\mathrm{M}_{\text {Flet }}$.

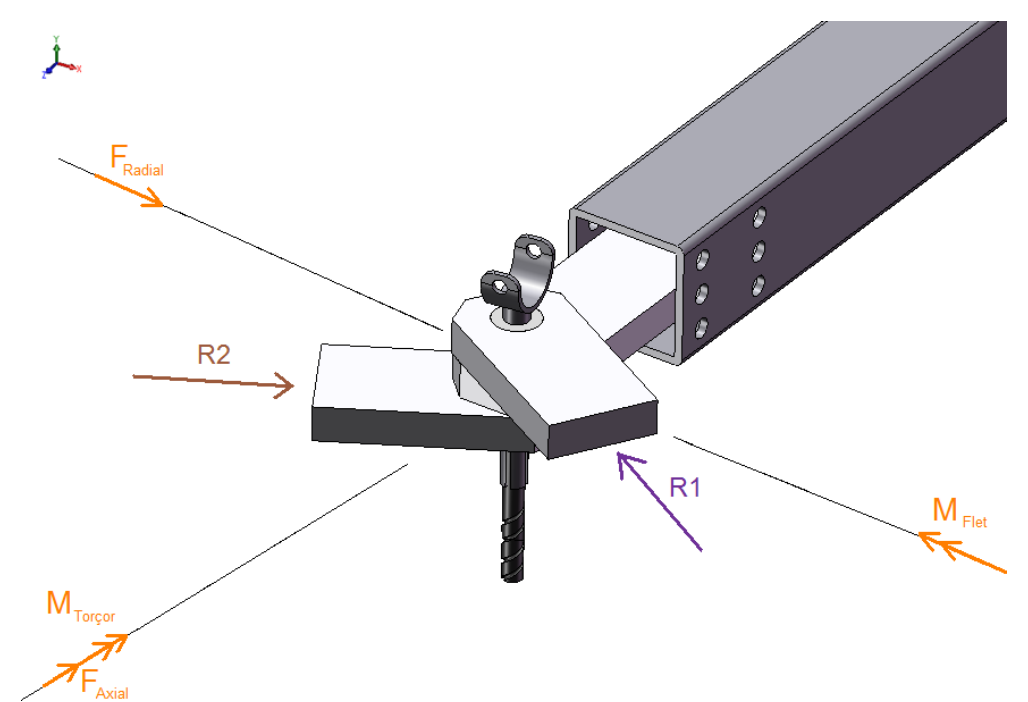

Figura 65 - Transporte dos esforços.

Realizando agora as mesmas operações de decomposição e transporte de vetores para as forças R1 e R2, pode-se obter a seguinte distribuição de esforços: 


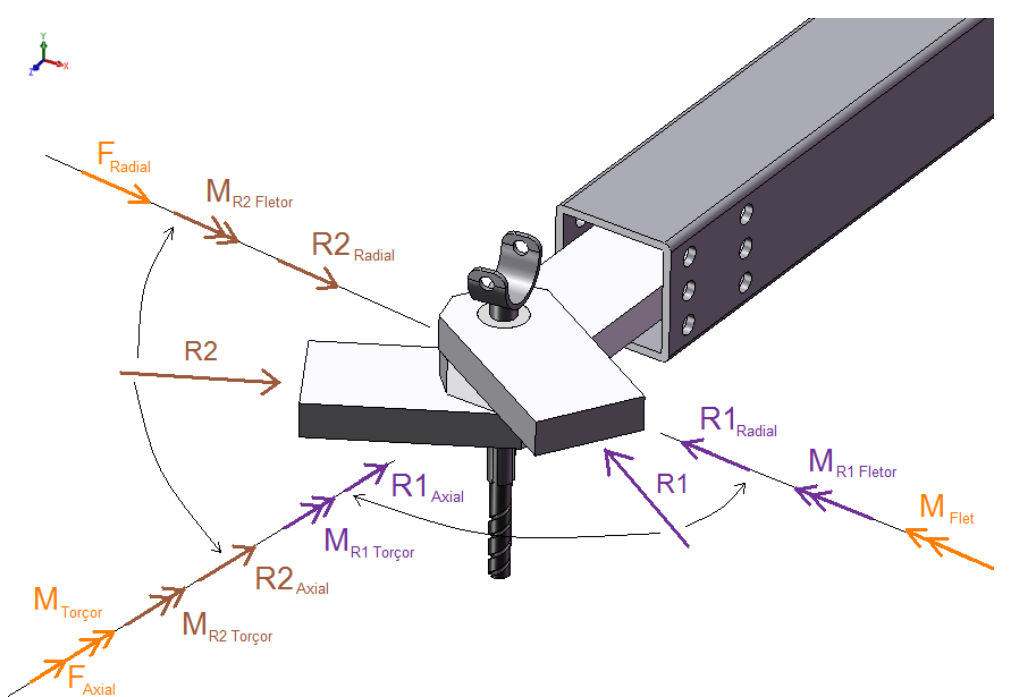

Figura 66 - Distribuição de esforços.

Por fim, de forma a simplificar a entrada de dados no programa deve-se agrupar todos os vetores de forma a gerar três resultantes: a componente de força axial, $\mathrm{R}_{\text {Axial, }}$ a componente fletora de momento, $\mathrm{M}_{\text {Flet }}$, e mais o momento torçor, $\mathrm{M}_{\text {tor }}$.

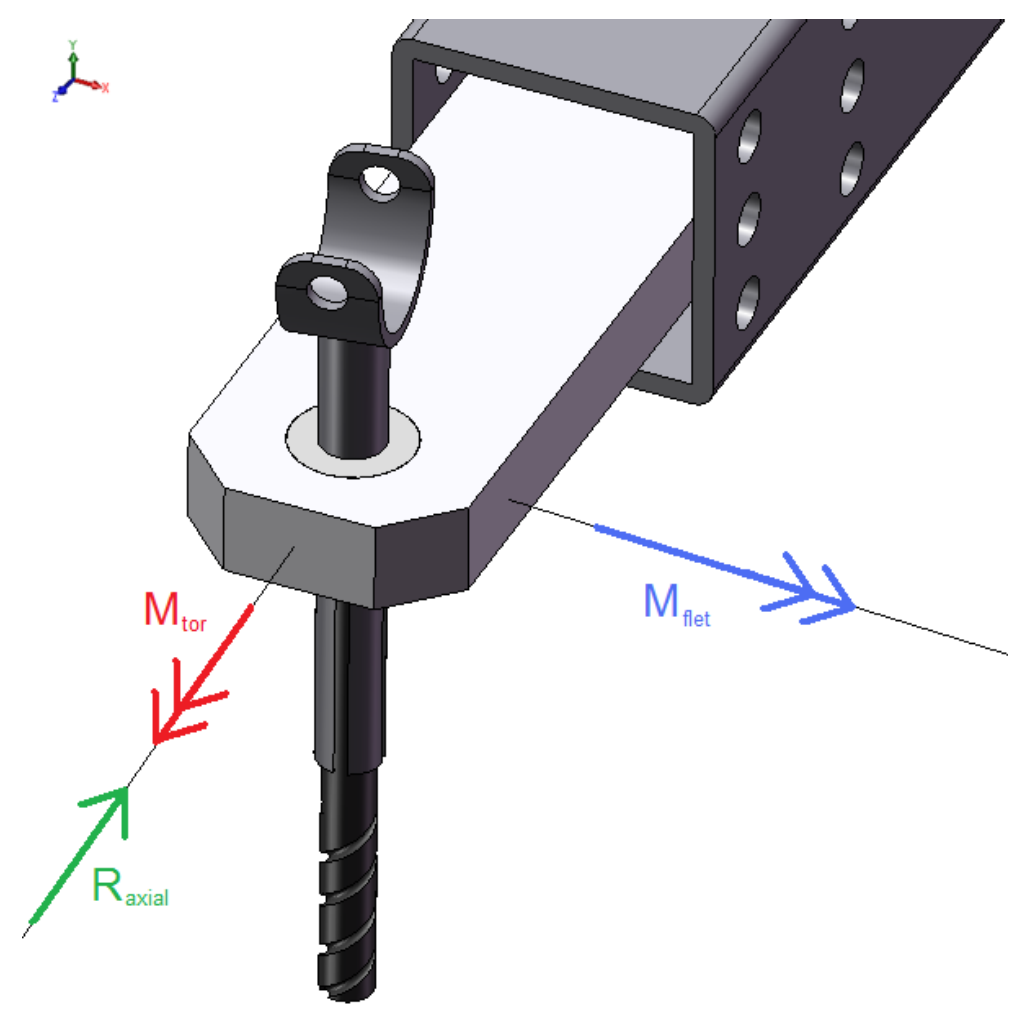

Figura 67 - Resultantes de esforços.

A força passiva de usinagem não foi considerada, pois depende de outras variáveis que não são o foco deste trabalho.

Para a comparação em questão, foram analisados três casos de aplicação: 
- Caso 1: força de $750 \mathrm{~N}$ na horizontal em $(0,0)$;

- Caso 2: força de $-3500 N$ na vertical em $(200,0)$;

- Caso 3: força de $3500 \mathrm{~N}$ a $45^{\circ}$ em $(200,200)$.

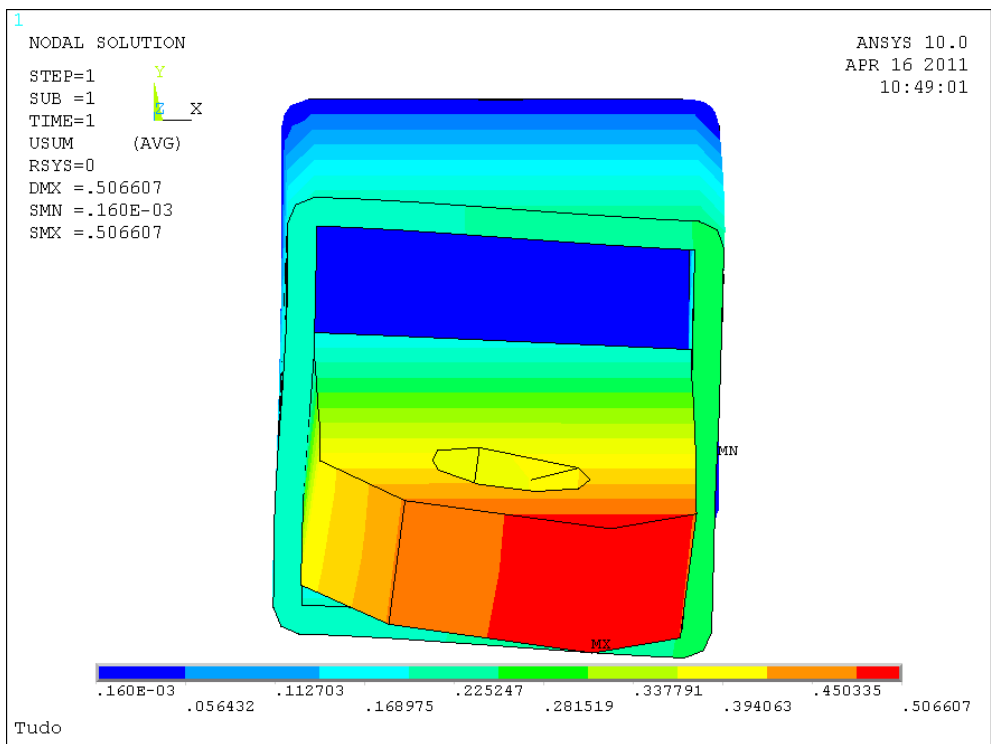

Figura 68 - Resultado do caso 1.

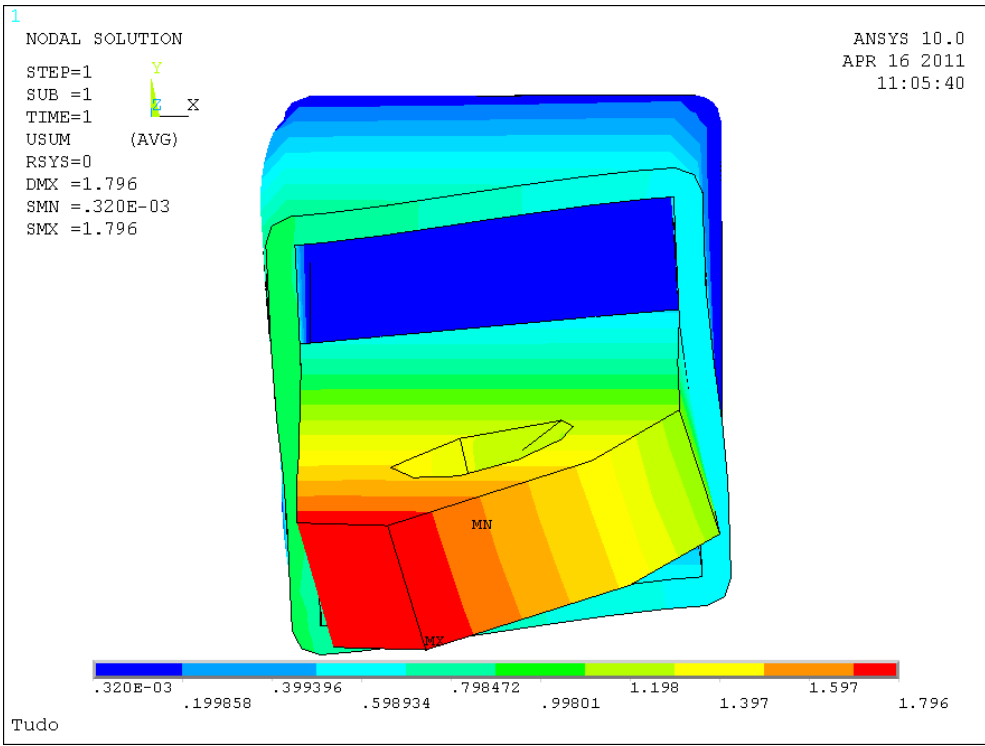

Figura 69 - Resultado do caso 2. 


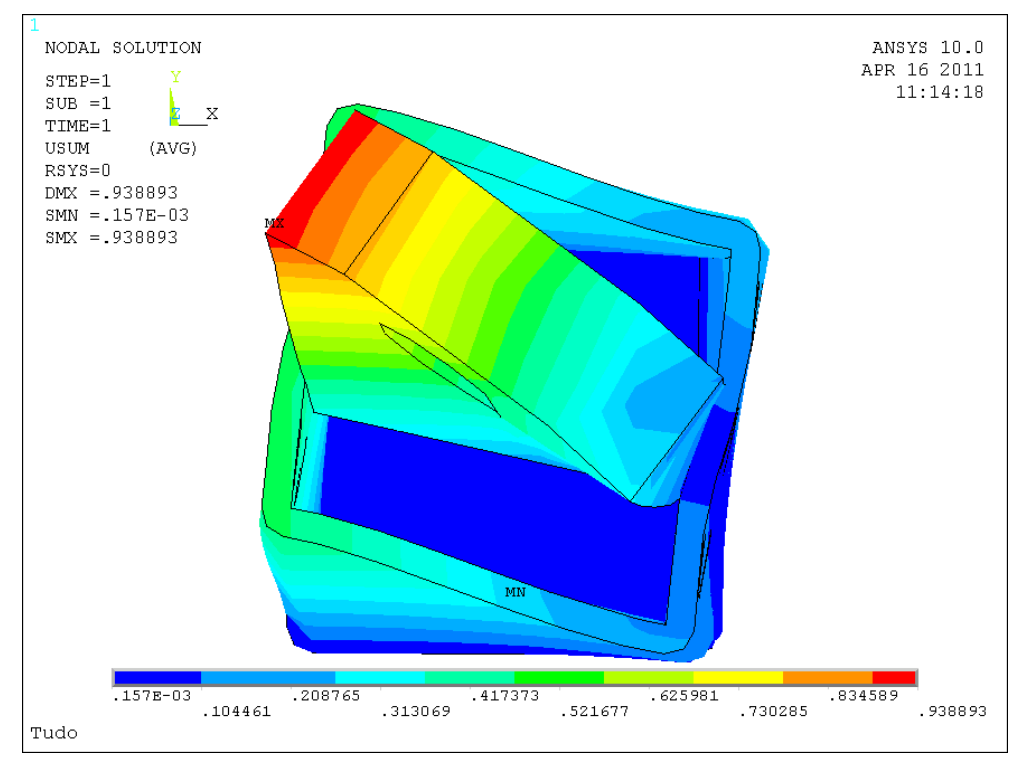

Figura 70 - Resultado do caso 3.

Observa-se que as deflexões encontradas dependem da direção e sentido da força aplicada, devido à interação entre os braços. O peso próprio da estrutura gera uma deflexão de apenas $0,02 \mathrm{~mm}$.

Tabela 7 - Deflexão no modelo 3D.

\begin{tabular}{|c|c|c|c|c|}
\hline Caso & Força & Direção & Posição & $\begin{array}{c}\text { Deflexão } \\
(\mathrm{mm})\end{array}$ \\
\hline 1 & 750 & hor. & $(0,0)$ & 0,51 \\
\hline 2 & -3500 & vert. & $(200,0)$ & 1,80 \\
\hline 3 & 3500 & $45^{\circ}$ & $(200,200)$ & 0,94 \\
\hline
\end{tabular}

Os valores obtidos na simulação em 3D, de cerca de $1 \mathrm{~mm}$, não são correspondentes aos obtidos em duas dimensões. O desvio é alto devido às considerações feitas e à grande complexidade do modelo 3D em relação ao modelo 2D.

Tabela 8 - Comparação entre os dois modelos.

\begin{tabular}{|c|c|c|c|c|}
\hline \multirow{2}{*}{ Direção } & \multirow{2}{*}{ Força } & \multicolumn{2}{|c|}{ Modelo $(\mu \mathrm{m})$} & \multirow{2}{*}{ Desvio } \\
\cline { 3 - 4 } & & $3 \mathrm{D}$ & Ref. & \\
\hline Hor. & 750 & 510,00 & 2,57 & $-99,5 \%$ \\
\hline Vert. & -3500 & 1800,00 & 12,00 & $-99,3 \%$ \\
\hline $45^{\circ}$ & 3500 & 940,00 & 12,00 & $-98,7 \%$ \\
\hline \multicolumn{4}{|l}{} & $99,2 \%$ \\
\hline
\end{tabular}


A variação das forças locais envolvidas, devido à modificação do sentido da força resultante, assim como a componente passiva da força de usinagem, inicialmente abordada no capítulo 8.1, tornam interessante a comparação entre os dois modelos, que não será abordada neste trabalho. 


\subsection{MAPEAMENTO DO ERRO DEVIDO A CARGA ESTÁTICA}

\subsubsection{Máquina com dois atuadores}

Após a validação dos modelos, pode-se gerar agora o mapeamento da rigidez da área de trabalho com uma variação do programa em MatLab:

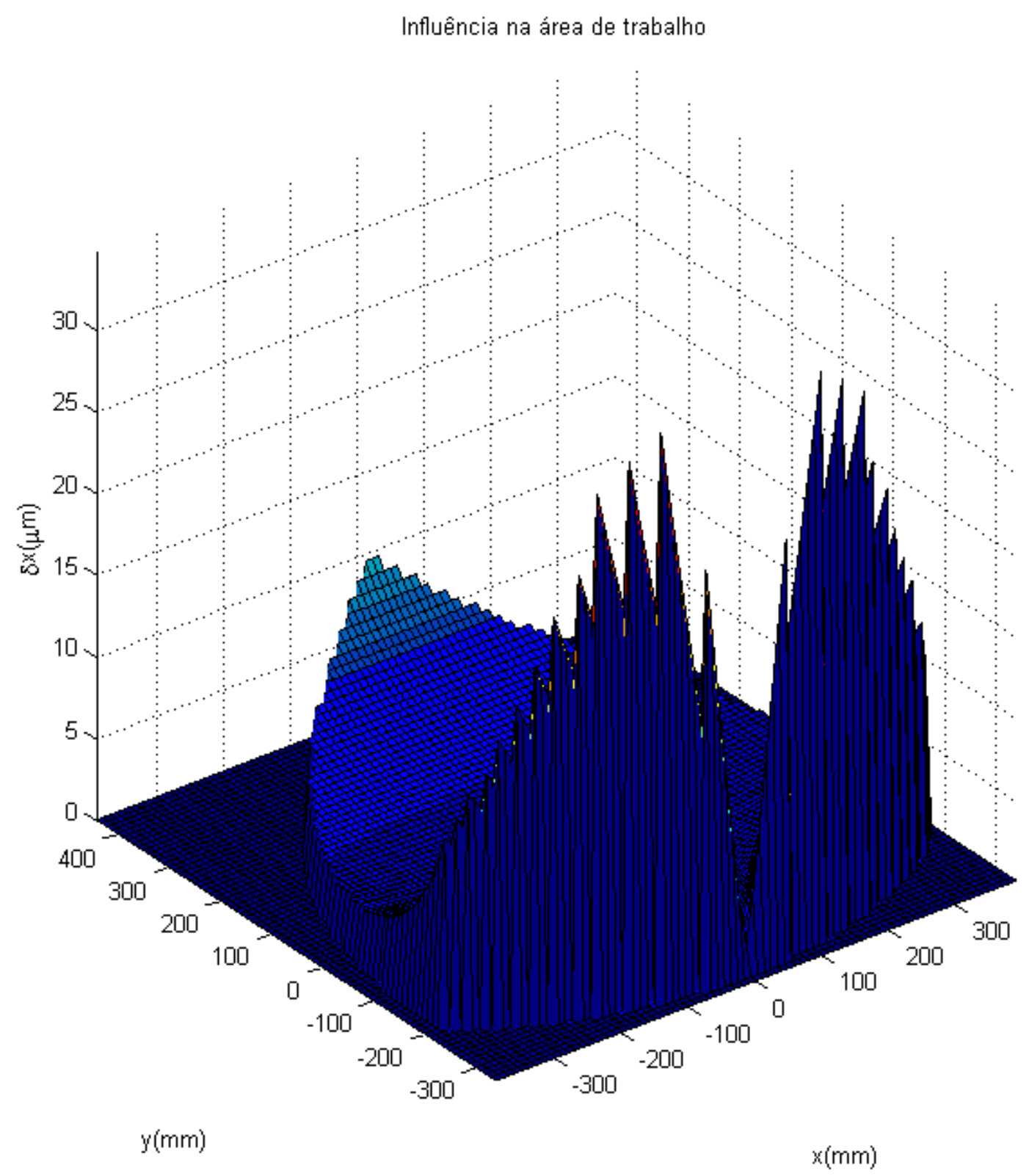

Figura 71 - Erro estático na área de trabalho, com dois atuadores, para 750N, horizontal. 
Pode-se observar a manutenção da relação de 4,6 para todos os valores do gráfico, que se apresentou igual em forma para as duas forças.

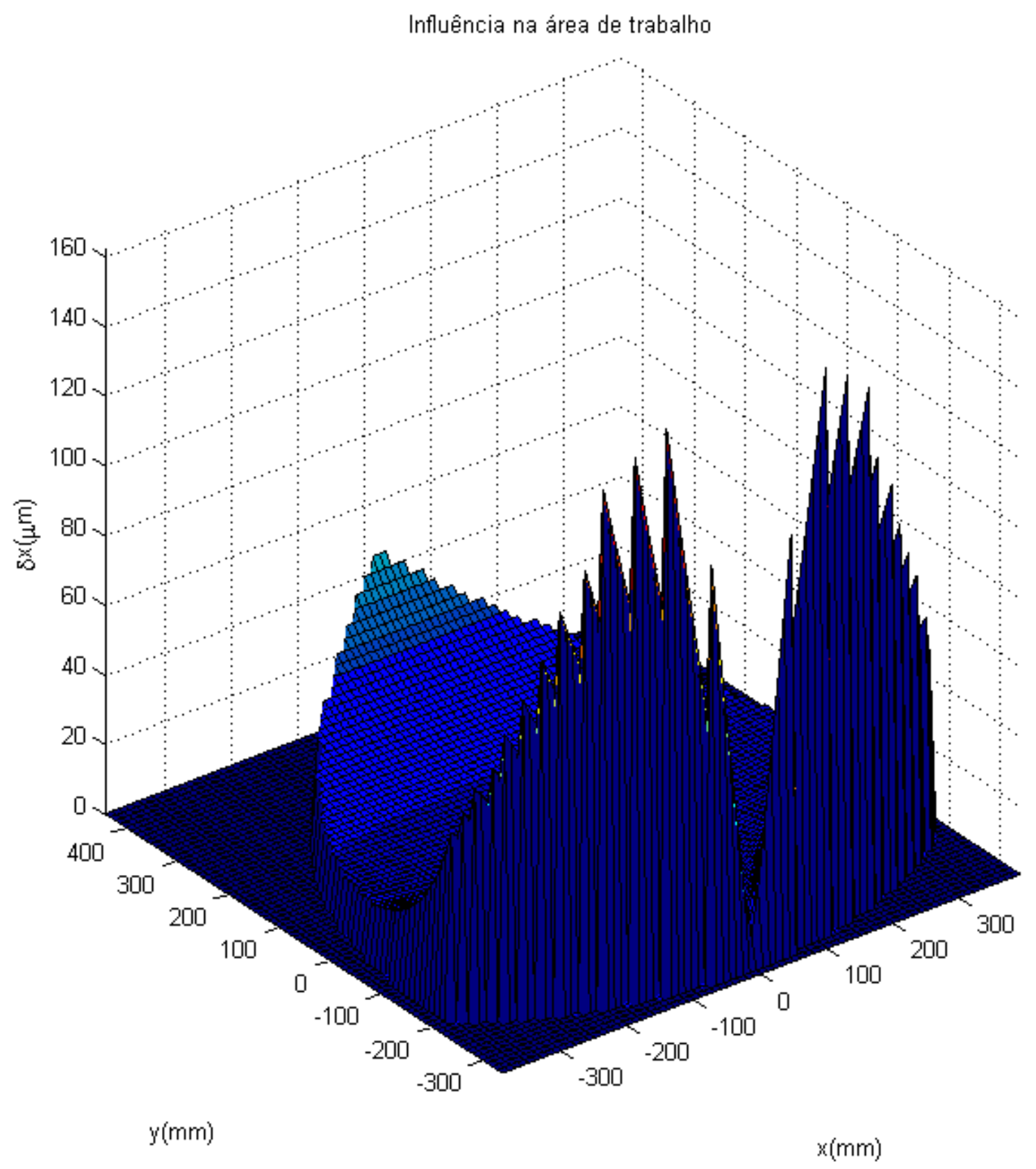

Figura 72 - Erro estático na área de trabalho, com dois atuadores, para $3500 \mathrm{~N}$, horizontal.

Para direção vertical, fica bem caracterizada a região de proximidade com pontos de singularidades, como mostram as duas figuras abaixo. 
Influência na área de trabalho

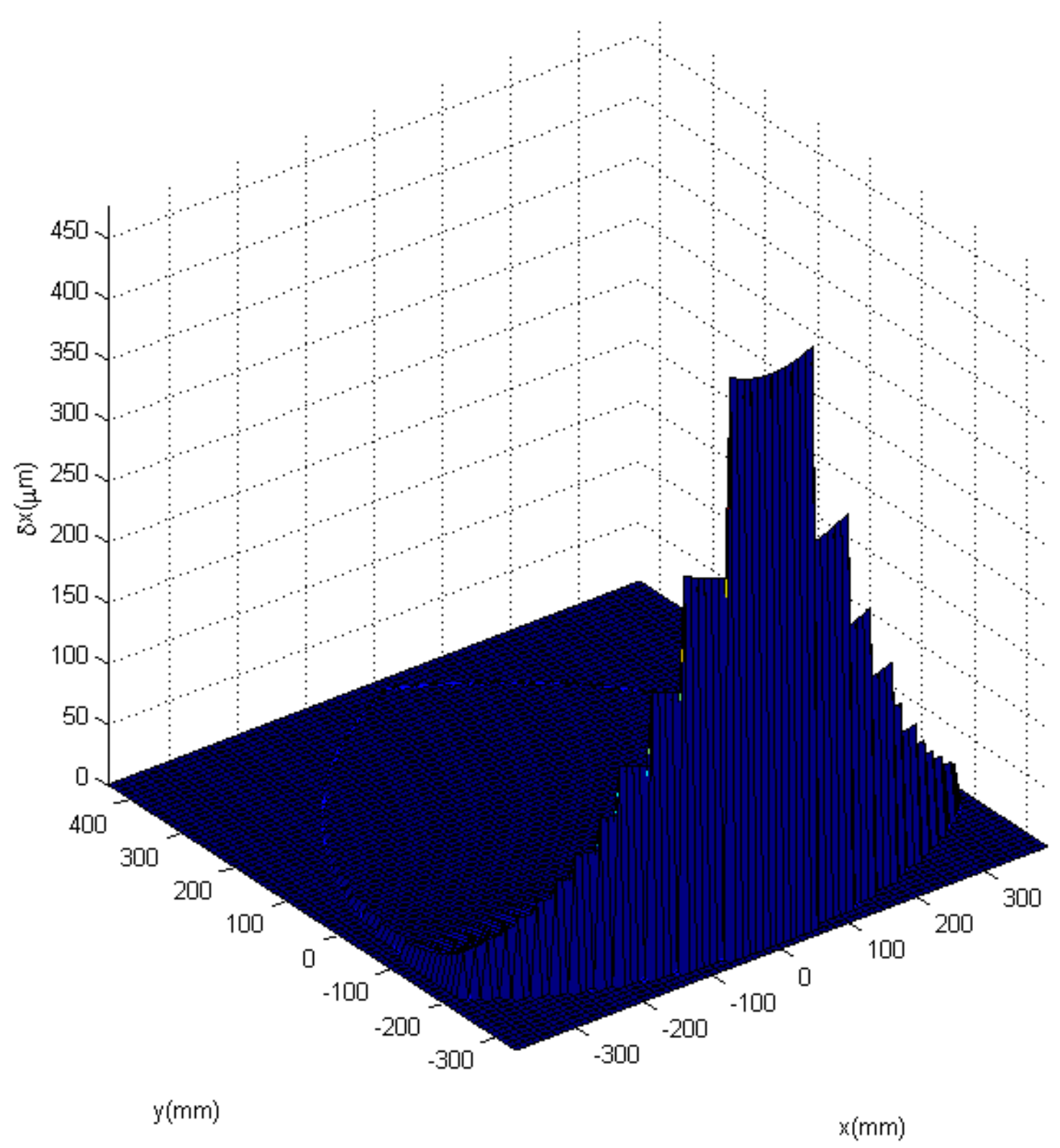

Figura 73 - Erro estático na área de trabalho, com dois atuadores, para 750N, vertical. 


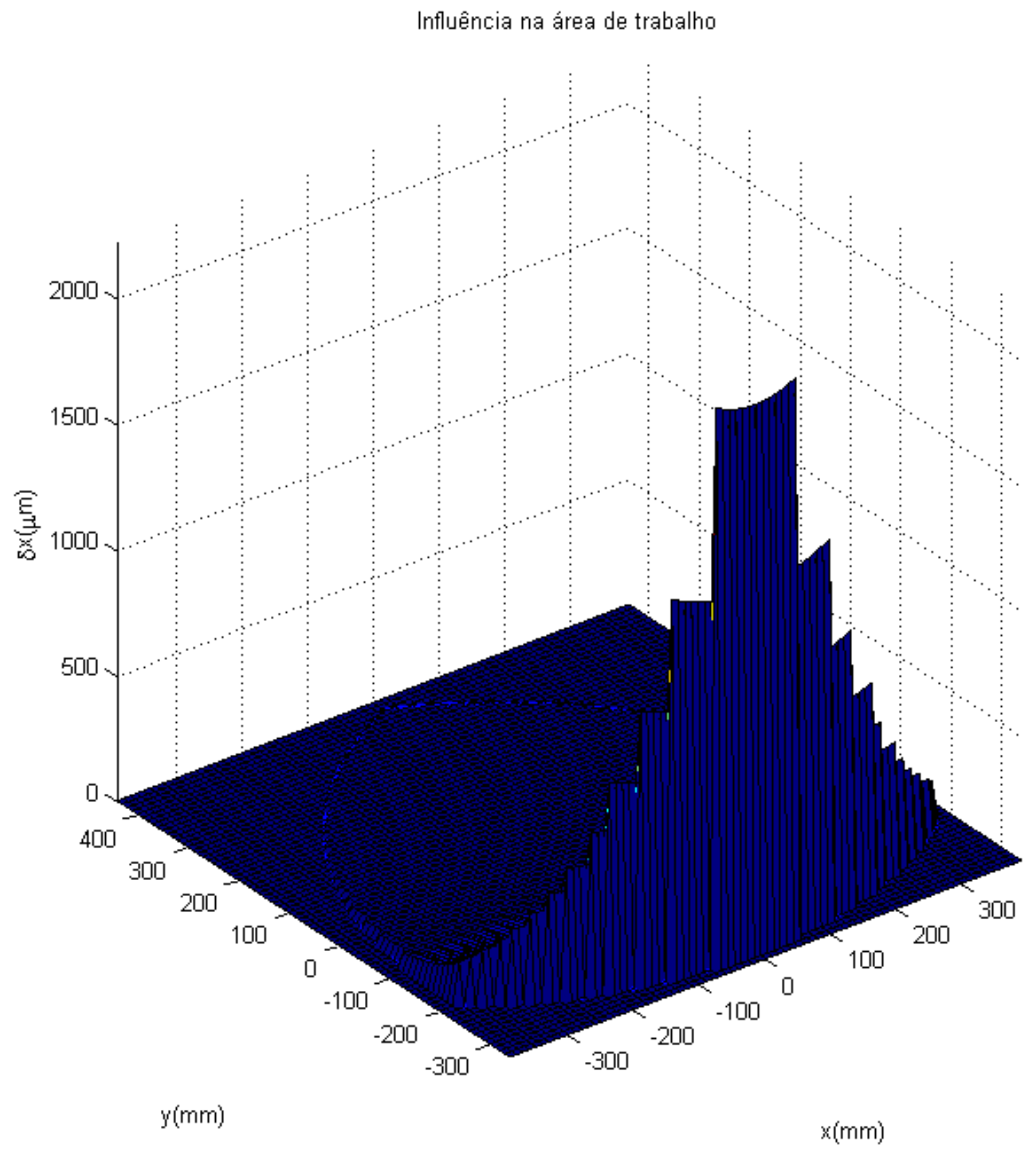

Figura 74 - Erro estático na área de trabalho, com dois atuadores, para 3500N, vertical.

Analogamente, observa-se o mesmo comportamento para o caso a $45^{\circ}$, devido principalmente à componente vertical da força. No entanto, existe uma pequena alteração de comportamento nas regiões negativas da área de trabalho, justamente devida à direção da solicitação. 


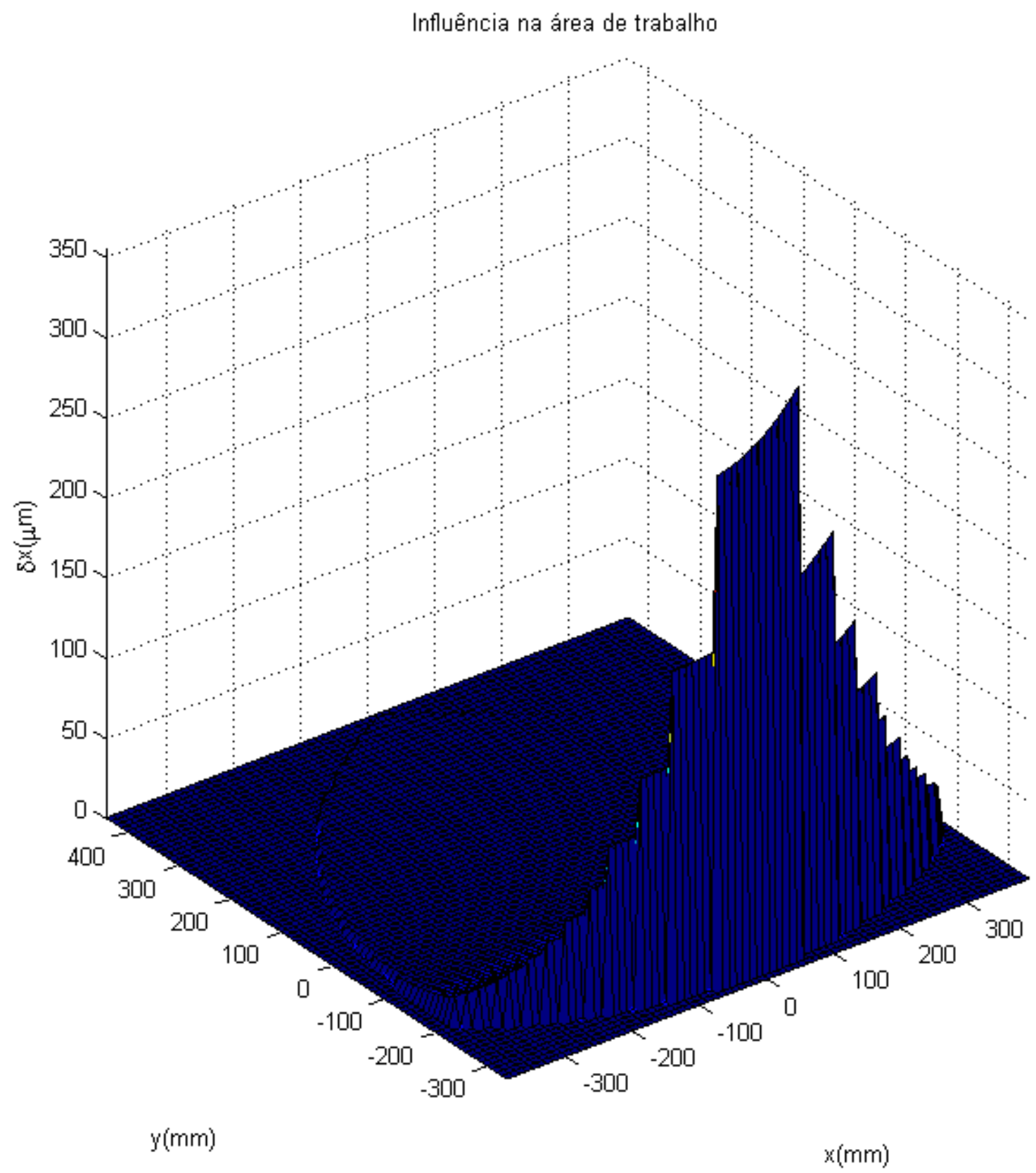

Figura 75 - Erro estático na área de trabalho, com dois atuadores, para $750 \mathrm{~N}$, a $45^{\circ}$. 




Figura 76 - Erro estático na área de trabalho, com dois atuadores, para $3500 \mathrm{~N}$, a $45^{\circ}$.

Deve-se observar que, para o ponto central, o deslocamento corresponde aos valores obtido com o FTool e Ansys, validando o programa. Assim sendo, as figuras acima estabelecem o mapeamento da máquina para as forças consideradas, tal como definidas anteriormente. Isso servirá de ponto de partida para a comparação com a máquina com três eixos.

A seguir são apresentadas curvas de nível para facilitar a visualização de regiões críticas do sistema. Deve-se observar que para os seis gráficos apresentados existe uma região bem caracterizada de baixa rigidez. Esse tipo de comportamento será 
analisado adiante, e fica bem reduzido para a máquina com três atuadores, conforme será visto no capítulo 8.2.2.

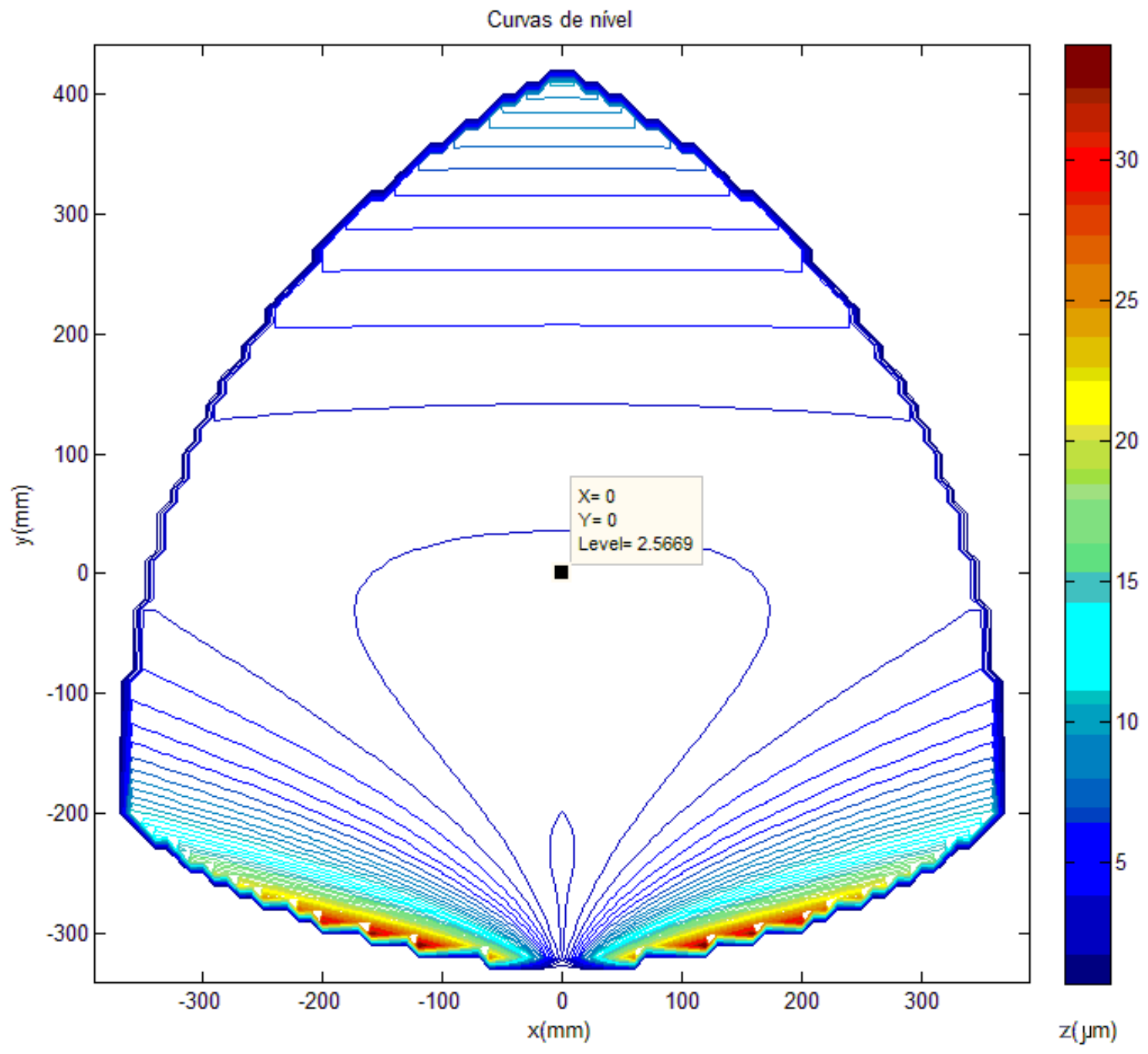

Figura 77 - Curvas de nível para máquina com dois braços, 750N, horizontal. 


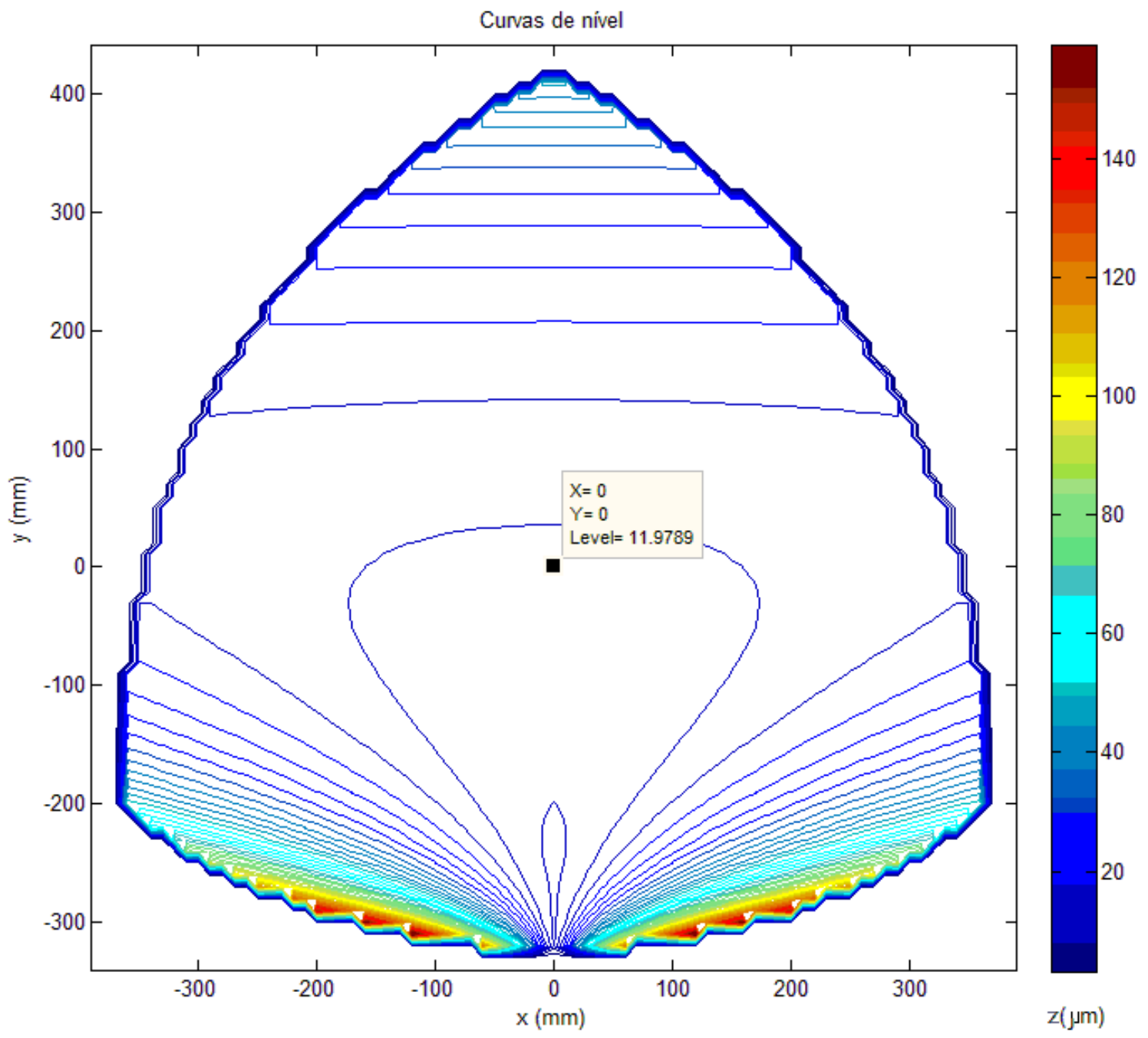

Figura 78 - Curvas de nível para máquina com dois braços, $3500 \mathrm{~N}$, horizontal. 


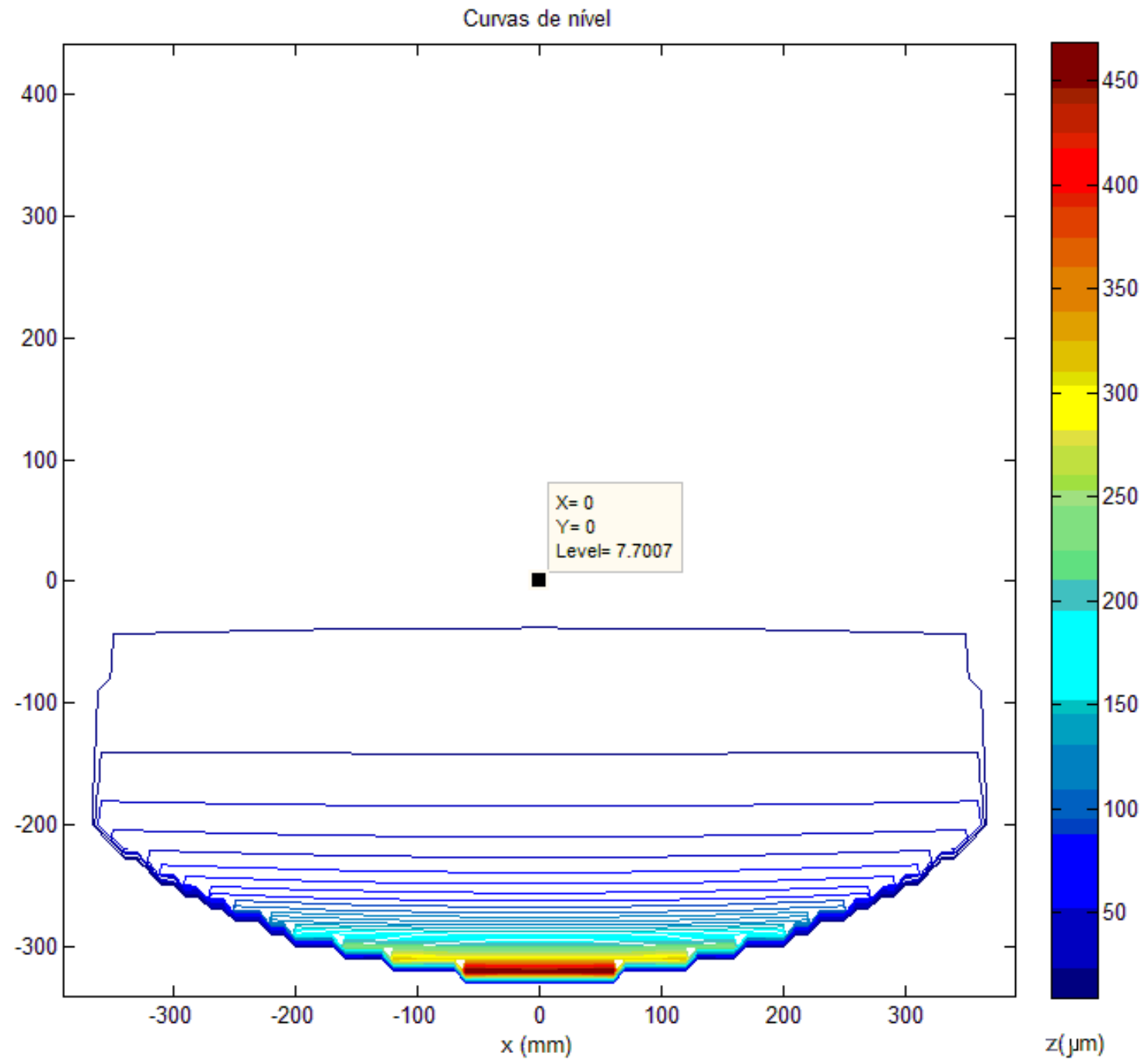

Figura 79 - Curvas de nível para máquina com dois braços, $750 \mathrm{~N}$, vertical. 


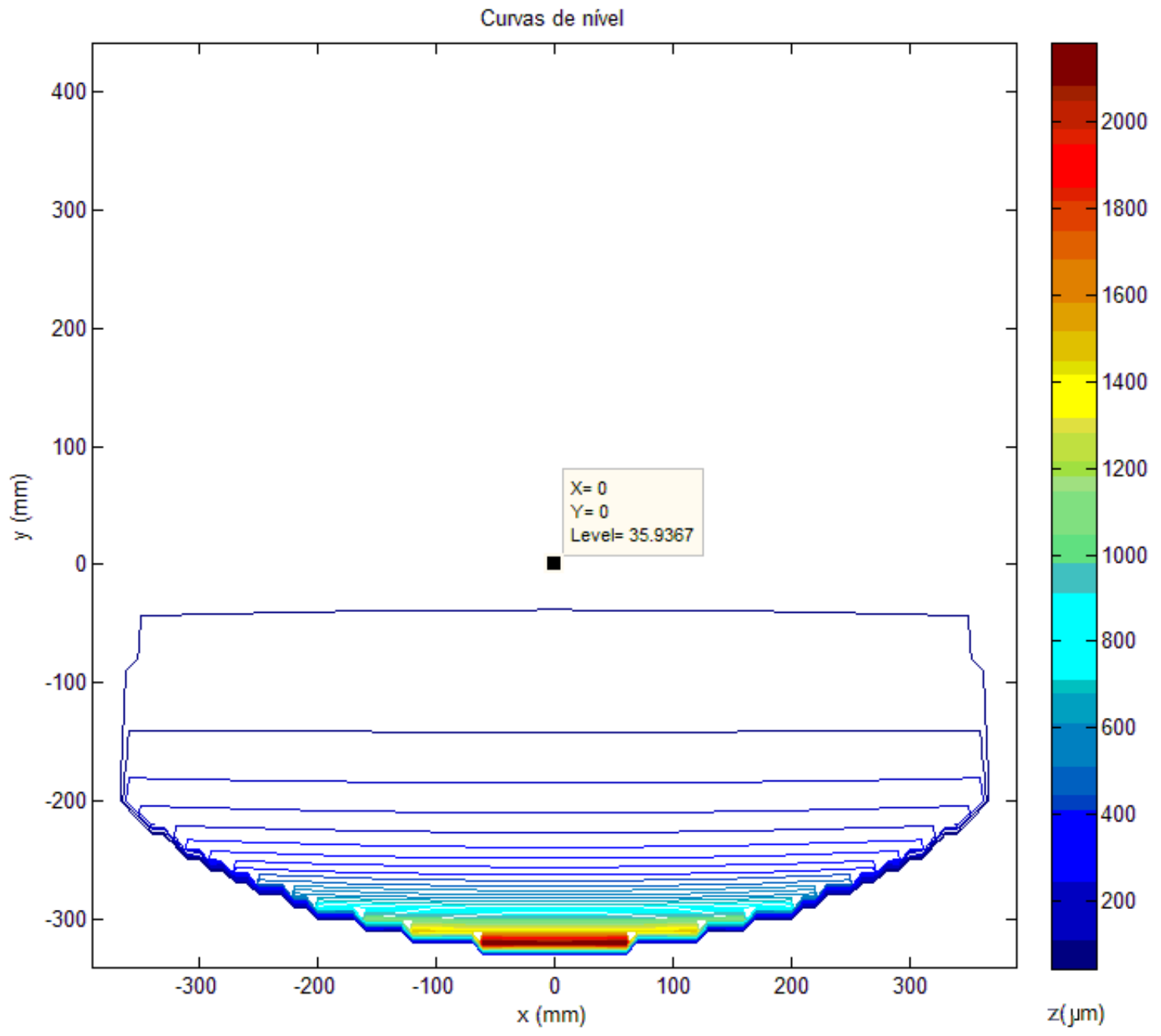

Figura 80 - Curvas de nível para máquina com dois braços, 3500N, vertical. 


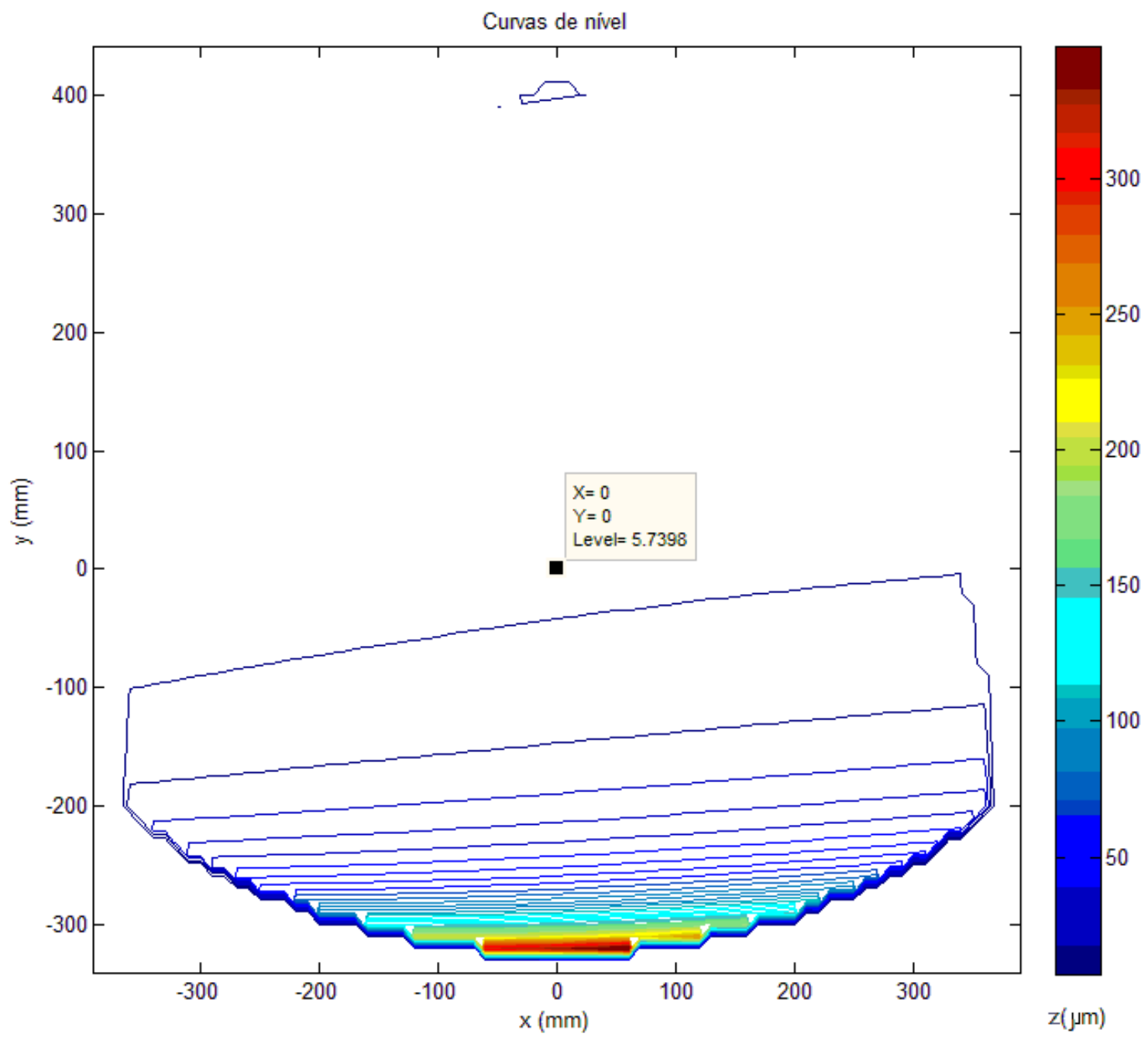

Figura 81 - Curvas de nível para máquina com dois braços, $750 \mathrm{~N}$, a $45^{\circ}$. 


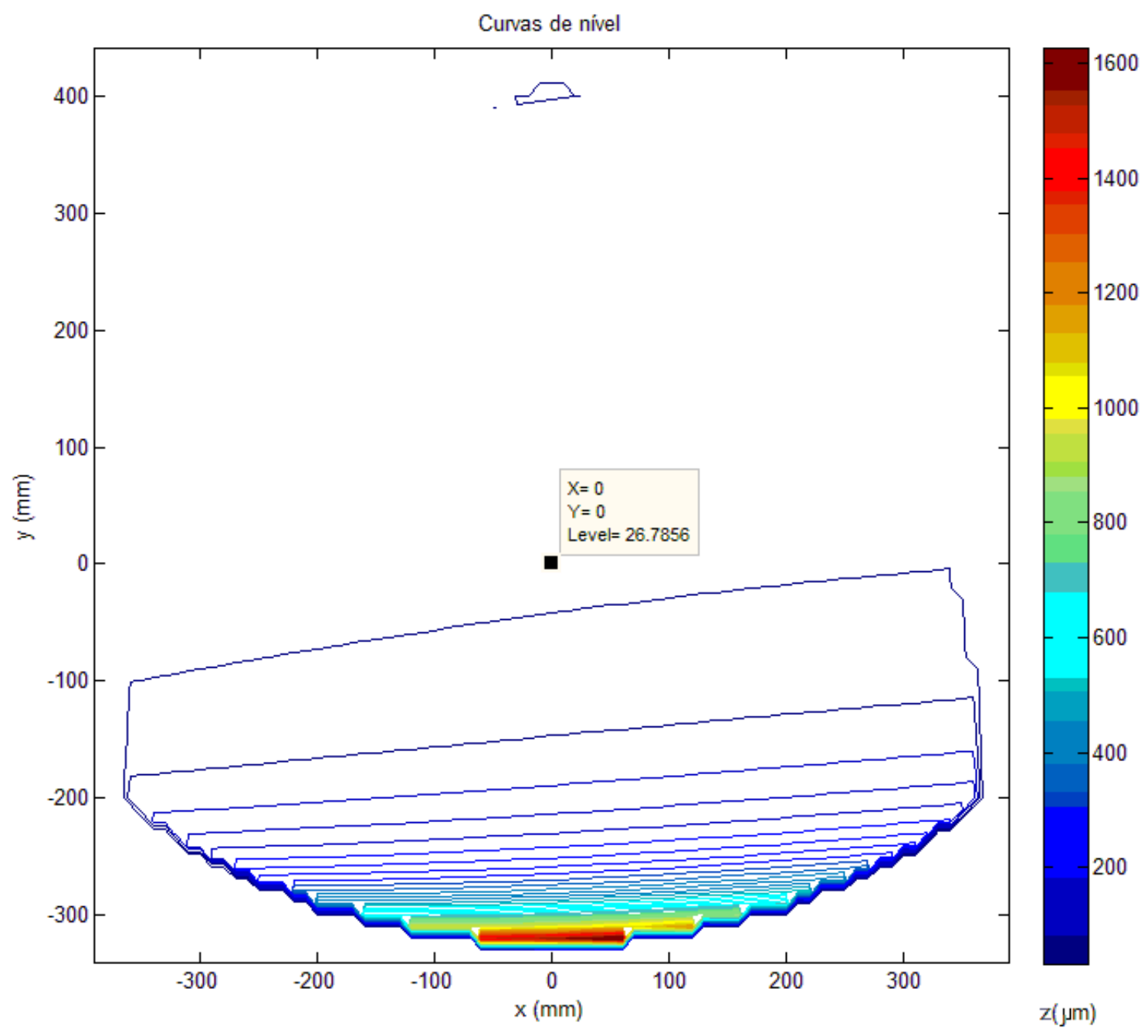

Figura 82 - Curvas de nível para máquina com dois braços, $3500 \mathrm{~N}$, a $45^{\circ}$.

Os extremos de deflexão, localizados próximos aos atuadores, devem ser analisados, pois chegam a atingir valores bem maiores que os encontrados nas demais regiões da área de trabalho.

Inicialmente poder-se-ia anular o resultado, já que a maior deflexão encontra-se perto dos atuadores, o que, intuitivamente, seria justamente ao contrário: quanto mais perto dos atuadores, maior a rigidez. Mas isso não é verdade.

A afirmativa é válida somente se o atuador é telescópico, ou seja, o comprimento do braço é reduzido nessa posição, aumentando a rigidez. No entanto, pelo fato de se estar trabalhando com atuadores de braço constante, em que é a porca do fuso que executa o movimento entre os pontos de fixação, a situação é diferente.

Sendo assim, a rigidez do braço por si só é constante. Quando, no entanto, considera-se o efeito da direção e sentido da força aplicada, assim como a posição 
da ferramenta, o resultado na máquina é que existe perda da rigidez devido ao posicionamento geométrico da ferramenta.

Para esse caso em questão, conforme se aproxima dos atuadores, o sistema se aproxima de uma região singular. Vale lembrar que, para esse sistema, ainda existem regiões singulares, apesar de não estarem dentro da área de trabalho considerada.

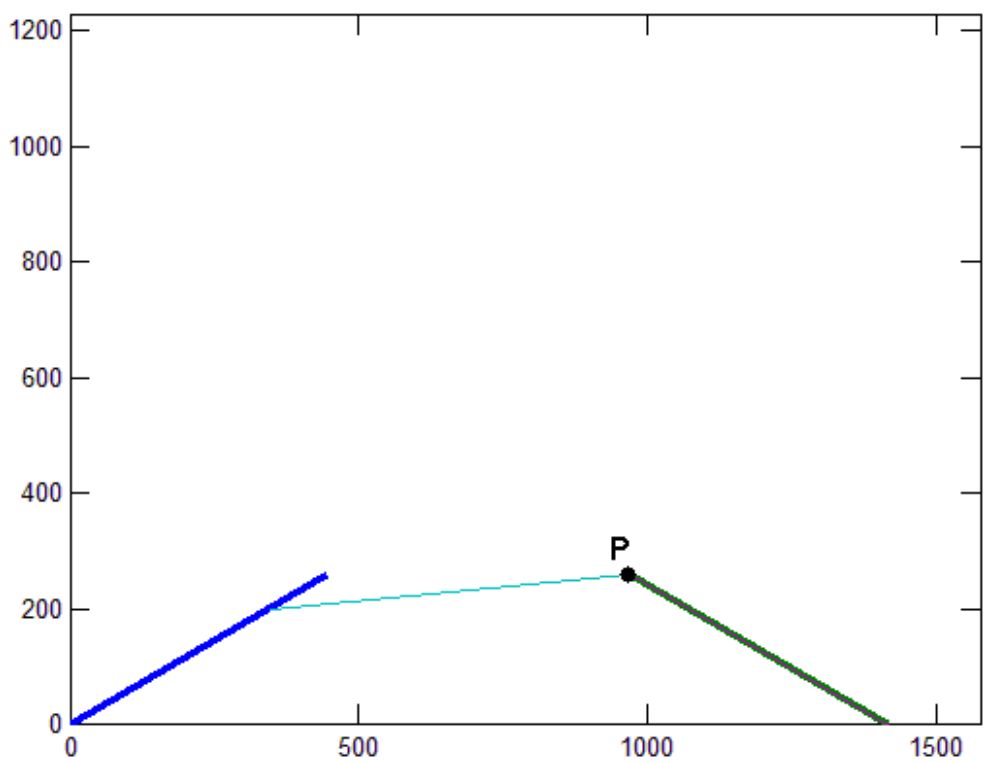

Figura 83 - Região de baixa rigidez em $(x, y)=(290,-170)$.

A Figura 83 representa um ponto próximo de uma região singular, que é o alinhamento dos braços num ângulo de $180^{\circ}$. Quanto mais perto se chega dessa situação, menor é a rigidez que a máquina pode fornecer. 


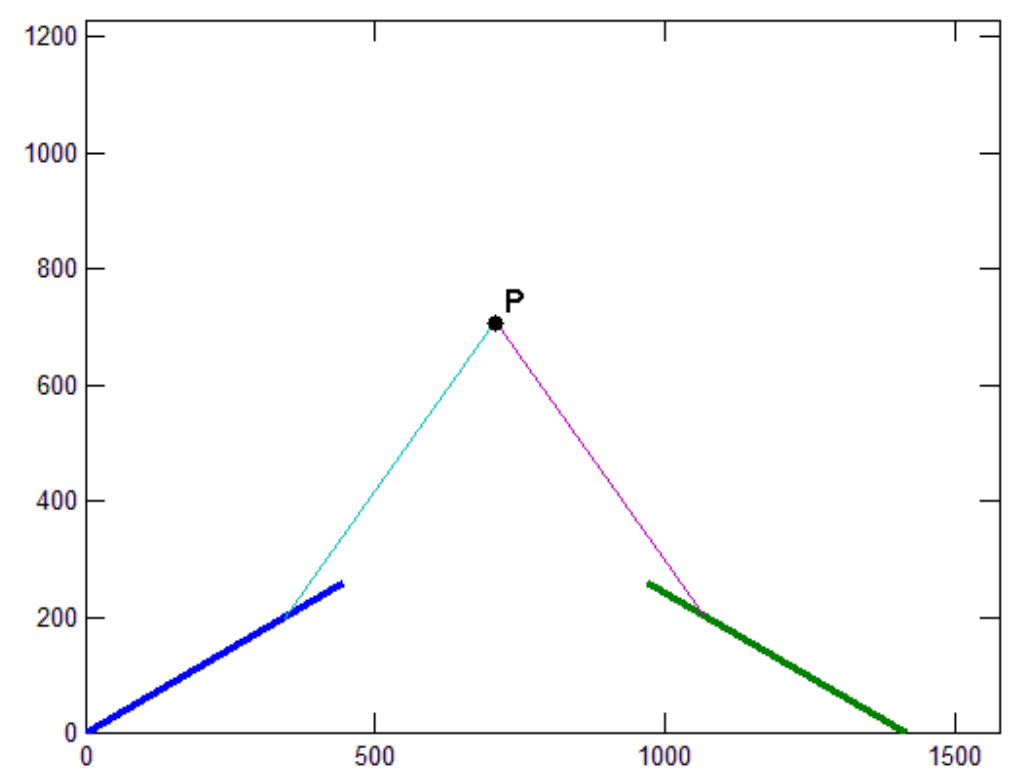

Figura 84 - Região de baixa rigidez em $(x, y)=(0,340)$.

Analogamente, a Figura 84 mostra outra região singular, que é o alinhamento dos braços com ângulo $0^{\circ}$ entre si. Conforme se aproxima dessa situação, existe perda da rigidez, já que o alinhamento, se fosse possível, não permitiria controle algum da posição da ferramenta. 


\subsubsection{Máquina com três atuadores}

O resultado do mapeamento para três braços, pelo mesmo programa escrito para dois braços, é o seguinte:

Influência na área de trabalho

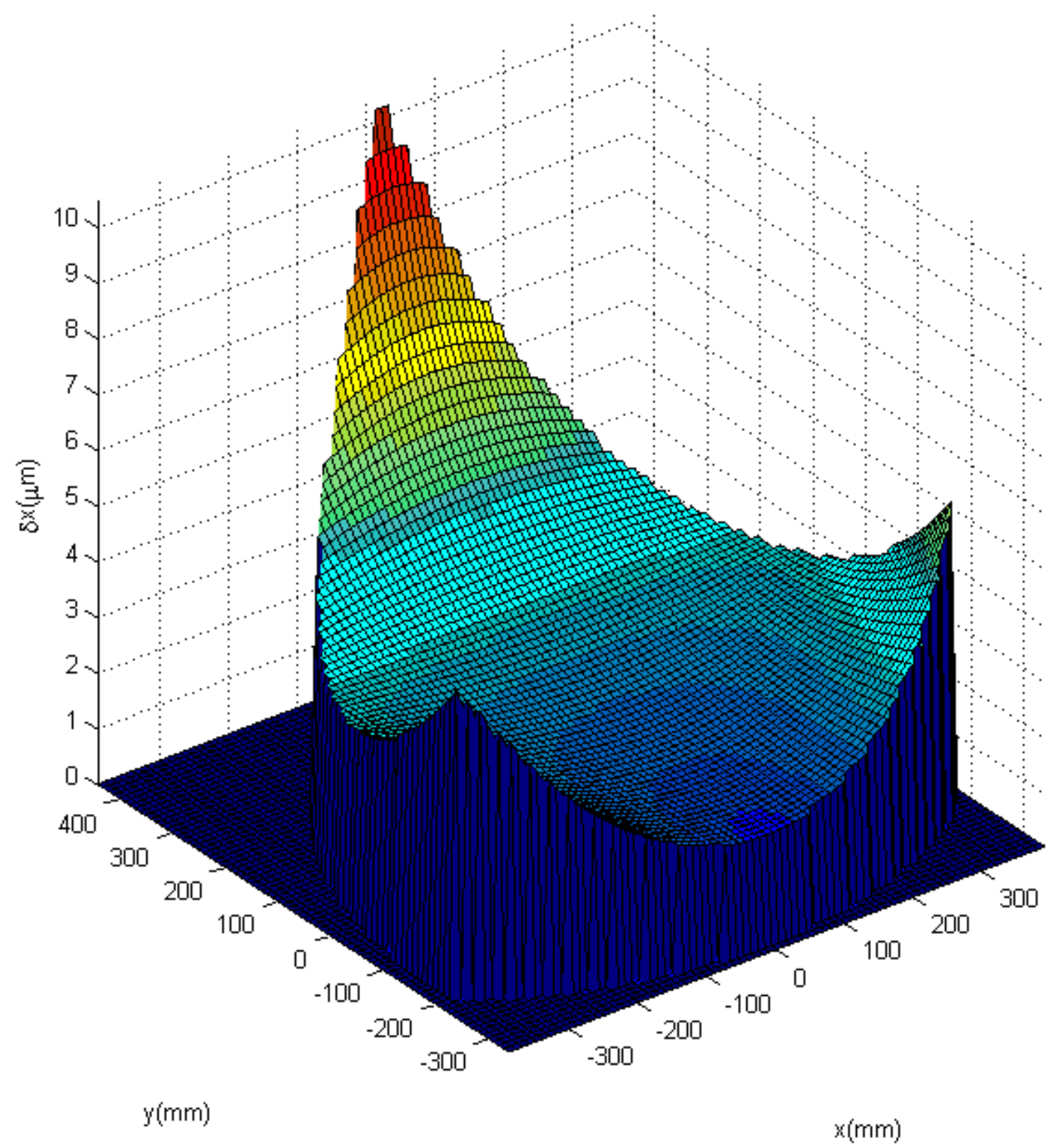

Figura 85 - Erro estático na área de trabalho, com três atuadores, $750 \mathrm{~N}$, horizontal. 
Influência na área de trabalho

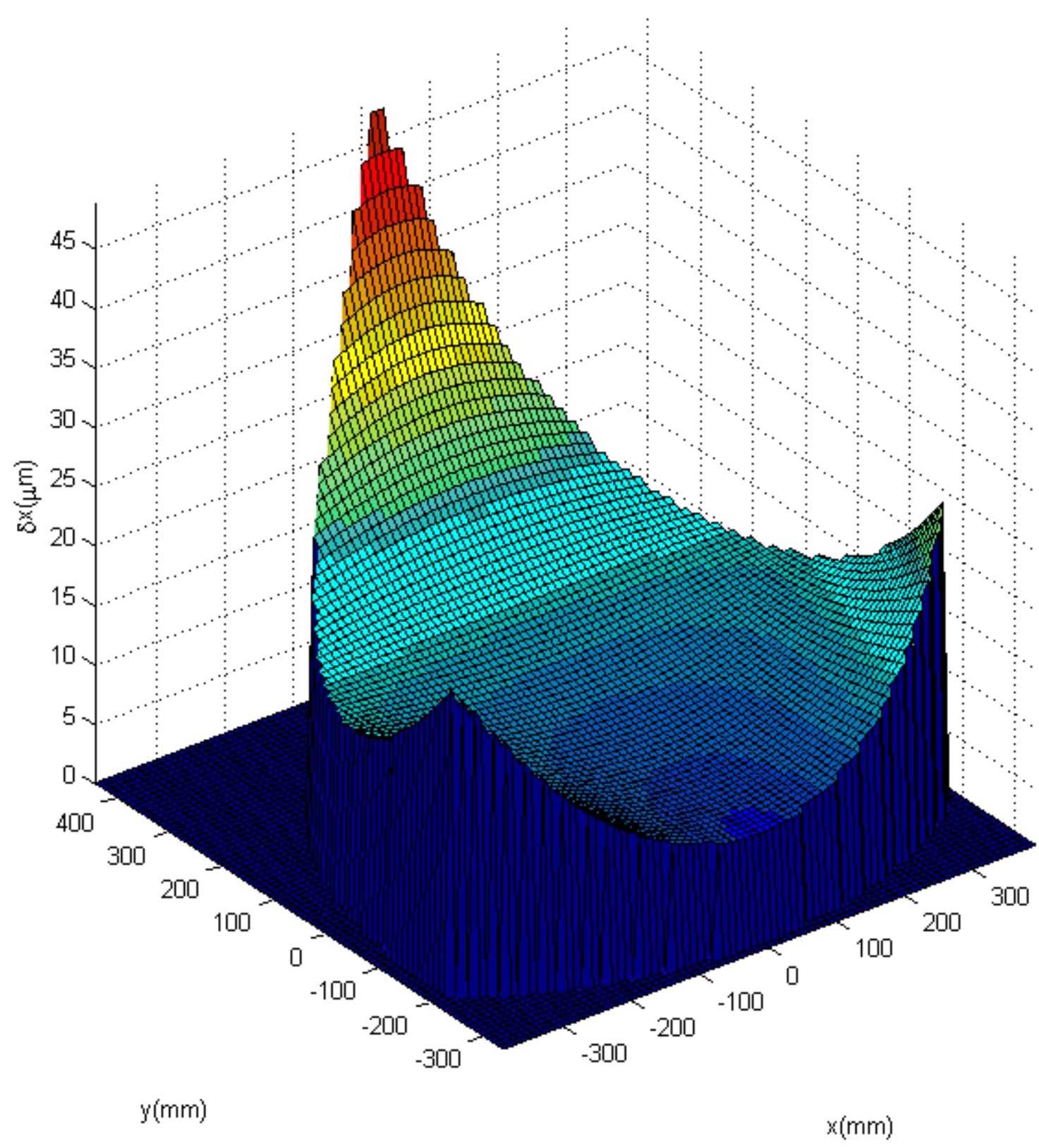

Figura 86 - Erro estático na área de trabalho, com três atuadores, 3500N, horizontal. 


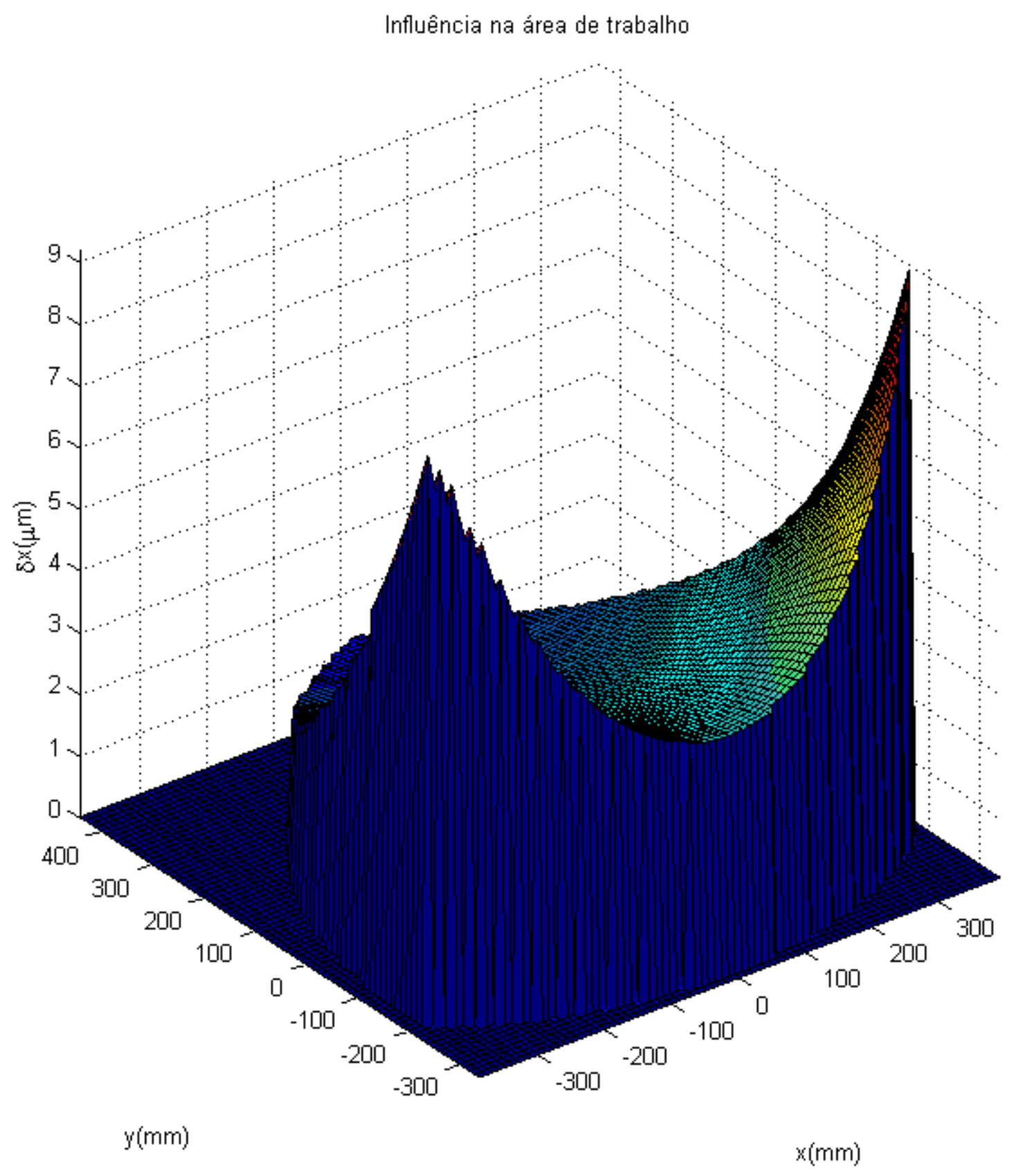

Figura 87 - Erro estático na área de trabalho, com três atuadores, $750 \mathrm{~N}$, vertical. 
Influência na área de trabalho

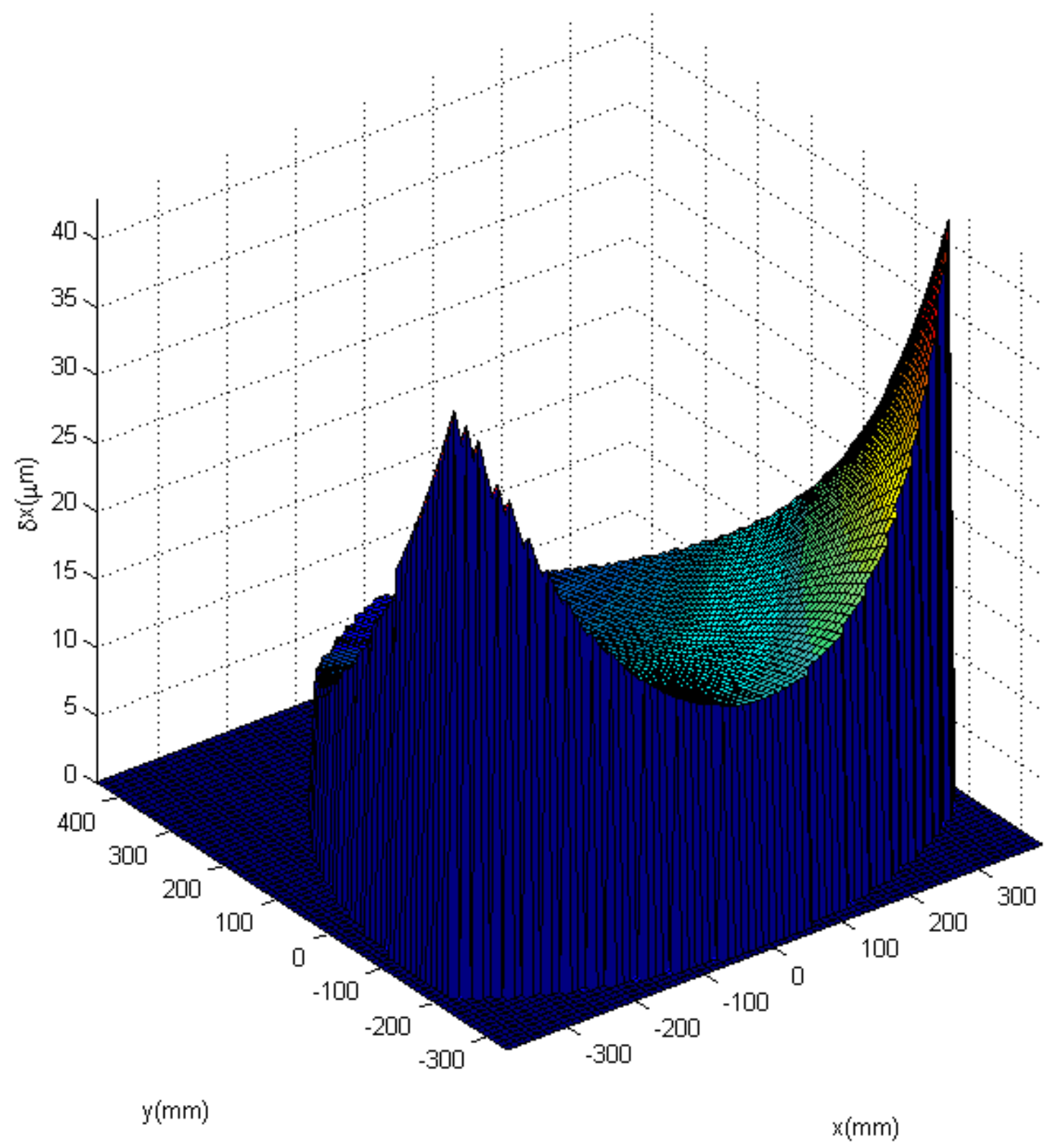

Figura 88 - Erro estático na área de trabalho, com três atuadores, 3500N, vertical. 


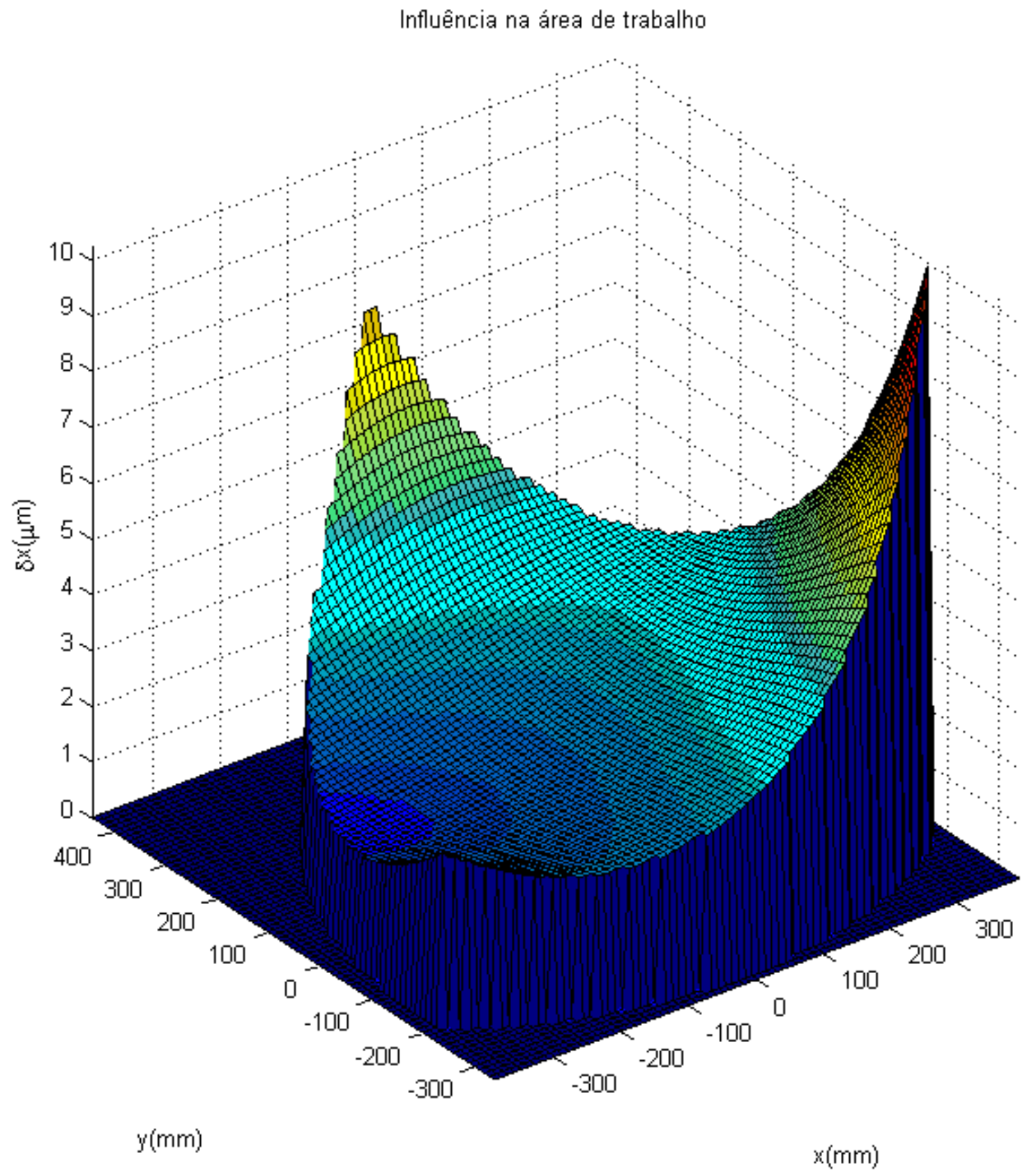

Figura 89 - Erro estático na área de trabalho, com três atuadores, $750 \mathrm{~N}$, a $45^{\circ}$. 


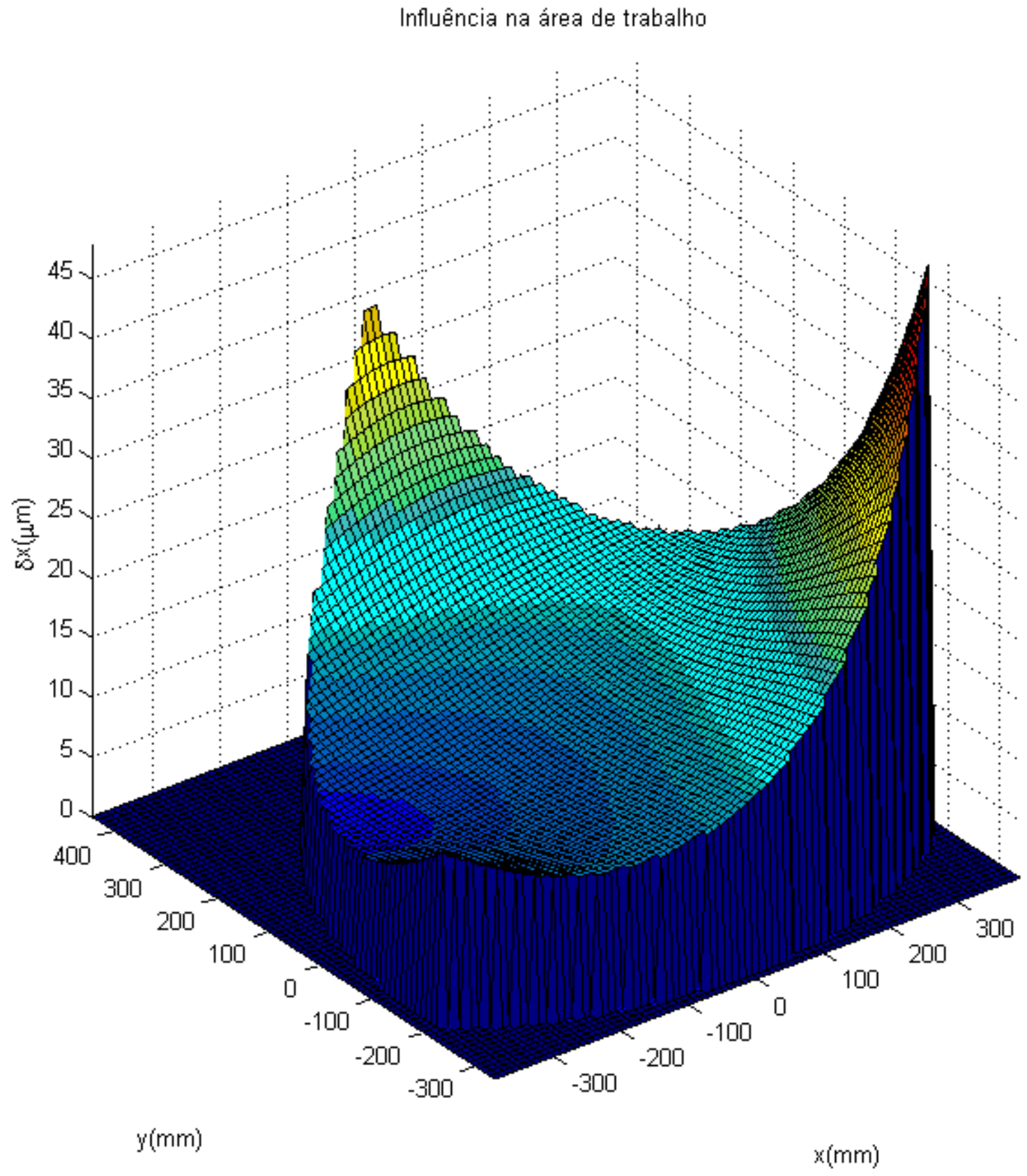

Figura 90 - Erro estático na área de trabalho, com três atuadores, $3500 \mathrm{~N}$, a $45^{\circ}$.

Para o ponto em estudo, o programa retornou o mesmo valor dado pelos programas de referência, consolidando o código e seus resultados. Observam-se também dois pontos importantes. 


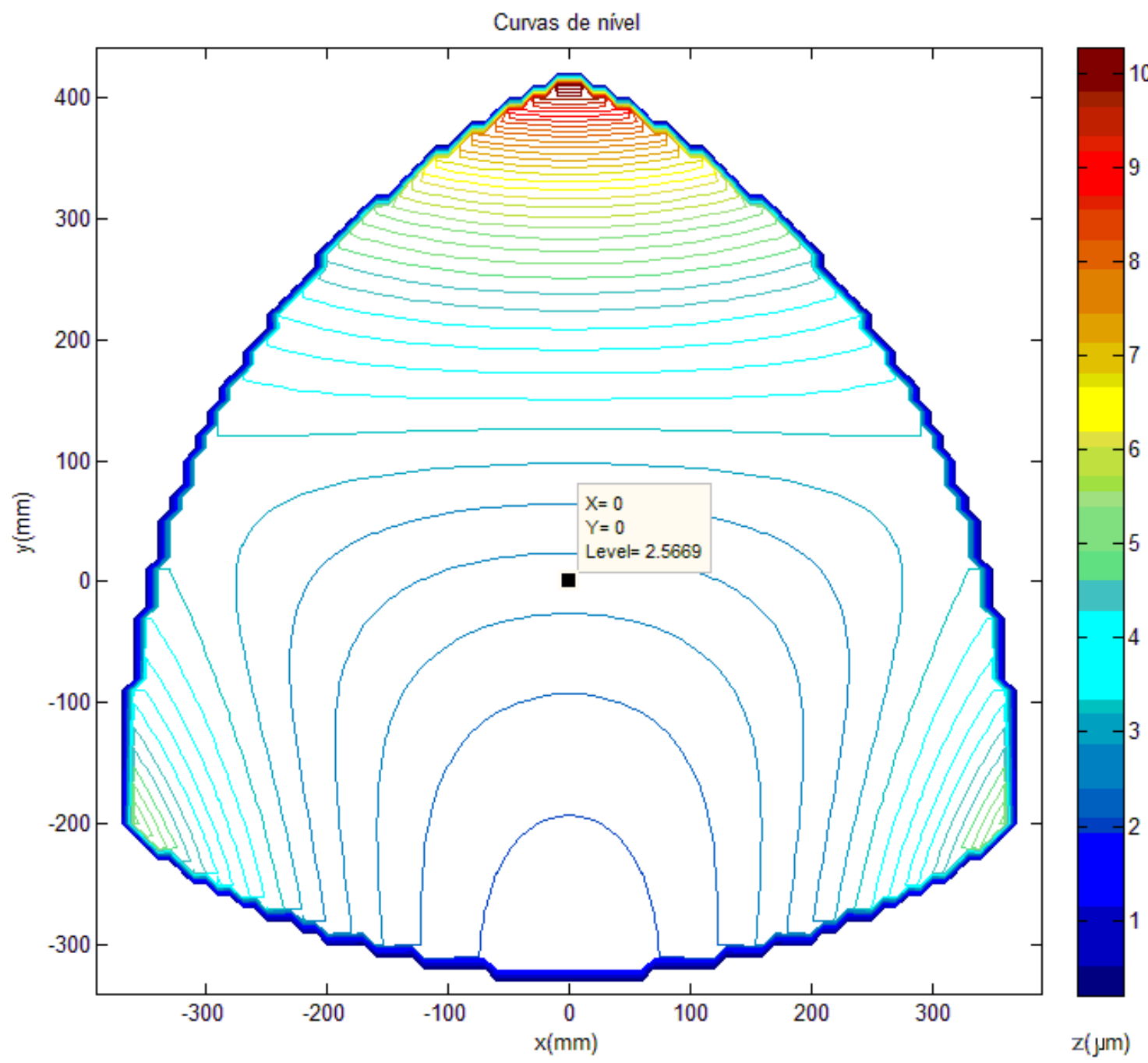

Figura 91 - Curvas de nível para máquina com três braços, $750 \mathrm{~N}$, horizontal. 


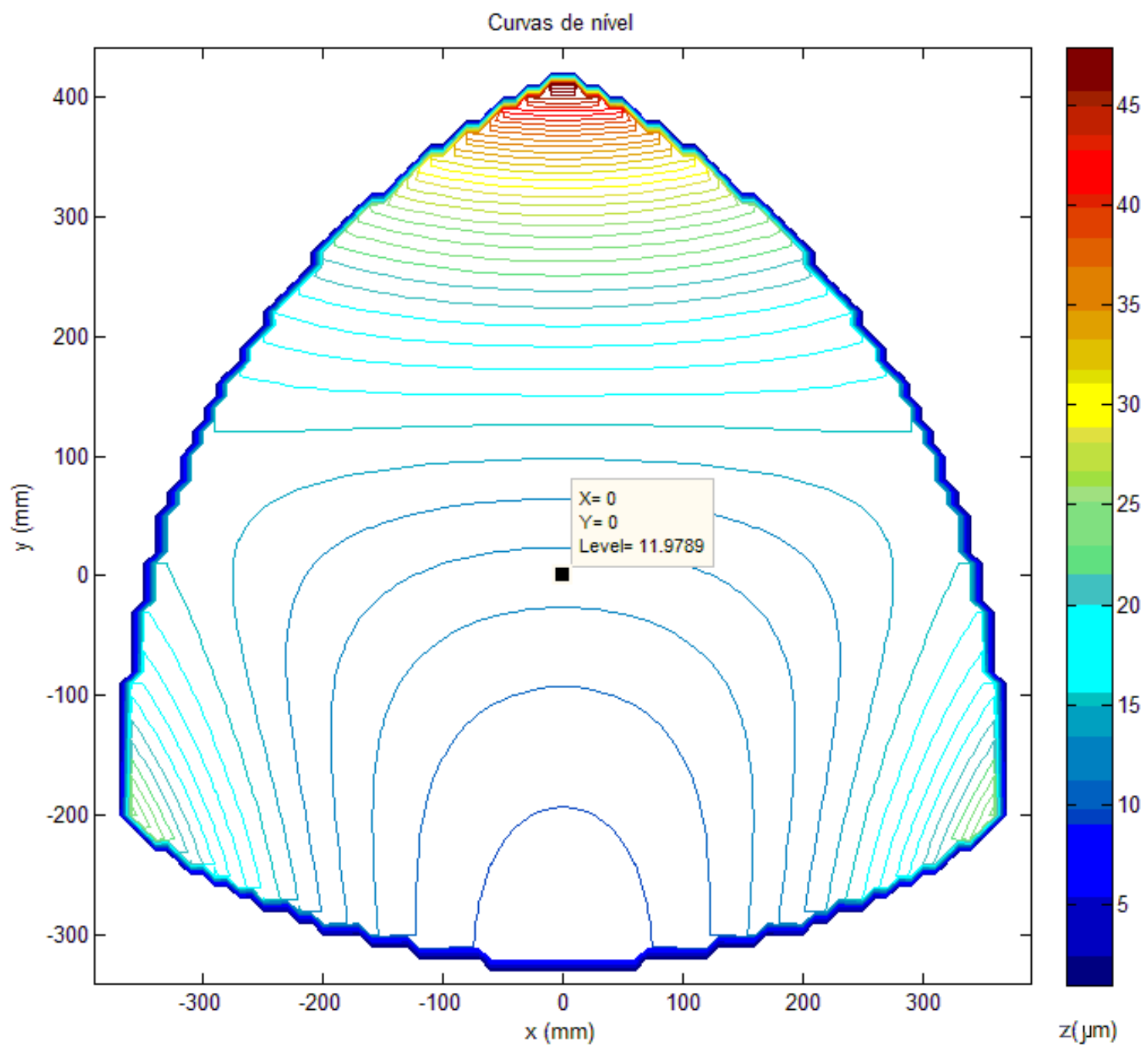

Figura 92 - Curvas de nível para máquina com três braços, $3500 \mathrm{~N}$, horizontal. 


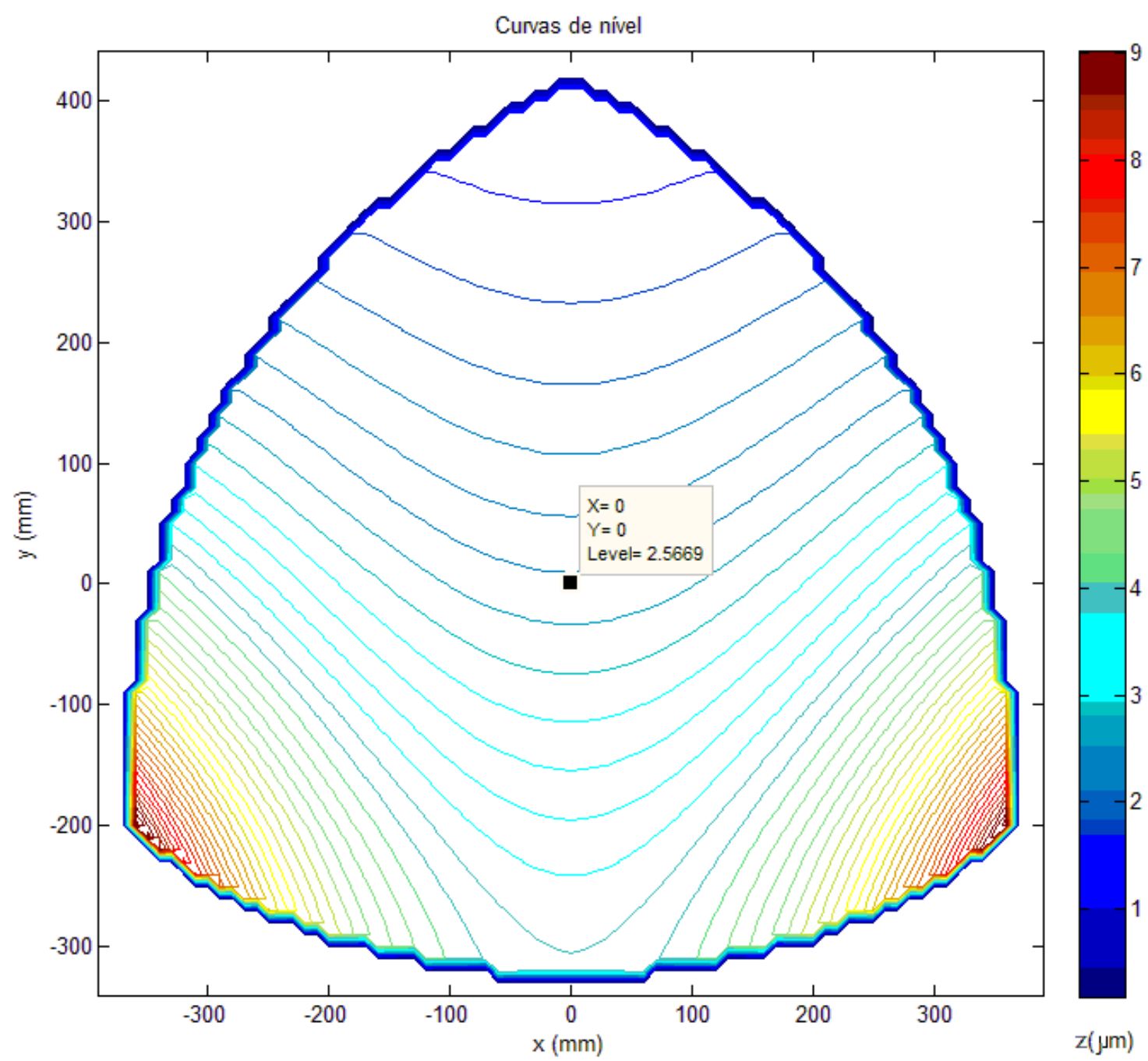

Figura 93 - Curvas de nível para máquina com três braços, $750 \mathrm{~N}$, vertical. 


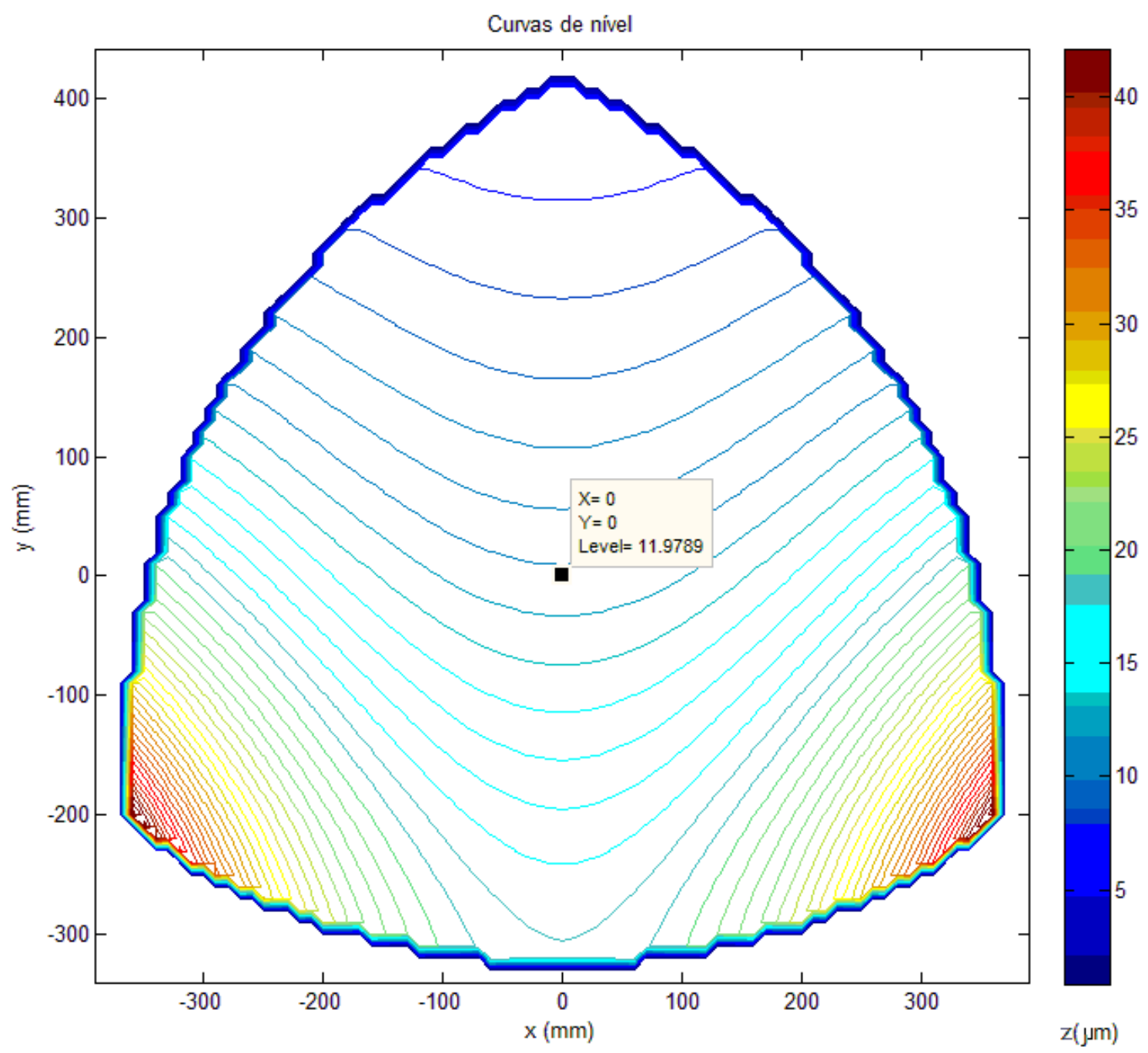

Figura 94 - Curvas de nível para máquina com três braços, 3500N, vertical. 


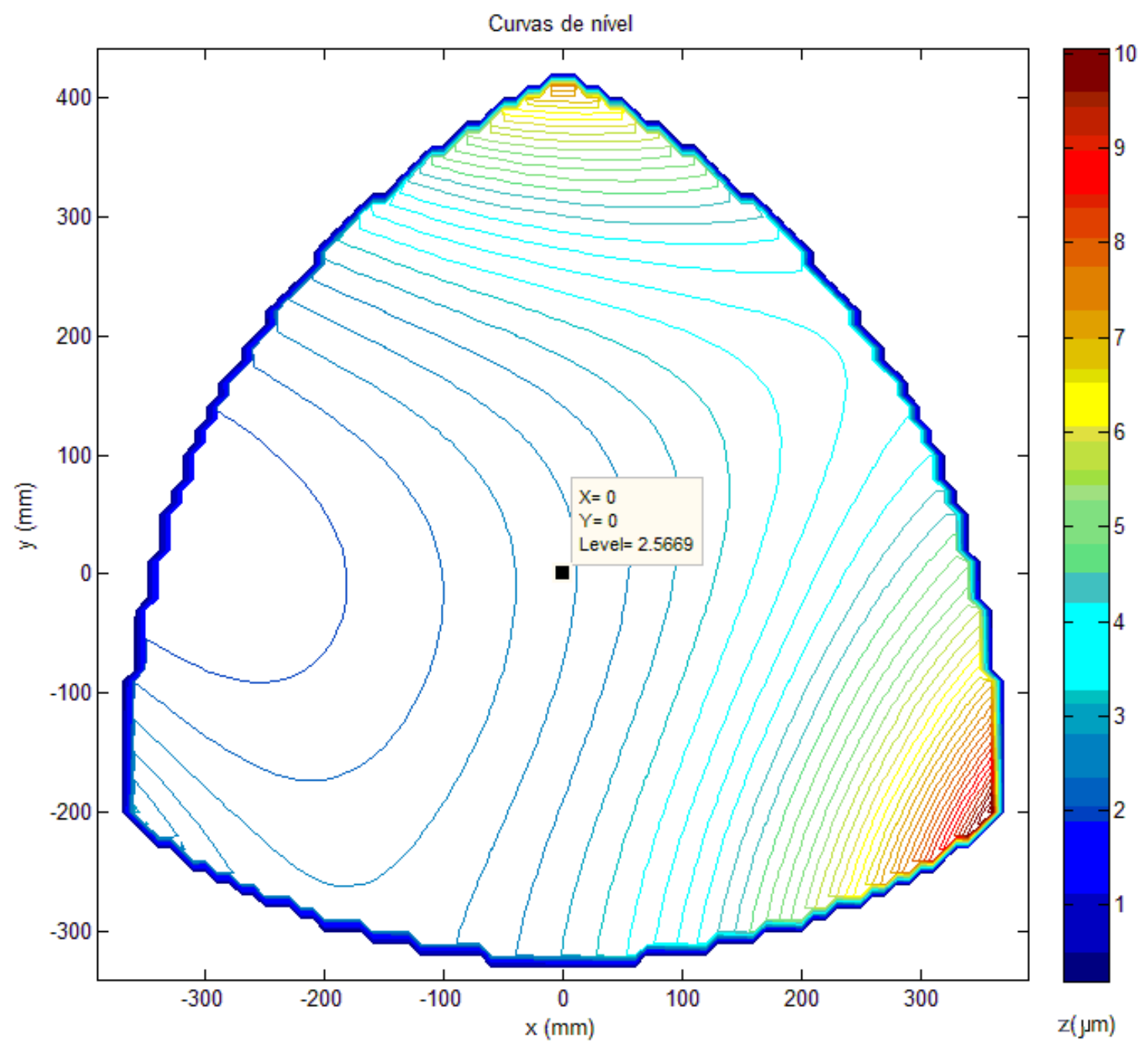

Figura 95 - Curvas de nível para máquina com três braços, $750 \mathrm{~N}$, a $45^{\circ}$. 


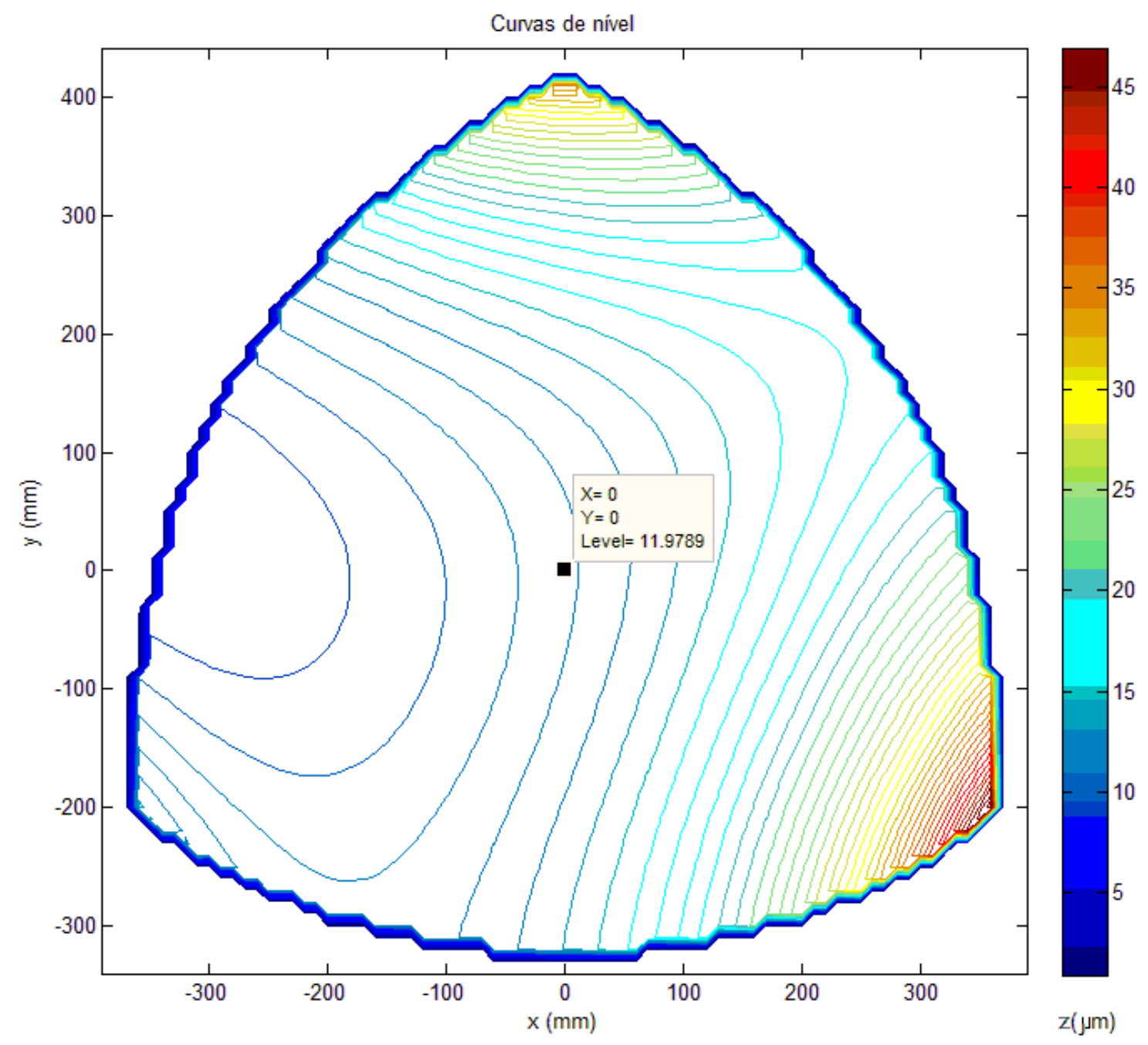

Figura 96 - Curvas de nível para máquina com três braços, $3500 \mathrm{~N}$, a $45^{\circ}$.

O primeiro deles é a clara diminuição da deflexão na área de trabalho, que é de até cerca de três vezes menor que a deflexão da máquina com apenas dois atuadores. O segundo é a alteração das regiões menos rígidas, do centro dos segmentos da área de trabalho para os vértices.

Com a adição do terceiro membro, a região inferior de singularidade, para força horizontal, foi eliminada e, apesar de ainda existir para o par de atuadores inferiores, é compensada através do terceiro, reduzindo assim a deflexão em relação ao resultado anterior. 


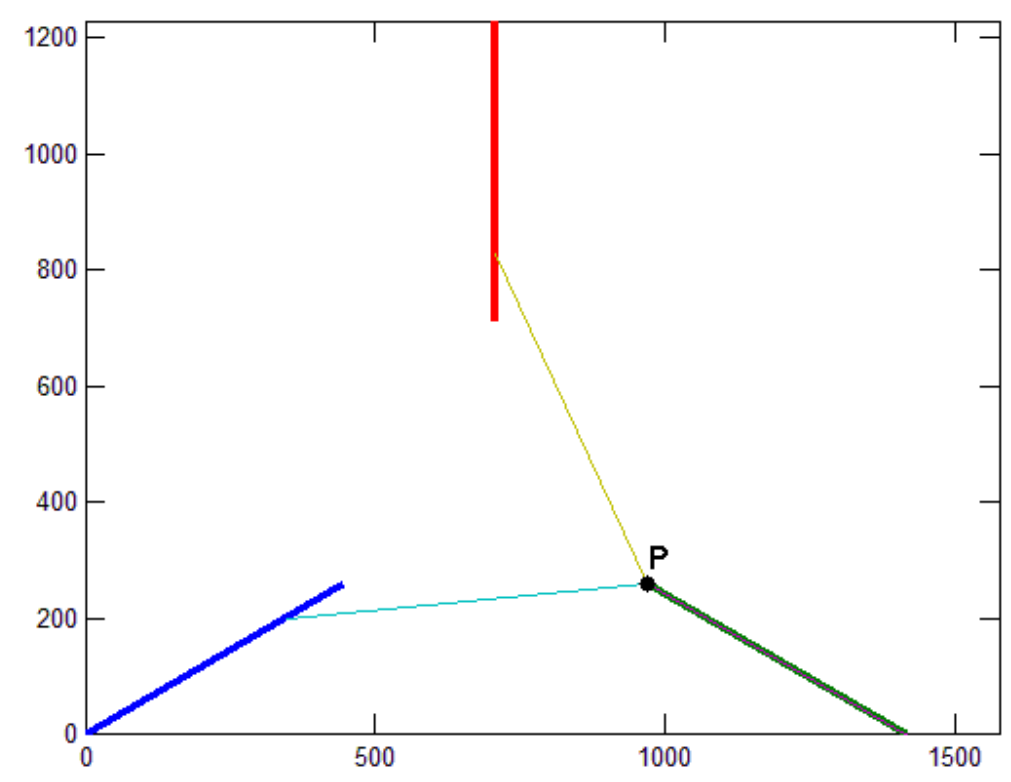

Figura 97 - Região de baixa rigidez em $(x, y)=(290,-170)$.

No entanto, como pode ser observado, na região superior não existe essa redução. Isso pois, mesmo com o terceiro membro, o sistema se aproxima de uma configuração singular como no primeiro caso: com todos os braços na direção vertical.

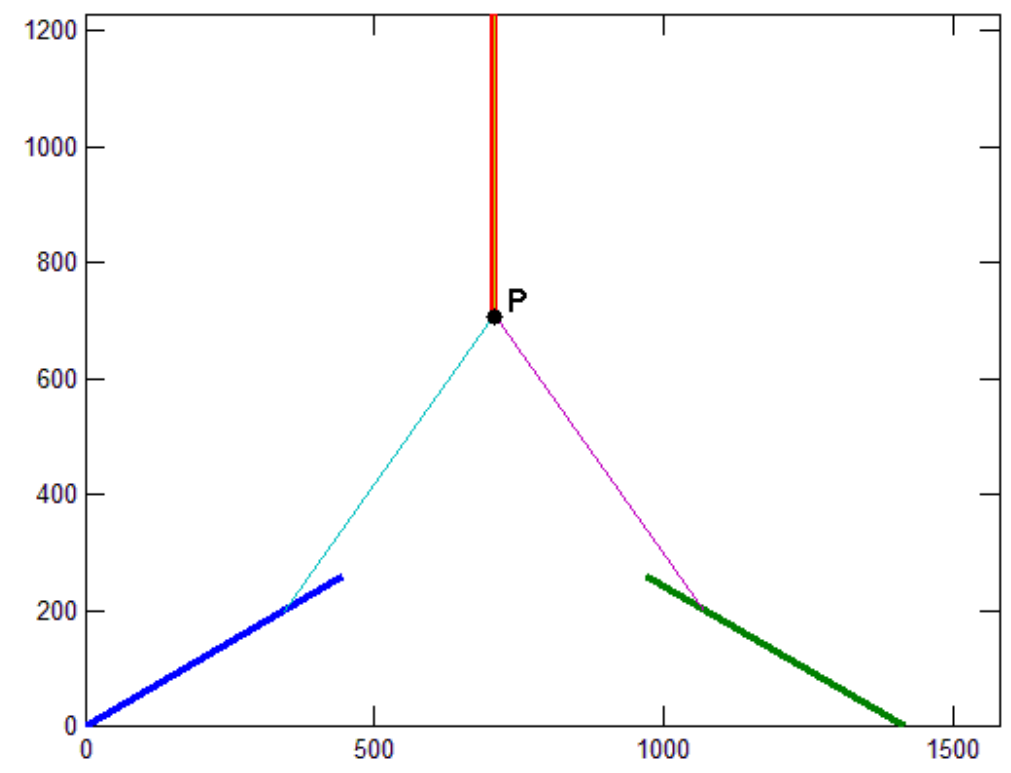

Figura 98 - Região de baixa rigidez em $(x, y)=(0,340)$.

Resultados similares também podem ser vistos para as demais situações, como já foi discutido no capítulo anterior. 
A seguir, são analisados os piores casos dos mapeamentos observados acima e comparados os valores obtidos para máquinas com dois e três braços. As conclusões podem ser generalizadas para qualquer outro caso, sem perda de validade.

Tabela 9 - Análise dos ganhos entre as simulações para o pior caso de deflexão $(\mu \mathrm{m})$.

\begin{tabular}{|c|c|c|c|c|}
\hline \multirow{2}{*}{ Direção } & \multirow{2}{*}{ Módulo (N) } & \multicolumn{2}{|c|}{ Número de atuadores } & \multirow{2}{*}{ Ganho (\%) } \\
\cline { 3 - 5 } & & 2 & 3 & \\
\hline \multirow{2}{*}{ Hor. } & 750 & 34,00 & 10,00 & $-70,6 \%$ \\
\cline { 2 - 5 } & 3500 & 148,00 & 47,00 & $-68,2 \%$ \\
\hline \multirow{2}{*}{ Vert. } & 750 & 460,00 & 9,00 & $-98,0 \%$ \\
\cline { 2 - 5 } & 3500 & 2160,00 & 42,00 & $-98,1 \%$ \\
\hline \multirow{2}{*}{$45^{\circ}$} & 750 & 340,00 & 10,00 & $-97,1 \%$ \\
\cline { 2 - 5 } & 3500 & 1600,00 & 47,00 & $-97,1 \%$ \\
\hline \multicolumn{4}{|c}{} & $-88,2 \%$ \\
\hline
\end{tabular}

Pode-se observar que existe uma grande redução dos deslocamentos gerados a partir das forças aplicadas, para a máquina construída com três atuadores. Em média, esse ganho na rigidez está em torno de $88 \%$, ou seja, uma máquina com três braços de acionamento possui uma deflexão média final bem inferior à observada numa máquina com apenas dois braços.

Outro ponto que pode ser confirmado é o de que esse ganho varia em função da direção e da posição relativa da ferramenta, como evidencia a faixa de redução de deflexão de $70 \%$ a $98 \%$. Deve-se ficar claro que essa redução nunca poderá ser de $100 \%$, pois isso implicaria num material completamente rígido, ideal.

\subsection{DISCUSSÃO SOBRE O PLANO DE OPERAÇÃO DA MÁQUINA: HORIZONTAL OU VERTICAL?}

Considerando que a simulação em 3D possa fornecer um melhor resultado na análise de influência da posição da máquina em relação ao solo, passa-se agora para a verificação de qual é a melhor: horizontal ou vertical. 
Em uma primeira análise, pode-se facilmente verificar que na posição horizontal não existem esforços agindo diretamente sobre os atuadores. Quando na posição vertical, o peso próprio da estrutura atua no sentido de dificultar o movimento para cima, e facilitar o realizado para baixo.

No entanto, esse mesmo peso atuante, quando na horizontal, deforma a estrutura na direção vertical, o que gera um desvio de posição da ferramenta e um momento maior no pino de rotação durante a usinagem. Apesar de parte dessa deflexão ser atenuada pela componente passiva da força de usinagem, e vice-versa, o módulo dessa relação não é constante.

Outro ponto em favor da posição vertical é a praticidade, ou seja, a máquina na posição vertical ocupa menos espaço útil que na horizontal, além de que, para ensino e visualização, essa posição oferece uma maior gama de ângulos passíveis de análise.

A seguir são apresentados os resultados obtidos nas simulações, incluindo agora o peso próprio dos elementos, e suas respectivas considerações.

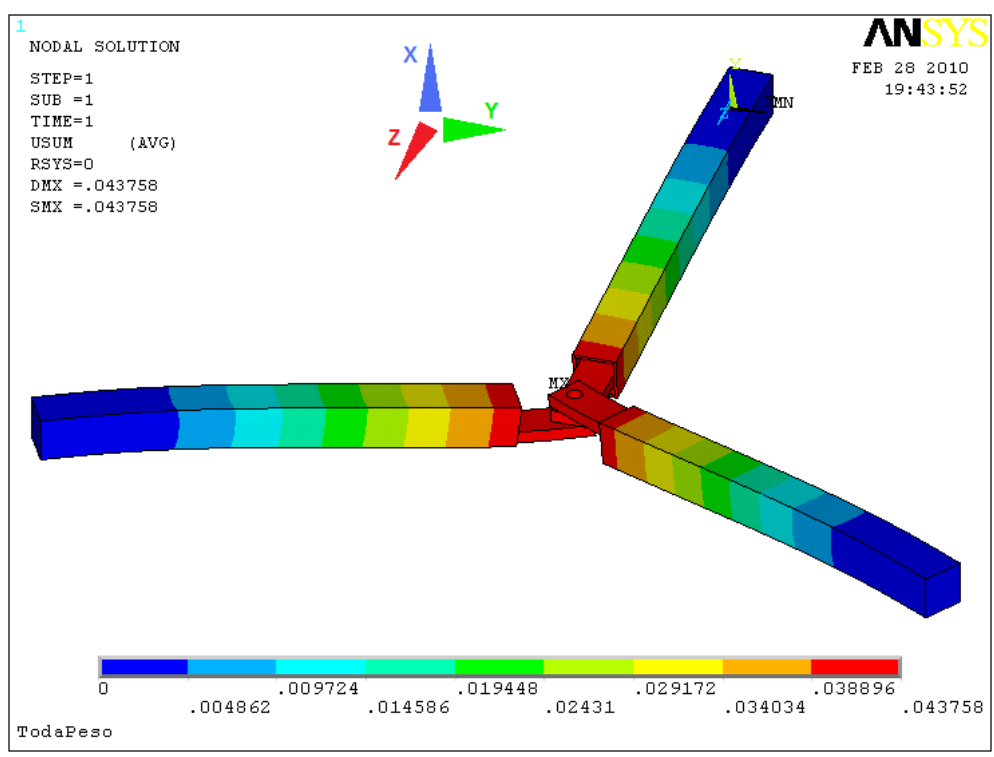

Figura 99 - Deflexão máxima para máquina na horizontal. 


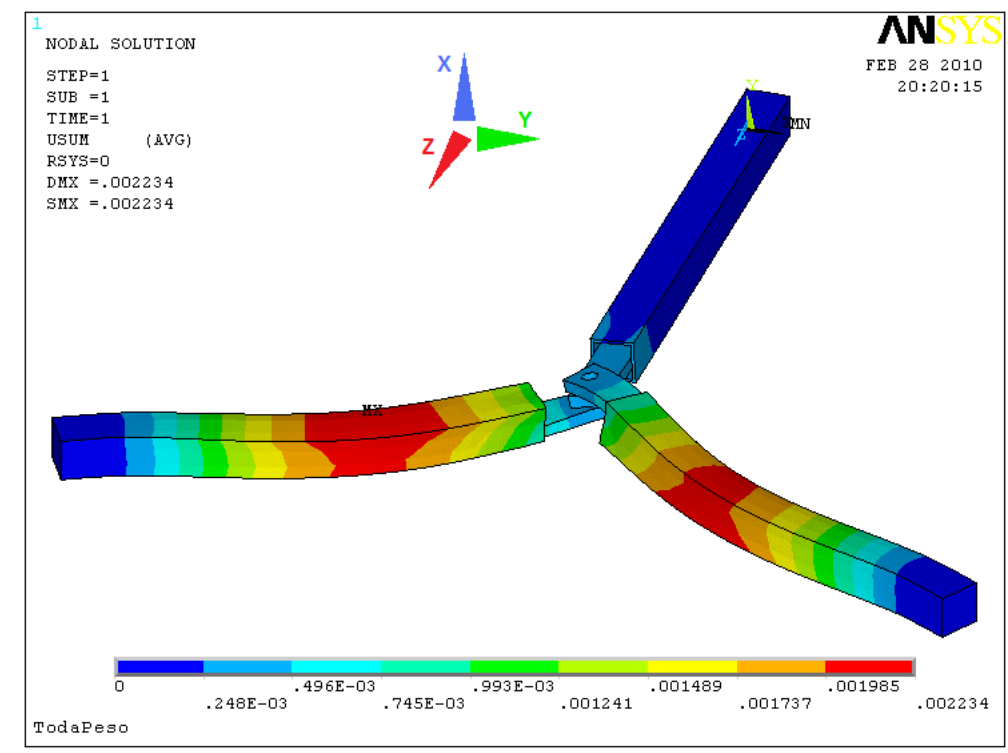

Figura 100 - Deflexão máxima para máquina na vertical.

Deve-se observar que o valor máximo da deflexão, no caso horizontal, é de $43,758 \mu \mathrm{m}$. Se forem comparados com o caso na vertical poderá ser percebida uma redução para cerca de $5 \%$ desse valor: $2,234 \mu \mathrm{m}$. Isso significa que a posição vertical é a mais indicada no que diz respeito ao deslocamento.

No entanto, deve-se também avaliar as tensões nos braços. O foco principal aqui não é a resistência do material, que já se sabe que será suficiente. O foco é a determinação dos motores que deverão ser utilizados para a movimentação da ferramenta.

Não existe muita variação das tensões nas barras entre as duas posições. Portanto, o peso das barras tem pouca influência, já que era o único carregamento que teve variação em sua aplicação.

No entanto, existe queda sensível da deflexão com a máquina na posição vertical, o que nos leva a crer que ocorre queda das tensões de cisalhamento nessa posição, como era de se esperar. Como o cisalhamento, nesse caso, com braços compridos, é um fator mais determinante que as forças normais, é natural que a maior deflexão ocorra na posição horizontal.

Considerando que em um tubo longo não se desejam tensões de cisalhamento, dando preferência para as normais, a posição vertical é a mais indicada para trabalho.

Dadas as condições geralmente encontradas em laboratórios acadêmicos, quais sejam espaço reduzido, necessidade de fácil acesso aos seus componentes e às 
suas partes, e baixo custo de aquisição e manutenção, recomenda-se o uso final da máquina na posição vertical.

\subsection{PROTÓTIPO CONSTRUÍDO}

Conforme previsto no capítulo 3, Metodologia, após a obtenção dos resultados dos modelos propostos, e sua validação, foi construído um protótipo funcional da máquina fresadora. Suas dimensões são $1.400 \mathrm{~mm}$ de lado (triângulo eqüilátero) e $300 \mathrm{~mm}$ de altura.

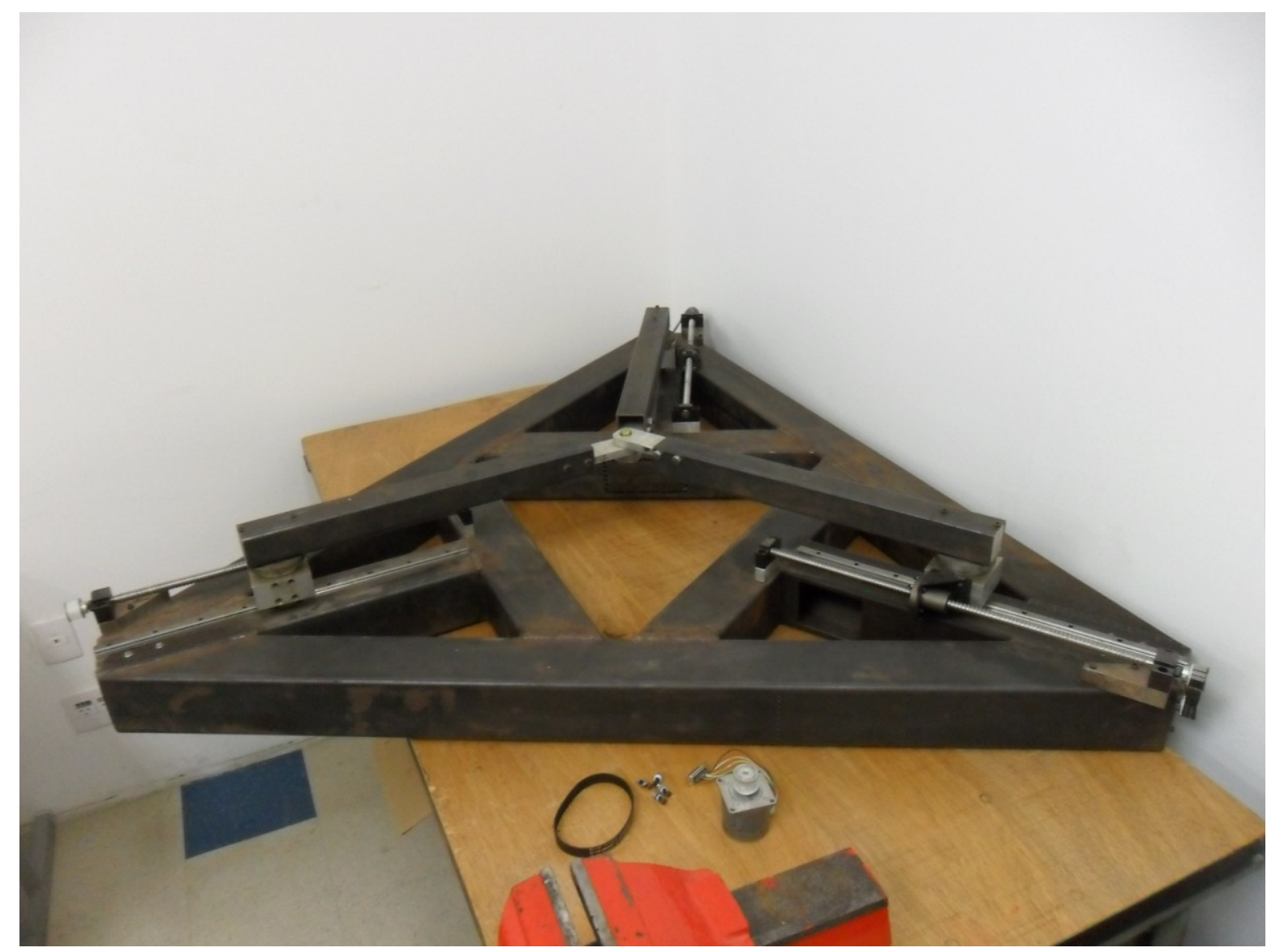

Figura 101 - Visão geral do protótipo. 
Como é possível observar, toda a parte mecânica foi montada e testada, sendo que as funções de controle e de interface serão implementadas no futuro, de forma a torná-la totalmente operacional.

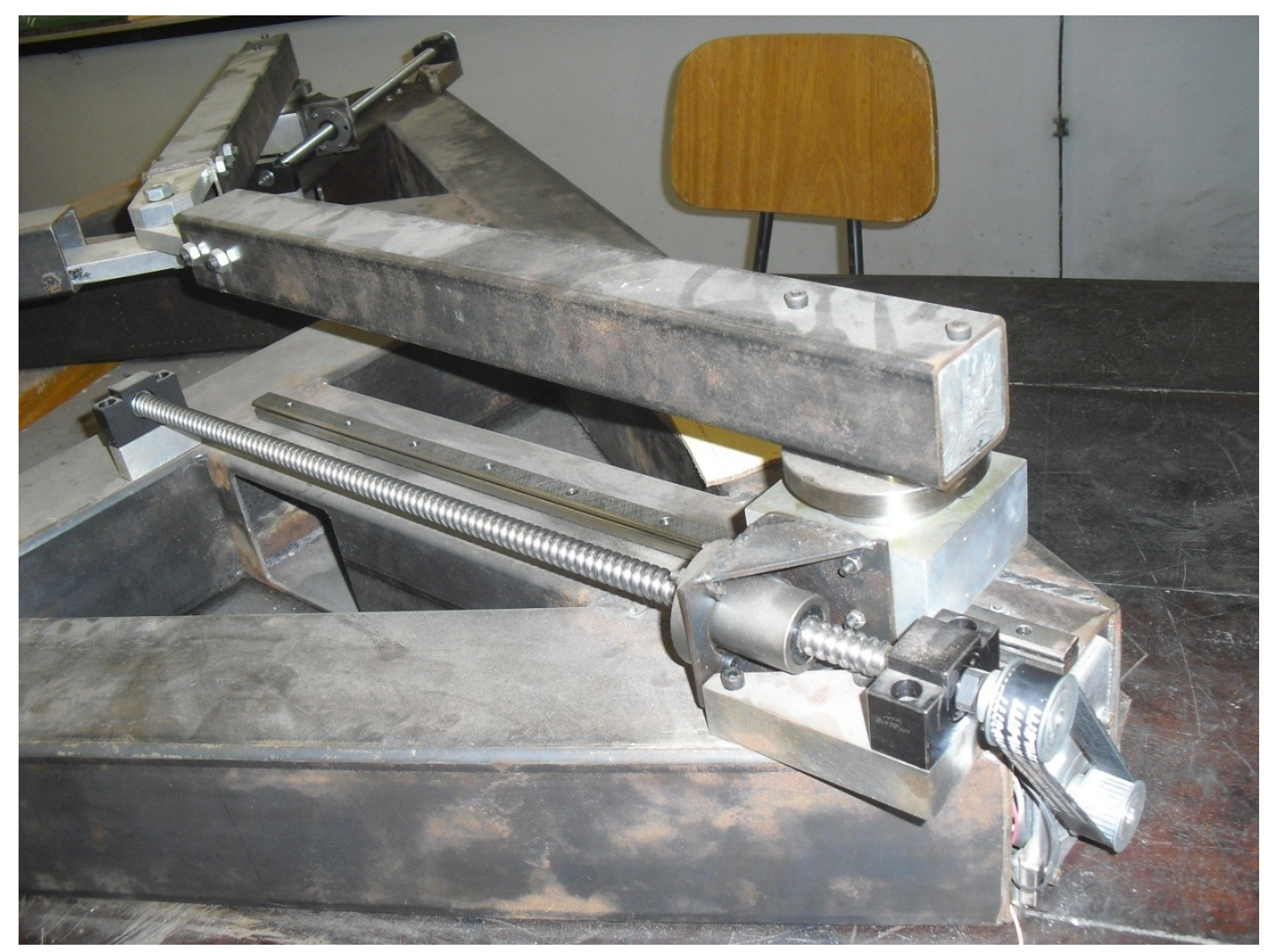

Figura 102 - Alterações efetuadas.

Algumas alterações foram necessárias para adaptar o projeto às peças fornecidas por fabricantes: na figura acima pode-se observar que a porca do fuso é cilíndrica, e não paralelepipédica, como previsto inicialmente. $\mathrm{O}$ motor $\mathrm{CC}$ também teve sua posição alterada para aproveitar melhor a estrutura e aumentar a rigidez do acoplamento. Por fim, o braço de acionamento teve seu material alterado para aço, uma vez que esses tubos já estavam disponíveis para utilização. 


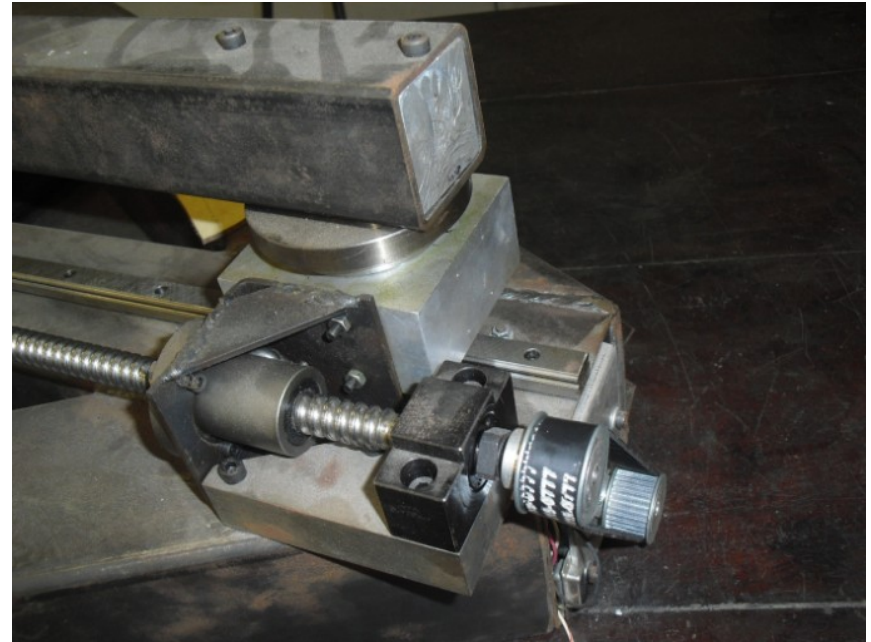

(a)

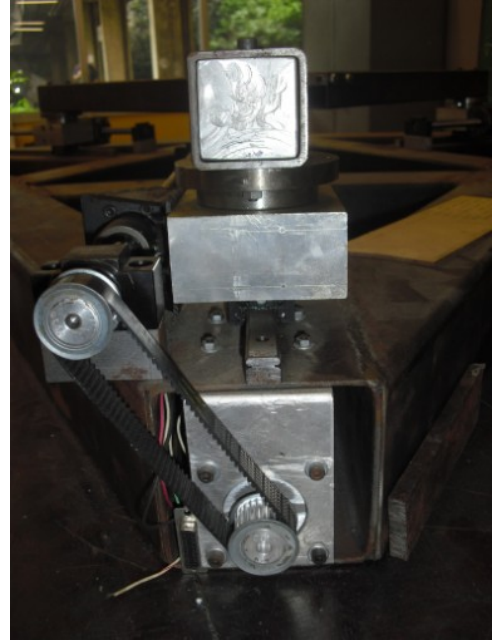

(b)

Figura 103 - Detalhe das alterações.
(a) Porca do fuso;
(b) Acoplamento do motor CC.

$\mathrm{Na}$ figura acima estão destacadas as principais modificações com relação ao motor CC e à porca de fixação; na figura abaixo, o limite mecânico de curso dos membros. Esse limite é dado apenas no lado dos motores de acionamento. Na outra extremidade não existe um limite: o fim de curso é dado pelos demais braços, também nas proximidades de seus respectivos atuadores.

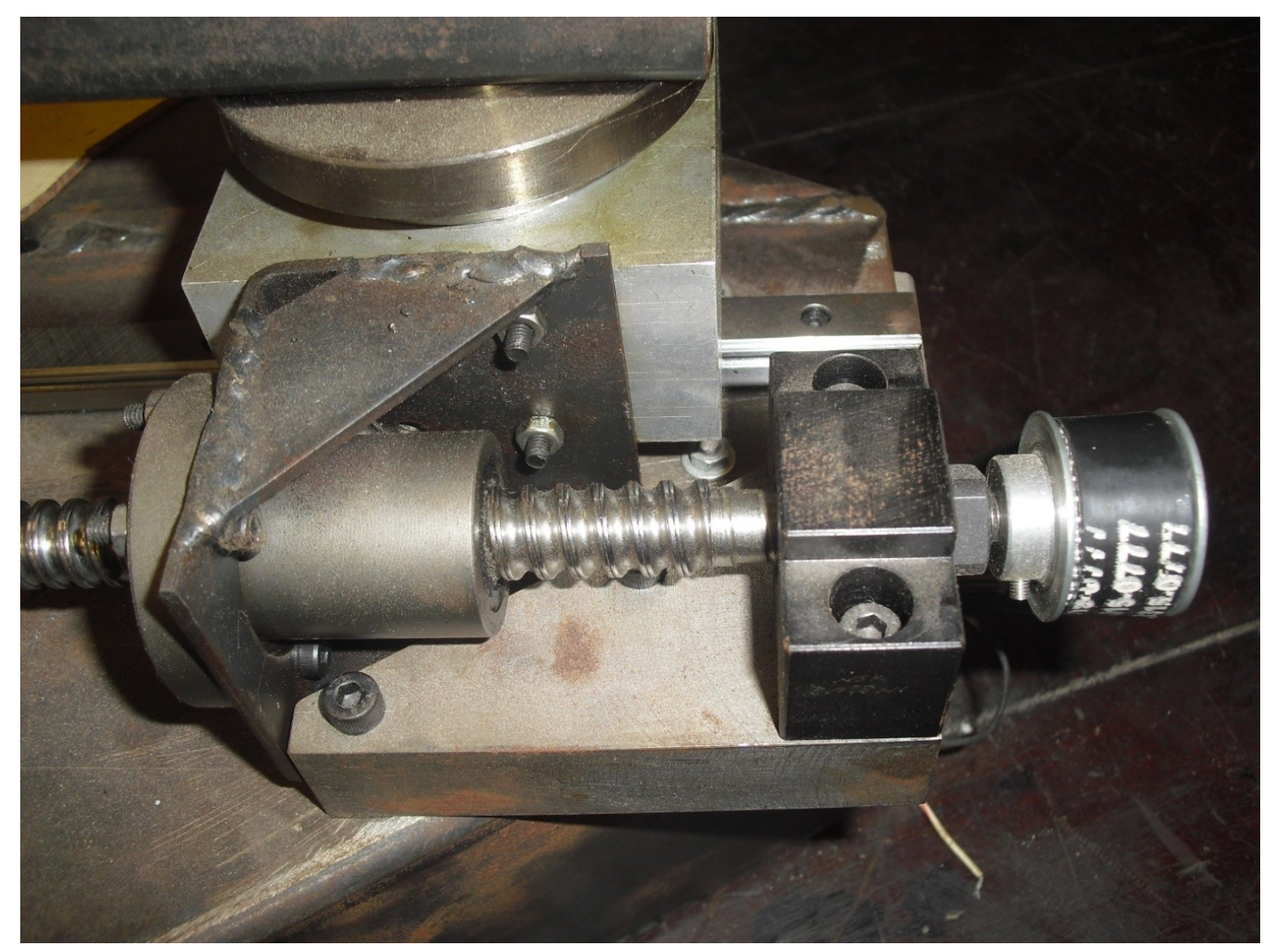

Figura 104 - Fim de curso dos membros atuadores. 
Por fim, nas figuras abaixo, detalha-se a conexão entre as três garras de fixação da ferramenta. Deve ser enfatizada aqui a intercambiabilidade entre as diversas peças. Observe na Figura 106 que a furação dos braços pode ser feita diretamente com os seis furos referentes às três posições de altura das garras. Isso permite que qualquer braço possa ser trocado de posição sem necessidade de adaptação ou correção da estrutura.

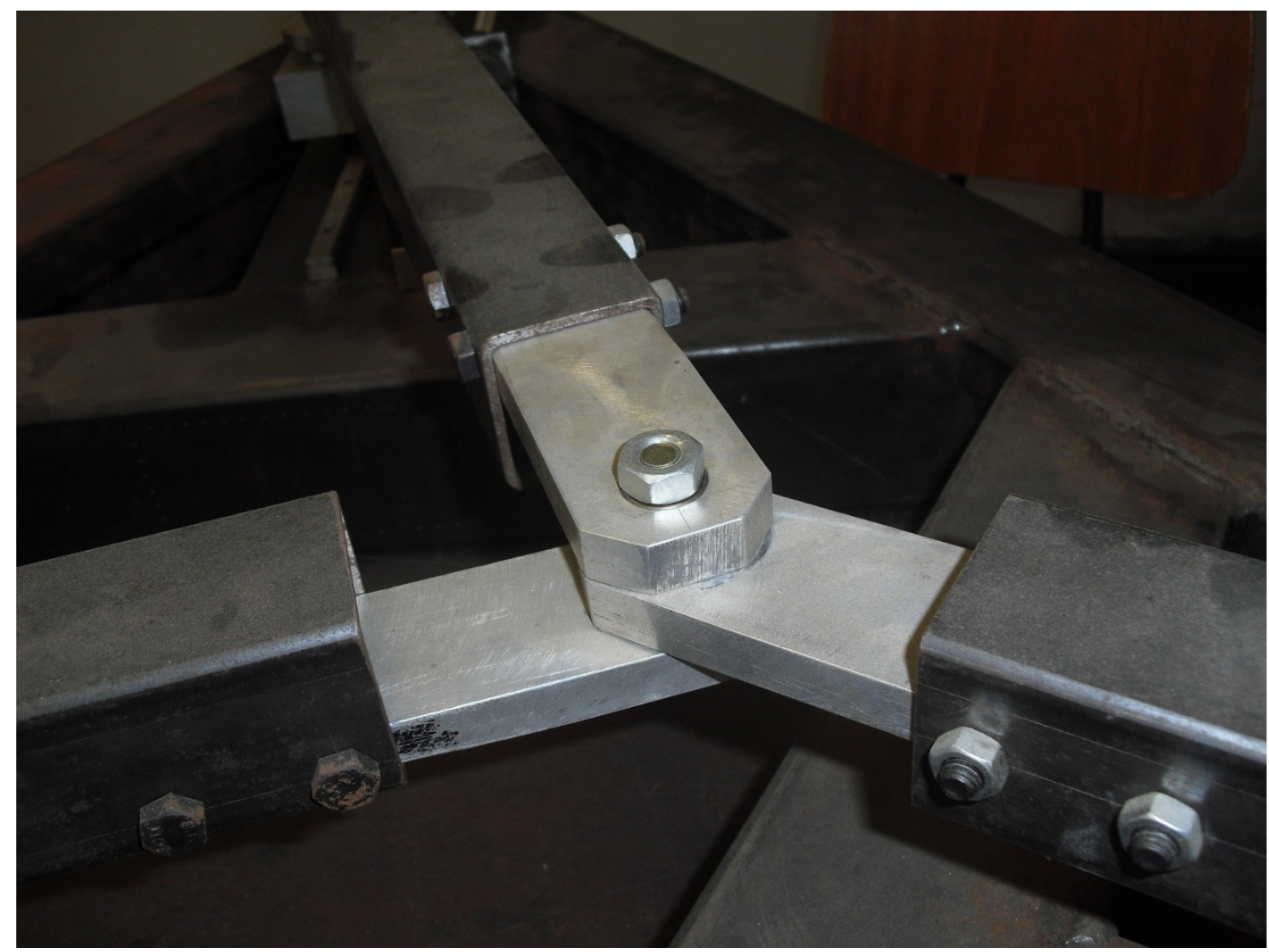

Figura 105 - Conexão com a ferramenta.

Da mesma maneira, observe que as três garras são idênticas do ponto de vista da fabricação. Assim, podem também ser trocadas com facilidade, além de serem fabricadas com um material relativamente fácil de ser trabalhado, podendo ser alteradas da maneira que for conveniente para o usuário. 


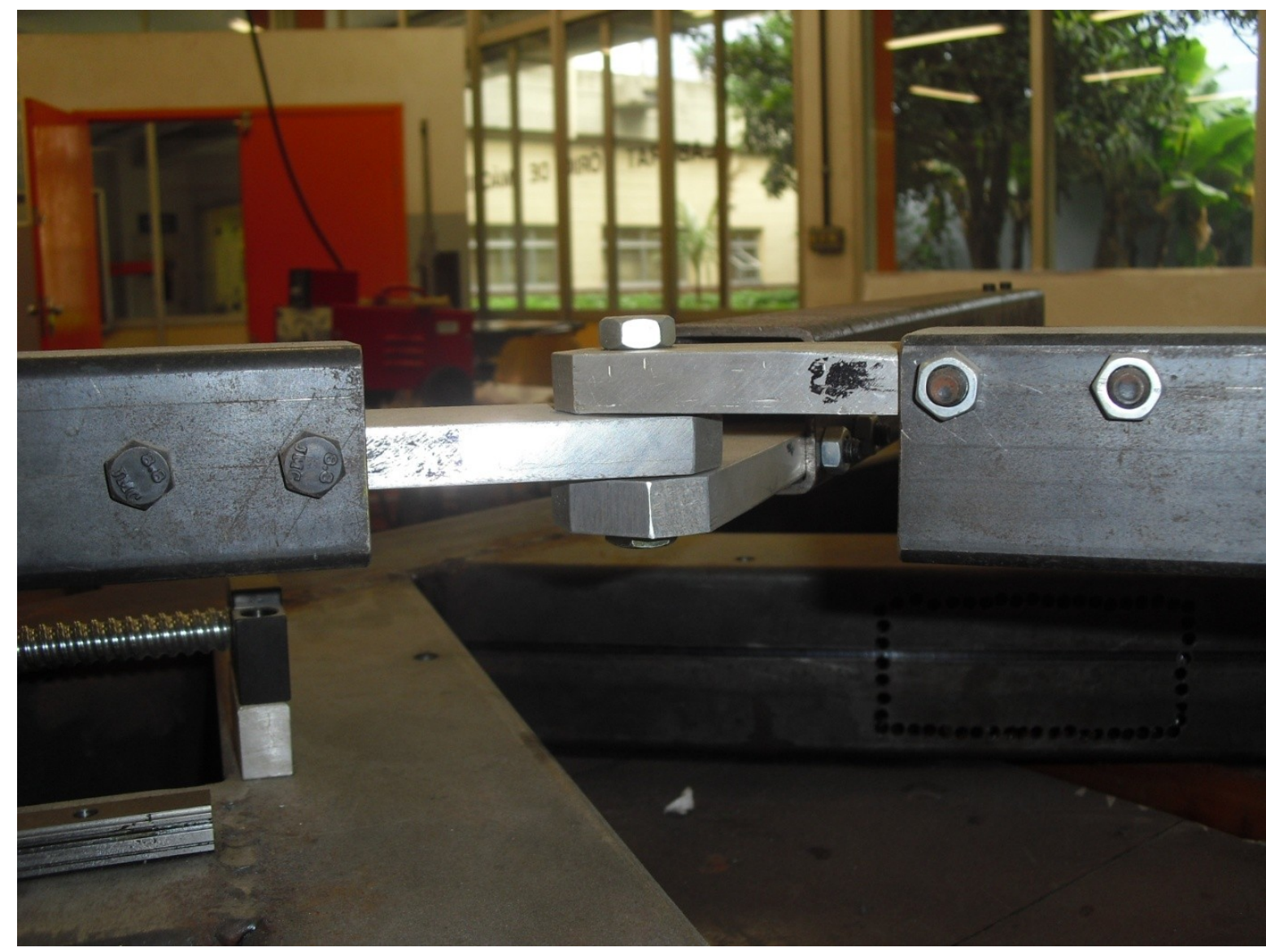

Figura 106 - Intercambiabilidade das peças.

De um ponto de vista acadêmico, de forma a permitir que estudantes de engenharia tenham o contato com esse tipo de equipamento em seus laboratórios, um robô similar a esse poderia ser parte de uma série de testes para analisar seu comportamento durante operações de fresamento.

A modelagem estática e cinemática, a avaliação do espaço de trabalho, erros geométricos, estáticos e cinemáticos, a dinâmica de funcionamento e seu controle são alguns dos pontos que podem ser trabalhados, e é aqui que entra a característica modular e a simplicidade construtiva desse trabalho. 


\section{CONCLUSÕES}

Neste trabalho apresentou-se uma contribuição ao desenvolvimento de uma máquina fresadora de arquitetura paralela, promissora quanto à sua precisão e simplicidade construtiva. Sua simetria, aliada à utilização de itens comerciais padronizados, permite que exista uma grande intercambiabilidade entre seus diversos componentes. Além disso, a modularidade deve ser destacada como facilitador da manutenção e alteração construtiva de suas partes.

Para avaliar o comportamento cinemático e estático da máquina foram desenvolvidos modelos matemáticos e computacionais, baseados no Princípio dos Trabalhos Virtuais, que permitem determinar o erro estático na ponta da ferramenta de corte durante a interação ferramenta-peça de trabalho.

Após diversas comparações com programas comerciais, o modelo computacional foi validado e o código do programa foi expandido de forma a apresentar o mapeamento dos erros previstos de posicionamento da ferramenta de corte, durante o fresamento, na área de trabalho considerada.

A vantagem desse desenvolvimento é a determinação de um mapa de rigidez da estrutura concebida, em função dos esforços solicitados. Isso reduz significativamente o tempo para igual determinação diretamente nos programas comerciais já existentes, que devem ser calculados ponto a ponto.

Através da simulação de três vetores de forças, associados a dois tipos construtivos de máquina, com dois e com três braços de acionamento, foi possível visualizar o ganho relativo de rigidez da fresadora com três atuadores, quando comparada com sua equivalente de apenas dois atuadores.

O ganho médio observado foi de $-88 \%$, calculado sobre a deflexão final da ferramenta, ou seja, uma máquina com três atuadores apresentou, em média, deflexão $88 \%$ menor que a observada na máquina equivalente com apenas dois atuadores.

Ficou claro que a utilização de membros redundantes aumenta significativamente a rigidez do sistema, e que a arquitetura proposta atingiu seus objetivos de redução do erro de posicionamento do órgão terminal. 
A posição de instalação da máquina, vertical ou horizontal, também foi discutida. Dado seu tamanho elevado, e levando-se em consideração a utilidade prática no ensino, concluiu-se que a posição vertical é a mais indicada para sua utilização.

O equipamento mostrou-se adequado para ser utilizado nas condições propostas. No entanto, algumas alterações construtivas devem ser realizadas no sentido de reduzir a folga inerente de seus componentes constituintes, pois aquela que existe hoje é de mesma ordem das deflexões que são desejadas para seu correto funcionamento.

Concluídas as etapas iniciais, o protótipo da máquina foi construído. Seus componentes já estão completamente montados, e pretende-se implementar as funções de controle e de interface no futuro, de forma a torná-la totalmente operacional. 


\section{REFERÊNCIAS}

ALTINTAS, YUSUF. Manufacturing Automation: Metal Cutting Mechanics, Machine Tool Vibrations, and CNC Design. Ed. Cambridge - USA, 2000. 298 p.

BERNARDES, F. J. F.; PAULO, R. G. R.; RODRIGUES, A. R. Estudo da Força de Usinagem no Fresamento High-Speed Cutting. In: XV Simpósio Internacional de Iniciação Científica da USP, 2007, São Carlos-SP. XV SIICUSP, 2007.

BRIOT, S.; BONEV, I. A. Accuracy analysis of 3-DOF planar parallel robots. Mechanism and Machine Theory 43 (2008). 445-458.

BROGHARD, T. PKM Research - Important Issues, as seen from a Product Development Perspective at ABB Robotics. In: Proceedings of the WORKSHOP on Fundamental Issues and Future Research Directions for Parallel Mechanisms and Manipulators, pp 68-82, Quebec, October 3-4, 2002.

CECCARELLI, M. Fundamentals of mechanics of robotic manipulation. Dordrecht: Kluwer, 2004.

CRUZ JUNIOR, E. J. ; KOMATSU, L. Y. T. ; RIGATTI, A. M. Y. ; RODRIGUES, A. R. Análise das forças em fresamento HSC. In: XXI Congresso de Iniciação Científica da UNESP, 2009, São José do Rio Preto-SP. XXI CIC/UNESP, 2009.

DI GREGORIO, R.; PARENTI-CASTELLI, V. Position analysis in analytical form of the 3-PSP mechanism. Journal of Mechanical Design. , 123: 51-57, 2001.

FLEISCHER, J.; STENGELE, G.; NEIHARDT, W.; ALBERS, A.; BROOS, A.; SCHMIDT-EWIG, J. P. Optimization of a machine tool with hybrid kinematics structure using coupled multi-body simulation and finite element analysis. Vol. 
24, Parallel Kinematic Machines in Research and Practice, R. Neugebauer, Ed. Zwickau: Verlag Wissenschaftliche Scripten, pp. 545-556, 2004.

FRISOLI, A.; SOLAZZI, M.; SOTGIU, E.; BERGAMASCO, M. A new method for the estimation of position accuracy in parallel manipulators with joint clearances. In: 12th IFToMM World Congress, Besançon, June 18-21, 2007.

GOJTAN, GERD ERWIN ERNST; HESS-COELHO, TARCISIO ANTONIO. An unified approach to evaluate and compensate the tool positioning error in parallel kinematic machines. In: COBEF, 2007.

GOSSELIN, C.M.; KONG, X.; FOUCAULT, S.; BONEV, I. A. A fully-decoupled 3dof translational parallel mechanism. Vol. 24, Parallel Kinematic Machines in Research and Practice, R. Neugebauer, Ed. Zwickau: Verlag Wissenschaftliche Scripten, 2004.

HARTMANN, VITOR NEVES. Desenvolvimento do protótipo de um robô de cinemática paralela para usinagem 2D com uma barra de ancoragem. Trabalho de iniciação científica. Processo FAPESP 07/50750-5 140p. 2007.

HESS-COELHO, T. A. An alternative procedure for type synthesis of parallel mechanisms. In: 12th IFToMM World Congress, 2007, paper A612.

HESS-COELHO, T. A.; BRANCHINI, D.; MALVEZZI, F. A new family of 3-dof parallel robot manipulators for pick-and-place operations. In: Proc. of 18th International Congress of Mechanical Engineering, Nov 6-11, Ouro Preto, 2005.

HESS-COELHO, T.A.; GOJTAN, G.E.E.; FURTADO, G. P. Kinematic analysis of a 3-dof parallel mechanism for milling applications. The Open Mechanical Engineering Journal. Special Issue on Kinematic Design of Manipulators, Marco Ceccarelli (org.) in press, corrected Proof, ISSN 1874-155X, Betham Science Publishers Ltd., 2010. 
KALPAKJIAN, SEROPE; SCHMID, STEVEN R. Manufacturing Engineering and Technology. Fourth Edition, Ed. Prentice Hall. 2000.

KAMODA, HUGO MAKOTO; HANADA, RODRIGO SATO. Controle e acionamento de um robô paralelo. Trabalho de formatura. Poli-USP. 40p. 2006.

KONG, X.; GOSSELIN, C. Type Synthesis of Parallel Mechanisms, BerlinHeidelberg: Springer-Verlag, 2007.

MARCELINO A. P.; DOMINGOS D. C.; CAMPOS D. V.; SCHROETER R. B. Medição e Simulação dos Esforços de Usinagem no Fresamento de Topo Reto de Ligas de Alumínio Tratável Termicamente 6061. In: XI Creem, Rio de Janeiro, 2004.

MERLET, J. P., Parallel robots, Kluwer Academic Publishers, Dordrecht, 2000.

OIWA, T. Ultra-precision machine tool or coordinate measuring machine using hexapod-type measurement device for six degree-of-freedom relative motions between cutting tool/probe and workpiece. In: 12th IFToMM World Congress, Besançon (France), June18-21, 2007.

RASZL, G.; HESS-COELHO, T. A. Characterization of a Prototype of a Robotic Parallel Structure Considering its Potential Application as a Machine Tool. Design, p421-436, 2006.

RIBEIRO, J. L. S.; ABRÃO, A. M.; SALES, W. F. Forças de Usinagem no Fresamento de Aços para Matrizes. In: 16 POSMEC, Uberlândia, 2006.

RODRIGUES, M. A., HASSUI, A. Análise dos esforços de corte no fresamento da liga a base de níquel - Inconel 625 - depositada em forma de revestimento 
metálico. In: IV Congresso Brasileiro de Engenharia de Fabricação, 2007, Estância de São Pedro. Anais do IV Congresso Brasileiro de Engenharia de Fabricação - em CD-ROM, 2007.

STIPKOVIC FILHO, MARCO; RABELO, SERGIO LUIZ; HESS-COELHO, TARCISIO ANTONIO. Desenvolvimento de máquina $C N C$ de pequeno porte com configuração paralela para uso educacional. Linha de financiamento PIPE Fase I. Processo Fapesp 05/04107-8. 2007.

TRENT, E. M.; WRIGHT, P. K. Metal Cutting (4 ${ }^{\mathrm{a}}$ edição), Butterworth-Heinemann, Boston (USA), 2000.

TSAI, L.-W. , Robot analysis: the mechanics of serial and parallel manipulators, John Wiley \& Sons, New York, 1999.

VALÁŠEK, M.; ŠIKA, Z.; HAMRLE, V. From Dexterity to Calibrability of Parallel Kinematical Structures. In: 12th IFToMM World Congress, Besançon (France), June18-21, 2007.

ZHANG, YANFEI; GONG, JINLIANG; GAO, FENG. Singularity elimination of parallel mechanisms by means of redundant actuation. In: 12th IFToMM World Congress, Besançon (France), June18-21, 2007. 
APÊNDICE A - Desenho de Conjunto da máquina

Na figura seguinte apresenta-se o desenho de conjunto da máquina desenvolvida, assim como uma lista numerada dos principais componentes que a constituem. 


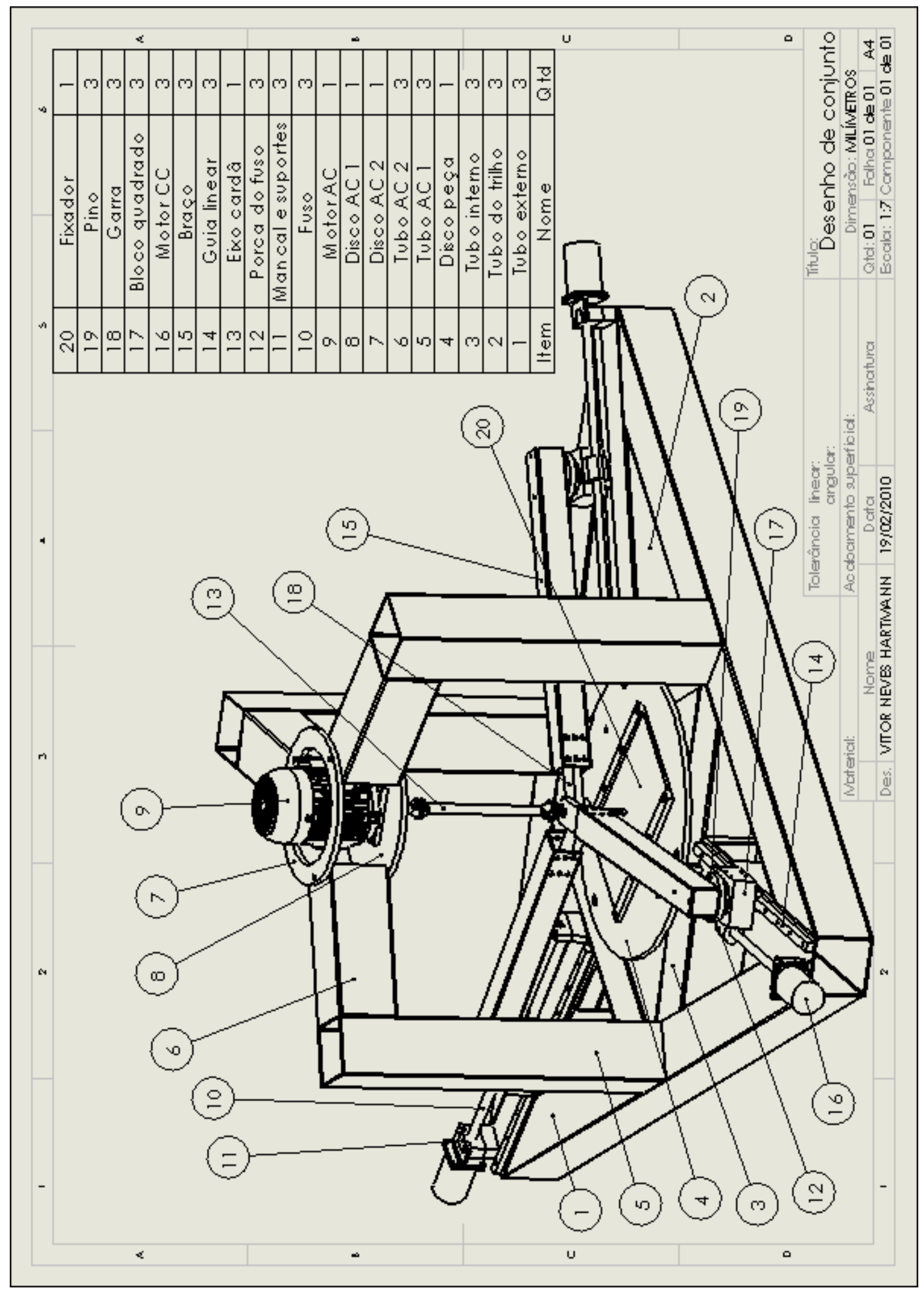




\section{APÊNDICE B - Desenhos de Montagem}

Nas figuras seguintes apresentam-se os desenhos de montagem do braço de acionamento e do bloco de fixação da máquina desenvolvida, compostos respectivamente pelo pino de rotação, pelo tubo retangular e pelo prisma sólido; e pela porca do fuso, pelo patim deslizante, pelo bloco de alumínio e suas buchas. 


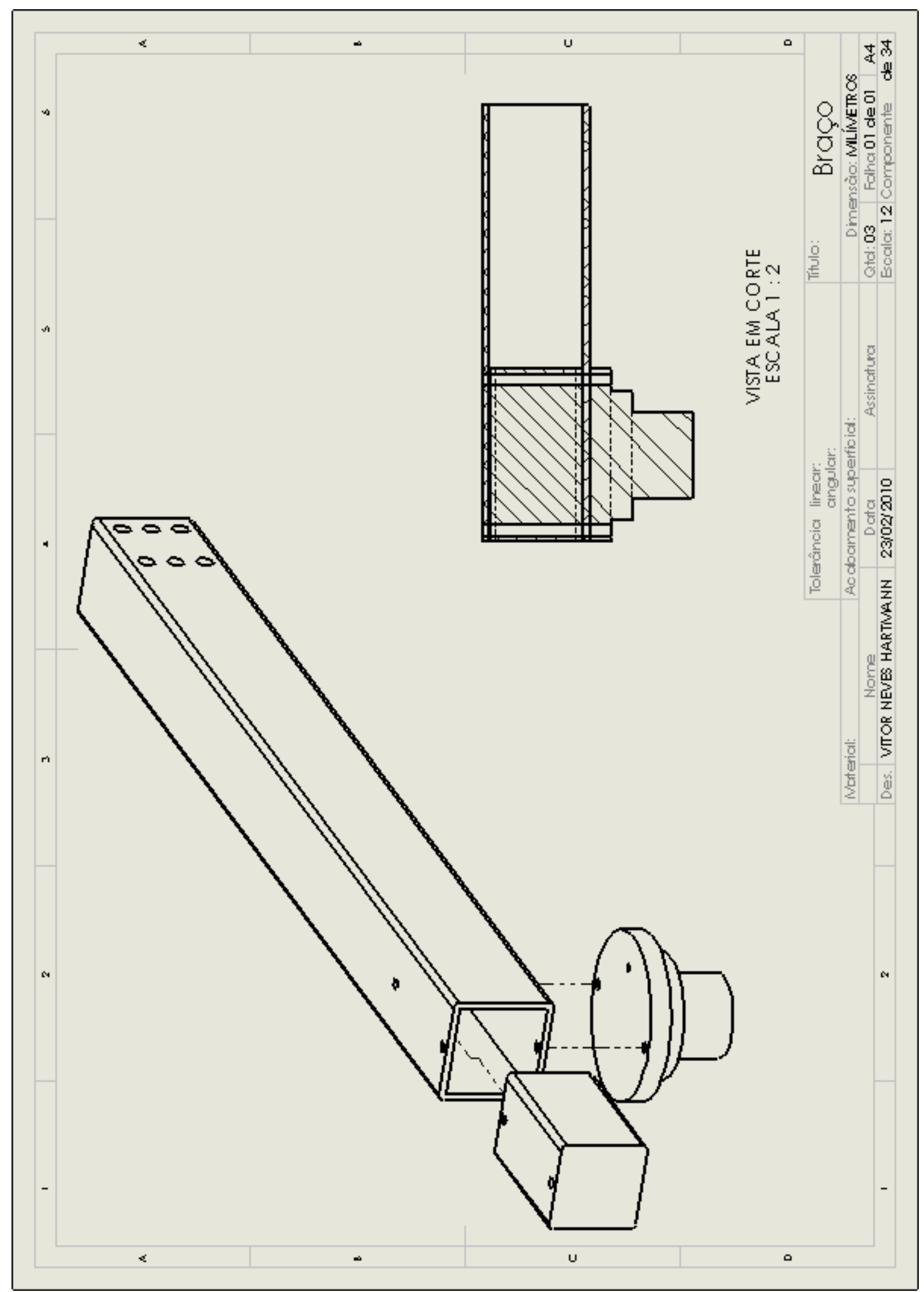




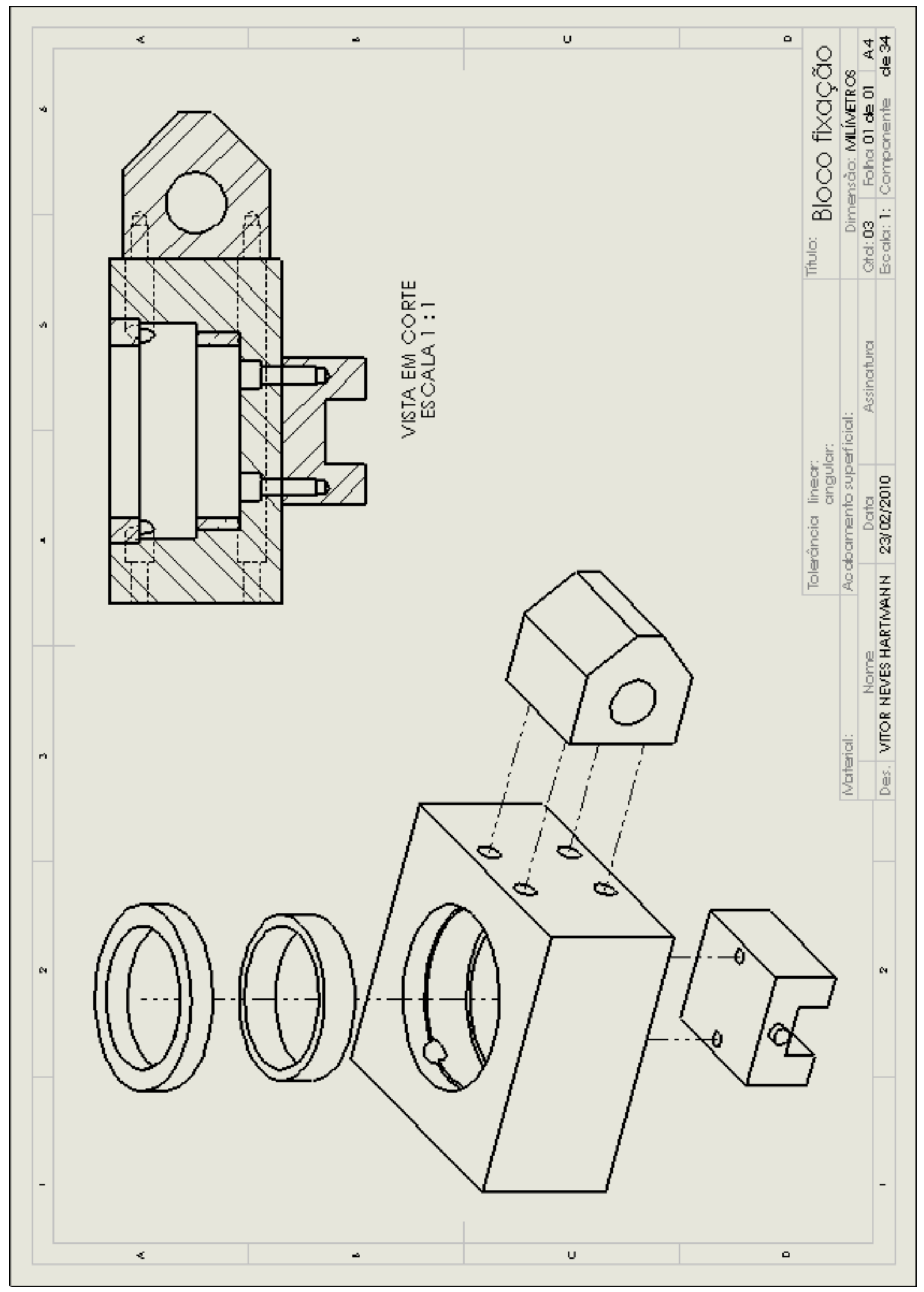

